\title{
Potential applications of confocal Raman spectroscopy in ophthalmology
}

Citation for published version (APA):

Bauer, N. J. (1999). Potential applications of confocal Raman spectroscopy in ophthalmology. [Doctoral Thesis, Maastricht University]. Universiteit Maastricht. https://doi.org/10.26481/dis.19991217nb

Document status and date:

Published: 01/01/1999

DOI:

10.26481/dis.19991217nb

Document Version:

Publisher's PDF, also known as Version of record

\section{Please check the document version of this publication:}

- A submitted manuscript is the version of the article upon submission and before peer-review. There can be important differences between the submitted version and the official published version of record.

People interested in the research are advised to contact the author for the final version of the publication, or visit the DOI to the publisher's website.

- The final author version and the galley proof are versions of the publication after peer review.

- The final published version features the final layout of the paper including the volume, issue and page numbers.

Link to publication

\footnotetext{
General rights rights.

- You may freely distribute the URL identifying the publication in the public portal. please follow below link for the End User Agreement:

www.umlib.nl/taverne-license

Take down policy

If you believe that this document breaches copyright please contact us at:

repository@maastrichtuniversity.nl

providing details and we will investigate your claim.
}

Copyright and moral rights for the publications made accessible in the public portal are retained by the authors and/or other copyright owners and it is a condition of accessing publications that users recognise and abide by the legal requirements associated with these

- Users may download and print one copy of any publication from the public portal for the purpose of private study or research.

- You may not further distribute the material or use it for any profit-making activity or commercial gain

If the publication is distributed under the terms of Article $25 \mathrm{fa}$ of the Dutch Copyright Act, indicated by the "Taverne" license above, 
Potential applications of confocal

Raman spectroscopy in ophthalmology 
O NJC Bater, Mastricht 1999

ISBN 9052782636

Layout en dink: Datawyse | Universitaire Pers Maastricht 


\section{Potential applications of confocal Raman spectroscopy in ophthalmology}

Proefschrift

ter verkrijging van de graad wan doctor

aan de Universiteit Mastricht,

op gezag wan de Rector Magnificus,

Prof. dr A.C. Nieuwenhuijzen Kruseman,

volgens het beshit van het College van Decanen,

in het openbar te verdedigen

op vrijdag 17 december 1999 om 10.00 unr

door

Noël Jozef Catharinus Bauer

geboren op 11 november 1968 te Heerlen

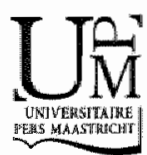




\section{Promatores}

Prot. dr F. Hendrikse

Prof. dr W.F. March (University of Texas Medical Branch, Galveston, Texas)

\section{Co-promotaren}

Dr. M. Motamedi (University of Texas Medical Branch, Galveston, Texas)

Dr. ir G.J. Puppels (Erasmus Universiteit Rotterdam)

\section{Beoordelingscommissie}

Prof. dr H.A.J. Struijker-Boudier (voorzitter)

Prof dr W.Th. Hermens

Prof. dr A. Persoons (Universiteit van Leuven)

Prof. dr F. Spans

Dr. ir D. Sterenborg (Erasmus Universiteit Rotterdam)

This work was performed at the ophthalunic division of the Biomedical Laser and Spectroscopy Program of the Department of Ophthalmology (Professor W.F. March, MD) at the University of Texas Medical Branch, Galveston, Texas, USA, and was sponsored in part by a grant tron the Department of Energy (DOE-FG03-95ER61971), a Research to Prevent Blindness Development grant, and a Research to Prevent Blindness Unrestricted grant. 
To my loning wife Elaine and my son Brandon In loving memory of my mother 



\section{Contents}

CHAPTER 1 - Introduction 9

General g

Aim of the thesis 11

Theoretical aspects 11

Practical aspects $\quad 12$

Optical aspects 12

The applications $\$ 5$

References 17

CHAPTER 2 - Raman spectroscopy 19

Theory of Raman scattering 19

Principles of applied Raman spectroscopy 20

Raman spectroscopic techniques and systems 21

Applications of Raman spectroscopy in biochemistry 23

Applications of Raman spectroscopy in the eye 23

Design considerations for a Raman spectroscopy

system for ophthalmic use in wivo 35

References $\quad 39$

Appendix 47

CHAPTER 3 - Confocal Raman spectroscopy system for noncontact scanning of ocular tissues: an ill vitro study 49

CHAPTER 4 - Applications of confocal Raman spectroscopy for biachemical characterization of ocular tissues and fluids

CHAPTER 5 - Noncontact assessment of the hydration gradient across the comea using confocal Raman spectroscopy 87

CHAPTER 6 - In wivo confocal Raman spectroscopy of the human comea

CHAPTER 7 - Noncontact assessment of ocular pharmacokinetics using contocal Raman spectroscopy 
CHAPTER 8 - Remote temperature measurements in the eye using confocal Raman spectroscopy

Summary and Conclusions

Samenvatting en Conclusies

Dankwoord

Curriculum Vitae

Publications 
CHAPTER 1

\section{Introduction}

\section{General}

The eye, as the sensory organ of vision, has a tissue composition oprimal for its main function of transmission, refraction and detection of light. ${ }^{\prime}$ Because of its function and delicate anatomy, the eye does not easily allow for invasive diagnostic procedures. Ophthalmology therefore has to its disposal a wide variety of non-invasive diagnostic technques which by definition do not lead to additional cell damage of the ocular tissues or the regions around the eye.2 Non-invasive procedures include non-contact or remote sensing techniques (i.e. fundoscopy, refractometry, keratometry, slitlamp biomicroscopy, specular microscopy, optical coherent tomography, fuorophotometry), contact or marginally invasive techniques (1.e. ultrasonography, tononetry, pachymetry), and parainvasive techniques, in which a non-invasive observation in the eye is performed after an invasive procedure elsewhere (i.e. fluorescein angiography, indocyanine green angiography). ${ }^{2}$ The aforementioned techniques lack the ability to provide specific information on the biochemical properties of ocular tissues. Biochemical information, however, is of clinical importance, since numerous physiological and pathological processes and therapeutic as well as diagnostic interventions have significant effects on the biochemical composition of the eye. ${ }^{3}$

The biochemistry of the eye can be influenced by physiological, degenerative, metabolic, inflammatory, toxicological, and neoplastic processes, as well as through iatrogenic interventions, such ats topical drug application.

Comeal hydration control is an example of a physiological process involving biochemical changes. The water content of the comeal stroma is actively regulated by means of the endothelial pumpmechanism, and this is crucial for the transparency of the comea 4.5 Corneal dystrophies are characterized by functional and morphologic abnomalities resulting in progressive comeal opacification, which can lead to loss of vision. Many forms of coneal dystrophy have been described, and can be classified as epithelial, stromal, or endothelial. ${ }^{6}$ Prevention of vision loss needs early and accurate diagnosis of the disease state, including comeal thickness measurements and slitlamp examination. ${ }^{7}$ The various different corneal dystrophies suggest differences in the under lying pathology, possibly expressed in the biochemistry. 
Cataractogenesis is a pathophysiological process of the crystalline lens, which involwes biochemical changes that seen to be pathognomic for this degenerative disorder. Apart from the underlyng causes, opacification occurs following disturbance of the ordered packing of the lens crystallins, induced by changes in hydration, aggregate formation of lems proteins, and vacuole formation within the lens fibers. These morphologic changes need a quantitative measurement of the biochemical composition with high sparal resolution.

Metabolic disorders are usually systemic in nature and can possibly also manifest themselwes through local ocular biochemical alterations. In uncontrolled insulin dependent diabetes mellutus (IDDM), the level of glucose in the aqueous humor correlates with that of the blood. 910 Many investigators have focussed on the non-invasive detection of glucose in the eye, with the objective of developing a real-time 'closed loop' system for control of the blood glucose level. $9, \|$ il

A breakdown of the blood-aqueous barrier during inflammation of the eye (uveitis) involvas elewated levels of cells and proteins in the aqueous humor and vitreous. Recently, a non-invasive Helium-Neon laser based cell-and flare meter was developed and applied clinically for diagnostic puposes of uveitis. ${ }^{12}$ Although highly sensitive, no specific information about the proteins involved is obtained which could possibly be of additional value in the diagnosis and follow-up this diseased state.

Local ocular biochemical changes can also occur due to elevated levels of potentially toxic substances in the blood (i.e excitatory amino-acids in inborn errors of metabolism, endotoxins) with initially no obvious detrimental effect to the eye, but which car potentially be detected utilizing a non-invasive technique for biochemical assessments in the aqueous humor. ${ }^{13}$

The detection of biochemical changes che to neoplastic alterations of tissues using tumor specific markers is applied in the diagnosis, treatment and follow-up of varions cancers (prostate, breast, lung). ${ }^{4}$ Although the overall incidence of ocullo tumors is relatively low, neoplasia have becu documented for all tisues in the cye (pignented and nompigmented epithelial, numscular, nervous, vascular, fibroadipose. connective, lymphoid and glandular tissues), and non-invasive biochenical analysis could provide the information needed for carly diagnosis and treament of the specific tumor.

Latly, surgical interventions ${ }^{15}$ and topical ocular drug delivery ${ }^{16}$ can cause detectable biochemical changes, whether desirable or not. An impending corneal graft rejection after a penetrating keratoplasty (PKP) could be detected by assessing the water content of the cornea well in advance of clinically objective changes in the comeal momphology. Furthermore, it could be useful to assess the comeal uptake of a topical ocular drug in order to test its efficacy, or to assess whether or not the concentration of an intracular depot drug (Ganciclovir implant) is still at a therapeutic level. 
In the light of the aforementioned, it is worthwhile to perform qualiative and quantitative detection of ocular biochemical changes prior to thempeutic interventions and during follow-up of a disease. The application of a successful non-invasive biochemical analytical technique could also increase our understanding of nomal physiological processes in the eye. 17 This is analog to the assesment of biochemical parameters in various readily acoessible other rissues (blood, urine, feces, saliva).

\section{Aim of the thesis}

The aim of this thesis was to investigate the potential application of a novat optical sectioning technique utilizing Raman spectroscopy for non-contact biochemical assessments of (intra) ocular tissues and thids of the intact eye under in vivo circumstances.

\section{Theoretical aspects}

Raman spectroscopy (RS) is a powerful optical technique for biochemical assessments, and utilizes the Raman phenomenon which occurs when light interacts with molecules. Incident light from a sample is mostly scattered elastically, i.e. without energy transfer between light and matter. Raman scattering on the other hand is the small fraction of light that is scattered inelastically due to the transfer of energy between photons of the incident light and molecules, on the molecular vibrational level. The change in photon energy (E) equals the change in molecular vibrational energy, which is inherently specific for the molecular bond inwolwed, and results in a change in photon frequency " since $\mathrm{E}=\mathrm{h} w(\mathrm{~h}=\mathrm{Planck}$ 's constant). Utilizing spectroscopy these frequency changes are spatially resolved into a spectrum depicting Raman bands with a certan intensity and Raman (frequency) shift postion (in wavenumber or $\mathrm{cm}^{-1}$ ), over a certain wavenumber region. Each band can be assigned to a known nolecular vibrational mode and spectral analysis provides qualicative and quantative infomation on the molecular content and contormation.

Advantageous characteristics of RS include its inherent high specificity, the ability to assess solids, liquids and gases, and the remote sensing capability which. reduces probing artifacts. On the other hand the low Raman yield (only $10^{-4}$ to $10^{-6}$ of the scattered light is Raman scattering) usually requires the whe of high incident light energes for an adequate spectral signal-to-noisc ratio. A typical Raman spectroscopy system consists of a monochromatic light source (a laser), focusing and collecting optics, a spectrometer, and a photon counting devica. In 
Chapter 2 a detaled oulne of the principles and practice of Raman spectroscopy is given.

\section{Practical aspects}

Raman spectroscopy has been applied in the past in every aspect of biochemistry, from the biochemical characterization of nucleic acids and related compounds, amino-acids, polypeptides, proteins, lipids and cellular membranes, carbohydrates, and bacteria and viruses, to the application of $\mathrm{R}$ aman spectroscopy in biology and medicine for the study of cells, tissues and even whole organs. 19

Applications of Raman spectroscopy in ophthalmology have mainly focused on the elucidation of the process of cataract formation, ${ }^{20}$ although applications for biochemical analysis of the comea ${ }^{21}$, aqueous humor ${ }^{13,17}$, vitreous humor ${ }^{22}$, and the retinal pigments have also been suggested. ${ }^{23}$ Most of these studies have been performed under in witro conditions, because of significant limitations in the proposed RS systems for probing the intact eye in wivo.

First, the inherently weak $R$ aman signals require tissue samples to be exposed to high doses of laser light for prolonged periods of time in order to achieve an adequate signal-to-noise ratio. Thus, light induced damage to the ocular tissues in general and the retina in specific is likely to occur, limiting safe application of $\mathbb{R S}$ in the living intact eye (see below).

Secondly, the heterogeneous nature of the ocular tissues can significantly contribute to the occurrence of strong fluorescence masking most of the Raman signals. This event is generally minimized through the use of thin tissue preparations which, apat from the likely occurence of artifacts, excludes wiwo application of RS in the eye by definition.

Lastly, most of the proposed Raman spectroscopic techniques in ophthalmology usually lack adequate resolution in time, essencial for reducing movew ment artifacs in living specintens, and spatial resolution, essential for optical sectioning through laminated ocular tissues. In the latter part of Chapter 2 the design considerations are outlined for a suitable Raman spectroscopy system for ophehamic use in vivo.

\section{Optical aspects}

The key factors for the successful application of $R$ aman spectroscopy for the non-invasive assesment of biochemical parmeters in the eye are: adequate working distance (i.e. an objective lens capable of probing superficial as well as deeper ocular tissues in a non-contact manner), high sensitivity (high 
signal-to-noise ratio spectra without interfering signals from nearby tissues), high specificity (inherent to Raman spectoscopy), adequate spatial resolution for optical sectioning, temporal resolution for rapid spectral acquisition, and safery. Chapter 3 describes the detalls and performance of such a system in the form of a laser confocal Raman spectroscopy (CRS) system. Spatial resolution and reduction of fluorescence interference was achieved using confocal optics (see Figure 1) effectively reducing light from out of focus places, thus increasing the signal-to-noise ratio, while decreasing the actual probing volume at the expense of the absolute Raman signal. Since interchangeable fiber-optics were used as the "confocal pinhole", the thickness of the optical sections could be adjusted from $20-900 \mu \mathrm{m}$. High sensitivity was guaranted by using a microm scope objective lens both for focusing the laser light onto the sample as well as collecting it, in conjunction with a highly sensitive CCD-camera as a photon counting device. The microscope objective lens (LDMO) ensured an adequately long working distance of $-13 \mathrm{~mm}$ and a high numerical aperture (solid angle of acceptance) of $N A=0.5$. This lens could be moved along its optical axis without changing its focal distance, thus enabling axial probing of static objects, and permitted probing of the comea, aqueous humor, the ocular lens, and the anterior vitreous humor, while projecting a large defocused spot onto the retina of $\sim 2 \mathrm{~cm}$ in diameter, irrespective of the probing depth $(0-1)$ $\mathrm{mm}$ ) into the eye. This is depicted in graphical format in Figure 2. At a given power setting the defocused spotsize is safer than a focused spot. For example, a collimated light beam (NA $=0$ ) from a $1 \mathrm{~mW}$ laser will focus to a spotsize of $\sim 15$ $\mu \mathrm{m}$, yielding a retinal irradiance of $\sim 650 \mathrm{~W} / \mathrm{cm}^{2}$, while the sime laser utilizing the high NA LDMO would yield a retinal irradiance of $\sim 0.3 \mathrm{~mW} / \mathrm{cm}^{2}$. Since the reduction of light load was an important issue in this thesis, this system as a whole was designed with the eye on maximum signal collection, throughput and detection.

Although the proposed CRS system has various advantageous characteristics, as described, true non-inwasive application of this novel optical technique for clinical diagnosis in the living eye will highly depend on its safery. This means that the exposure to laser light should not damage the ocular tissues. Since the ocular media are transparent to light with a wavelength between 400 and $1400 \mathrm{~nm}$, retinal exposure becones the limiting factor when using a visible lightsource ( $400-700$ nm). Prolonged exposure of light to the retina can lead to either themal or photochemical damage and is wavelength dependent. Below 500 mm predominanty photochemical damage occurs, as a result of the absorption of light in the photopigments and the retinal pigment epithelial layer (RPE). Above $600 \mathrm{~nm}$ mainly thermal damage ensues when the temperature increase is $>20^{\circ} \mathrm{C}$ causing proteins to denature. Between 500 and 600 nom, thermally enhanced photochemical damage may occur. Thus, the retinal inadiance (in $\mathrm{mW} / \mathrm{cm}^{2}$ ) should stay within certain limits to guarantee retinal safery. For 


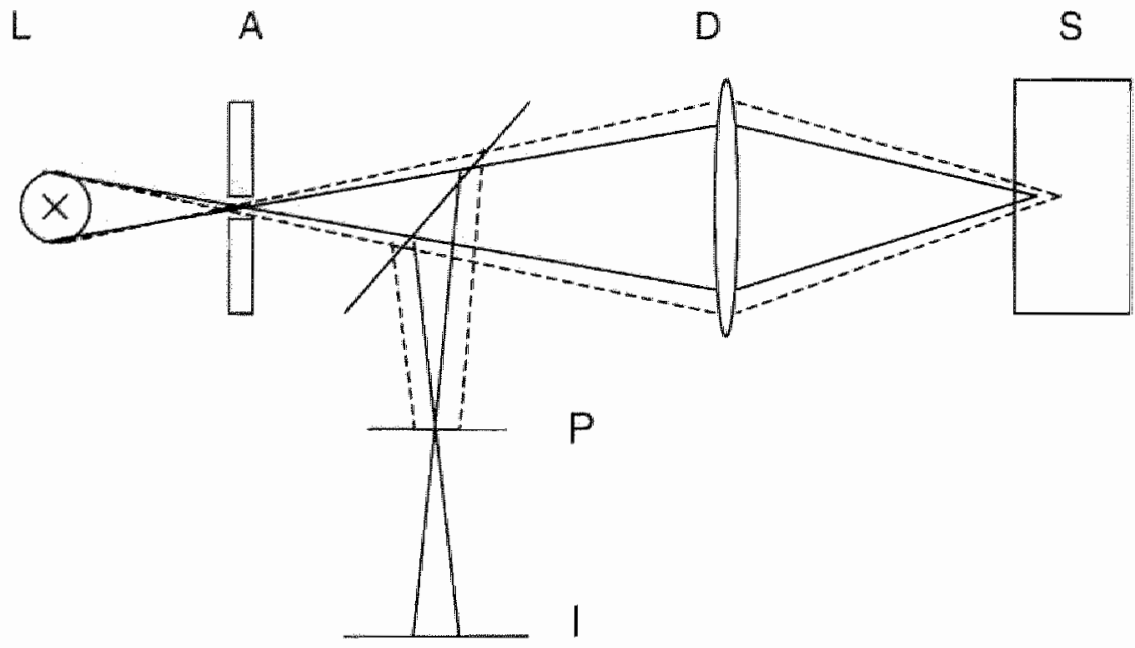

Figure 1. Principles of confocal optics. Light from out of focus places (dashed ays) are blocked by the pinhole $(P)$ and are not imaged. $L=$ lighr source, $A=$ aperture, $D=$ positive lens, $S=$ sanplen, $I=$ inage plane.

14

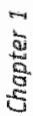

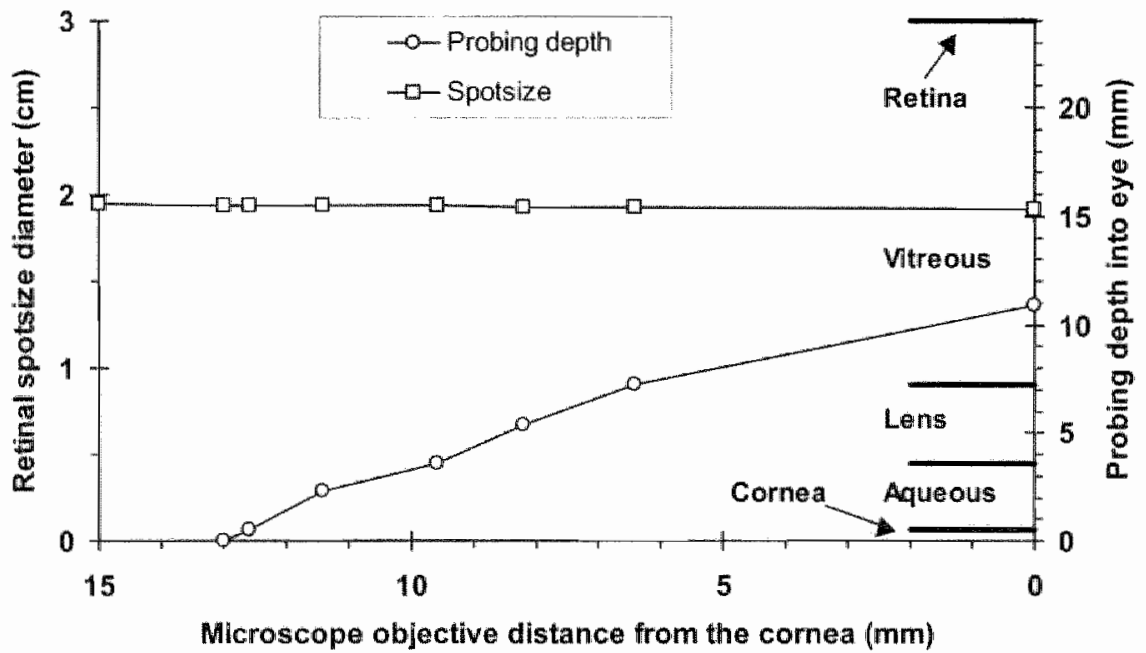

Figute 2. Redationship benwen the microscope objective distance $(N A=0.5)$ from the cornea $(0-13 \mathrm{~mm})$ and both the retinal spotsize diameter as well as the probing depth into the eye (emmetropic non-acomodated Gullstrand-Littman model-eye with a pupil size larger than the dianuter of the light-beany). 
lasers these limits are given by the maximum permissible exposure (MPE) as set forth by the ANSI Standard for the Safe Use of Lasers. ${ }^{24}$ These MPE-values are dependent on the wavelength, energy $(\mathrm{D})$, exposure duration ( $\mathrm{s}$ ), and rocinal spotsize diameter. In general, for continuous wave hasers at a given wavelength in the visible range, it can be stated that the longer the exposure tine and the larger the retinal spotsize, the lower the maximum permissible romal irradiance (in $\mathrm{mW} / \mathrm{cm}^{2}$ ). The latter dependence can be explained through the fact that in larger retinal spotsizes $(>10 \mu \mathrm{m})$, the radial dissipation of heat becomes megligible, effectively decreasing the threshold for retinal damage (Figure 3 ). In Figure 4 , the maximum permissible retinal irradiance for visible light as a function of both the exposure time as well as the retinal spotsize is depicted in graphical format. The retinal irradiance at the nomal range of operation of the laser confocal Raman spectroscopy system $\left(5-8 \mathrm{~mW} / \mathrm{cm}^{2}\right)$ is also outined. In addition to this, Table 1 depicts the retinal inadiances of various common lightsources as well as some frequently used ophthahmic equipment. It can be seen that the normal mode of operation of the CRS is in the blue light hazard range. However, high signall-to-noise ratio $R$ aman spectra could be recorded utilizing the proposed confocal $\mathbb{R}$ aman spectroscopy technique at a significantly reduced light load when compared to other sudies, thus yielding the possibility to perform in-vivo animal studies.

\section{The applications}

Chapter 4 provides an overview of the in vith animal (pilot)studies performed and describes the potential applications of confocal Raman spectroscopy in ophthalmology. The following chapters will deal in more detail with these applications.

The application of confocal Raman spectroscopy for the non-contact assessment of the nomal extent and cistribution of comeal hydration in the anesthetized rabbit is discussed in Chapter 5. In Chapter 6, confocal Raman spectroscopy is utilized for the non-contact assessment of changes in comeal hydration following topical application of a dehydrating agent in two legally blind paticnts. Chapter 7 reports on the application of confocal Raman spectroscopy fon the non-contact assessment of the drug transpot into the comea. The feasibility of CRS to perform remote temperature measurements in the eye is described in Chapter 8 .

Lastly, the summary describes what has been accomplished with this project and contains suggestions for future improvennents in order to increase the impact of Raman spectroscopy as a clmical diagnostic tool in ophthalmology. Although most studies have dealt with anmal experiments, one of the consistent features was the minimization of the amount of light needed to obtain an 
A

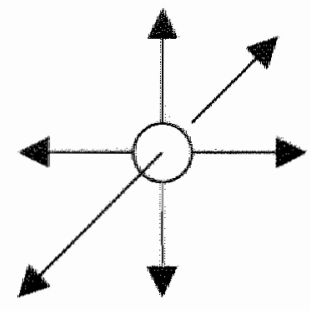

B

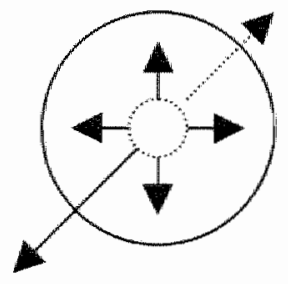

Figure 3. Heat transter in the retina during irradiation with wible light. In a small spot $<10$ Hon diameten. $[\mathrm{A}]$, heat can dissipate in all directions. In larger spot sizes, $[\mathrm{B}]$, dissipation of heat in the radial direction becomes negligible, effectively decreasing the threshold level for thermal damage to the retina. 1.e., if $10 \mathrm{~mW} / \mathrm{cm}^{2}$ would be the maximum safe irradintion lewel in situation [A], this would not be sate in situation [B].

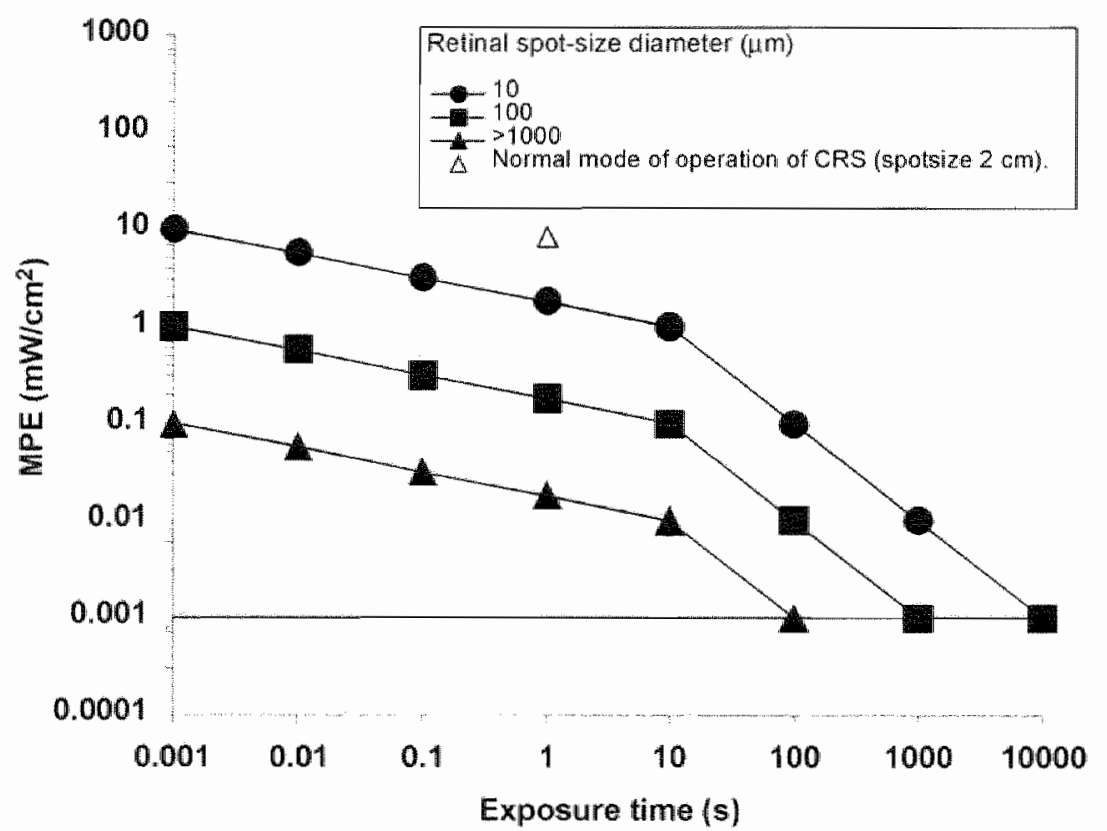

Figure 4. Maxinum permissible retinal irradiance (MPE; $m W / \mathrm{cm}^{2}$ ) to the retina of $1 \mathrm{~A}-$ ser-light $(400.550 \mathrm{~nm}$ ) as a function of exposure time (s) and retinal spot-size dianeter. Typcal mode of operation of CRS (open triangle) is: 1 s. exposures with $25 \mathrm{~mW}$ on retinal spotsize of $3 \mathrm{~cm}^{2}$. Horizontal line is the normal retinal irradiance caused by a TV-set or $1 / 10^{\text {th }}$ the retinal irradiance of a candle. 
Table 1. Retrial inradiance levels for continuous exposure to vanous lightsources

\begin{tabular}{|c|c|}
\hline Light source & Retinal irradiance (mW/cm') \\
\hline Daylight (inside) & 0.0001 \\
\hline TV & 0.001 \\
\hline Daylight (outside) & $0.001-0.1$ \\
\hline Candle & 0.01 \\
\hline Lightbulb: & 0.1 \\
\hline Blue light hazard & $0.1-1000$ \\
\hline Firework flash & 1 \\
\hline The sun & $10^{\circ}$ \\
\hline $1 \mathrm{~mW}$ Waser & $10^{6}$ \\
\hline Overhead surgical lamps & 24 \\
\hline Indirect ophthalmoscopy & 70 \\
\hline Slit lamp biomicroscopy & 210 \\
\hline Surgical operating microscope & 460 \\
\hline Typical operating mode CR5 & -8 \\
\hline *Short expsosure (<10 s.). & \\
\hline
\end{tabular}

acceptable signal, in order to increase the safety and applicability of this optical technique in the human eye. In future we expect to direct this research to a truly non-invasive Raman spectroscopy technique suitable for in vino diagnostic purposes in patients suffering from eye diseases.

\section{References}

1. Forresta JV, Dick AD, MCMenamin P, and Lee WR. Eds. Anatomy of the Eye. In: The Eye; Bati Stientes in Prathe, Saunders, London (1996), pp. 13-86.

2. Masters BR, Ed., Nonimasime Diagnosic Tedmintes in Ophnahmology. Springer-Verlag. New-York (1990).

3. Beman ER. Ed., Biohemistry of the Eyc, Plenum Bress, New York (1991).

4. Davson H. The Hydration of the Comea. Bixdem. J. 1955; 59: pp. $24-28$.

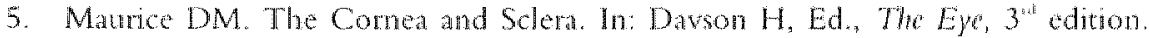
Academic Press Inc. Orlando (1984). Vol 1b: pp. 1-158.

6. Kanski J]. Disorders of the Connea and Sclera. In: Kanskj Jl, Ed., Clinwal Ophuhat mology, 1" edition. The C V Mosby Co. St. Louts (1984), pp. 5. 1-5.34.

7. Polse KA, Brand RJ, Vastine DW, et al. Clincal Assessment of Cormeal Hyctration Control in Fuchs' Dystrophy. Opton. Vis. Sa. 1991; 68(11): pp, 831-841.

8. Forrester IV, Dick AD, McMenamin P, and Lee WR, Eds., Biochemistry. In: The Eye; Basi Sientes in Protic, Saunders, London (1996). pp. $180-182$. 
9. Rabinovitch B, March WF, and Adams RL. Noninvasive Glucose Monitoring of the Aqueous Humor of the Eye: Part 1. Measurement of Very Small Optical Rotat tons. Diables Care 1982; 5 ; pp. 254-258.

10. March WF, Rabinovitch B, and Adams RL. Noninwasive Glucose Monitoring of the Aqueous Humor of the Eye: Pare IL Animal Studies and the Scleral Lens. Diabetes Care 1982; 5: pp. 259.

11. Cameron BD, and Cote GL. Noninvasive Glucose Sensing wtilizing a Digital Closed Joop Polarmetric Approach. IEEE Transations on Bionediat Enguneerimg 1997; 4,12): pp. 1221-1227.

12. Sawa M, Tsurimaki $Y$, Tsuru T, and Shmizu H. New Quantitative Method to Determine Protein Concentration and Cell Number in Aqueous in wow. Jpm. J. Ophihalmol. $1988 ; 32$ : pp. $132 \ldots 142$.

13. Erckens RJ, Motamedi M, Wicksted JP, and March WF. Raman Spectroscopy for Non-Invasive Characterization of Ocular Tissue: Potential for Detection of Biological Molecules. Jonmal of Raman Spectrosopy 1997; 28: pp. 293-299.

14. Damjanov l. Cell, tissuc and organ specific tumor markers; an overview. Cum. Top. Path. 1987; 77: pp. 367-384.

15. Dougherty PJ, Wellish KL, and Maloney $K$. Excimer Laser Ablation and Comeal Hydration. Am.J. Ophth, 1994; 118: pp. 169-176.

16. Lee VHL. Preconeal, Comeal, and Postcomeal Factors. In: Mitra AK, Ed.,

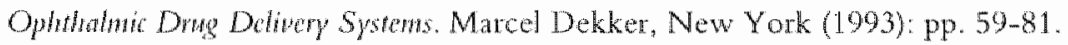

17. Wicksted JP, Erckens RJ, Motamedi M, and March WF. Raman Spectroscopy Studies of Metabolic Concentrations in Aqueous Solutions and Aqueous Humor Specimens. Applied Spetroxopy 1995; 49(7): pp. 987-993.

18. Puppels GJ. Confocal Raman Spectroscopy: a new look at cells and chromosomes. Thesis. University Twente, The Netherlands. 1991.

19. Ozaki Y. Medical Application of Raman Spectroscopy. Applid Spertosopy Revicus $1988 ; 24(384): \mathrm{pp} .259-312$.

20. Huizinga $A$, Bot $A C C$, de Mul FFM, Vrensen GFJM, and Greve J. Local Variation in Absolute Water Content of Human and Rabbit Eye Lenses Measured by Raman Microspectroscopy. Exp. Eyc Res. 1989: 48: pp. 487-469.

21. Siew DCW. Clover GM, Cooney RP, and Wiggins PM. Microm Raman Spectroscopic Study of Organ Culumed Comeac. I Raman Spectrosmpy 1995; 26: pp. $3-8$.

22. Sebar J. Nie S, Reiser $K$, Chatles MA, and Yu N-T. Raman Spectroscopy of Human Vitreous in Proliferative Diabetic Retinopathy. Inest. Ophinalwal. Vis. Si. 1994; 35: pp. $2976-2980$

23. Bernstein PS. Yoshida MD, Katz NB, MCClane RW and Gellermann W. Raman Detection of Macular Carotenoid Pigments in Intact Human Retina. Invest. Ophthalmel. Wis. Sil 1998; 39:2003-2011.

24. ANSI Standard Anerrican National Standards Institute. Safe Use of Lasers In: ANSI Srandad Z136.1. Laner Institute of America, Orlando, 1993. 


\section{Raman spectroscopy}

\section{Theory of Raman scattering}

When light interacts with a material, this usualy results in elastic (Rayleigh) scattering of the incident light, i.e. without the exchange of energy between photons and material (Figure 1). Raman scattering on the other hand is the result of an inelastic light scattering process, in which an exchange of energy between photons and molecules in the material occurs. A Raman scattered photon will therefore have an energy that is different from the energy of the incident photon. Since photon energy is linearly related to photon frequency (Appendix; Formulas 1-3) when monochromatic light is incident onto the material, the spectrum of the scattered light will show lines at frequencies different from that of the incident light. In a Stokes-Raman scattering process a specific amount of energy is transferred from the photon to the molecule, thereby exciting a molecular vibration in this molecule. The amount of energy that is transferred depends on the molecular vibration that is excited. Thus, the assessment of the frequencies of Raman scattered light can be utilized to identify specific molecular vibrations. In applied Raman spectroscopy a spectrometer is used to spatially resolve these frequencies into a spectrum of vibrational modes, the so-called Raman spectrum. The peak position of a particular Raman line is depicted as the difference between the incident light frequency and the Raman scatter frequency $\left(v_{1} \pm v_{v i b}\right)$, and is independent of the irradiation wavelength used. Raman scattering can either be the result of acceptance or transfer of photon-energy by the molecule, hence a decrease or increase in scattered light frequency, respectively (Appendix; Formula 4 and 5). The former is commonly represented by the so-called "Stokes lines" of a Raman spectrum with a frequency of $v_{0}-v_{\text {vib }}$, while the latter are the "anti-Stokes lines" $\left(v_{0}+v_{\text {vib }}\right)$ (Figure 2). At room temperature the amount of molecules in the unexcited vibrational state is higher than molecules in excited vibrational states (Appendix; Formula 6). Consequently, more molecules will accept energy rather than transfer energy. Thus, in a typical Raman spectrum the Stokes lines are significantly more pronounced than the anti-Stokes lines, and in general the latter are omitted from a Raman spectrum. The Raman scatter intensity is linearly dependent on the concentration of the species of molecules giving rise to the Raman line, the intensity of the incident light, the frequency of the scattered 


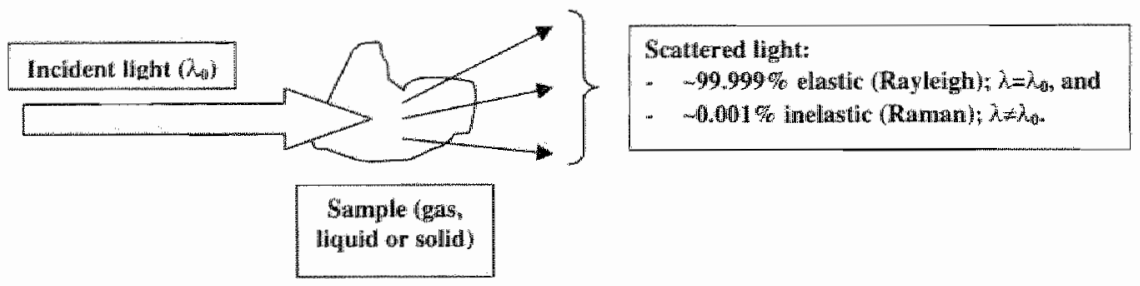

Figure 1. Elastic and inelastic (Raman) light scattering.

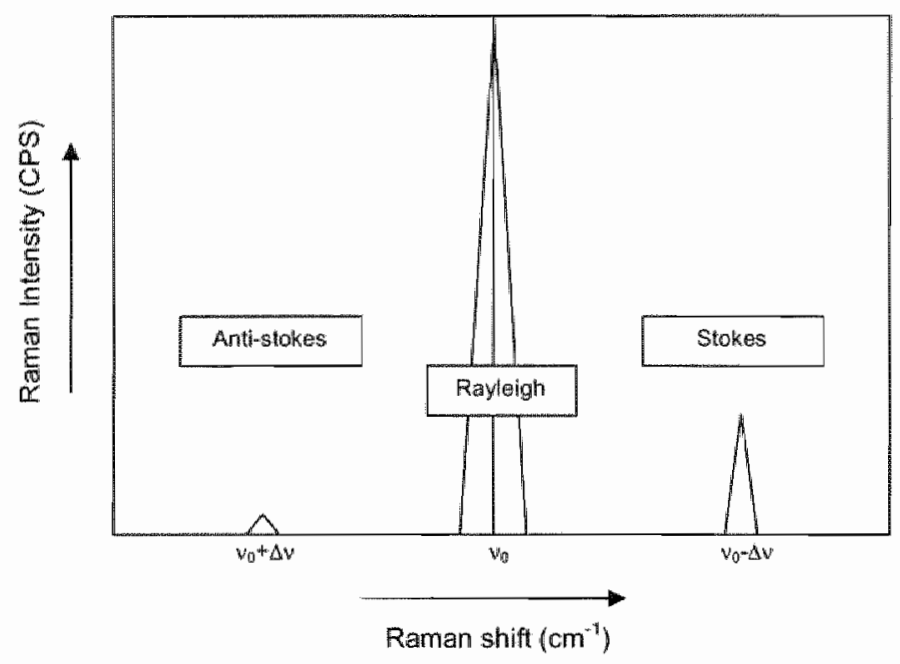

Figure 2. Principles of a Raman spectrum (see text voor derails).

light to the fourth power and the molecular polarizability to the second power (Appendix; Formula 7).

\section{Principles of applied Raman spectroscopy}

In essence, Raman spectroscopy yields information on intramolecular chemical bonds and the interaction of molecules with their direct environment. Various advantageous characteristics make this technique suitable for biochemical analysis of biological media. The inherent specificity of Raman scattering yields the possibility to identify entire biomolecules at once. Furthermore, the dymamics of processes involving biochemical changes in living material can be 
studied with time-resolved (nano- or even pico-second) Raman spectroscopy since Raman scattering occurs very fast $\left(-10^{-16} \mathrm{~s}\right)$. In addition the medium of interest in Raman spectroscopy can either be in gaseous, liquid, or solid fom. Unlike infrared absorption spectroscopy Raman spectroscopy is not hampered by the presence of water, and the ability to assess bionolecules in aqueous solutions is not trivial since most of the biological media in living physiological systems contain water. Lastly, Raman spectroscopy systems yield the possibiliny for remote sensing and in vito application since non-contact probing is possible with the use of (fiber)optics. All these characteristics make Raman spectroscopy a versatile and powerful biochemical analytical tool, and with the right system design this technique can be applied in various fields of medicine ${ }^{3}$, including ophthalnology.

\section{Raman spectroscopic techniques and systems}

In general, all Raman spectroscopy systems consist of the same basic components: a (monochromatic) light-source, some auxiliary optics, a specmometer, and a photon-counting device (Figure 3).

Because the intensity of Raman scattering is ustally very weak $\left(\sim 10^{-4}-10^{-6}\right.$ of the intensity of Rayleigh scattering), a light-source of sufficient intensity is needed in applied Raman spectroscopy. Furthermore, it is obvious that this light-source should be monochromatic in order to identify changes in scattering frequency (C.V. Raman used filtered sunlight). "With the introduction of the laser in the 1960 's a wide variety of stable monochromatic light-sources of sufficient intensity and coherency have become available. The laser is now the light-source of choice in Raman spectroscopy. Because the Raman shift position is independent of the wavelength of the irradiating photons a multitude of different laser-wavelengths can be used, depending on the conditions necessary during the Raman scattering experiment. Ultraviolet (UV) is utilized in those cases where the use of visible light might lead to the occurrence of interfering Auorescence, and is applied in time-resolved UV resonance Raman scattering experiments. 4 Raman spectroscopy using infrared (IR) and nearinfrated (NIR) wavelengths for excitation have found significant applications in for example the detection of cancers and pre-cancers. ${ }^{6-9}$ The possibility to include tumable dye lasers $(280-1500 \mathrm{~mm})$ into a Raman spectroscopy systen has allowed investigators to find the most suitable wavelength with regards to Raman yeld and fluorescence reduction. 10,11 However, in general mostly visible laser sources are used of which the Argon and Krypton laser are the most universal. 12

The auxiliary optics can be divided into two functional categories (although both categries are sometimes combined to perform both functions at the same 


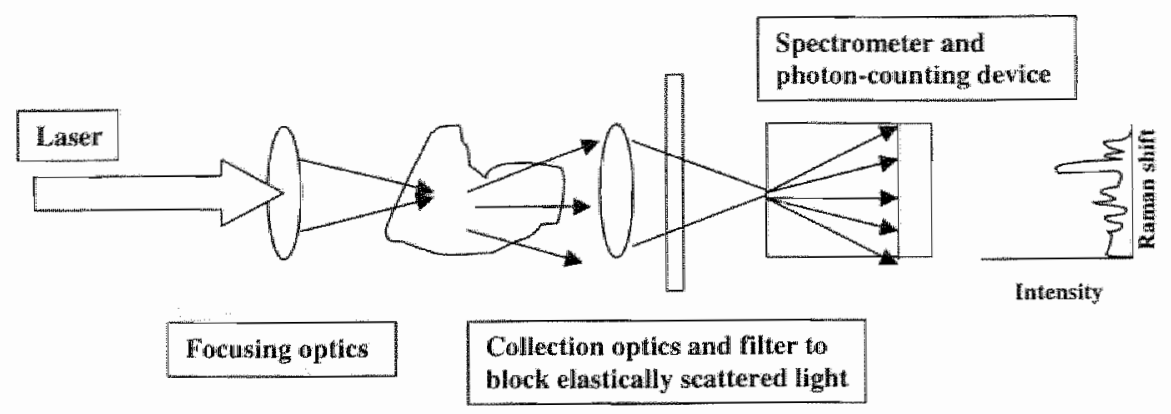

Figure 3. Basic Raman spectroscopy system.

time): optics to transfer and focus the irradiation light onto the sample, and optics to collect as much of the scattered light as possible while transferring only the Raman scattered portion to the detector-site, by blocking elastically scattered light. In both instances the use of fiber-optics is becoming increasingly popular. ${ }^{13-15}$

A spectrometer spatialy disperses the incoming Raman scattered light like a prism, and effectively resolves this light into a spectrum of Raman frequencies. At the exit port of the spectrometer this spectrum is detected and recorded either sequentially by a single scanning photonultiplier tube (PMT), or in real-time by a multichannel detector, i.e. a charged coupled device (CCD) array. 16

The Raman yield during a Raman spectroscopic experiment is determined. by the aforementioned different components used as well as the sample itself. The absolute Raman intensity is directly proportional to the intensity of the incident laser light, the frequency of the scattered light to the founth power (mostly with the same wavelength as the incident light), and the dipole polarizability of the molecules to the second power (Appendix; Formula 7). As mentioned before, the Raman intensity is also a function of the concentration of molecules in the sample of interest which yield the potential for quantitative biochemical analysis. Small probing volumes are sometimes necessary and can be achicved using high magnification microscope objectives. ${ }^{17}$ The collection site of a Raman spectroscopy system should be optimized for maximum (Raman) light gathering power, and this can be achieved using a high numerical aperture (NA) objective at the site of the sample or by multiple collectors in the form of a multi-fiber. ${ }^{4}$ In addition, the losses in the remaining optics (filters, focusing lenses, and spectrometer) should be kept at a minimum, while the actual photon counting device should obviously be sufficiently sensitive for the scattered frequencies. 


\section{Applications of Raman spectroscopy in biochemistry}

Over the last 30 years, the interest in Raman spectroscopy (RS) has been advanced steadily as can be seen by the increasing amount of scientific publications on this topic during this period (Figure 4). Two technological developments clearly boosted the potential for applicability of Raman spectroscopy in biology and medicine: the introduction of the laser in the late 1960's, and the application of highly sensitive detectors in the visible range that started in the 1980 's. However, it was the knowledge that the Raman signature of simple molecular bonds (i.e. O-H, C-H, S-H, N-H, S-S, C=C, C=O) could be used to explain the Raman features of larger and more complex bionolecules, that has contributed more significantly to the applicability of RS in biochemistry ${ }^{2}$. The fact that these so-called group-frequencies (see for example Table $1.3 \mathrm{~m}$ Ref. 19) are characterized by Raman-lines with highly consistent positions, regardless of the biochemical compound studied, has actually been the key factor in interpreting a Raman spectrum as being the 'blue-print' of a biomolecule with regards to its chemical composition (=primary structure), confomation (Esecondary, tertiary, and quatemary structure) and environment. Thus, Raman spectroscopy has been applied in every aspect of biochenistry, from the biochemical characterization of nucleic acids and related compounds, amino-acids, polypeptides, proteins, lipids and cellular membranes, carbohydrates, and bacteria and viruses, to the Raman spectroscopic study of cells, tissues and even whole organs. The application of RS in biochemistry has always been in close relation with, if not the necessary stepping stone to, applica tions of RS in medicine, although dinical applications have been limited to the use of Raman spectroscopy in anesthesiology for the quality control of expired gases. ${ }^{18}$ Since the scope of this thesis does not permit for a thorough discussion on all the applications of Raman spectroscopy in the field of analytical biochemistry, biology, and medicine. I would like to refer the reader to the abundance of excellent works that have been written about this subject, ${ }^{2.19-2.3}$ and will focus on the applications of RS in ophthalmology in particular.

\section{Applications of Raman spectroscopy in the eye}

Biochennical characterization of proteins in general entails the assessment of the chemical signatures of the individual protem constituents, being the polypeptides and amino-acids, for which Raman spectroscopy is inherently suitable. Although specific signatures can be obtained from each biochemical, the assessment of the primary structure (i.e. the order in which the polypeptides appear and the sequence of amino-acids herein) is much morc difficult to attain, 


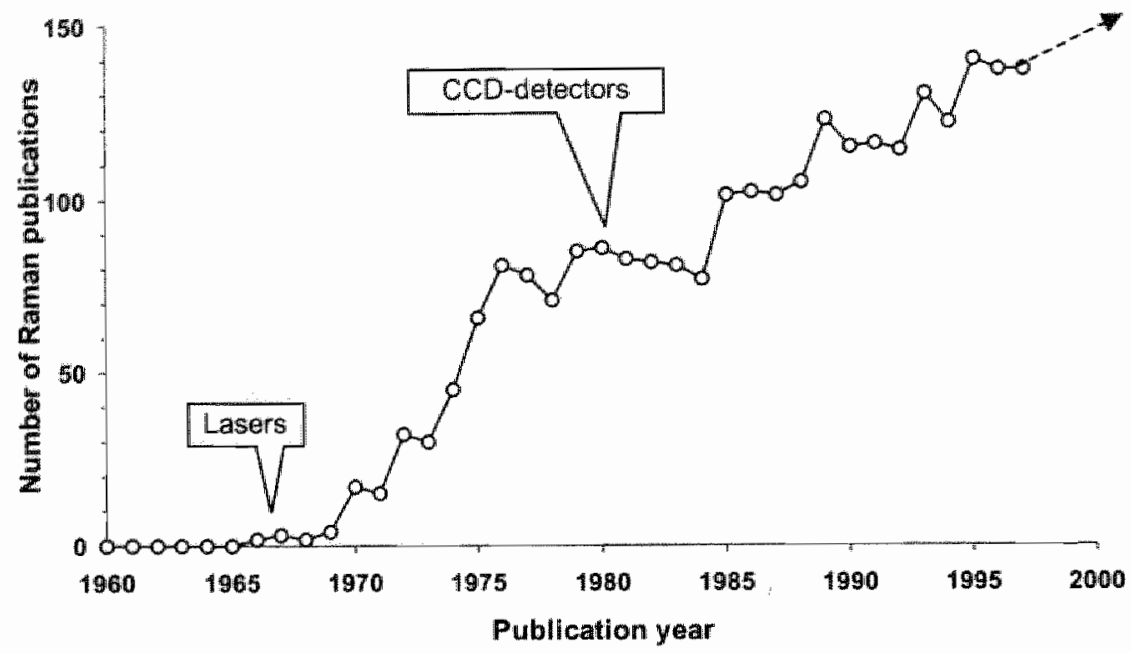

Figure 4. Number of new MEDLINE-publications on "Raman" from 1960-1997. "Lasers' and 'CCD-detectors" refer to the application of the laser and the CCD-detector in Raman spectroscopy systems, respectively.

and usually other biochemical assays have to complement the Raman spectroscopic findings. However, Raman spectroscopy offers valuable information on the conformational structure of proteins, which is almost equally important to their function as primary structure. 24,25 The secondary protein structure is detemined by the shape of the protein backbone of amide-bonds, $-\mathrm{O}=\mathrm{C}-\mathrm{N}-\mathrm{H}-$. Both the amide-bonds and the shape of the protein backbone determine the position of the Raman-amide bands, which are denoted Amide I through VIl, A and B. Amide-modes I and III are particularly Raman-active, and their signals are used to determine the contormation of the peptide in question. The Amide I Raman signal is the combined result of the vibrations of $\mathrm{C}=\mathrm{O}(80 \%), \mathrm{C}-\mathrm{N}(10 \%)$, and $\mathrm{N}-\mathrm{H}(10 \%)$. Its Raman bancl ranges from 1645-1680 $\mathrm{cm}^{-1}$, depending on the conformation. The Amide lll mode frange $1225-1310 \mathrm{~cm}^{-1}$, which is much more difficult to interpret due ro overlapping $\mathrm{CH}$-and several amino-acid ring vibrations, involves $\mathrm{C}-\mathrm{N}(40 \%), \mathrm{N}-\mathrm{H}(30 \%)$, $\mathrm{CH}, \mathrm{C}(20 \%)$, and very litte $\mathrm{C}=\mathrm{O}$ vibrations. Since a protein is made up of many peptides, the Amide 1 and IIl modes of this protein in a Raman spectum will be the result of the sum of all individual peptide bond vibrations. Thus, in order to determine the conformation of a protem, or rather peptide back-bone, it is custom to analyze both the Amide I as well as the Amide III mode. In an a helix conformation the Amide I mode can be found at $\sim 1645-1657 \mathrm{~cm}^{-1}$, 
while the Amide III is at $-1260-1310 \mathrm{~cm}^{-1}$. A $\beta$-sheet conformation has an Amide I mode at $\sim 1665-1680 \mathrm{~cm}^{-1}$ and an Amide IIl at $\sim 1225-1245 \mathrm{~cm}^{-1}$. A random coil protein confomation is present when the Amide I mode is found at $\sim 1660-1665 \mathrm{~cm}^{-1}$ while the Amide III mode is at $\sim 1240-1250 \mathrm{~cm}^{-1} 24$

The biochemical contents of the ocular media consist for a large part of water and proteins and are closely related to the nomal function of these tissues (Table 1). Not only do proteins mantain the structual integrity of ocular tissues (i.e. collagen fibrils in the comea), but certain non-structural proteins also perform specialized functions as homones, enzymes, and neurotransmitters, on more importantly function in such a way that they pemit optimal light transmission in the case of lens crystallins, 26,27 When nomal function and physiology of these proteins is hampered by biochemical changes within the cissues various acular pathologies may arise which might ultinately lead to vision loss or blindness. It has been the abject of many investigations to try to identify these biochemical changes in order to decrease the accurrence of pachology by providing a basis for early diagnosis and therapy. Also Raman spectroscopy has been applied in the biochemical analysis of ocular tissues and has made significant contributions to the field of ocular biochemistry.

Applied $\mathbb{R}$ aman spectroscopy in ophthalmology has mainly focused on the elucidation of biochemical processes in the ocular lens in particular with regards to cataract fomation, and a vast amount of publications are available in the literature. ${ }^{28-71}$ This can be understood when considering the high incidence of cataract in the nomal population and the potentially significant clinical importance of early diagnosis and treament of this degenerative disorder. ${ }^{27}$ In addition, the lens contains a high concentration of proteins yielding strong Raman signals, and human tissues are readily available. The ocular lens is a transparent medium composed of closely packed lens fiber cells which, upon maturation, specialize in producing the lens crystallins $(\alpha, \beta$, and $\gamma$-types and subtypes, all in the $\beta$-pleated sheet confomation that are mbedded in a cytoskelotal marrix. Protein synthesis stops when the lens fiber cells are mature and ancuckate. The lens has an epitheliallayer for maintenance of the flud and electrolyte trasport, and is bordered by apd-containing semi-permeable capsule. The water content of the lens ranges from $68 \%$ in the nucleus to $80 \%$ at the periphary. Aging of the lens is accompanied by changes in macromolecular structure, protein and water content, monphologically characterized by disorganization of the lens fiber cells, and the formation of wacuoles and electron-dense bodies. Functional changes during lens aging include ion channel dystunctions, and decrease in enzyme activity in the nucleus but not the cortex or cpithelium. Vision loss in cataract is caused by decreased transmission of light as a result of a disruption in the ordered packing of the lens crystallins due to increased water accumulation in the lens, formation of high molecular weight protein aggregates 
Table 1. Anatomy of the ocular media with respect to biochemistry and physiology (Adapted from Ret. 26).

Deular tissue (thickness)

Tearofilm ( $45 \mathrm{fm})$

- Lipid layer

- Aquous layer (60\%)

- Mucus laver (30-40\%)

Comea $(\sim 520 \mu \mathrm{m})$

- Epithelium (50-60 $\mu \mathrm{m})$

- Bowmans layer (8-12 $\mu \mathrm{m})$

- Stroma $(\sim 4.50 \mu \mathrm{m})$
Biachemical contert

- Meibomian linvids

- Water with soluble lactoferrin, lysozyme, and Igth.

\section{- Mucin}

- Keratin-expressing cells: collagen Types IV, WII, DX, and $X V I$, and heparan sulfate (basal Lamina)

- Collagen Type I, III and IV

- $80 \%$ water, structural fibrillar collagen Types I $(-50 \%), \mathrm{V}$ $(10 \%)$, and III $(\sim 2 \%)$, structural non-fibrillar collagen Type VI

$(\sim 35 \%)$, and $\sim 5 \%$ glycosaminaglycans, all produced by the keratocytes

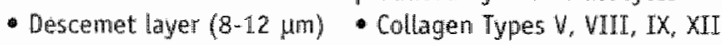

- Enctothelium (5-6 $\mu \mathrm{m})$

Anterior chamber $(2-3, \mathrm{~mm})$

- Aqueous humor

Lens $(\sim 4 \mathrm{~mm})$

- Capsule (9-28 um)

- Epithelium

- Cortex and nucleus
- Single endothelial cell-layer

- Water $(\sim 100 \%)$ and glucose, lactate, ascorbate, albumin, transferrin, fibromectin, IgG, Na, $\mathrm{K}, \mathrm{HCO}_{3}, \mathrm{Mg}, \mathrm{Ca}, \mathrm{Cl}$

- Collagen Type IV and heparan sulfate

- Single cell layer

- Water (68-80\%) and cytorkelletal matrix embedded crystallins $(\alpha, \beta$, and $\gamma)$ produced by the ters fiber cells, which contain various mambrane protenins (ATP-ases, calpactin-1, $N$-cadherin)
Physiological function

- Prevention of ewaporation, and tear-spillover, and provides clear aptical medium

- Lubrication, equalizing optical imperfections of comea, and bacteriostatic function.

- Tear-film stabilization

- Barrier-function and light refraction

- Elasticity and deformability

- Corneal structure and transparency

- Strength and resistance to IOP.

- Water transport out of the stroma.

- Intraacular pressure (IOP), and metabolism and transport

- Diffusion barrier

- Mainteniance of fluid and electrolyte ballance

- Lens structure and transparency (300-1400 nm) 
and vacuole formation within the lens fibers. A mulcitude of biochemical factors are involved in the process of cataract formation, including increased proten cross-linking and aggregation, oxidation of ammo-acids (tryptophan photolysis), decreases in the antioxidanes and glutathone, increased proteolysis, loss of $\alpha$-and $\gamma$-crystallins, and nonenzymatic glycation of lens proteins. The latter is possibly inhibited by the reducing action of glutathione on ascorbic acid. 26

Raman spectroscopy of the ocular lens yields specifie signals in both the lower as well as the higher Raman shift region as depicted in Figure 5 f for band assignments see Table 2). Clearly visible are Raman bands that can be assigned to the amino-acids tyrosine (Tyr: 644, 828,857, 1175, 1208, and $1620 \mathrm{~cm}^{-1}$ ), phenylalanine (Phe: 622, 1003, 1032, 1175, and $1610 \mathrm{~cm}^{-1}$ ), and tryptophan (Trp: $756,878,1340,1546$, and $1581 \mathrm{~cm}^{-1}$ ), some group-frequencies (C-C, $\mathrm{C}-\mathrm{N}, \mathrm{CH}, \mathrm{CH}_{2}$, and $-\mathrm{CO}_{2}$ ), and the Amide modes $I$ (at $1668 \mathrm{~cm}^{-1}$ ) and $\mathrm{III}$ (at $\left.1238 \mathrm{~cm}^{-1}\right)$, denoting the $\beta$-sheet conformation. The higher spectral region exhibits the aliphatic (at 2880, 2930, and $2960 \mathrm{~cm}^{-1}$ ) and aromatic $\left(3060 \mathrm{~cm}^{-1}\right)$ $\mathrm{C}-\mathrm{H}$ vibrations of the lens proteins (crystallins), and the $\mathrm{O}-\mathrm{H}$ vibrations of water (at 3230,3390 , and a shoulder at $\sim 3550 \mathrm{~cm}^{-1}$ ). The Raman intensity ratio $1(3390) / 1(2930)$ is in direct proportion to the relative hydration of the lens, and has been used in the past to spatially resolve the regional variations of water within the lens along the optical axis, ${ }^{56,61}$ The local differences in Raman spectral features are quite obvious in the higher spectral region (Figure $5 \mathrm{~B}$ ), where it can be seen that the the water content is higher in the cortical than in the unclear region of the lens, which is in agreement with earlier finds.

In 1975, Yu et al. Were the first to publish their results on Raman spectroscopic investigations of the ocular lens proteins, and lay the basis for all future investigations on aging and cataract-fomation in the lens, ${ }^{28,29} \mathrm{R}$ aman spectra of the lens crystallins $(\alpha, \beta 1, \beta 2, \beta 3$, and $\gamma)$ and albuminoid showed that these compounds are mainly in the antiparallel $\beta$-pleaded sheet conformation. Furthemone, in the intact lens the amount of $\gamma$-crystallin was found co be higher in the nucleus while the $\alpha-c r y s t a l$ in amonn increased from the nucleus to the cortical region of the lens. They also found that lens opacification does not necessarily entail oxidation of sulfhydryl or involye conformational changes, since heat denaturation does not result in an altered SH content or a change in P-sheet conformation. ${ }^{2}$ Opacification might rather be the result of macromolecular rearrangement causing large refactive index differences. Experimental proof of latter suggestion was given by Schachan and Solin and later by Ondruska and Hanson. ${ }^{30,31}$ Former authors showed a remarkablo similarity in lens protein macro-structure (lens fiber cross-section) and micro-structure (the $\beta$-sheet conformation), and conchded that cortical cataracts are the result of fuctuations in the orientational order or lens proteins. ${ }^{36}$ 

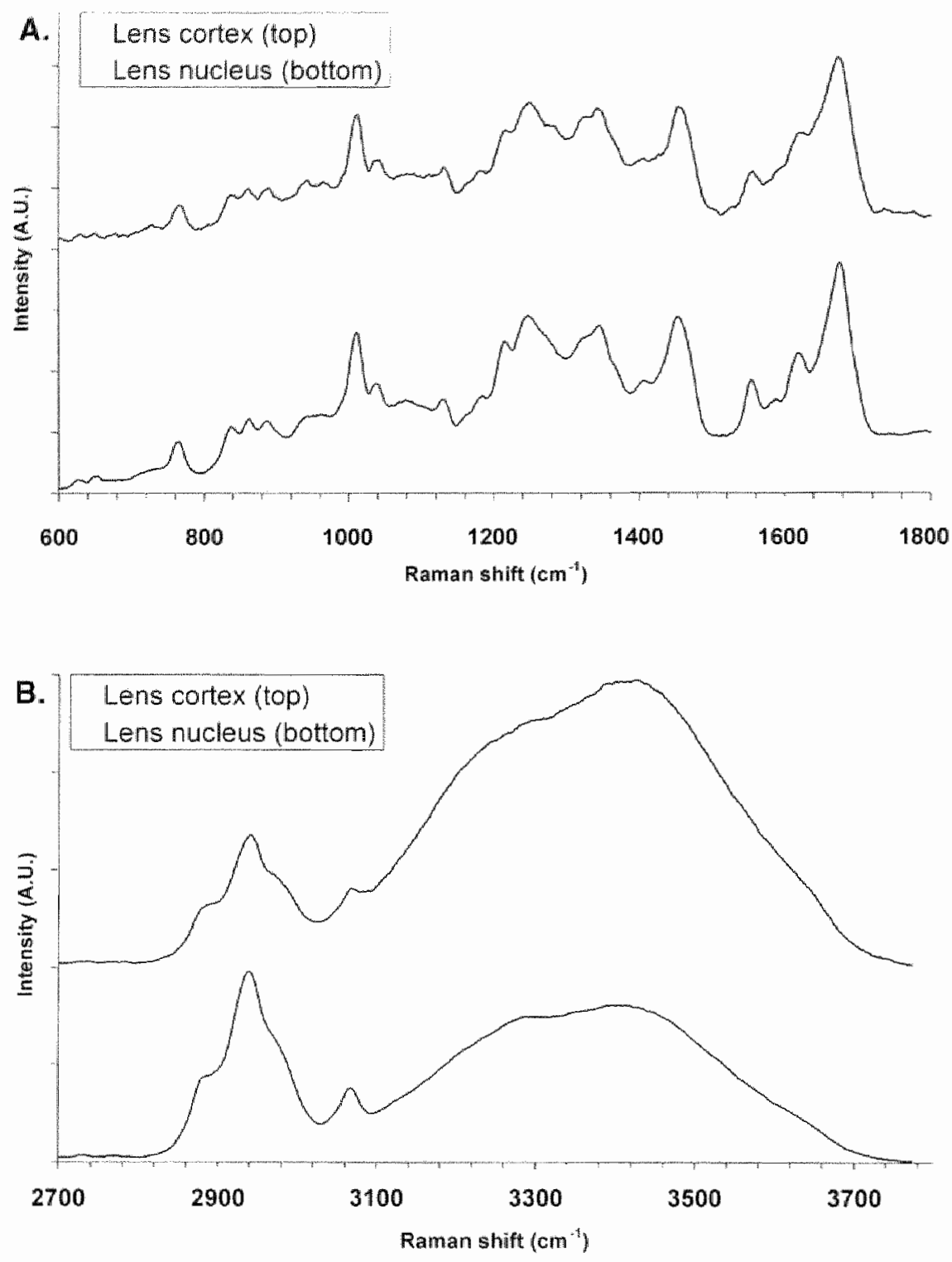

Figure 5. Raman spectra in the lower (A) and higher (B) Raman shift region from 600-1800 $\mathrm{cm}^{-1}$ ind from $2700-3800 \mathrm{~cm}^{-1}$, respectively, of the cortical and nucleat region of a nomal NZW rabbit lens ins sto Experinental conditions: CRS with Argon laser (514.5 nm, 25 mW). $25 \times$ NA 0.5 long-Working distance nicroscope objective, 50 Hm fiber as confocal pinhole, I s exposure times (spectra are digitally smoothed). Top spectra are off-set for clarity. 
Table 2. Raman band assignments of in-situ NZW rabbit ocutar lens.

Raman shift position $\left(\mathrm{cm}^{-1}\right)$

\begin{tabular}{|c|c|c|}
\hline Cortex & Nucleus & $\begin{array}{l}\text { Raman band assignnent } \\
\text { Adapted from Ref } 29\end{array}$ \\
\hline 622 & 618 & Phenylatanine(Phe) \\
\hline 644 & 645 & Tyrosine (Tyr) \\
\hline 756 & 758 & Tinptophan (Tp) \\
\hline 828 & 828 & Tyr \\
\hline 857 & 854 & Tyr \\
\hline 878 & 877 & Trp. \\
\hline 938 & 927 & $C C$ vibration \\
\hline 960 & 957 & C-C vibration \\
\hline 1003 & 1003 & Phe \\
\hline 1032 & 1032 & Phe \\
\hline 1072 & 1072 & C-N vibiation \\
\hline 1127 & 1125 & C-N vibration \\
\hline 1157 & 1151 & C-N vibration \\
\hline 1175 & 1171 & Tyr and Phe \\
\hline 1208 & 1203 & Tyr \\
\hline 1238 & 1241 & Amide II \\
\hline 1320 & 1320 & $\mathrm{CH}$ deformation. \\
\hline 1340 & 1340 & Trp \\
\hline 1401 & 1398 & $\mathrm{CO}_{2}$ \\
\hline 1447 & 1444 & $\mathrm{CH}_{2}$ deformation \\
\hline 1546 & 1546 & Trp. \\
\hline 1581 & 1584 & Trp \\
\hline 1610 & 1604 & Phe \\
\hline 1620 & 1618 & Tyls \\
\hline 1668 & 1669 & Amldel \\
\hline$\sim 2880, \sim 2930, \sim 2960$ & $\sim 2880_{4} \sim 2930 \sim 2960$ & Aliphatic CH ytortion \\
\hline-3060 & -3082 & Aromatic cl vibration \\
\hline$\sim 3230, \sim 3390,-3550$ & $-3230, \sim 3390, \sim 3550$ & OH vibrations \\
\hline
\end{tabular}

The first proof that conformational changes do prelude opacification was shown in young bird and reptile lenses, since on hat-coagulation a conversion from an $\alpha$-helical (nomal in these species) to the $\beta$-pleated sheet conformation was observed. ${ }^{32}$ Over the years various species, including the human, have been the subject of investigations on cataract formation, and numerous cataractogenic factors have been studied from nomal aging, to UV-induced cataract, heat-or 
cold-induced catart, glucocorticoid-induced cararact, herediary cataract, and galactose-induced catarace, by characterizing structural changes in the ocular lens with Raman spectroscopy. A significant amount of these studies focused on the conformation of the lens proteins, on the contents of sulfiydryl $(\mathrm{SH})$ and disulfide (SS) in the ocular lems, and consequenty on the so-called 2-SH $\rightarrow$ SS conversion, a possible causative factor in cataractogenesis ${ }^{29,33-51}$ Furthemore, the water content of the lens has been of considerable interest, since lens hychation changes during cataractogenesis. $29,31,40,42,44,47,52-64$ In addition, lens membrane lipids and the changes in cholesterol content and distribution have been studied, since they are thought to be inwolved in the process of cataractogenesis. $49,63,65-71$ Nowwithstanding different findings among the various species and cataract models used, the overall results of these studies could be summarized as follows:25

1. Raman spectroscopy is a powerful diagnostic tool for biochemical characterization of the lens protein structures, protein side chain groups (tyrosine, tryptophan, phenylalanine, sulfhydryl, disulfide), and water;

2. Normal biochemical content of the ocular lens and the protein structural changes that occur upon lens aging and cataract formation are not necessarily the same for each species;

3. Mammalian lens crystallins are all in the $\beta$-pleated sheet conformation, as assessed using the information of the Amide I and III Raman vibrational modes;

4. The spatial distubution of sulfhydryl (SH), disulfide (SS), amino-acids (tyrosine and tryptophan), crystallins, and water is not uniform in a nomal lens. Both the extent and distribution of these biomolecules change with age and upon cataract formation as a result of posttranslational changes in protein synthesis (i.e. cross-linking, decreased solubility, proteolytic denaturation and degradation, and aggegation);

5. Cataractogenesis is not necessarily preceded by protein conformational changes, but the result of macromolecular disorganization. Furthemore, the $S H \rightarrow S S$ conversion does not seem to be a predominant factor in catartogenesis, but rather occurs during stabilization of alleady fomed prorein aggregates;

6. In the human, a slight change in SH but not in SS content is detectable upon aging. Possibly, glutathione (GSH) is oxidized by a reaction with protein-disulfide (P-SS) groups to form protein-sulfhydryls (P-SH) and mixed disulfides of protein and glutathione. The mixed disulfictes are reduced to P-SH and glutathione-disulfide (GSSG), which is extruded from the lens. Thus, P-SH is kept in a reduced state, while P-SS concentrations remain low. Other reasons for the observed difference between the extent of $\mathrm{SH}$ reduction and $\mathrm{SS}$ formation could be that during aging $\alpha$-and 
$\beta$-crystallins (low in SH) synthesize faster than $\gamma$-crystallins (high in $S H$ ). and/or the rate of ghtathione synthests changes during anging:

7. Elevated levels of hydrogen peroxide in the agueous humor of diabetic patients could be the oxidizing agent during this process of cataractogenesis;

8. Changes in tyrosine-hydrogen bonding is caused by protein-water phase separation and is a possible causative factor for cataract formation;

9. Changes in lens biochemistry can be detected prior to visually detectable opacification, and entail changes in hydration and a faster $\mathrm{SH} \rightarrow \mathrm{SS}$ conversion as compared to nomal aging. This yieds the possibility for canly diagnosis and intervention.

Although less frequently, Raman spectroscopy (RS) has also been applied for biochemical analyses of the comea and its constiment ${ }^{72}-7 \%$, the aqueous humor ${ }^{77,78}$, the vitreous body, ${ }^{79}$ and the retina and its visual pigments ${ }^{\text {siths }}$,

In a study by Sebag et al., RS was applied for the biochemical analysis of human vitreous humor in order to investigate the reported increase in nonenzymatic glycation of the vitreous in diabetic retinopathy. With the occurm rence of a $R$ aman band at $3057 \mathrm{~cm}^{-1}$ (aromatic $\mathrm{C}-\mathrm{H}$ strerching) and a thee-fold increase in a Raman band at $1604 \mathrm{~cm}^{-1}(\mathrm{C}=\mathrm{C}$ vibations), assigned to $\pi$-conjugated and aromatic molecules, the occurrence of advanced nonenzymatic glycation could be confirmed. ${ }^{9} 9$

Raman spectroscopic studies of the aqueous humor were carried out by our group with the initial objective of detemining the feasibility of $R S$ for the non-contact assessment of glucose in the eye ${ }^{77}$ Although the mature of the glucose molecule does not permit unambiguous identification in a misture of biomolecules, since the Raman signal of glucose is usually non-specific, it was shown that $\mathbb{R} S$ is a potentially valuable tool for the non-contact characterization of biomolecules in the aqueous humor. ${ }^{78}$

Only a fow studies have focused on using RS for the biochemical chancterization of the comea. ${ }^{72-75}$ The typical Raman specra or a fresh NZW rabbit comea, a similar comea after yophilization (complete dehydration), and a therapeutic collagen sheld are depicted in Figure 6, to help illustrate the findings in mentioned RS studies. The Raman band assignments of these spectra are summarized in Table 3 . In the lower spectral region (400-1800 $\mathrm{cm}^{-1}$ ), Raman bands for aminowacids (Ty, Trp, Phe, Pro, Hypro) are ensily distinguishable, together with some group-frequencies $\left(\mathrm{C}-\mathrm{C}, \mathrm{COO}, \mathrm{CH}_{3}, \mathrm{CH}_{2}, \mathrm{C}-\mathrm{N}\right)$, and the Amide modes I and III. In the fresh comea, an Anide I mode $1648 \mathrm{~cm}^{-1}$ and wo Amide III modes, of which the one at -1270 is much smonger than the one at $\sim 1244 \mathrm{~cm}^{-1}$, are visible. The occurrence of two Anide 1 ll modes has been explained by Frushour and Koenig as being the result of the polar and non-polar regions of the collagen polypeptide chains. ${ }^{76}$ The Amide I mode at $1648 \mathrm{~cm}^{-1}$ is suggestive for an $\alpha$-helical protein conformation, and this confirms 

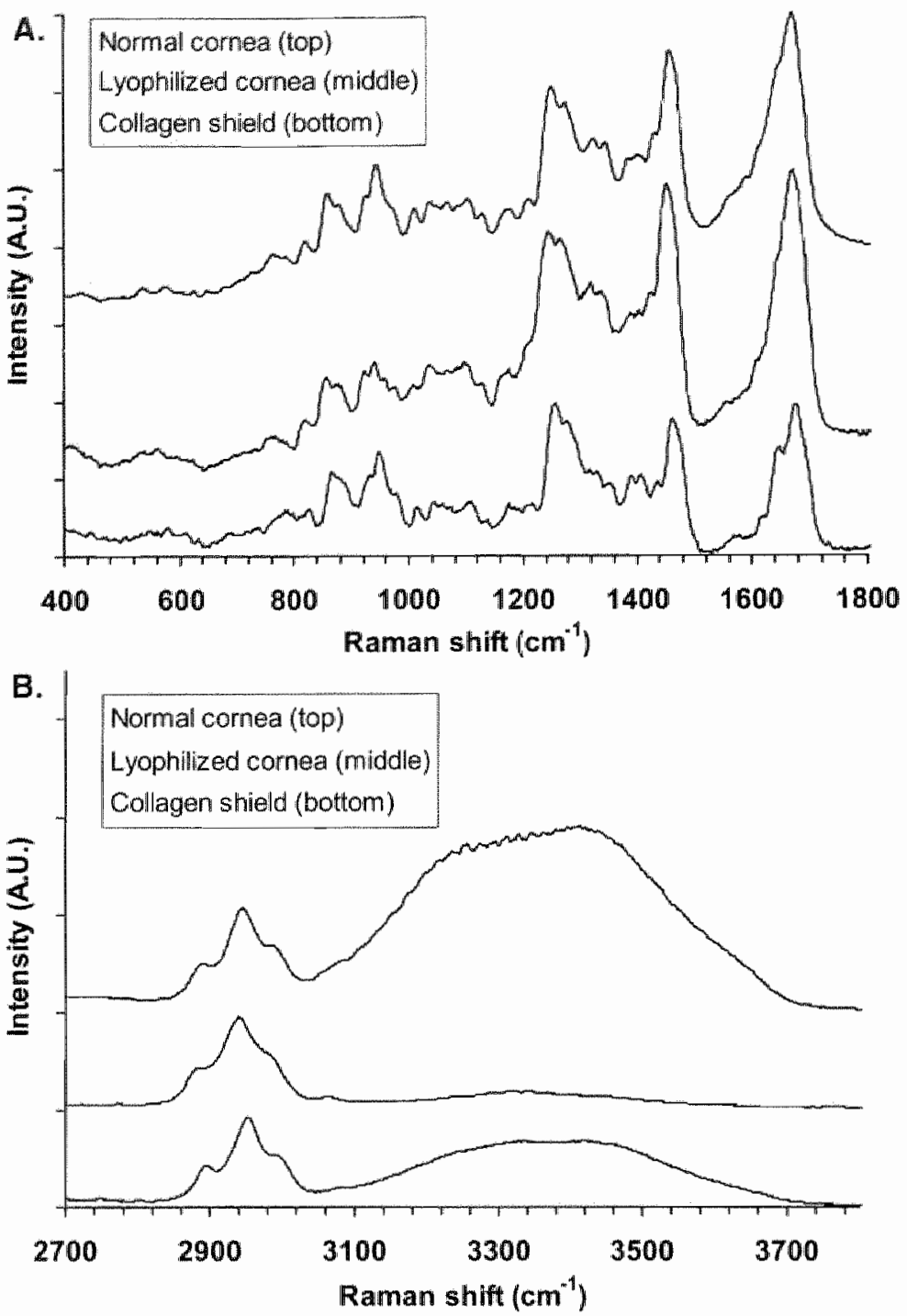

Figure 6. Ramin specta in the lower $(A)$ and higher (B) Raman shift region from $400-1800 \mathrm{cnh}^{-1}$ and from $2700-3800 \mathrm{~cm}^{-1}$, respectively, of a nomal NZW rabbit comata measured in sim, a jyophlized (completely water-frec) $N Z W$ rabbit comen in with. and a therapeuric collagen sheld (Biocor II, Bausch \& Lomb, Tapa, $\mathrm{F}$ ), made of porcine collagen. Experimental conditions: CRS with Argon haser ( 514.5 mm, $25 \mathrm{~mW}$ ), 25x NA 0.5 long-working distance microscope objective, 50 Hm fiber as confocal pinhole, Is exposure times (spectra are digitally smoothed). Top spectma are off-set for charity. 
Table 3. Raman band assignments in nomal and lyoptilized WWW rabbit connea and a collagen shield.

\begin{tabular}{|c|c|c|c|}
\hline \multicolumn{4}{|c|}{$\begin{array}{l}\text { Raman shift position }\left(\mathrm{cm}^{2}\right) \\
\text { Nomal cornea } \\
\text { Lyophitized }\end{array}$} \\
\hline & & & Adapted from Ref, 74 and 76. \\
\hline 622 & - & 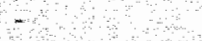 & Phenylallanme (Phe) \\
\hline 645 & 8 & 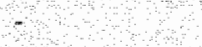 & Tyrosine (Tyr) \\
\hline 824 & 827 & 832 & Crovibration of backbone \\
\hline 854 & 857 & 863 & CC vibration of Pro ning \\
\hline 875 & 875 & 883 & C-C vibratian of Hypro ling \\
\hline 921 & 921 & 924 & C-c stretch of Proline (Pro) ring \\
\hline 939 & 936 & 944 & $C \subset$ stretch of protein backbone \\
\hline 968 & 971 & 968 & Cestmetch \\
\hline 1003 & 1006 & 1011 & Phe ling mode: \\
\hline 1029 & 1031 & 1038 & Pro \\
\hline 1102 & 1099 & 1102 & CoN stretch \\
\hline 1203 & 1203 & 1215 & Hydroxyproline (Hypro) \\
\hline 1244 & 1245 & 1253 & Amide III \\
\hline 1270 & 1261 & 1273 & Amide III \\
\hline 1320 & 1317 & 1328 & $\mathrm{CH}_{3}, \mathrm{CH}_{2}$ stretching \\
\hline 1343 & 1334 & 1349 & $\mathrm{CH}_{3}, \mathrm{CH}_{2}$ stretching \\
\hline 1378 & 1386 & 1386 & 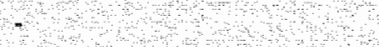 \\
\hline 1398 & 1401 & 1404 & 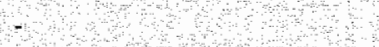 \\
\hline 1427 & 1421 & 1633 & coo stretching \\
\hline 1453 & 1448 & 1456 & $\mathrm{CH}_{3}, \mathrm{CH}_{2}$ deformation \\
\hline 1587 & 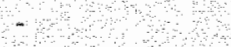 & 3 & Pro, Hypro \\
\hline- & 1604 & 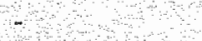 & Phe, Jye \\
\hline & $=$ & 1613 & Tyr \\
\hline 1648 & 1645 & 1645 & Anide I \\
\hline $2886,2940,2984$ & $2890,2941,2978$ & $2898,2951,2991$ & Alphotic CH stretch \\
\hline 3065 & 3066 & 3070 & Aromatic C.H stretch \\
\hline & 3350 & + & $\mathrm{N}-\mathrm{H}$ \\
\hline $3230,3390,3550$ & - & $3300,3396,3542$ & $\mathrm{O}-\mathrm{H}$ vibrations \\
\hline
\end{tabular}

earlier findings that corneal collagen (mainly Type $\mathrm{I}$ ) is composed of three $\alpha$-chain fibrils; two identical $\alpha 1$ chains, and one $\alpha 2$ chain. Significant differences in the Raman intensity between a fresh and a lyophilized comed appear at $-939 \mathrm{~cm}^{-1}$ (C-C stretch of protein backbone) and $1244 \mathrm{~cm}^{-1}$ (Amide III), while the Amide I mode is broader in the fresh comea in comparison to the 
lyophilized cornea. These differences are suggestive for conformational changes possibly caused by altered fibrillar arrangement due to differences in the water content, similar to events taking place after heat denaturation. ${ }^{74}$ The significant differences in relative Raman intensities at $1328,1349,1404$, and $1645 \mathrm{~cm}^{-1}$ between the hydrated collagen shield and the fresh cornea probably are the result of differences in the collagen type, and fibrillar arrangement. Furthermore, Raman spectra of collagen Type I of the sclera has been shown to be lower in intensity for proline and hydroxyproline, suggestive for a larger content of phenylalanine residues in Type 1 collagen in the cornea. ${ }^{72}$

The comeal water content has also been the object of interest, since maintaining a normal comeal hydration. is crucial for the transparency of the cornea. ${ }^{73.75}$ The Raman signal of water can be found in the higher spectral region from $3100-3700 \mathrm{~cm}^{-1}$, as depicted in Figure $6 \mathrm{~B}$ for a normal and a lyophilized conea and a rehydrated corneal collagen shield (Table 3). It can be seen that the $\mathrm{O}-\mathrm{H}$ vibrations (at 3230,3390, and a shoulder at $-3550 \mathrm{~cm}^{-1}$ ) are rather strong when compared to corneal Raman signals obtained in the "signa" ture'-region from $400-1800 \mathrm{~cm}^{-1}$. The lack of Om vibrations in the lyophilized cornea is in agrcement with the fact that this cornea is totally devoid of water; the remaining faint structure at $\sim 3350 \mathrm{~cm}^{-1}$ is assigned to $\mathrm{N}-\mathrm{H}$ stretching vibrations of primary amides. Furchermore, all these spectra feature four resolved signals that can be assigned to the aliphatic $(2886,2940$, and 2984 $\mathrm{cm}^{-1}$ ), and aromatic $\left(3065 \mathrm{~cm}^{-1}\right) \mathrm{C}-\mathrm{H}$ vibrations of proteins (collagen). Like in the lens, the Raman intensity ratio $\mathrm{I}(3390) / \mathrm{I}(2940)$ is in direct proportion to the relative water content of the comea, and has been used to assess the total and spatially resolved water content of the comea ${ }^{73,75}$

Siew et al. studied total corneal water content using the Raman intensity ratio $I(3390) / I(2940)$ in organ cultured corneas, and sought to correlate this with the metabolic state of the procured corneas. They concluded that RS might provide for a more sensitive non-contact means for quality control of eye-bank corneas, for reasons that a disturbed corneal water content might be indicative of corneal endothelial dysfunction..$^{73}$ We extended the application of Raman spectroscopy in the study of conneal hydration by spatially resolving the comenl water content in the rabbit comea under itr-pinw circunstances, potentally applicable in those instances where topical changes in comeal hydration are expected to be more important than changes in total comeal hydration, as is the case in for example comeal dystrophies and comeal decompensation after penctrating keratoplasty (this thesis Chapter 5) ${ }^{75}$

Most of the aforementioned Raman spectroscopic studies of ocular tissues have been performed under in wirro circumstances because the inherently low Raman signal requires the application of high-level light doses and long probing times. In addition, the signal-to-noise ratio can diminish rapidly with the occur- 
rence of fluorescence, which is a likely possibility in biological tissues. Although system designs keep improving and other optical techniques are being used to complement Raman spectroscopy ${ }^{17,90-96}$. the applications of Raman spectroscopy in the eye under in-pivo circumstances have been limited so $6{ }^{8} .89$ With this in mind we considered the design of a Raman spectroscopy system that would allow for application of this oprical technique for the biochemical characterization of ocular tissues in-tino.

\section{Design considerations for a Raman spectroscopy system for ophthalmic use in-vivo}

The inherent versatility of Raman spectroscopy systems allows for a system design most optimal for the biological medium of choice. Puppels et al. for example designed a confocal Raman microspectroscopy (CRM) system with the aim to non-invasively assess biochemical properties of cells and chromosomes. ${ }^{17}$ Their design considerations were governed by the aim to obtain spectra of a single metaphase chromosome with a volume of $\sim 1 \mu \mathrm{m}^{3}$. Thus, apart from optimizing the throughput of the whole system they incorporated a high numerical aperture microscope objective lens with high magnification (63x Zeiss water inmersion objective, NA 1.2) for optinum signal collection from probing volumes $\leq 1 \mathrm{~mm}^{3}$, and were able to non-invasively assess single cells and chromosones, as well as carotenoids in granulocytes and natural killer cells, and applied this novel system for the spatially resolved Raman microspectroscopic studies on water, protein, and cholesterol content of the ocular lens. 17,50,51,56,61. $67,68,92,94,97-1.03$

As stated in the introduction, our aim was to investigate the application of a Raman spectroscopy system for non-contact biochemical assessments of (intra)ocular tissues and fluids in-pivo. The ocular tissues consist of multi-hyered structures all varying in biochemical content, optical quality, thickness, intraocular location, and light-sensitivity, posing a challenging problem (Table 1 and 4). In order to non-invasively probe all layers of the eye under in wivo and thus constantly changing biochemical conditions, the following design parameters for a suitable Raman system had to be considered:

1. use of an irradiation source with low absorbency (high transmittance) in the ocular media of choice;

2. capability to obtain high signal-to-noise ratio Raman spectra of the tear-film, the cornea, the aqueous humor, the lens, and the vitrcous humor in a non-contact manner;

3. axial scanning capabilities with adequate spatial resolution; 
4. adequate axial resolution in order to spacially resolve thin ocular tissue layers while reducing the detection of fuorescence;

5. the intensity of the chosen irradiation source should be safe;

6. rapid spectral acquisition ( -1 s temporal resolution); and

7. elimination of movement artifacts (the incorporation of an eye-tracking device into our Raman spectroscopy system is still under development, and will not be discussed here);

These considerations led to the development of a high-gain laser scanning confocal Raman spectroscopy (CRS) system of which the characteristics and performance are discussed in more detail in Chapter 3 of this thesis. 104 The following will describe in short the most significant components of this system with regards to the aforementioned design parameters.

The choice of laser source was mainly detemined by the incorporation into our system of the most sensitive photon-counting device in the visible region (parameter 1) available at the time, a liquid nitrogen cooled CCD (charged coupled device) camera for real-time high signal-tomoise ratio spectral data acquisition (parameter 6). Thus, we opted for either a continuous wave (CW) Argon (514.5 nm) or Helium-Neon laser (632.8 nm). Since the Stokes-lines of interest in a Raman spectrum lie in the region of $0-3800 \mathrm{~cm}^{-1}$, the application of either laser source will result in spectra with a frequency range within the detection limits of the CCD detector. In theory, the high sensitivity of this detector would also permit spectral acquisitions at low laser irradiation intensities (parameter 5). It can be understood that this requirement is as stringent as it is necessary (see Introduction). Notwithstanding the capabilities of this detecton, the requirement to use low levels of irradiation and the need for high temporal and spatial resolution (parameters 4 and 6 ) in conjunction with the inherently ineffcient nature of the Raman scattering process, demands optimal signal collection and transport from the sample. This was achieved using a 25x, NA 0.5 long-working distance microscope objective (LDMO), with a backaperture cqual to the emitter area of $12.5 \mathrm{~mm}$. The application of this lens not only yidded high light gathering power, but also noncontact probing of all ocular tissues of interest (paraneter 2), by virtue of its long working distance of $~ 13$ mun. This entrance lens was applied in a $180^{\circ}$ backscatter configuration (analog to an cpi-illuminated microscope), and hence utilized for focusing as well as for collecting the Raman scattered light. Furthemore, the optics of this Raman spectroscopy system were setup in a telecentric configuration, meaning that the entrance lens (LDMO) could move along its optical axis without change in distance between the image plane and the focal plane of the exit lens (Figure 7). After placing this lens on an automated translation stage, axial scanning was. made possible with $10 \mu \mathrm{m}$ steps (paraneter 3). Incorporating an optical fiber at the exit site of this Raman spectroscopy system, for transport of the Raman scat- 
Chapter 2 Ranian spectroscopy

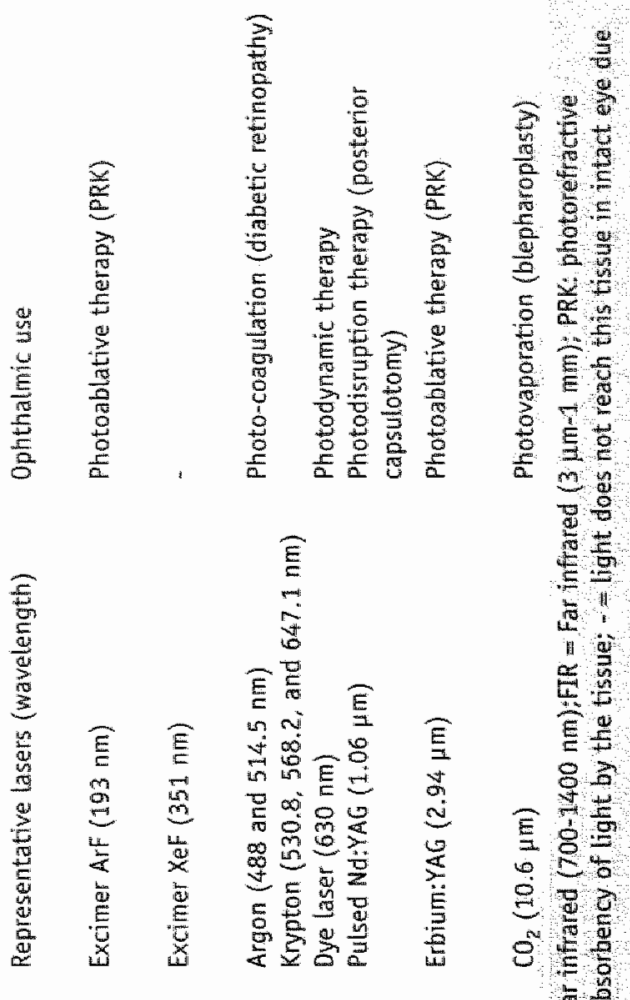

9

a) 


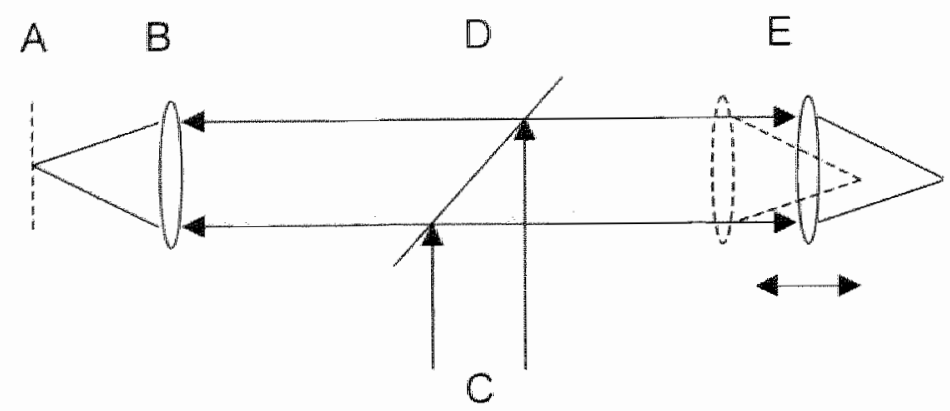

Figure 7. Telecentric principle of the optics of the confocal Raman spectroscopy system. $A=$ focal plane of exit lens $(B) ; C=$ incident light beam as well as the light collected (D) by the entrance lens (E) is collimated. The entrance lens (E) can be moved along the optical axis, which changes the position of the focal plane of the entrance lens, but not of the exit lens.

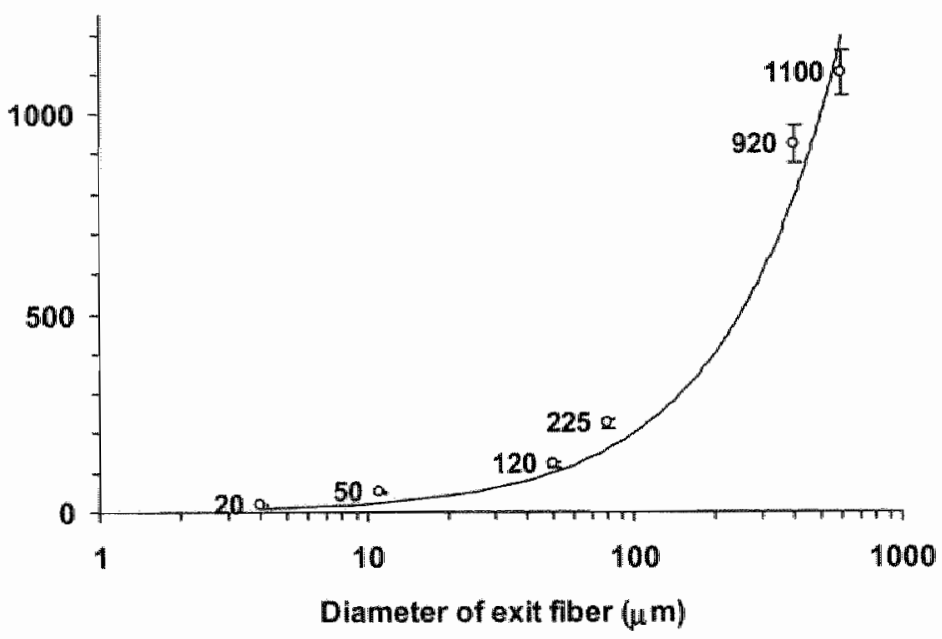

Figure 8. Relationship between fiber dianeter (confocal pinhole) and axial resolution ( $15 \%$; Labels). Experimental conditions: CRS-systen with Ar-laser $(514.5 \mathrm{~nm} ; 25 \mathrm{~mW}$ incident power), 25x NA 0.5 LDMO, and slit widn of the spectrometer set at twice the size of fiber diameter (see Chapter 3).

tered light towards the spectrometer, elegantly solved design parameter 4 . Because this fiber is placed in confocal alignment with the entrance lens (LDMO) it acts like a confocal pinhole, effectively eliminating light from out-of-focus places and reducing the detection of fluorescence (see Chapter 
1). ${ }^{17,163,106}$ This confocal setup allowed for optical sectioning with a maximum axial resolution of 20 th when using a 4 m fber diameter. Furthemore, the easy exchangeability of this fber yielded the possibility to optimize the axial resolution to specific needs during the assessment of the ocular tissue of interest. Figure 8 depicts in graphical format the various optical fiber diameters used as function of the axial resolution achieved for each fiber.

The next Chapter will deal in more detail with the optics of the proposed confocal Raman spectroscopy system.

\section{References}

1. Raman C.V., and Krishon K.S. A New Type of Secondary Radiation. Nonute 1921; 121: $501-505$.

2. Carey PR. Biochemical Applications of Raman and Resonance Raman spectroscopies. In Horecker B, Kaplan NO, Marmur J, and Scheraga HA Eds., Molectar Biology: An Intenational Sertes of Monographs and Textooks. Academic Press Inc., New York (1982).

3. Ozaki Y. Medicall Application of Raman Spectroscopy. Applied Spectrosopy Revicus $1988 ; 24(384): 259-312$.

4. Asher S.A. UV resonance Raman spectroscopy for analytical, physical, and biophysical chemistry. Part 2. Amalytical Chemisty 1993; 65(4);201A-210A.

5. Asher S.A. UV resonance Raman studies of molecular structure and dymamics: applications in physical and biophysical chemistry. Ammal Revieu of Physical Chemistry 1988; 39:537-88.

6. Keller S, Schader B, Hoffnan A, et al. Application of Near-Infrared-Fourier Transform Raman Spectroscopy in Medical Research. Jowmal of Raman Spectroscopy 1994: 25: pp. 663-671

7. Schrader B, Keller S, Loche T, et al. NIR FT Raman Spectroscopy in Medical Research. Joumal of Molechlar Sirtature 1995; 348: pp. 293-296.

8. Feld MS, Manoharan R, Salenits J, et al. Detection and Chatacterization of Human Tissue Lesions with Near Infrared Raman Spectroncopy. SPIE 1995; 2388: pp. 99-104.

9. Mahadevan-Jansen $A$ and Richards-Kortum R. Raman Spectroscopy for the

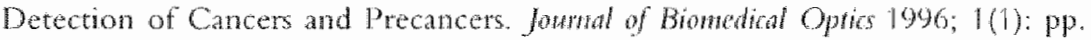
$31-70$

10. Lewis A. Tunable laser resonance Raman spectroscopic inyestigations of the transduction process in vertebrate rod cells. Federation Procedings 1976:35(1):51-3.

11. Lewis A., Spoonhower J., Bogomolni R.A., Lozer R.H., Stockenus W. Tunable laser resonance raman spectroscopy of bacteriorhodopsin. Pronedings of the Nadional Academy of Saches of the United Stafes of Ameria 1974; 71(11):4462-6. 
12. Bursell S-E and Yu N-T. Fuorescence and Raman Spectroscopy of the Crystalline Lens. In: Masters BR Ed. Noninasive Diagrostic Tedmignes in Ophthalmology. Springer Verlag, New York (1990): pp, 319-341.

13. Schwab SD and McCresy $\mathbb{R} L$. Versatile, Efficient Raman Sampling with Fiber Oprics Anal. Chem. 1984; 56: 2199-2204.

14. Myrick ML, Angel SM, and Desiderio R. Comparison of Sone Fiber Optic Configurations for Mearurement of Luminescence and Raman Scattering. Applied Optirs $1990 ; 29(9): 1333-1344$.

15. Schoen CL, Cooney TF, Shama SK, and Carey DM. Long Fiber-Optic Remote Raman Probe for Detection and Identificarion of weak Scatterers. Applied Optics $1992 ; 31(36): 7707-7715$.

16. Baraga JJ. Feld MS, and Rava RP. Rapid Near-Infrated Raman Spectroscopy of Human Tissue with a Spectrograph and CCD Detector. Applied Spectoscopy 1992; $46(2): 187-190$

17. Puppels G), Colier W, Olminkhof JHF, et al. Descriprion and Performance of a Highly Sensitive Confocal Raman Microspectrometer. In: Puppels GI. Confocal Raman Spectroscopy: a new look at cells and chromosomes. Thesis. University Twente, The Netherlands. 1991.

18. Tu AT, Ed., Ramon Specwoscopy in Biology. Wiley \& Sons, New York (1982). Lock-wood GG, Landon MJ, Chakrabarti MK, and Whirwam JG. The Ohmeda Rascal 11. A New Gas Analyzer for Anesthetic Use. Anaesthesia 1994; 49(1): 44-53.

19. Parker FS, Ed. Applications of lifrared, Raman, and Resonane Raman Spectrosopy in Biochenstry. Plenum Press, New York (1983).

20. Harada I, and Takeuchi H. Raman and Ultraviolet Resonance Raman Spectra of Proteins and Related Componnds. In: Clark RJH and Hester RE, Eds., Spenosiopy of Biolaytal Systems. Volwme 13: Aduanes in Spetrosopy. John Wiley \& Sons, Chichester (1986), pp113-176.

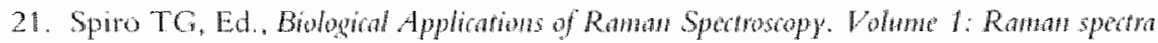

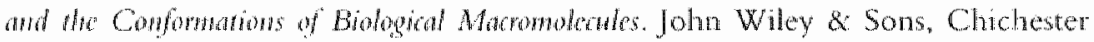
(1987)

22. Hame Jr. EG and Grasselli JC, Eds., Pratial Spectoropy. Volume 1: lnfrated and Ranon Syetroropy. Pant A-C. Marcel Dekker, Inc. New York (1977).

23. Winctordnet JD and Kolthoff IM. Series Eds. Chemal Amalysis: A Series of Mono-

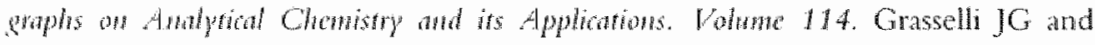
Bulkin Bj. Eds.. Analytial Ramans Spetroscopy. John Wiley \& Sons, New York (190,1).

24. Tu A.T. Peptide Backbone Confomation and Microenvironment of Protein Side Chains. In: Clark RJI and Hester RE, Eds., Spcorosoppy of Biolugial Spstems. Volmme 13. Advances in Sprotrosopy. John Whley \& Sons, Chichester (1986), pp 47-112. 
25. Yu N-T., De Nagel D.C.. and Kuck J.F.R. Ocular Lenses In: Spiro TG, Ed., Biologial Applicanows of Raman Spedroropy. Folwme 1: Raman spetmand the Gonfor matrons of Biologial Macomolecules. John Wiley \& Sons, Chichester (1987).

26. Fontester JV, Dick AD, McMenamin P, and IEe WR, Eds, Anatomy of the Eye. In: The Eye; Basic Sciences in Practic, Sannders, London (1996), pp. 13-86.

27. Gans, L. A et al. Basic and Chinal Srence Conse. Section 11: Lens atd Caramad. American Academy of Ophthallmology, San Francisco (1995-1996), pp. 45-67.

28. Yu N.T. Jo B.H., Chang R.C., Hubet J.D. Single-crystal Raman specta of mative insulin. Structures of insulin fibrits, glecagon fibrils, and incact calf lens. Ardive of Biodhenistry G Biophyotos, 1974; 160(2): 614-22.

29. Yu N.T. East EJ. Laser Raman spectroscopic studies of ocular lens and its isolated protein fiactions. Joumal of Bological Chemistry, 1975; 250(6): 2196-202.

30. Schachar R.A. Solin S.A. The microscopic protein structure of the lens with a theory for cataract formation as deternined by Raman spectroscopy of intact bovine lenses. Investigatime Ophthalmology, 1975; 14(5): $380-96$.

31. Ondruska O., Hanson D.M. Raman spectra of duck, rat, and flounder lenses and the formation of dty and cold catanacts. Experinnental Eye Researd, 1983, 37(2): 139-43.

32. Yu N.T., East E.J, Chang R.C., Kuck J.F. Raman spectra of bird and reptile lens proteins. Experinwenal Eye Researd, 1977; 24(4): 321-34.

33. East EJ., Chang R.C., Yu N.T., Kuck J.F., Jr. Raman spectroscopic measurement of total sulfhydryl in intact lens as affected by aging and ultraviolet irradiation. Deuterim exchange as a probe for accessible sulfhydryl in living tissue. Jomnd of Biological Chemistry, $1978 ; 253(5): 1436-41$.

34. Kuck J.F., Yu N.T. Askren C.C. Total sulfhydryl by raman spectroscopy in the intact lens of several species: variations in the nucleus and along the optical axis during aging. Expermental Eye Researh, 1982; 34(1): 23-37.

35. Itoh K. Ozaki Y., Mizuno A., Iriyana K. Structural changes in the lens protcins of hereditary cataracts monitored by Raman spectoscopy. Biodicwistry, 1983:22(8): $1773-8$

36. Yu N.T., DeNagel D.C. Pruett P.L., Kuck J.F.J. Disulfide bond formation in the

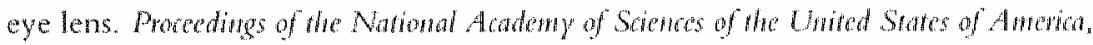
1985: 82(23): 7965-8.

37. Ozaki $Y$., Mizuno A. Itoh K., Iriyama $\mathbb{K}$. Inter and intramolecular disulfide bond formation and related structural changes in the lens proteins. A Raman spectrow scopic study in wign of lens aging. Jownal of Bologiol Chemishr, 1987, 262(32): 15545-51.

38. Barron B.C., Yu N.T., Kuck J.F., Ir. Raman spectroscopic evaluation of aging and long-wave UV exposure in the gunea pig lens: a possible model for human aging. Experimental Eye Recard, 1988; $46(2) ; 249-58$. 
39. DeNagel D.C., Bando M., Yu N.T. Kuck J.F. Jr. A Raman study of disulfide and sulfydry in the Emory mouse caract. Inverigutive Ophthahology 6 Viswal Science, $1988,29(5): \$ 23-6$.

40. Cri M.Z., Kuck J.F., Jr., Yu N.T. Galactore-induced cataract in rat: Raman detection of sulfhydryl decrease and water increase along an equatonial diameter. Experiwertal Lye Retsand, 1989; 49(4): $531-41$.

41. Yu N.T., DeNage D.C., Slingby C. Raman spectroscopy of calf lens gamma-II crystailin: direct evidence for the formation of mixed disulfide bonds with 2-mercaptoethanol and glutathone. Experimental Eye Researt, 1989; 48(3): $399-410$.

42. Mizuno A., Ozaki Y. Aging and cataractous process of the lens detected by laser Ramaty spectroscopy. Lens 8 Eye Toxidy Researh, 1991; 8(2-3): 177-87.

43. Pande J., McDermote M.J., Callender R.H., Spector A. The calf gamma crystallins-a Ramar spectroscopic study. Experimental Eye Researd, 1991; 52(2): $193-7$.

44. Zigman S., Paxhia T, McDaniel T., Lou M.F., Yu N.T. Effect of chronic near-ultraviolet radiation on the gray squirrel lens in who. Investigratipe Ophthalmology G Visual Scictuce, 1991; 32(6): 1723-32.

45. Chiou S.H. Chen W. Structural analysis of pigeon lens crystallins by near-infrared Fourier transfom Raman spectroscopy. Biwhemisty Intemational, 1992; 28(3): 401-12.

46. Mizuno A., Shumiya S. Toshima S., Nakano T. Alteration of lens disulfide bonds in newly developed hereditary cataract rat. Japanese Joumal of Ophthalmology, 1992; 36.(4): $417-25$.

47. Ozaki Y., Mizuno A. Molecular aging of lens crystallins and the life expectancy of the animal. Age-telated protem structural changes studied in situ by Raman spec. troscopy. Biodtimica et Biophysica Acta, 1992; 1121(3): 245-51.

48. Tonohiro M., Mizuno A. Atteration of lens sulfhydryl groups induced by oxidarie stress: Roman spectroscopic study of hydrogen peroxide-treated rat lens. Japanese

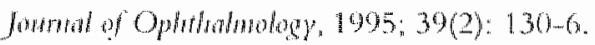

49. Duindan JJ., Vrensen G.F., Otto C., Greve J. Cholesterol, phospholipid, and protein changes in focal opacicies in the human eye lens. hnvestigative Ophthatmology o Visual Somme 1998; 39(1): 94-103.

50. Sicbinga I., Vrensen G.F. Otto K., Puppels G.J., et al. Ageing and changes in protem confomation in the human lens: a Ranan microspectroscopic study. Exp Eje Res 1992; 54(5):759-67.

51. Snvets M.H., Vrensen G.F., Otto K., Puppels G.J. Greve J. Locd variations in protein structure in the human eye lens: a Ranan microspectroscopic study. Biodim Biophys Afin 1993; 1164(3):236 42 . 
52. Thomas D.M. Schepler K.L. Raman spectra of normal and ultraviolet-induced

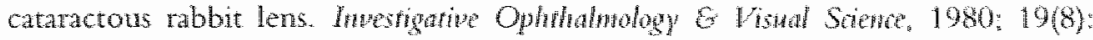
$904-12$.

53. Iriyama K., Mizuno A., Ozaki Y., Itoh K., Matsuzaki H. An application of laser Raman spectroscopy to the study of a hereditary cataractous lens: on the Raman band for a diagnostic marker of cataractous signatures. Cimrat Eye Resem, 1982; $2(7): 489-92$

54. Ozaki Y., Mizuno A., Itoh K., Yoshiura M., et al Raman spectroscopic study of age-related structural changes in the lens protems of an intact movise lens. Biodhentisfry. $1983 ; 22(26): 6254-9$

55. Mizuno A., Kanematsu E.H., Suzuki H., Ihara N. Laser Raman spectroscopic study of hereditary cataractous lenses in ICR/I-strain tat Japawese Joumal of Ophthatmology, $1988 ; 32(3): 281-7$.

56. Huizinga A., Bot A.C., de Mul F.F., Vrensen G.F., Greve J. Local variation in absolute water content of human and rabbit eye lenses measured by Raman microspecroscopy. Experimental Eye Researh, 1989; 48(4); 487-96.

57. Mizuno A., Nishigor $H$., Iwatsuru M. Glucocorticoid-induced cataract in chick embryo nonitored by Raman spectroscopy. Investigatinc Opdthatmology $G$ Fisual Science, $1989 ; 30(1): 132-7$.

58. Takise S., Horiguhi S. Fukumura H., Hayashi K., et al. Morphological change and Raman spectrum of rabbit lens irradiated with ultraviolet laser beam. Osaka City Medical Jownal, $1989 ; 35(1): 29-37$.

59. Mizuno A., Toshima S., Mori $Y$. Confirmation of tens hydration by Raman spectroscopy. Expetimental Eye Reseach, 1990; 50(6):647-9.

60. Toshima S., Miyazaki H., Mizuno A. Raman study of the lenses of spontaneouslymoccuming and streptozotocin-induced diabetic rats. Japonese Jommal of Ophthalmology, $1990 ; 34(4): 436-41$.

61. Siebinga I. Vrensen G.F., De Mul F. F., Greve J. Age-related changes in local water and protein content of human eye lenses measured by Raman microspectroscopy. Experinentes Eye Researd, 1991:53(2): 233 w9.

62. Horkiri K., Nakajima H., Matsuura T., Narana 1., et al. Estination of strucual changes in the cataractous rat lens using Raman spectroscopy. Jikken Dobusw. Experimental Animals, 1992; 41(2): 225-30.

63. Bonchman D., Lamba O.P., Ozaki Y., Czarnecki M. Raman structural characterization of clear human lens lipid membranes. Curten Eye Rearata, 1993; 12(3): $279-84$

64. Dai S., Qi S., Zhang L., Bai C., et al. Laser Raman spectrometry study on experi-

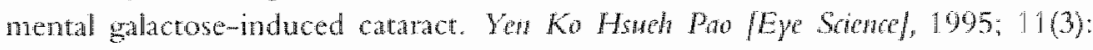
143-6. 
65. Shun-Shin G.A., Vrensen G.F., Brown N.P., Willekens B. at al. Morphologic characteristics and chemical composition of Christmas tree cataract. Investigature Ophihanology \& Vistal Scicuce, 1993; 34(13): 3489-96.

66. Borchman D., Ozaki Y., Lamba O.P., Byrdwell W.C., et al Structural characterization of clear human lens lipid membranes by near-infrared Fourier transform Raman spectroscopy. Cument Eye Researh, 1995; 14(6): 511-5.

67. Duindam H.J., Vrensen G.F., Ono C., Puppels G.J., Greve J. New approach to assess the cholesterol distribution in the eye lens: confocal Raman microspectroscopy and filipin cytochemistry. Jownal of Lipid Researh, 1995; 36(5): $1139-46$.

68. Vrensen G.F., Dundam H.J. Maturation of fiber membranes in the human eye lens. Uteratructural and Raman microspectroscopic observations. Ophthalmic Researh, 1995; 27 (Suppl 1): $78-85$.

69. Duindam JJ., Vrensen G.F., Otto C. Greve J. Aging affects the conformation of cholesterol in the human eye lens. Ophthalnic Researd, 1996; 28(Suppl 1):86-91.

70. Sato H. Borchman D., Ozaki Y., Lamba O.P., et al. Lipid-protein interactions in human and bovine lens membranes by Fourier transform Raman and infrared spectroscopies. Experimental Eye Researh, 1996; 62(1): 47-53.

71. Paterson C.A., Zeng J., Hussein Z., Borchman D., et al Calcium ATPase activity and membrane structure in clear and cataractous human lenses. Current Eye Researd, $1997 ; 16(4): 333-8$

72. Mizuno A., Tsuji M. Fujii K., Kawauchi K., Ozaki Y. Near-infrared Fourier transform Raman spectroscopic study of comea and sclera. Japanese foumal of Ophthat mology $1994 ; 38(1): 44-8$.

73. Siew DCW, Clover GM, Cooney $\mathbb{R P}$, and Wiggins PM. Micro-Raman Spectro scopic Sudy of Organ Cultured Comeae. Joumal of Raman Spectroscopy 1995; 26: 3-8.

74. Goheen SC, Lis LJ, and Kanffinan JW. Raman Spectroscopy of Intact Feline Comeal Collagen. Biodimica et Biophysica Acta 1978; 536(1): 197-204.

75. Batuer NJC, Wicksted JP, Jongsma FHM, March WF, Hendrikse F, and Motamedi M. Noninvasive Assessment of the Hydration Gradient Across the Comea Using Confocal Raman Spectroscopy. Wwest. Ophthatmol. Wis. So. 1998; 39(4):831-835.

76. Frushour B. C. and Koenig J.L. Raman Scatrering of Collagen, Gelatin, and Elastin. Biopolymers 1975; 14:379-391.

77. Wicksted JP, Erckens RJ, Motamedi M, and March WF, Ranan Spectroscopy Studies of Metabolic Concentrations in Aqueous Solutions and Aqueous Humor Specimens. Appliod Spectrosopp 1995; 49(7): 987-993.

78. Ercken. RJ, Motamedi M, Wicksted JP, and March WF. Raman Spectroscopy for Non-Invasive Characterization of Ocular Tissue: Potental for Detection of Biological Molecules. J. Raman Spertrosiopy 1997; 28: 293-299.

79. ScbagJ., Nie S. Reiser K. Charles M.A., Yu N.T. Raman spectroscopy ohuman vitreous in proliferative diabetic retinopathy, linestigntwe Ophthathology \& Visual Sinuce 1994; 35(7):2976-80. 
80. Eyring G., Cuny B., Mathes R., Fransen R. et al. Interpretation of the resonane Raman spectrum of bathorhodopsin based on visual pigment analogues. Bub homitg $1980 ; 19(11): 2410-8$

81. Eyring G., Mathes R. Resonance Raman studies of bathorhodopsin: evidence for a

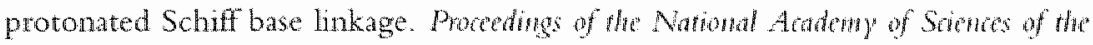
United States of Ameria 1979; 76(1):33-7.

82. Huang $L$., Deng $H$, Koutalos $Y$., Ebrey $T$. ct al. A resonance $R$ aman study of the $\mathrm{C}=\mathrm{C}$ stretch modes in bovine and octopts visual pigments with isotopically labeled retinal chromophores. Photodentisy \& Photobology 1997; 66(6):747-54.

83. Loppnow G.R., Miley ME., Mathies R.A., Liu R.S., et al. Strucure of the retinal chromophore in 7,9-dicis-rhodopsin. Biochemistry 1990; 29(38):8985-91.

84. Oseroff A.R., Callender R.H. Resonance Raman spectroscopy of rhodopsin in retinal disk membranes. Biodhemistry 1974; 13(20):4243-8.

85. Palings 1., Pardoen J A., van den Berg $\mathbb{E}$., Winkel $C$., et al. Assigmment of fingerprint vibrations in the resonance Raman spectra of thodopsin, isorhodopsin, and bathorhodopsin: implications for chromophore structure and enwromment. Biochemisny $1987 ; 26(9): 2544-56$

86. Pande C., Deng H., Rath P., Callender R.H., Schwemer J. Resonance raman spectroscopy of an ultaviolet-sensitive insect rhodopsin. Biodrmantry 1987; 26(23):7426-30.

87. Rinai L., Kilponen R.G. Gill D. Resonance-enhanced Raman spectra of visual pigments in intact bovine retimas at low tempenatures. Biohemical B Biophysial Reseand Communiations $1970 ; 41(2): 492-7$.

88. Yoshizawa T., Imamoto $Y$. Structure and photobleaching process of chicken iodopsin.

89. Yu N.T., Kuck J.F. Jr., Askren C. C. Laser raman spectroscopy of the lens in sim, measured in an anesthetized rabbit. Current Eye Rescarch 1981; 1(10):615-8.

90. Mizuno A. Ozaki Y. Kamada Y. Miyazaki H. et al. Direct measurement of Raman spectra of intact lens in a whole eyeball. Cument Eye Resend, 1(10),609-13. 1981.

91. Yu N.T., Cai M.Z., Ho D.J., Kuck J.F., Jr. Automated laser-scanning-microbeam fluorescence/Raman image analysis of human lens with multichannel detection: evidence for metabolic production of a green fluorophor. Pracedings of the National Acadeny of Scionces of the United Siafes of Antrica, 85(1):103-6. 1988.

92. Bot A.C., Huizinga A., de Mul F.F., Vrensen G.F. Greve J. Ramm microspectroscopy of fixed rabbit and human lenses and lens slices: new potentiallties. Experimental Eye Resemh, 49(2):161-9, 1989

93. Nie S.M., Bergbauer K.L., Kuck J.F., Ju., Yu N.T. Near-infrared Fourier transform Raman spectroscopy in human lens research [eetter]. Experinchal Eye Rescard, $51(5) \cdot 619-23,1990$. 
94. Schyns M. W. Huzinga A., Vrensen G.F., de Mul F.F., Greve J. Paraformaldehyde fxation and some characteristics of lens proteins as measured by Raman microspectroscopy. Experimental Eye Rewearh, 50(3):331-3, 1990

95. Yaroslavsky I.V., Yaroslavsky A.N., Otto C. Puppels G.J., et al Combined elastic and Raman lighe scattering of human eye lenses. Experimental Eye Researh, $59(4) \cdot 393-9,1994$.

96. Coldstein S.R., Kidder L.H., Heme T.M., Levin I.W., Lewis E.N. The design and mplementation of a high-fidelity Raman imaging microscope. Jownal of Microscopy, $184(\mathrm{Pr}): 35-45,1996$.

97. Bakker Schut T.C., Puppels G.J., Kraan Y.M., Greve J., et al. Intracellular carotenoid levels measured by Raman microspectroscopy: comparison of lymphocyes from lung cancer patients and healthy individuals. Inf I Cancer 1997; $74(1): 20-5$

98. Puppells G.J., de Mul F.F., Otto C., Greve J., et al. Studying single living cells and chromosomes by confocal Raman microspectroscopy [see comments]. Nature 1990; $3476290): 301-3$.

99. Puppels G.J., Garritsen H.S., Kummer J.A., Grewe J. Carotenoids located in human lymphocyte subpopulations and natural killer cells by Raman microspectroscopy. Cyrontery $1993 ; 14(3): 25 \rrbracket-6$.

100. Puppels G.J., Garritsen H.S. Segers-Noten G.M., de Mul F.F., Greve J. Raman microspctroscopic approach to the study of human ganulocytes. Biophys $\int 1991$; $60(5): 1046-56$

101. Puppels G.J., OlminkhofJ.H., Segers-Nolten G.M., Otto C., et al. Laser iradiation and Raman spectroscopy of single living cells and chromosomes: sample degradation occurs with $514.5 \mathrm{~nm}$ but not with $660 \mathrm{~mm}$ laser light. Exp Cell Res 1991; $195(2): 361-7$

102. Puppels G.J, Otto C., Greve I., Robert Nicoud M., et al. Raman microspectroscopic study of low pH-induced changes in DNA structure of polytene hromosomes. Biod hontstry 1994; 33(11):3386-95.

103. Salinaso B.L., Puppels G.J., Caspers P.J., Floris R., et al. Resonance Raman microspectroscopic characterization of eosinophil peroxidase in human eosinophilic granulocytes [see comments]. Biophys J 1994; 67(1):436-46.

I04. Jongsma F.H.M., Erckens R.J., Wicksted J.P., Bauer N.J.C., et al Confocal Raman Spectroscopy System For Noncontact Scanning Of Ocular Tissues - an in Vitro Study. Opron Enuinhering 1997; 36(11):3193-3199.

105. Tabaksblar R. Meier RJ, and Kip BJ Confocal Raman Microspecroscopy: Theory and Applicarion to Thin polymer Sumples. Applied Spectroscopy 1992; 46(1): 60-68.

106. Bireman $\mathrm{CJH}$ and Hunter IW. Confocal Image Properties of a Confocal Scanning Laser Visible Light FT-Raman Microscope. Applied Speorosopy 1995; 49(7): $971-976$. 


\section{Appendix}

Formulas

1. Light energy: $\mathrm{E}=\mathrm{hv}$ (in $\mathrm{J}$ ); with $\mathrm{h}=$ Planck's constant, and $\mathrm{v}=$ frequency

2. Wavelength: $\lambda=c / V($ in $\mathrm{cm})$; with $c=\operatorname{lightspeed~}\left(\sim 3 \cdot 10^{11} \mathrm{~cm} / \mathrm{sec}\right)$

3. Photon-energy: $E_{p}=1.986 \cdot 10^{-16} / \lambda(\mathrm{nm})$ (in J)

4. Raman scattering frequency (in wave-numbers):

$\mathrm{v}=\mathrm{v}_{0}-\mathrm{v}_{\mathrm{vib}}$ (Stokes lines)

$\mathrm{v}=\mathrm{v}_{0}+\mathrm{v}_{\mathrm{vib}}$ (anti-Stokes lines)

5. Wave-number: $\omega=1 / \lambda\left(\right.$ in $\left.\mathrm{cm}^{-1}\right)$

6. Population ratio of molecular vibrational states: $N_{1} / N_{0}=\exp \left(-h v_{v i b} / k T\right)$; with $N_{1}$ and $N_{0}=$ number of molecules in the $v^{\prime \prime}=1$ and $v^{\prime \prime}=0$ vibrational states in the ground electronic state, respectively; $\mathrm{v}_{\mathrm{vib}}=$ difference between incident and scattered frequency; $h=$ Planck's constant; $k=$ Boltzmann's constant; $T=$ the absolute temperature (in Kelvin).

7. Raman intensity: $\mathrm{I}=\mathrm{Cl}_{0} v_{\mathrm{s}}{ }^{4} \alpha^{2}$ (in photons/s); with $\mathrm{C}=$ constant, $\mathrm{I}_{i}=$ intensity of incident light, $v_{\mathrm{s}}=$ frequency of scattered light, and $\alpha=$ molecular polarizability 

CHAPTER 3

\section{Confocal Raman spectroscopy system for noncontact scanning of ocular tissues: an in vitro study}

Franciscus HM Jongsma, Roel J Erckens, James P Wicksted,

Noël JC Bauer, Fred Hendrikse, Wayne F March, Massoud Motamedi

Optical Engineering 1997; 36(11): 3193-3199 


\section{ABSTRACT}

Purpose: A long-working distance fiber-optic based confocal Raman spectrascopy (CRS) system, operating in the backscatter mode, was developed for rapid non-contact characterization of ocular tissue.

Materials and methods: In vitro near real-time axial scanning through ocular tissue was achieved using a CCD camera and a thigh numerical aperture long-working distance microscope objective in a telecentric configuration. The system provides high spatial resolution (20-150 $\mu \mathrm{m}$ ) of transparent ocular tissues up to $11 \mathrm{~mm}$ deep into the eye in a non-contact fashion while utilizing low argon laser power and rapid scanning times $(25 \mathrm{~m}$ ) ) yielding a $S / N$ ratio range from $30-75$. To test the performance of the system for characterizing ocular tissue, Raman spectra from rabbit eyes were obtained in vitro.

Results: Axial scans of the cornea, the aqueous humor and the lens provided discrete and specific Raman spectra from each tissue, in both the lower and the higher wavenumber region. Characteristic Raman signals common to all tissues are the OH-vibrations (1650 and 3100-3700 $\mathrm{cm}^{-1}$ ) and the vibrations corresponding to amino acids (Phenylalanine at $1003 \mathrm{~cm}^{-1}$. Tryptophan at 760 and $881 \mathrm{~cm}^{-1}$, and Tyrosine at 646 $\mathrm{cm}^{-1}$ ). The ocular lens can be identified by three distinct peaks (aromatic- and atiphatic $\mathrm{CH}$ stretching and $\mathrm{OH}$ bending mades) of which the aromatic $\mathrm{CH}$ stretching mode $\left(-3057 \mathrm{~cm}^{-1}\right)$ is lens-specific. The cornea can be identified by the presence of two distinct peaks (aliphatic $\mathrm{CH}$ stretching and $\mathrm{OH}$ bending), and the absence of the aromatic $\mathrm{CH}$ stretching mode. The aqueous humo can be identified by the presence of the $\mathrm{OH}$ bending mode, and the lack of the both $\mathrm{CH}$ stretching modes.

Conctusion: A long-working distance confocal Raman spectroscopy system may offer a novel techmique for the non-contact spatially resolwed biochemical characterization of various tissue layers of the anterior segment of the eye. 


\section{Introduction}

The human eye provides an ideal site for the use of non-contact optical techniques for diagnostic purposes because of the transparency of its tissues to wisible and near infrared light 1,2 However, most of the currently used clinical methods in ophthalmology, such as slitlamp examination of the anterior segment, fundoscopic visualuzation of the retina and specular microscopy of the endothelial layer of the cornea, provide no specific information on the biochemical properties of the ocular tissues. ${ }^{2}$ This however may be of great importance since many ocular diseases involve changes in the biochemical content of the eye. For example, diabetics have an elevated level of glucose in their aqueous humor, the early onset of cataract formation involves changes in the water content of the ocular lens, and a decreased optical acuity is present as a result of increased water content and swelling of the comeal stroma in patients with decreased coneal endothelial function. Thus, a technique capable of detecting these changes in an early stage of the disease could have important diagnostic applications in the practice of ophthalmology. ${ }^{3,4}$

In recent years many studies have explored the potential application of Raman spectroscopy for the biochemical characterization of various tissues, ${ }^{5-8}$ In particular, Raman spectroscopy has been applied to investigate various structures of the eye in vitro, demonstrating that specific Raman signals can be obtained for the comea, ${ }^{9,10}$ the ocular lens, ${ }^{11-14}$ and the vitreous humor. ${ }^{15}$ However, these studies have shown that the inherently weak Raman signals generally require the application of high level light doses and long scanning times in order to obtain an acceptable signal-to-noise ratio (SNR). Furthermore, the heterogeneous nature of the tissue structures can significantly contribute to the emission of sizable broad fluorescence which tends to mask most of the Raman signature. The low SNR in both situations is the main. reason that in vipo ophthalmic applications of Raman spectroscopy have been limited. ${ }^{11}$

Two recent developments could significandly improve the potential biomedical applications of Raman spectroscopy. First, confocal Raman systems have been developed in order to limit the size of the probing volume, thus mintmizing the influence of autofluorescence and background noise, and effectively improving the signal-to-noise ratio ${ }^{16,17}$ Puppels et al. recently reported on a confocal Raman microspectrometry setup, specifically optimized for the in witro study of single cells and chromosomes, yielding high signal-to-noise ratio spectra while resolving volumes as small as $1 \mu \mathrm{m}^{3}$, in The second development is the application of highly sensitive CCD detectors, which has significantly contributed to the deployment of Raman spectroscopy as a powerful diagnostic tool for characterization of biological materials. 
Our main objective has been to develop a Raman spectroscopy system for ophthalmic application, capable of characterizing the biochemical content of the anterior segment of the eye (comea, aqueous humor and lens). This required the development of a flexible high-gain system capable of assessing all three tisstes in a non-contact fashion while using low light dose. Furthermore, the axial depth resolution was considered to be more important in the laminated structure of the ocular tissues than the radial resolution. These considerations led to the development of a novel high-gain, long-working distance fiber-optic based confocal Raman spectroscopy (CRS) system. The system works in a backscattered mode and incorporates a high NA long working distance microscope objective lens in a telecentric configuration. The system provides high spatial resolution (20-150 $\mathrm{mm}$ ) of transparent ocular tissues up to 11 min deep into the eye in a non-contact fashion. The fiber-optic probe acts as the pinhole for confocal measurements and for flexible coupling with the spectrometer. The degree of confocality (and consequently the depth resolution) can be adapted to the tissuc. A single grating spectrometer with a liquid nitrogen cooled CCD camera is applied for the collection of high signal-to-noise ratio spectra over a large Raman shift range. This manuscript will describe the details of this newly developed confocal Raman spectroscopy system and evaluates its performance in characterizing fresh rabit eyes in vitro.

\section{Materials \& Methods}

A schematic of the optical components of the confocal Raman spectroscopy (CRS) system is given in Figure 1 . The light source is an argon-ion laser (Coherent Radiation model CR-4, Coherent Laser Group, Palo Alto, CA) emitring a linearly polarized beam at $514.5 \mathrm{~nm}$. A combination of a polarization rotator (model 310-21, Spectm Physics, Mountain View, CA) and a bean expander, consisting of a microscope objective (NA=0.66/43x, Bausch and Lomb, Rochester. NY) and a 80 mm achromatic lens (model 063200 , Spindler \& Hoyer Inc. Milford, MA), is used to provide a collimated p-polanized laser beam with a diameter of $12.5 \mathrm{~mm}$, matching the back aperture of the entrance lens ("aus Jena", Planachromat LD, $f=10 \mathrm{~mm}, \mathrm{NA}=0.5 / 25 x$, Karl Zeiss, Jena, Gemuny?.

To probe ocular tissue with high spatial resolution, it is important to select a microscope objective with adequate compensation with respect the the optics of the target. Most microscope objectives are corrected for the thickness of a cover glass (170 $\mathrm{km}$ ), and optical perfomance diminishes drastically in samples with greater thicknesses (for example the comea). To ensure effective operation of the CRS system, we have chosen an objective lens as entrance lens ("aus Jena" 


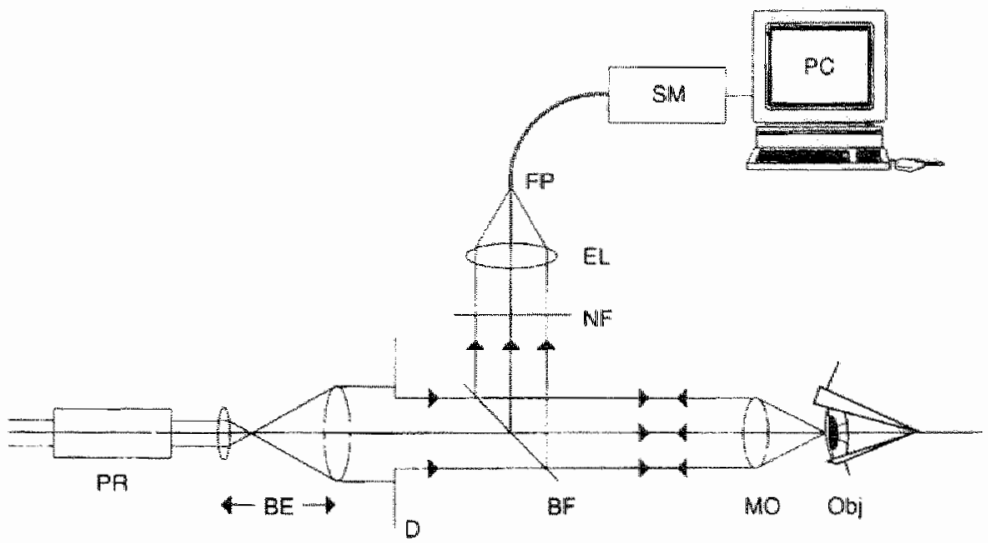

Figure 1. Confocal Raman spectroscopy (CRS) system consisting of a polarizition rotator (PR), bean expander (BE), diaphragn (D), band pass filter/Raman scattered light reflector (BF), long working distance microscope objective ( $\mathrm{MO}$ ), noteh filter (NF), exic lens, (EL), fiber probe (FP), spectrometer (SM), and computer (PC). See text for details.

Planchromat) that allows for correcting astignatism that can be introduced by the optics of the target tissue (for example when probing the ocular lens through the comea). The entrance lens used in our system is corrected for a 2 mm window glass. ${ }^{19}$ If there are no optical barriers between the lens and the sample, a $2 \mathrm{~mm}$ thick correction window must be fitted onto the lens to obtain the maximum optical performance. In the integration depth measurements, with the excitation beam focused into the saline through the cuvette, the cuvette wall (1) nm) acts partly as the compensating window. In this case and also while probing the various ocular tissues of the in-sim rabbic eye, the comecting optical component was removed from the entrance lens.

Due to the anatomy of the eye, both non-contact detection of the Raman signal and working in a backscattered mode is desired. This is achieved whon using the long working distance $(\sim 13 \mathrm{~mm})$ entrance lens, of which the secondary conjugate plane is located at infinity. This lens is amployed both for focusing the laser light into the sample as well as for collecting the scattered Raman light. Since this lens is part of a telecentric configuration, we are able to obtain a free mechanical distance. ${ }^{20}$ This configuration allows us to move the entrance lens axially in order to focus the light within the sample without influencing the position and the size of the spot in the focal plane of the exit lens. Thus, the entrance lens is placed on a tramshation stage (model 433 with SM-50 actuator, Newport Research Co., Mountain Valley, CA) suitable for micro 
positioning (motion $=1$ fmm, range $51 \mathrm{~mm}$ ) and can be step wise moved along the optical axis of the Raman probe and sequentially focused in the sample of interest. A holographic beamsplitter (model 514.5NB1, Omega Optical Corporated, Brattleboro, VE) designed to work at a $45^{\circ}$ angle with respect to the laser beam serves as a bandpass filter for the incident p-polanized laser beam and also for the backscatrered light, allowing most of the scattered Rayleigh light to pass while reflecting the scattered Raman shifred light sideways. The Raman shifted light is then directed through a notch filter (TNF-514-1.0, Kaiser Optical Systems Inc. Ann Arbor, MI) to minimize the effects of elastically scattered light. A camera lens (25 mm, F:0.95, Navitar, Rochester, NY) is used as the ext lens and couples the Ranan scattered lighe into a collection fiber $(50 \mu \mathrm{m}$ core, $N A=0.22$, CeramOptec, East Longneadow, MA), which acts as the confocal pinhole and allows for Aexible coupling into the spectrometer (Model $500 \mathrm{M}, \mathrm{Spex}$ Industries, Edison, NJ). The exit lens is diaphragmed to match both the etendue of the telecentric system and the NA $(0.22)$ of the $50 \mu \mathrm{m}$ collecting fibet. The collecting optics on the spectrometer receives light from the fiber and focuses it with a $0.125 \mathrm{NA}$ onto the $200 \mu \mathrm{m}$ entrance slit of the spectrometer. The spectrometer has a focal length of 0.5 meter and an aperture of F: 4 . A holographic type grating blazed at $500 \mathrm{~mm}$ with 1.200 grooves/mm, a resolution of $0.02 \mathrm{~nm}$ and a size of $110 \times 110 \mathrm{~mm}^{2}$, is used to disperse the light. The spectrometer is equipped with a liquid nitrogen cooled backthinned Charge Coupled Detector aray (Spectrum One LN 2, Spex Industries, Edison, NJ) consisting of $1024 \times 256$ pixels with a spectral response of $400-1000$ nm. The gain of the CCD was set at 8 electrons / counr. Signal processing and presentation are performed by a computer employing DM3000S software (DM3000s ver2.50, Spex Industries, Edison, NJ) interfaced with the Raman spectrometer.

In order to establish the spectral response of the entire system we have used a 100 W Quatz Tungsten halogen lamp (QTH \#6333, Oriel, Stratford. CT) at a setting of $12 \mathrm{~V}$ and a distance of $50 \mathrm{~cm}$ from the entance lens. The lamp is positioned in its housing which contans lenses that are adjusted to get a collinated beam. The irradiance of the QTH-lamp at $50 \mathrm{~cm}$ over the spectral range from 200 to $900 \mathrm{~nm}$ was deriwed using curves, in power units, provided by the company. Spectra with our CRS system are obtained over a broad spectral range from 450 to $750 \mathrm{~mm}$. The spectral response of our entire system is given by: $\mathrm{S}(\mathrm{I})$ $=$ Out $(0) / \ln (1)$, with Out(l) being the spectral ontput of our system as it measures the intensity of the light, and In(I) the real spectral irradiance of the QTH-lamp. This response is nomalized for a throughput of $13.6 \%$ at 632.8 nm, as measured with a Helium-Neon laser (NEC Co, Minato-Ku, Tokyo, Japan) in front of our entrance lens, to obtain the throughput vs. wavelength for unpolarized light. 
The performance of the entire confocal system with respect to sxial resolution is evaluated in a phantom medium. The phantom medium consists of a fused quartz cuvette filled with saline $(0.9 \% \mathrm{NaCl}$ Irrigation USP, Baxter, Deerfield, IL). In order to demonstrate the advantages of confocal probing. the influence of the fiber diameter on the integration depth is established, by comparing two fibers with a diameter of 50 and $400 \mu$ m diameter ( $400 \mu \mathrm{m}$ corc, NA $=0.22$, CeramOptec, East Longmeadow, MA), respectively. In both siruations $25 \mathrm{~mW}$ of argon light was used and all spectra were the result of a single acquisition ( 1 second). The focal plane of the entrance lens was positioned outside the cuvette, and with step increments of $10 \mu \mathrm{m}$ the focus was moved towards and into the sample. After background correction, the relative Raman intensity of the $\mathrm{OH}$ bending mode at $3430 \mathrm{~cm}^{-1}$ was plotted as function of the probing depth.

The ability of the confocal setup to detect Raman spectra of various ocular tissues is examined in vitro in four normal eyes of three NZW rabbits (Ray Nichols Rabbitry, TX), less than 10 minutes following euthanasia with 100 $\mathrm{mg} / \mathrm{kg}$ sodium pentobarbital (Nembutal, Abbot Labs., Chicago, IL). We used the configuration with the $50 \mu \mathrm{m}$ fiber (integration depth of $120 \mu \mathrm{m}$ in air), an incident laser power of $25 \mathrm{~mW}$, and an acquisition time of 1 second to obtain the entire spectrum. No spectral averaging was performed, unless mentioned otherwise. Axial scans with step increments of $50 \mu \mathrm{m}$ were made to obtain spatially-resolved Raman spectra of the connea, the aqueous humor and the ocular lens. The spectral response of all three tissues is analyzed qualitatively over two Raman shift ranges; the lower region ranges from $300-1833 \mathrm{~cm}^{-1}$, and the higher region ranges from $2580-3750 \mathrm{~cm}^{-1}$. The Raman spectra were baseline corrected by subtracting the offset of the $\mathrm{CCD}$-camera from the raw spectral data. The SNR for the spectral response of each tissue is calculated by dividing its maximum Raman intensity by its noise level at a region without Raman activity (usually $\sim 2750 \mathrm{~cm}^{-1}$ ).

\section{Results and Discussion}

The imperfection in the collimation of the laser beam, objective lens and the holographic beamsplitter, could introduce a considerable distortion in the probing beam size. In order to estimate the actual size of the beamwaist produced using a collimated argon laser beam and microscope objective $(25 \mathrm{x} / \mathrm{NA}=0.5)$, we inserted three pinholes with diameters of 6,12 , and $25 \mu \mathrm{m}$ in the focal plane of the entrance lens. The measurement of the transmitted laser power through each pinhole showed that $71 \%$ of the available laser power was present in the central $6 \mu \mathrm{m}, 21 \%$ was present in the ring between the 6 and 12 
$\mu m$ diameters, $7 \%$ in the ring between the 12 and $25 \mu \mathrm{m}$ diameters, and the remaining $1 \%$ outside the $25 \mu \mathrm{m}$ diameter of the beam. Therefore, the diameter of the bearnwaist was estimated to be $\sim 6 \mu \mathrm{m}$. Thus, when using $25 \mathrm{~mW}$ of laser power the incident irradiance is $\sim 9 \cdot 10^{4} \mathrm{~W} / \mathrm{cm}^{2}$

The measured spectral response of the system is shown in Figure 2. The spectrum of the QTH lamp, the measured spectral distribution of this lamp with our CRS system, and the spectral response of the CRS system for unpolarized light are shown in Figure 2A, B, and C, respectively. The spectral response of our entire system depicted in Figure 2C, is highly influenced by the quantum efficiency of the CCD array, in the wavelength range of $400-1000 \mathrm{~nm}$. The large drop around $515 \mathrm{~nm}$ is caused by the notch filter, which blocks any Rayleigh scattered light. The small dips around 650 and $680 \mathrm{~nm}$ are believed to be caused by the holographic beamsplitter. Since our regions of interest lie in the range of $520-630 \mathrm{~nm}$, where no significant Raman signals can be detected beyond this region, these dips are of minor importance here.

Next, the performance of the CRS system using different size collection fibers $(50 \mu \mathrm{m}$ and $400 \mu \mathrm{m}$ ) was assessed. Saline was used as a phantom because of its relatively strong Raman scattering signature and its biological compatibility. In Figure 3 the normalized Raman peak intensity of the $3430 \mathrm{~cm}^{-1}$ Raman mode of saline is plotted against the translation of the entrance lens along the optical axis for the $50 \mathrm{~mm}$ fiber. Using this setup, a knife edge response curve for both the small $(50 \mu \mathrm{m})$ and large ( $400 \mu \mathrm{m})$ collection fiber was obtained, and the depth resolution for both instances could be established. Conventionally, the depth resolution in microscopy has been defined as the full-wicth-athalf-maxinum (FWHM) of a knife edge response curve. ${ }^{21,22}$ As described earlier by Tabaksblat et al. this approach is justified in fluorescence microscopy in general but in Raman spectroscopy this approach does not suffice. ${ }^{23}$ In a spatial map of, for instance, a fluorescent sample, the spatial differences remain more or less visible even when they are (locally) greatly distorted by the light from out-of-focus planes. However, in Raman spectroscopic sampling where quantitative infomation is required, the data become unreliable with such a considerable distortion. Therefore we have arbitrarily defined the depth resolution of our system as the change in nomalized Raman intensity from $10 \%$ to $90 \%$ of the maximum signal, comprising the straight part of the knife edge response curve as seen in Figure 3. Thus we determined the depth resolution of the $50 \mu \mathrm{m}$ fiber to be $120 \mu \mathrm{m}$ (Figure 3) and $920 \mu \mathrm{m}$ when using the $400 \mu \mathrm{m}$ fiber (see also Chapter 2, Figure 8).

Some remarks about the integration depth of this confocall Raman spectroscopy system have to be made. Puppels et al. already noted that, in confocal Raman spectroscopy, the depth resolution for point like objects is controlled by a defocusing effect, in which the Raman signal decreases if the dimensions of the 

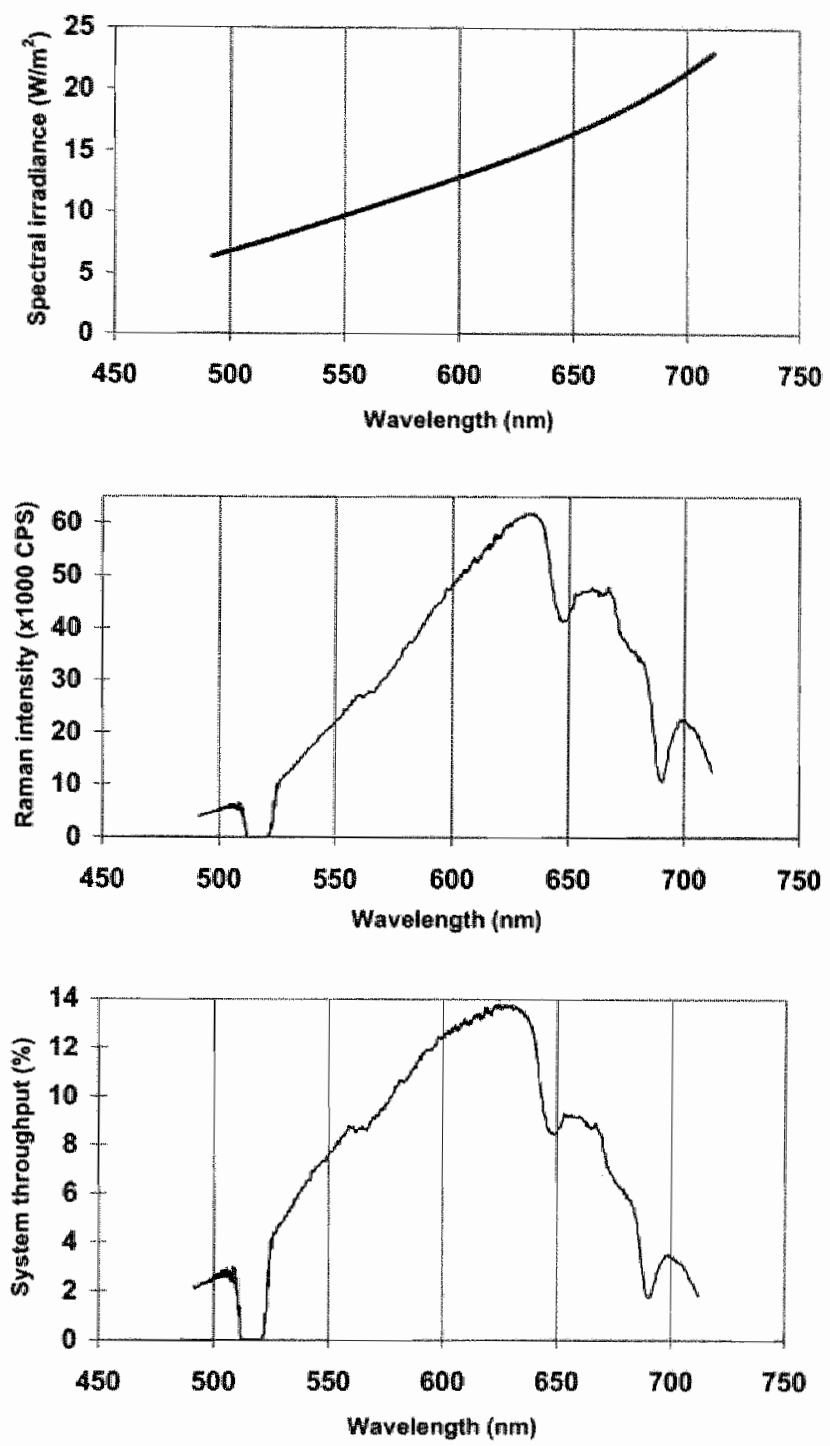

Figure 2. Spectral response of the CRS system for unpolatized light over a range of $50010700 \mathrm{~nm}$, fiomalized for an effeiency of $13.6 \%$ at $632.8 \mathrm{~mm}$. A. Spectral irmaliance of Quartz Tungsten Halogen (QTH) lamp, B. the spectral distriburion of the QTH-lamp as measured with the CRS system, C. the resulting spectral response of the CRS system (wavelength vs. relarive throughput) 


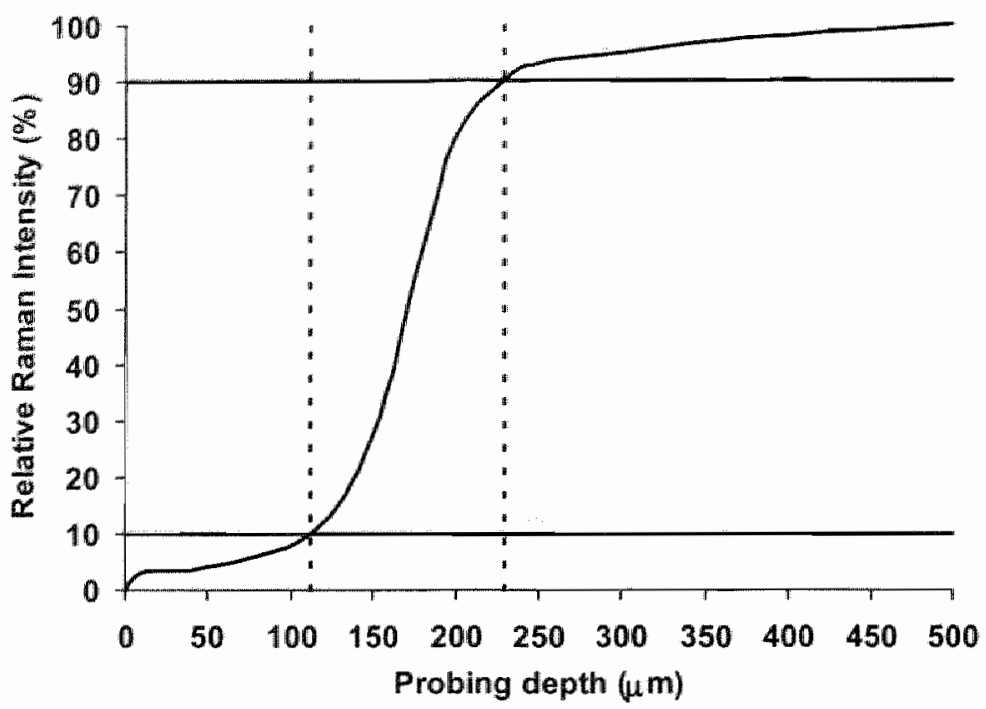

Figure 3. Relative Raman intensity of the $\mathrm{OH}$ bending mode of water as function of the distance of the microscope objective in relation to the sample. This resolution in deptry "edge response curve" of the CRS setup yields an integration depth of 120 $\mu m$ with the $50 \mu \mathrm{m}$ optical fiber. The same setup with the 400 fm optical fiber yielded an integration depth of 920 um (data not shown). Phantom sample was a quartz cuverte filled with $0.9 \%$ saline solution. Step increments through sample were 10 p.m.

object are smaller than that of the light cone of the laser focus in the optical axis. This resolution however, is considerably higher than the depth resolution for planar objects (as used in this study). which manly depends on the spatial filtering of the contocal pinhole. ${ }^{8}$ Optimizing the size of this pinhole implies a balance in blocking light from out of focus places (depth of field control) and preserving the Raman signal from the sample under investigation. Puppels et al. explain, that when a planar object is moved along the optical axis through the laser focus, the light intensity on the object decreases as is the case for the point object, but since light intensiry times irradiated area remains constant, the Raman intensity from the object will not change. ${ }^{8}$ In fact, a decrease of the Raman intensity occurs as the emitter area increases with respect to the lens diameter. This implies that the longer the working distance of the entrance lens is the less the extent of this decrease will be. Finaly, it should also be noted that due to the adaptation of the numerical apenture from the exit fiber to the spectrometer, the minimum width of the entrance slit of the spectrometer must be twice the efective dimeter of the exit fiber. Consequently, it depends on the 
required spectral resolution if the full gain in light gathening power can be used when using larger fiber drameters. A lot of useful light was lost using the $400 \mathrm{~mm}$ fiber at an entrance slitwidth of $200 \mu \mathrm{m}$. However, for the biochemical characterization of the ocular tissues, the $50 \mu \mathrm{m}$ optical fiber was used since it yields a relarively small integration volume and a high SNR (SNR in the comea is 70 for a laser power of $25 \mathrm{~mW}$ and an acquisition time of 1 second). Since the combination of entrance lens $(f=10 \mathrm{~mm}$ ) and exit lens $(\mathrm{f}=25 \mathrm{~mm})$ provides a sample spot size of $20 \mu \mathrm{m}$ when using the $50 \mu \mathrm{m}$ fiber (depth resolution of $120 \mathrm{\mu m}$ ), this volume is considerably larger than the $1 \mu \mathrm{m}^{3}$ sample volume obtaned by Puppels et al., using a $63 \mathrm{x}$ water immersion objecrive. 18 However, our objective is not to study single living cells or chromosomes, but to determine the spatially-resolved assessment of various laninated ocular tissues within the eye in a non-contact fashion.

To test the performance of our system in assessing various ocular tissues within the eye, rabbit eyes were characterized in witro (not enucleated after euthanasia of the animal). Axial scans of the comea, the aqueous humor and the lens prowide discrete and specific Raman spectri from each tissue, in both the lower and the higher wavenumber regions, as can be seen in Figures $4 A$ and $4 B$. In the lower wavenumber range (Figure $4 \mathrm{~A}$ ), we find the so-called signature-region. As far as the aqueous humor is concerned, no distinct features can be seen in the lower spectral range, apart from the region around $1640 \mathrm{~cm}^{-1}$ (fundamental bending mode of $\mathrm{OH}$ ). In the comea and the lens, we can clearly resolve several peaks. Here we identify only the most clearly resolved features of both tissues. The Amide-modes of proteins can be seen (Amide III 1225- 1275 $\mathrm{cm}^{-1}$. Amide I $\sim 1640-1675 \mathrm{~cm}^{-1}$ ), and are usually used to study protein conformation, i.e. the $\alpha$-helix or $\beta$-sheet conformation of proteins. ${ }^{24}$ Furthemore, several other peaks can be identified for example those corresponding to various amino acids (Phenylalanine at $1003 \mathrm{~cm}^{-1}$. Tryptophan at 760 and $881 \mathrm{~cm}^{-1}$. Tyrosine at $\sim 646 \mathrm{~cm}^{-1}$ ) and the $\mathrm{CH}_{2} / \mathrm{CH}_{3}$-bending band at $\sim 1375-1500$ $\mathrm{cm}^{-1} .25$ The peak at $-935 \mathrm{~cm}^{-1}$, which is clearly resolved in the connea but could not be resolved in the lens, is assigned to C-C stretching vibrations. In the higher wavenumber region from 2580 to $3750 \mathrm{~cm}^{-1}$ (Figure $4 B$ ), the strong signal of the $\mathrm{OH}$ bending mode at $-3100-3700 \mathrm{~cm}^{-1}$ and the $\mathrm{C}-\mathrm{H}$ stretching mode at $\sim 2850-3030 \mathrm{~cm}^{-1}$ are clearly distinguishable in both the cornea and the lems, and are mainly caused by the high amount of water and structural protens in both tissues, respectively. The $\mathrm{OH}$ response consists of three tesolved peaks. ${ }^{19}$ The CH signal depends on the kind of proteins or lipids found in the comea and the lens. In the comea mostly collagen, glycosaminoglycans and proteoglycans whereas in the lens the contribution of the lipids and crystallins can be found. In both tissues, the peak at $-2886 \mathrm{~cm}^{-1}$ is most likely caused by the antisymmetric stretching mode of $\mathrm{CH}_{2}$. In both the lens and the comea a 

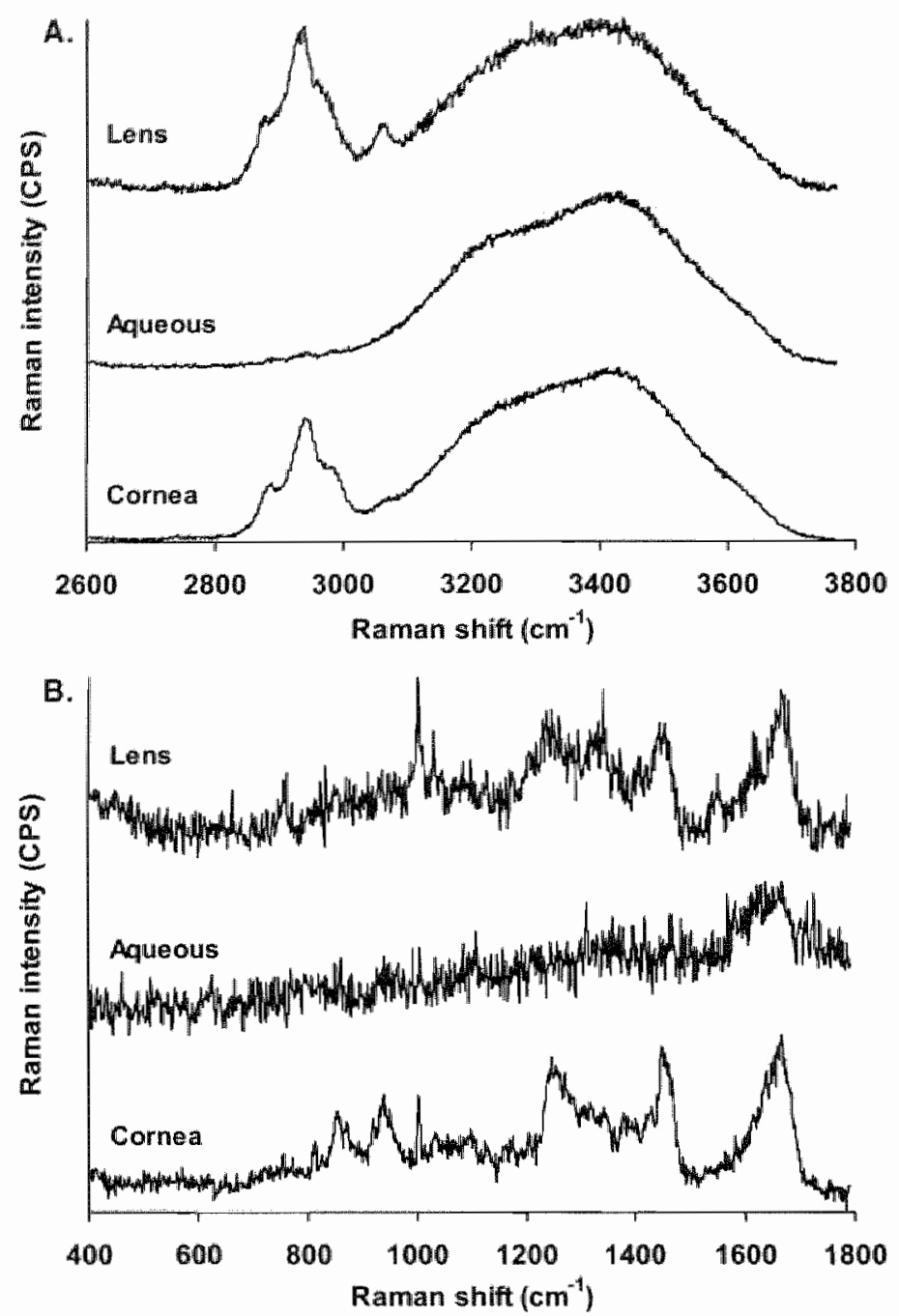

Figure 4. Post nortem Raman spectrum of an whith eye of a mabit showingrepal Raman spectra for the comean, aqueous humor, and the lens in both the lower and higher Raman shift region (ser text for dowils). Depicted is the Raman incensity as function of the Raman shifred wavelength $\left(\mathrm{cm}^{-1}\right)$. $\mathbf{A}=$ higher wavenumber region, $\mathbf{B}=$ lower waverumber region. Nowworthy is the decrease in SNR when going from the comea through the aqueous hunor to the ocular lens. SNR for the comea, aqueous humor and lens spectra is $75,50,30$, respectively. All spectra are obtained with the 50 un optical fiber as the contocal pinhole, using $25 \mathrm{~mW}$ of sample laser power and acquisition times of 1 second per spectrum (no averaging). 


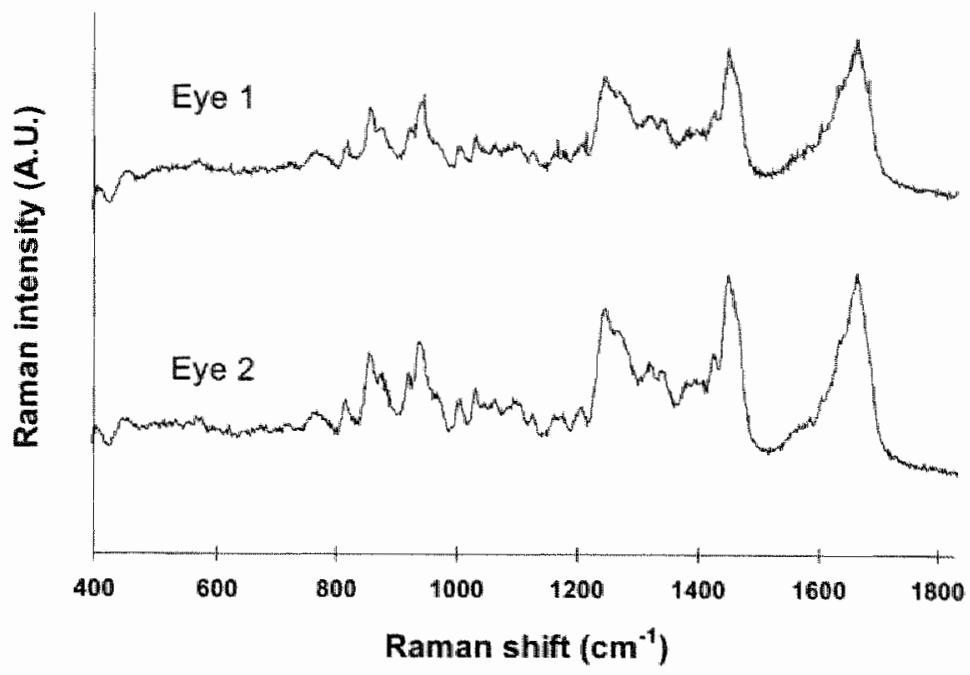

Figure 5. Raman spectra in the lower Raman shifted region $\left(400-1830 \mathrm{~cm}^{-1}\right)$ from two eyes (left and right) of the same rabbit. Parameters: $25 \mathrm{~mW}$ sample? laser power, 1 second per spectrum (no averaging), 50 um optical fiber (spectra are digitally smoothed).

combination of the anti-symmetric $\mathrm{CH}_{2}$ stretch $\left(-2930 \mathrm{~cm}^{-1}\right)$, the symmetric stretching mode of $\mathrm{CH}_{3}\left(2935 \mathrm{~cm}^{-1}\right)$ together with the out of plane asymmetric $\mathrm{CH}_{3}$ stretching mode $\left(-2960 \mathrm{~cm}^{-1}\right)$ can be seen. The signal at $\sim 3057 \mathrm{~cm}^{-1}$ is the so-called aromatic C-H strerching mode and, as can be seen in Figure $4 \mathrm{~B}$, its presence is rather confined to the lens. Thus, a distinction between both the comea and the lens tissues can be made based on this finding. The aqueous humor mainly shows the spectral response of the OH bending mode since it almost solty consists of water, and its Raman shift position closely resembles that of pure water at $-3400 \mathrm{~cm}^{-1}$. In order to investigate the reproducibilicy of the tissue signalls, four different eyes in three different animals were compared with each other. Figure 5 shows the result in wo of these samples. The spectra were obtained from about the same position within the comea. It can be seen that the spectra show comparable profiles as far as peak positions are concerned.

The $\mathbb{R}$ aman intensity of each specific peak depends on the concentration of the molecule(s) that cause it. Therefore, a closer andlysis is always necescary to obtain either relative or absolute values for the biochenical content of a cerain sample. This was investigated with regard to the phenylanine peak intensity. The Raman intensity ratio $I_{1003 /} I_{16,40}$ represents the relative content of phenylalanine, with $I_{1003}$ being the absolute Raman intensicy for phenylatamine and $I_{1640}$ being the absolute Raman intensity for the fundamental bending mode 
for water. For similar places in the comea of the four different eyes this rario was: $0.120,0.112,0.125,0.113$, with a mean of 0.118 and a standard deviation of 0.006 , proving high reproducibility between tissues from different subjects.

\section{Conclusions}

The CRS system as presented here has several unique modalities conbining the features of confocal microscopy with Raman spectroscopy. These modalities include: (1) a high NA long working-distance entrance/collection lens with correction for $2 \mathrm{~mm}$ window glass in a telecentric configuration, yielding high gain scanning properties for optical sectioning through transparent media in a nor-contact fashion; (2) a rapid CCD detector array, for fast spectral acquisition of a broad Raman shift range; (3) controllable integration depth by being able to change the degree of confocality by adjusting the collection fiber diameter.

In summary, the novel confocal Raman spectroscopy system allows for the non-contact spatially-resolved biochemical characterization of the anterior ocular segment. However, future ophthalmic applications of this system requires determining the optimum dose of light for safe diagnosis as well as the integration of an eye tracking system which will correct for movement artifacts.

\section{Acknowledgements}

The experiments for this study were performed in the Biomedical Laser and Spectroscopy Program at LTMB, Texas and funded in part by a grant from the Deparment of Energy and a Research to Prevent Blindness Development Grant.

\section{References}

1. P. Gwyme, "A new window on biomedicine with spectroscopy," Biophatonis 1 , $52-59(1994)$.

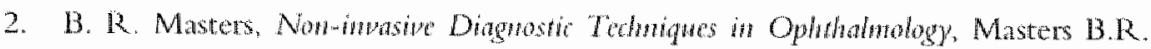
Ed., Springro-Verlag, New York, NY (1990).

3. J. Eppstein and S. E. Bursell, "Non-invasive detection of diabetes mellitus," in Proceding of the Physiological Montioning and Eatly Detection Diagnastic Methods Symposimu, SPIE 1641, (1992). 
4. J.A. wan Best and P.H. van Gessel, "Autoluorescence and light scater in the human lens as measured by a fuorophotometer," Experintertal Eye Resedw 49, 511-3 (1989).

5. C.J. Frank, R. L. McCreery and D.C. Redd, "Raman spectroscopy of normal and diseased human breast tisues," Analynal Chennisty 67, 777-83 (1995).

6. A. Mizuno, T. Hayashi, K. Tashibu, S. Marashi, K. Kawauchi and Y. Ozaki, "Near-infrared FT-Raman spectra of the rat boin tissues," Newrotiente Letrers 141, $47-52$ (1992).

7. R.H. Clarke, J.M. Isner, T. Gauthier, K. Nakagawa, F. Cerio, E. Hanlon, E. Gaffney, E. Rouse, and S. Dejesus, "Spectroscopic characterization of cardiovasm cular tissue," Lasers in Surgery \& Mediane 8, 45-59 (1988).

8. M. Pezolet, M. Pigeon-Gossehn, R. Savoie and J.P. Caille, "Laser Raman investigation of intact single muscle fibers. On the state of water in muscle rissue," Brodimica et Biophysici Acta 544, 394-406 (1978).

9. S. C. Goheen, L.J. Lis, and J.W. Kauftman, "Raman spectroscopy of intact feline comeall collagen," Biodishica et Biophysica Acta 536, 197-204 (1978).

10. D.S.W. Siew, G.M. Clover, R. P. Cooney, P.M. Wiggins" "Micro-Raman spectroscopic study of organ cultured conneae," J. Raman Spec, 26, 3-8 (1995).

11. N-T. Yu, J.F.R. Kuck,Jk. and C.C. Askren,"Laser Raman spectroscopy of the lens in sitw, measured in an anesthetized rabbit," Cument Eye Researd 1, 615-618 (1982).

12. N-T. Yu, M. Bando, J.F.R. Kuck, "Fluorescence/Raman intensity ratio for monitoring the pathologic state of human lens," Investigative Ophthalmolegy of Visual Sicne 26, 97-101 (1985).

13. A.C.C. Bot, A. Huizinga, F.H.M. de Mul, G.F.J.M. Vrensen, J. Greve. "Raman microspectroscopy of fixed rabbit and human lenses and lens slices: new potentialities," Experimental Eye Reseamh 49, 161-169 (1989).

14. S. Dai, S. Qi, L. Zhang, C. Ba, T. Ni, X. Deng, "Laser Raman spectrometry study on experinental galactose-induced catanct. Yen Ko Hsueh Pao lEye Sciencel $11(3) .143-6(1995)$.

15. J. Sebag, S. Nie, K. Rewer, M.A. Charles and N-T Yu, "Raman spectroscopy of human vitreous in proliferative diabetic retinopathy," Inwestigave Ophthahwology 8 Visual Sotuce $35,2976-80(1994)$.

16. J. Pawley, Fundanchal Linits in Confocal Mirosopy. Handbook of biologicat anfocal whrosiopy. J.B. Pawley, Ed., pp. 15-26, Plenum Press, New York and London (1990).

17. G.J. Brakenhoff, P. Blom, and P. Barends, "Confocal scaming light microscopy with high aperture immersion lenses," J of Micros. 117, 219-32 (1979).

18. G.J. Puppels, W. Collier, J.H.F. Olminkhof, C. Otto, F.M.M. de Mul, and J. Greve, "Description and perfomance of a highly sensitive confocal Raman microspectrometer,"J. Ranan Spct. 22, 217-25 (1991). 
19. H. Beyer, H. Resenberg, Handbuh der Mikroskopic, VEB Verlag Techuik, Berlin 1988).

26. D. W. Slat, R. Alweinse, and H. Wayland, "Use of telescopic imaging in intravial microscopy: a simple solution for conventional microscopes," Interational Joumal of Microcitulation: Clinical and Experimental 1, 121-134(1982).

21. H. T. M. van der Voort, G. J. Brakenhot, and G. C. A. M. Janssen, "Determination of the 3-dimensiomal optical properties of a confocal scaning lasermicroscope," Optile $70,48-53(1988)$.

22. R. W. Winnaendts van Resand, H. I. B. Marsman, R. Kaplan, J. Davoust, E. H. K. Stelzer, and R. Stricker, "Optical fluorescence in three dimensions: microtomoscopy,"J. Micose. 138, 29-34 (1985).

23. R. Tabaksblat, R. J. Meier, and B. J. Kip, "Confocal Raman Microspectroscopy: theory and application to thin polymer samples," Appl. Spece.46,60-8 (1992).

24. I. Siebinga, G.F.M.M Verasen, K. Otto, G.J. Puppels, F.F.M. de Mul, J Greve. "Ageing and changes in protein confomation in the human lens: a Raman microspectroscopic study," Exp. Eye Res. 54, 759-67 (1992).

25. A. Mizuno and Y. Ozaki, "Aging and cataractous process of the lens detected by laser Raman spectroscopy," Lem E Eye Tox. Res. 8(2-3). 177-187 (1997). 


\section{Applications of confocal Raman spectroscopy for biochemical characterization of ocular tissues and fluids}

Noël JC Bauer, Massoud Motamedi, James P Wicksted, Gerwin Jan Puppels, Wayne F March, Fred Hendrikse 
The first and, until recently, only report on the in vivo application of Raman spectroscopy (RS) in the eye was published in 1981 by Yu et aL. It showed promising results on obtaining high signal-to-noise ratio Raman spectra of the intraocular lens of an anesthetized rabbit. The lack of spatial resolution and the need for high, potentially hazardous, laser light energies have limited the in vivo application of RS in the eye. Hence we initiated investigations into the application of Raman spectroscopy for biochemical characterization of ocular tissues and fluids under in vivo circumstances.

The proposed optical system consisted of a high gain and sensitive confocal Raman spectroscopy (CRS) system with a long working distance enabling non-contact optical sectioning of the pre-corneal tearfilm, the cornea, the aqueous humor, the ocular lens, and the vitreous humor in vivo. This paper summarizes our investigation into the potential uses of a this optical system for diagnostic purposes in the field of ophthalmology.

Apart from the biochemical characterization and identification of normal rabbit ocular tissues in vivo, the main topics in this paper deal with the in wivo application of CRS for the assessment of transport rates of a topical acular drug from the pre-corneal tearfitm into the cornea, the assessment of the extent and distribution of corneal hydration in the rabbit eye under normal conditions, directly after epithelial debridement, and during corneal procurement, and the assessment of comeal hydration in legally blind patients. Furthermore, the potential use of CRS for non-contact biochemical characterization of the aqueous humor for diagnosing and monitoring systemic metabolic alterations such as diabetes mellitus and phenylketonuria was investigated in vitro. In addition, the potential application of CRS for non-contact intraocular temperature measurements is described. Lastly, future clinical application of CRS in the seeing human eye is considered with the eye on system safety and practicality.

The CRS system portrays various advantageous characteristics such as an inherently high specificity, non-contact probing, rapid biochemical characterization of complete tissues, the confocal property, enabling optical sectioning and effectively increasing the signal-to-noise ratio, and the ability to apply this optical system in vivo. Hence it is concluded that CRS is suitable for biochemical characterization of ocular tissues and fluids in a non-contact manner under in vivo circumstances. 


\section{Introduction}

Raman spectroscopy (RS) is an optical vibrational spectroscopic technique. It provides detailed information about the molecular composition of a sample and about molecular structure and interactions between molecules. It enables non-contact investigation of very small samples or sample volumes, e.g. multi-component analysis of complex molecular mixtures. The optical design of the sampling compartment of a Raman instrument can easily be optimized to the specific application. For biological or biomedical applications Raman spectroscopy holds a significant advantage over infrared spectroscopy, which provides information of the same nature. Water strongly absorbs in the infrared. This makes it very hard to obtain infrared spectra of the molecules of interest in solution or in the presence of water. The Raman signal of water on the other hand does not appreciably interfere with the other Raman signals of the molecules of interest.

Applications of RS in biology and medicine have been the field of interest of many investigators. ${ }^{~}$ Our investigations deal with the application of RS in the anterior portion of the eye, including the tearfilm, the connea, and the aqueous humor. The eye as a whole consists of different lamellar tissue structures, each with a different biochemical content, optical properties, thickness, intraocular location, and light-sensitivity, which poses a challenging problem. Thus, our initial aim was to apply a novel confocal Raman spectroscopy (CRS) system for non-contact biochemical characterization of ocular tissues. ${ }^{2}$ We have applied this technique under in viro circumstances to assess the spatial distribution of comeal hydration and the drug transport through the eye. ${ }^{3,4}$ Furthermore we were the first to apply this technique in legally blind subjects to detect changes in comeal hydration after topical application of a dehydrating agent. ${ }^{5}$ In addition. we have shown that CRS could play a significant role for the non-contact detection of biomolecules in the aqueous humor. ${ }^{6}$ These and various other potential applications of Raman spectroscopy in the anterior region of the eye are the subject of this paper.

\section{Methods}

The characteristics and performance of the confocal Raman spectroscopy system that we used (Figure 1) are discussed in more detail elsewhere. ${ }^{2}$ The monochromatic light is provided by either an argon $(514.5 \mathrm{~nm})$ or a helium-neon $(632.8 \mathrm{~nm})$ laser. Since the Stokes-lines of interest in a Raman spectrum lie in the region from 0 to $3800 \mathrm{~cm}^{-1}$, the application of either laser source will result in spectra with a frequency range within the detection limits of 


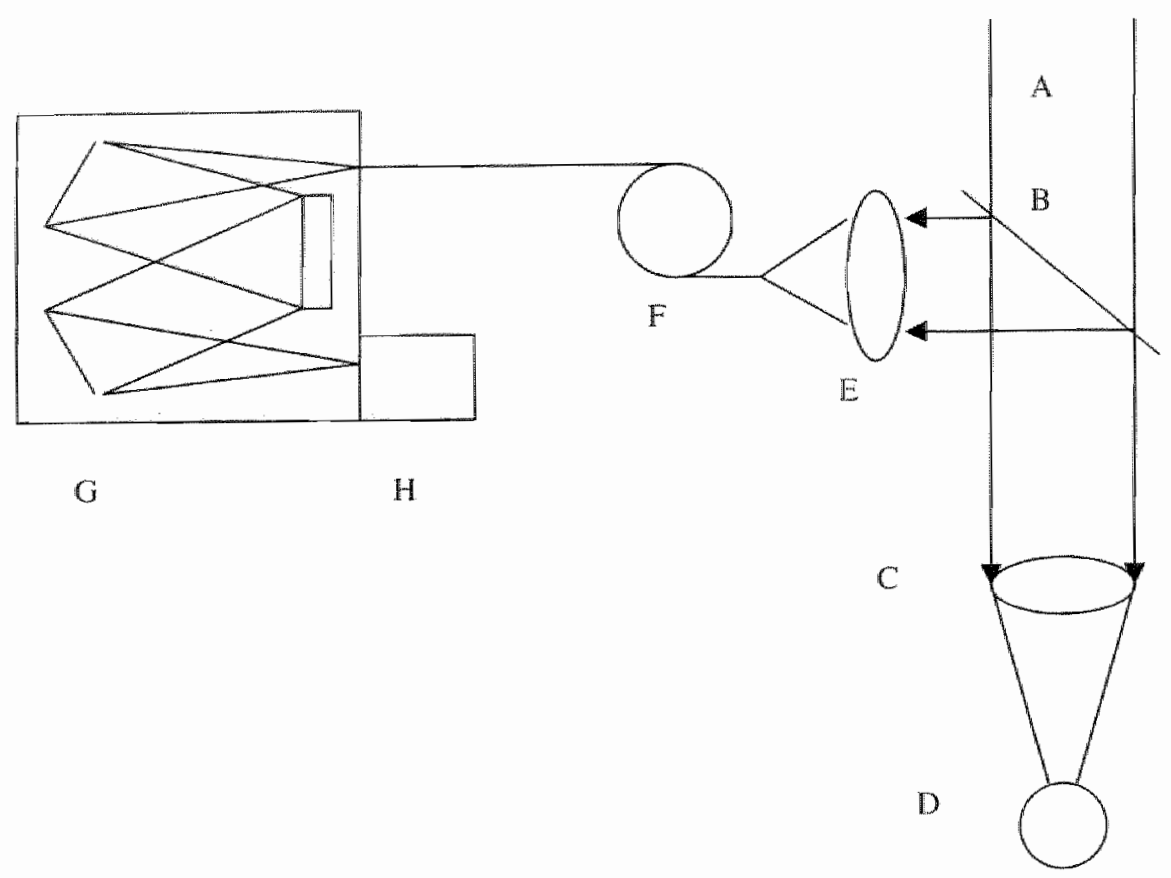

Figure 1. Schenatic of the confocal $R$ aman spectroscopy system. $A=$ collimated laser beam; $B=$ beamsplitter; $C=$ long working-distance microscope objective lens; $D=$ sample (i.e. the eyej: $\mathrm{E}=$ exit lens; $\mathrm{F}=$ oprical fiber; $\mathrm{G}=$ spectrometer; $\mathrm{H}=\mathrm{CCD}$-camera.

the photon-counting device, a liquid nitrogen cooled charge coupled device (CCD; detection limits 400-1000 $\mathrm{mm}$ with a maximum quantum yield of $80 \%$ at $-700 \mathrm{~mm}$. A long working distance microscope objective (LDMO, 25x, NA0.5, working distance $13 \mathrm{~mm}$ ) is employed in a $180^{\circ}$ backscatter configuration, and is used both for focusing the laser light onto the sample as well as for collecting the backscattered light. Furthermore, this lens is part of a telecentric setup allowing for axial displacement of this microscope lens without changing the focal distance at the exit lens, yelding axial scanning capabilities. The LDMO permits non-contact sampling of all ocular tissues of the anterior segment from tearfilm to the anterior vitreous humor just behind the ocular lens. An optical fiber at the exit site of the optical system is used for transporting the Raman scattered light to the spectrometer, but also acts like a confocal pinhole. The confocal configuration increases the signal-to-noise ratio (SNR) by decreasing the detection of light from out of focus places. By choosing the appropriate fiber diameter (dianeters ranging from 4 to $80 \mu \mathrm{m}$, or larger) probing volumes can be obtained that are either much larger or much smaller 
than the chickness of the tissue we prefer to probe, with a range of 20 to $225 \mu \mathrm{m}$, or larger. Depending on the experiments, we used laser light exposures of $3 \mathrm{~m}$ ] $(6 \mathrm{~mW}$ for $0.5 \mathrm{~s})$ to $3 \mathrm{~J}(50 \mathrm{~mW}$ for $60 \mathrm{~s})$. The animal studies mentioned in this. manuscript were performed in accordance with the ARVO Resolution on the Use of Animals in Research, while the reported human study was perfomed after approval of our Institutional Review Board and after signed informed consent.

\section{Results}

\section{Raman spectra of normal ocular tissues in vivo}

Using CRS we were able to obain thigh SNR Raman spectra from all ocular media of the normal rabbit eye under in wino circumstances, from pre-comeal tearfilm to the vitreous humor. The Raman features of these spectra are very specific for the tissues they originate from (Figure 2), thus RS can be applied to differentiate between the various ocular tissues. Even within the same tissue, biochemical differences can be observed, noticeable in both the lower as well as the higher $R$ aman spectral region. In the higher $R$ aman shift region for example, we can observe that the Raman intensity of the OH-vibrational modes $\left(-3100-3700 \mathrm{~cm}^{-1}\right)$ in relation to the $\mathrm{CH}$-vibrational modes $\left(\sim 2800-3050 \mathrm{~cm}^{-1}\right)$, is significantly higher in the posterior than the anterior region of the cornea. This corresponds well with the spatial distribution of comeal bydration as assessed using various other biochemical assays. ${ }^{7}$ For the ocular lens, the hydration is higher in the cortex than in the nucleus as indicated by the lower Raman intensity ratio $\mathrm{OH} / \mathrm{CH}$ in the central region of the lens, also in accord with the current literature.

The next few paragraphs will describe the potential applications of CRS in the tearfin, the comea, and the aqueous humor, respectively.

\section{The tearfilm}

Topical application of ocular drugs forms an important part of ocular therapy. It should be clear that the efficacy of topical ocular drugs or drug delivery systems is of umost importance for asuccessful treatment. Factors that determine this efficacy, apart from the actual working mechanism on receptor level at the target tissue, include the rate of absorption, distribution, and elimination of the drug, called the phamacokinetic behavion of the drug. In other words, how much of the drug gets to the target tissue at what speed and how long is its working action. This can be quantified by determining the drug 


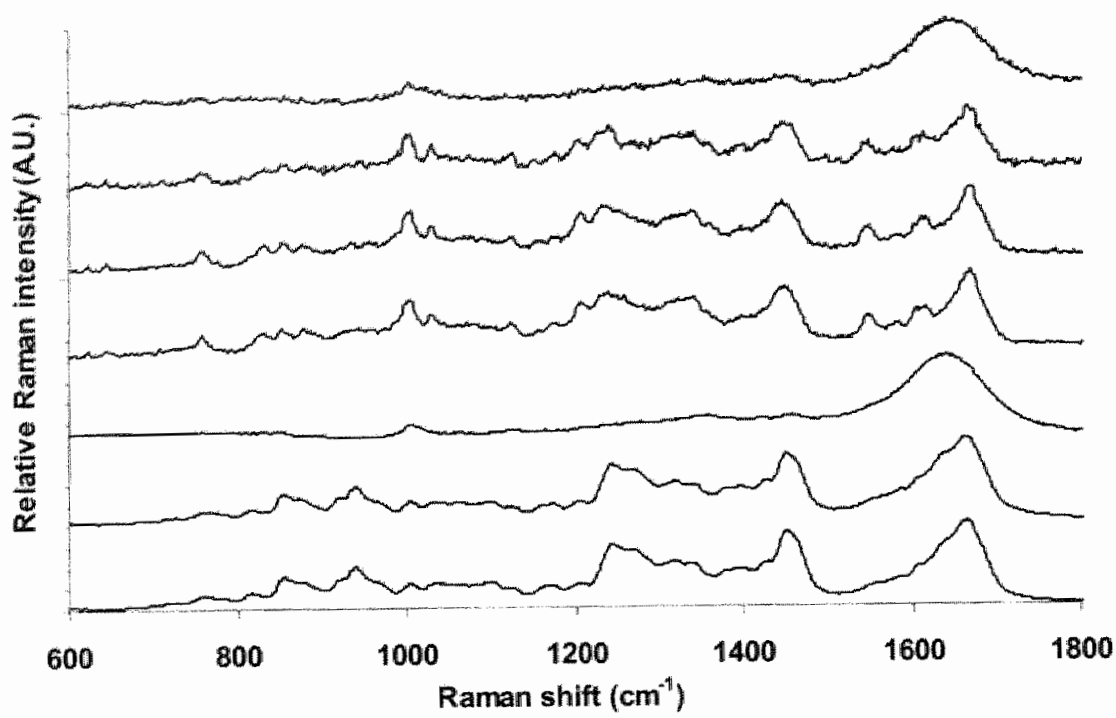

Figure 2A. Typical Raman specta of a nomal vabbit eye under w wo conditions in the lower Raman shift region. From botton to top: anterior comea, posterior comea, aqueous humor, anterior lens cortex, lens nucleus, posterior lens cortex, vitreous humor.

70

5
4
5
5
5
5

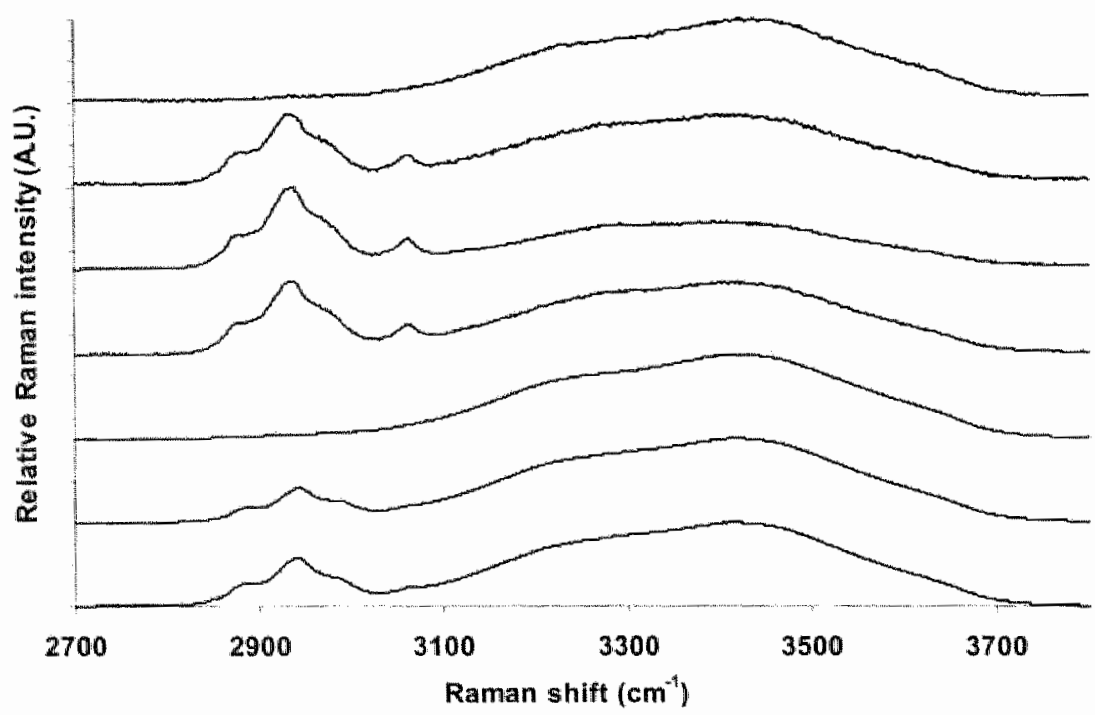

Figure 2B. Typical Ranan spectra of a nomal rabbit eye under in wive conditions in the higher Ranan shift region. From botom to top: anterior comea, posterior comea, aqueous humor, anterior lens correx, lens nucleus, posterior lens cortex, whteous humor. 
concentration as a function of time in the tissues of interest. For topical ocular drugs that have a target tissue situated inside the eye, such as anti-inflammatory or anti-glancoma drugs, it is important to know how well this drug crosses the various barriers that lie between the site of application and the site of action. Nowadays, phamacokinetic measurements are manly performed using invasive methods by quantifying drug concentrations in comea or aqueous humor specimens $x$ wo utilizing sensitive assays such as high performance liquid chromatography (HPLC). Apart from the potential introduction of artifacts it is clear that these invasive methods are rather destructive to the eye. The consequent need to use animal models has disadvantages because of the obvious differences in anatomy and physiology in relation to the human, and the non-continuous sampling, since one animal is used for one measurement. Non-contact means of determining the drug concentration in ocular tissues are limited to the quantification of drug concentrations by means of tuorescence detection. Although this method is sensitive and is sate to be appliad in humans, fuorometry is rather unspecific. An ideal method for phamacokinetic measurements should thus be non-invasive, sensitive, drugwpecific, and enable quick and continuous assessment of drug concentrations over time in one and the same tissue. We have investigated if $R S$ could be utilized to quantify drug concentrations in the eye using its inherent specificity and non-contact character. The first step in our investigations entailed the assessment of drug-concentrations as a function of time in the anterior most part of the living rabbit eye. Using a fiber diameter of $50 \mu \mathrm{m}$, an integration depth could be achieved of $120 \mu \mathrm{m}$, exclusively probing the tear film and comeal epithelial layer, the most important obstructive barrier to almost all topical ocular drugs. Figure 3 depicts the Raman spectra in the lower Raman shift region that we would find in a typical phamacokinetic experiment in the living rabbit eye, after topical application of a clinically used anti-glancoma medication with a specific Raman signal at 1420 $\mathrm{cm}^{-1}$. First of all it can be seen that the specificity of RS can be applied to discriminate between drug and tissue signals, since no Raman peak is found at $1420 \mathrm{~cm}^{-1}$ in the nomal comea before drug application. In addition, an important observation is that all measurements are performed in one and the same eyc, thus fewer animals are needed in relation to conventional phamacokinetic studies. Furthermore, it can clearly be seen that the Raman peak intensity at $1420 \mathrm{~cm}^{-1}$ decreases as a function of time due to drug absorption into the comea and non-absorptive losses from the tearfim. By quantifying this peak intensity as a measure for the relative drug concentration at sufficiently spaced time intervals, we were able to construct reproducible phatmacokinctic drugconcentration vs. time curves. Using these pharmacokinetic curves, rate constants for the drug transport from the tearfinn to the anterior cornea could be determined for this drug. Given these results we believe that confocal Raman 


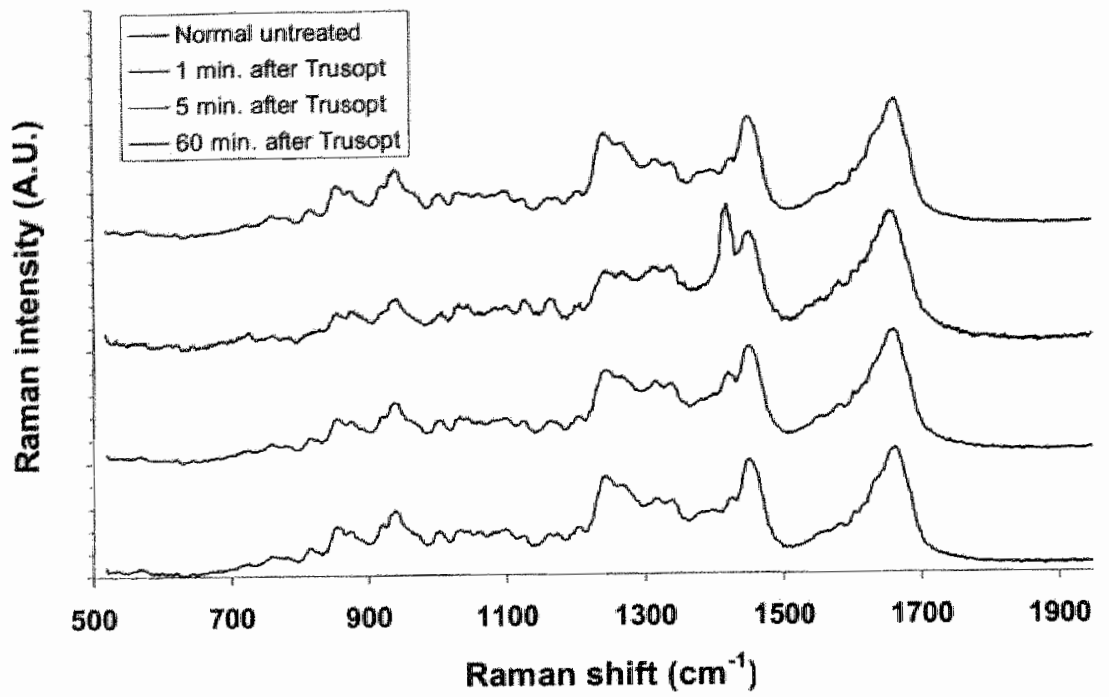

Figure 3. Raman spectral features of the anterior region of the comea during pharmacokinetic measurements. From top to bottom: prior to drug deposition (nomal), 1, 5 and 60 mint. after drug deposition.

spectroscopy could be a valuable tool for pharmacokinetic measurements, and with adequate improvements in the system, in particular the safety, could potentially be used in the human situation (Chapter 7 of this thesis).

\section{The cornea}

The comea forms the anterior border of the eye and consists almost entirely of water $(>75 \%)$ and structural proteins, mostly collagen. The comea is transparent because it is devoid of blood vessels, contains only a small number of cells, but mostly because of the spacing between the collagen fibrils which in turn is closely related to the hydration of the cornea. Comeal hydration is actively regulated by a single layer of cells at the posterior site of the cornea, the endothelial layer, which acts by pumping water out of the cornea which, by virtue of its swelling pressure, has the tendency to imbibe water. Dysfunction of the endothelial layer can lead to an increase in comeal hydration and comeal swelling which effectively increases the spacing berween the collagen lamellae, consequently leading to increased light scattering and some degree of vision loss. Since current methods to assess corneal hydration can only detect gross changes or do not possess the capabilities to perform spatially resolved measurements in wiw, we decided to investigate the possibility of non-contact RS to perform 
these kinds of measurements (Chapter 5 of this thesis). Huizingat al have shown that the Raman mtensity ratio of the OH-mode $\left(\mathrm{at}-3390 \mathrm{~cm}^{-1}\right)$ w the CH-node (at $-2935 \mathrm{~cm}^{-1}$ ) is in direct proportion to the hydration of the oculat lens. We employed a similar ratio in order to quantify comeal hydration under in vino circumstances. Figure $4 \mathrm{~A}$ shows the $\mathrm{R}$ aman spectra in the bigher $\mathrm{R}$ aman shift region of a rabbit comea at different degres of hydration; completely dehydrated after lyophilization ( $\mathrm{H}=0 \mathrm{mg}$ water / $\mathrm{mg} d \mathrm{dy}$ w.). nomally hydrated $(\mathrm{H}=3.05)$ and hyper-hydrated $(\mathrm{H}=8.3)$. The confocal configumion of our system permitted adjustment of the integration depth to $1 / 10$ th of the comeal thickness, yidding the possibility to spatially resolve comeal hydration along the optical axis of the comea. We employed CRS for these kinds of measurements in wito under normal circumstances, and also docmented the changes in corneal hydration over time during nomal expostre of the living eye to the surrounding environment ${ }^{3}$ Typical results of spatially resolved comeal hydration measurements are shown in Figure $4 \mathrm{~B}$. Clearly noticeable is the distinct difference in stromal hydration berween the antenor and the posterior region of the comed, in agreement with our current knowledge on the non-homogeneous distribution of water in the connea. This kind of assessment might be clinically useful to diagnose local variations in water content as a result of therapeutic interventions such as photorefractive keratectomy or topical application of ocular drugs, or as a result of local or systemic alterations in comeal physiology indicative of impending pathology, as is the case in various forms of comeal dystrophies. Furthemore, time-resolved assessment of the distribution of water in the comea might possibly be used to further our understanding in corneal deturgescence under various hyper- or hypo-osmotic perturbances. Spatially resolwed hydration measurements can also be performed in the radial direction (Figure $4 \mathrm{C}$ ). These results too agree favorably with the literature because comeal hydration has been found to be higher at the periphery than in the central part of the comea. "The clinical relevancy of these results has still to be determined.

Several studies have stressed that comeal hydration could play an inuporant role with regards to the therapeutic outcome and the observed side effects of laser refactive surgery of the comea. ${ }^{11,12,13}$ Duming the nomal procedures of this kind of treatment, comeal hydation can change as a resule of the application of a topical anesthetic, the remowal of the epithelial layer, called corneal debridement, and the laser-tissue interaction itself. Thus, an attractive hypothesis is that a more accurate prediction of the therapentic outcome is preceded by a better understanding of the laser-tissue interaction, especially through the assessment of changes in comeal hydration during this treatment. At present, comeal hydration is estmated through assessing comeal thickness (pachymetry) at merely one point in time: after topical application of the anesthetic and before 


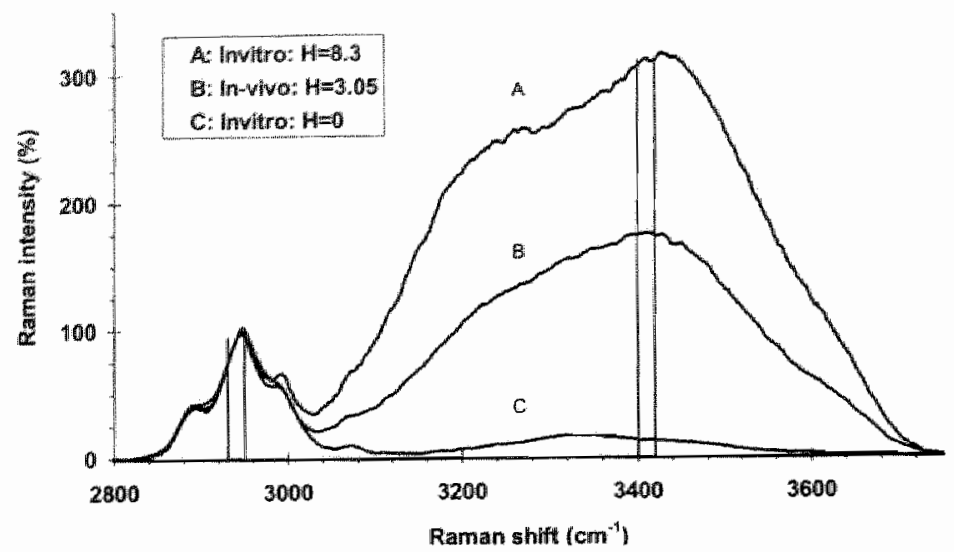

Figure 4A. Raman spectra in the high spectral region of the medial comeal stroma as assessed using sandard methods. (A) hyper hydrated, (B) normal, and (C) lyophilized comea. Spectra are nomalized to the Raman peak of the CH-vibrational mode at $-2950 \mathrm{~cm}^{-1}$.

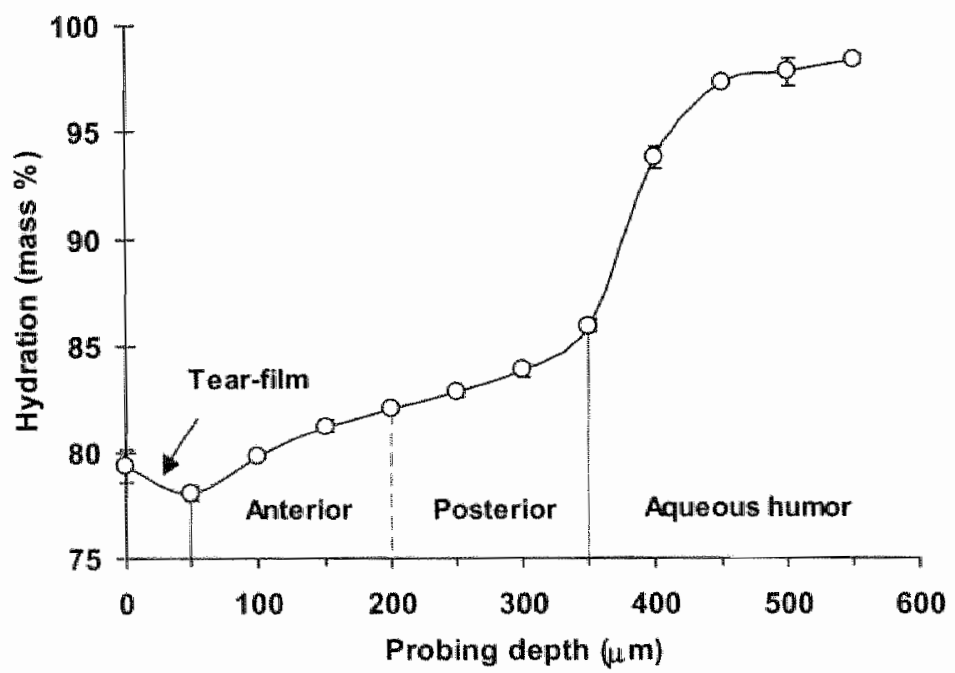

Figure 4B. Spatially resolved hydration assessments using CRS along the optian axis of the rabbit eve under in who conditions (average of 3 assessments).

comeal debridement. Furthermore, the routincly used ultrasound pachymetry can only determine the full thickness of the cornea, but is unable to assess local variations in comeal hydration, specifically of the comeal region to be treated. Thus, we decided to use CRS to document the acute changes in hydration of 


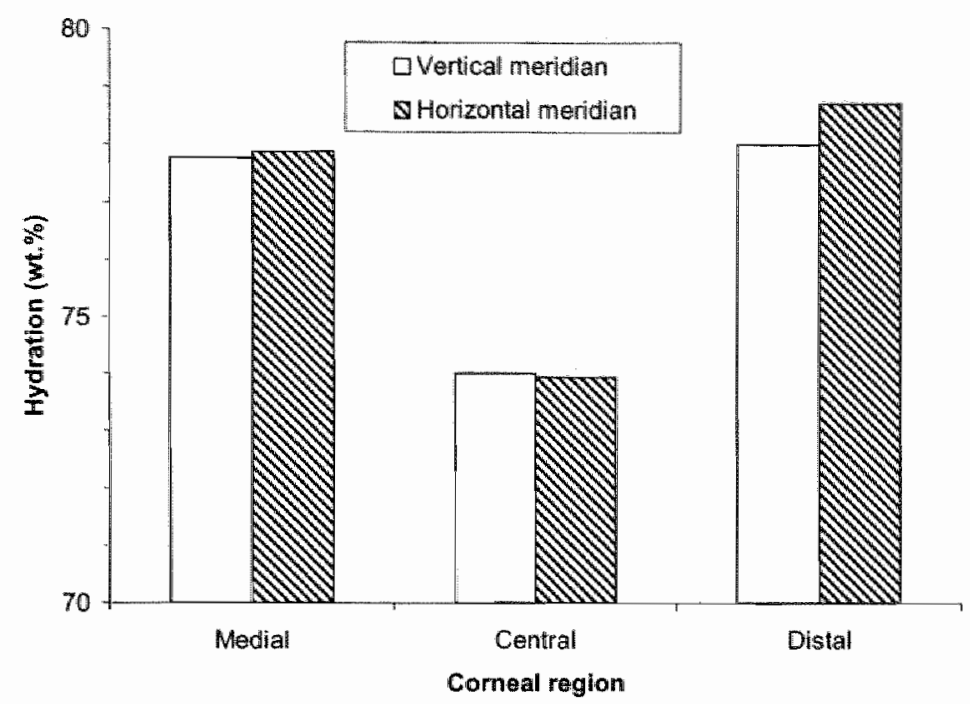

Figure 4C. Spatially resolved comeal hydation assessments using CRS at similar regions of the superticial corneal stroma along the vertical and horizontal meridian in the rabbit eye under in wino conditions.

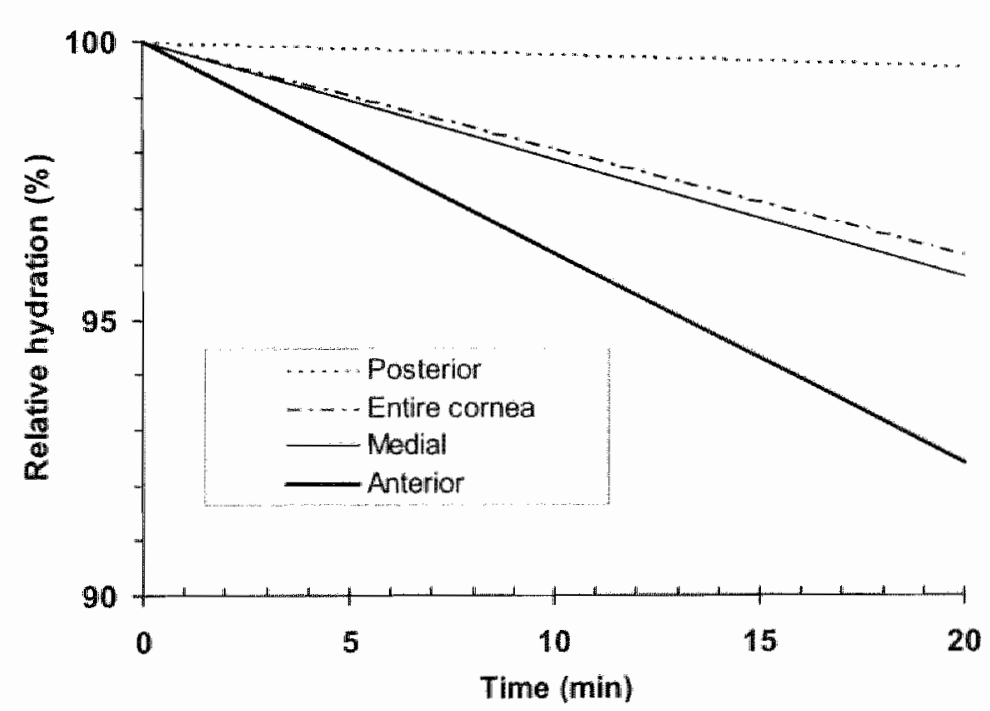

Figure 4D. Assessment of the changes in concal hydration as assessed using CRS of warious comeal regions of the in whe rabbit eye $(n=7)$ as a function of thme after epirhelial debridement. 
the anterior part of the comea after epithelial debridement in the rabbit under in wivo circumstances. Figure $4 \mathrm{D}$ shows the changes in stromal hydration of various regions within the rabbit comea (n=7 eyes) under in wo circumstances, as well as of the full thickness stroma hydration as a function of time after de-epthelialization. Significant changes in corneal hydration were noticed during the whole time-interval after de-pithelialization in the anterior and medial stromal region, but not at the posterior site $(0.38,0.21$, and $0.02 \%$ dehydration per minute, respectively). The relevance of these time-dependent changes has yet to be detemined, certainly because the inter-sample variation was found to be significanty higher than these dehydration rates. This led to the preliminary conclusion, that it might be valuable to assess comeal hydration from a subject to subject basis, in order to have a better control over the ablation process during photo-retractive surgery of the comea. By reducing the variability caused by comea hydration, the predictability of the refractive outcome might eventually be increased.

The assessment of the function of the endothelial layer is of utmost importance in order to determine the well-being of a comea, especially prior to transplantation, and can be estimated through assessing comeal hydration (see above). A study by Siew et al. recently reported on the potential use of RS for the assessment of comeal hydration in organ cultured comeas, possibly applicable for the quality control of transplant comeas. ${ }^{\text {th }} \mathrm{A}$ more sensitive and specific means of determining corneal viability could mean that the number of suitable comeas that would nomally be discarded using other methods could possibly be reduced. Siew et al. observed significant changes in full thickness comeal hydration that could be related to type of storage medium and conchuded that RS might make a valuable contribution to the quality control of cye bank comeas. We went one step further since we found it of significant interest to investigate the satial distribution of comeal hydration as a function of sorate fime, with the hypothesis that endothelial dysfunction might manifest atsalf through significant changes in hydration at the posterior region of the conca. Our inial experments entaled the assessment of the spatially resolved comeal hydration as described earlier (Ref. 3 ) of rabbit concas under in situ cincumstances, and after enucleation and storage of the sane eye in a moist chamber at $4{ }^{\circ} \mathrm{C}$ for different periods of time. Typical results are shown in Figure $4 \mathrm{E}$ in graphical format for one comea. The most striking feature of this Figure is whe incase in hydration at the posterior site of the comea from 120 to 190 minutes after cuchanasia, possibly due to the anti-metabolic effect of the euthanasia agent, effectively 'slowing' the endothellal cells down and causing local swelling of the comea. After an initial dehydration of the anterior comeal region in the furs -20 minutes after enucleation corneal hydration reaches an equilibrium. Storage of the whole eyes causes the whole comea to swell gradually, 

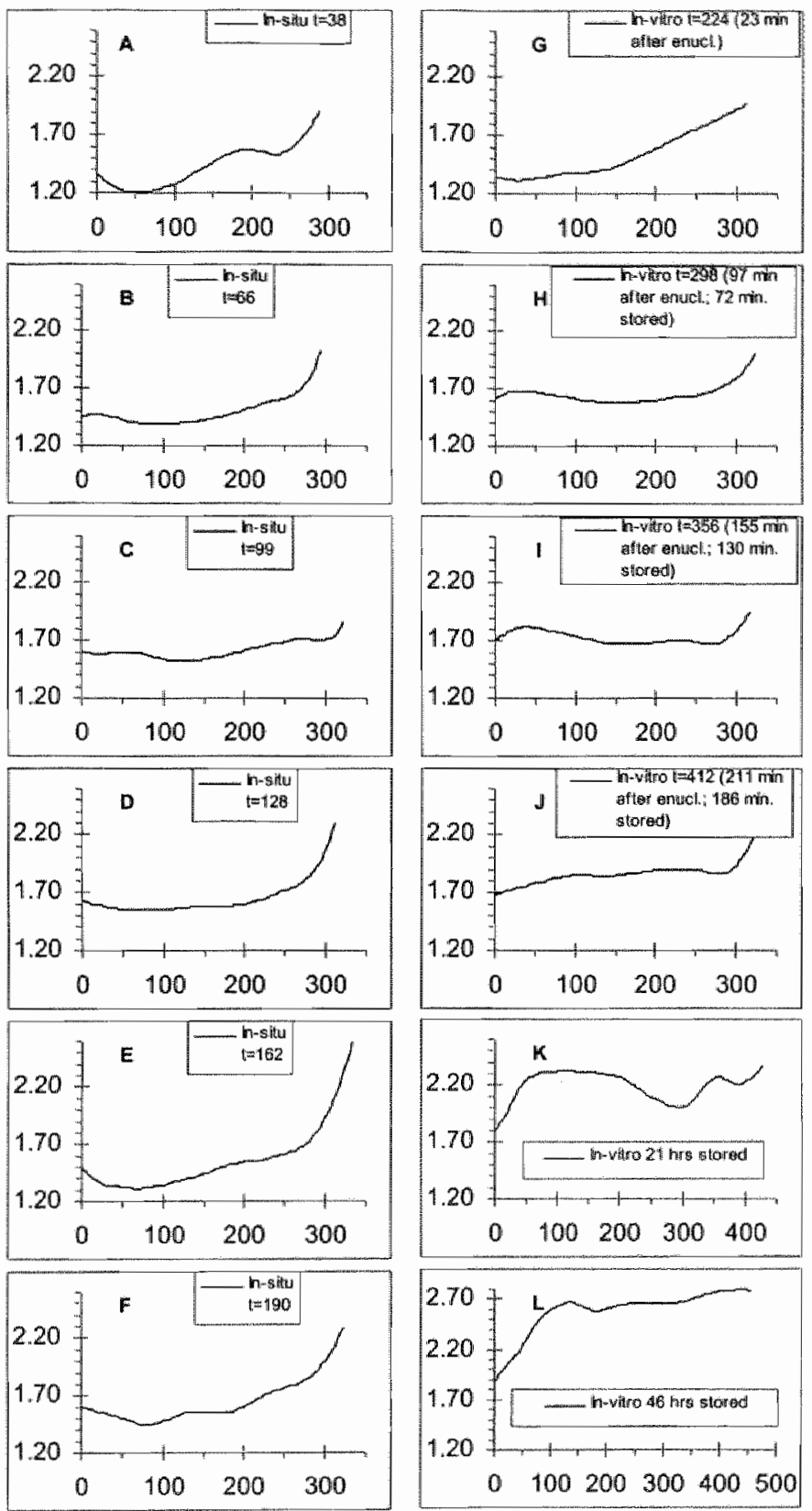

Figure 4E. The axtent ( $y$-axis) and distribution ( $x$-axis) of corncal hydration ans assesed using CRS in an experiment resenbling comeal procurement (ser also Fight 4f). Graph A through Fare obtained with the eye still iw-situ (time $t$ after euthanasia of the rabbit). Graph $G$ is obtained just after enucleation of the eye and just prior to cold storage. Graph $H$ through $L$ are obtained as a function of time after cold storage of the whole bulb at 4 " $\mathrm{C}$. 
which is depicted in numerical format in Figure $4 \mathrm{~F}$. Here the absolute water content of the anterior and posterior comeal stroma is plotted as a function of storage time. It can be seen that within three hours of storage, the difference between anterior and posterior stromal hydration has become insignificant, and both regions hydrate at an equal rate thereafter. The function of the endothelial cell layer, i.e. comeal hydration control, was not monitored in our or Siew's study. This requires the assessment of corneal hydration over a continuous period of time at physiological temperatures in order to quantify comeal deswelling as a measure of the pump function of the endothelial layer. This however can also be performed utilizing RS (see for example Figure $4 \mathrm{~B}$ in Ref. 3) and remains one of the interesting focuses of our studies.

With the experience gained from our animal experiments and preceding future clinical studies, we extended our investigations to the human situation. In two legally blind human subjects the hydration of the cornea was assessed using CRS. before and after topical application of a mild comeal dehydrating agent. Movement artifacts were unavoidable in the conscious humans, and prevented spatially resolved measurements. Thus, the focts of the laser beam was maintained at the same superficial region of the comea during the time of probing. Significant changes in comeal hydration could be observed in one subject but not the other because of the frequent blinking (Chapter 6 of this thesis).

\section{Pterygia}

A pterygium is a treatable ailment of the eye with an incompletely understood pathology, and entails the occurrence of abnormal fibrovascular tissue that can invade the comea potentially obstructing vision. Most of the time this growth is benign but in rare occasions can turn malignant. More importantly, after surgical removal of the pterygia a large percentage of patients experience recurrences. Thus, we investigated the possibility of using Raman spectroscopy as a diagnostic tool for the biochemical assessment of (superficial) ocular pathologies, such as preryglia. In Figure 5 typical (A through E) and atypical (F) Raman spectra are shown from human pterygium samples, and from a fresh cornea, and ocular lens of the rabbit for comparison reasons. In general is can be seen that the Raman spectrum of a human pterygum resembles the one from a comea with similar Anide I $\left(\mathrm{at} \sim 1665 \mathrm{~cm}^{-1}\right)$ and III $\left(\sim 1245 \mathrm{~cm}^{-1}\right)$ modes as expected for connective tisstes. Pterygia-specific Raman spectral features appear around $\sim 860$. $\sim 880$, and $\sim 1005 \mathrm{~cm}^{-1}$ (respectively the C-C vibration of the proline and hydroproline ring and the phenyl-ring mode). Furthermore, the very broad feature at $\sim 1100 \mathrm{~cm}^{-1}$ is not observed in the fresh comea, but could be assigned to the contributions of the formalin, the agent used to fixate the pterygia. The atypical spectral features of graph $F$ can be found at $\sim 1362, \sim 1555$, and $\sim 1610$ 


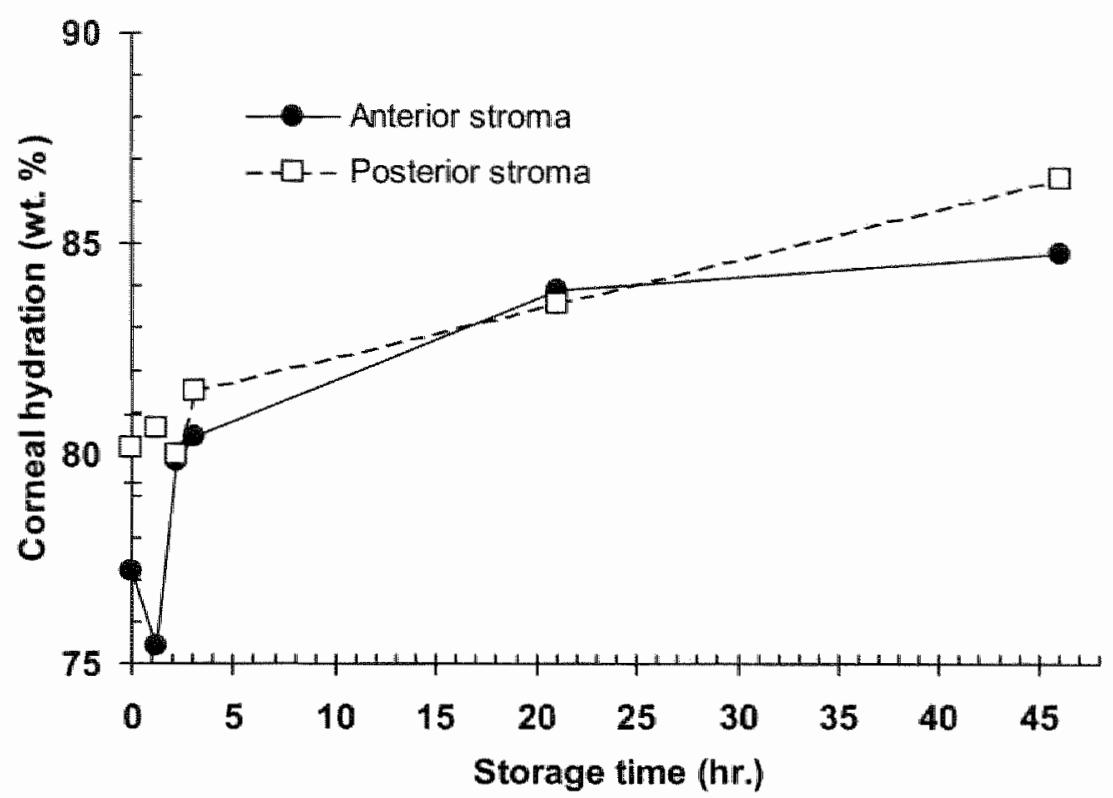

Figure 4F. Assessment of the hydration of the anteriot and posterior comeal region as a funcrion of time after cold storage of a whole rabbit eye (sce allso Figw 4 E).

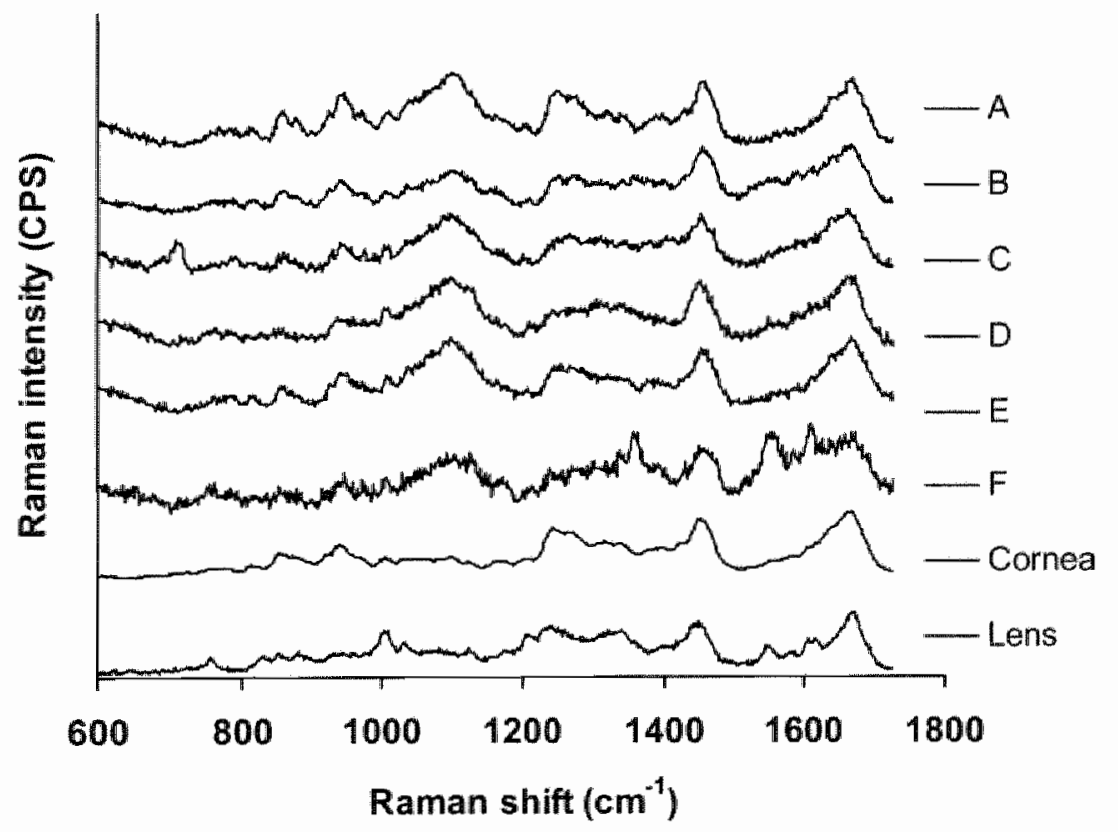

Figure 5. Typical (A through E) and atypical (F) Raman specta of human perygum sumples and from a human cornea and rabvit lens (for comparison reasons). 
$\mathrm{cm}^{-1}$ and are possibly due to contribution to the Raman signal of the haemoglobin of blood still present in the sample. This plot study suggests that Wi-contact probing of these translucent pterygia samples is possible in vitro and yield speciff Raman signals. With regards to the frequent recurrences of pterygiat afref surgical removal, a potential clinical application of RS might be to sample the surgery site for possible remnants in order to ensure complete renoval of the pterygium.

\section{The aqueous humor}

A very attractive chinical application for RS in ophthalmology is the possibility to detect bionolecules in the aqueous humor that might be indicative of systemic alterations in metabolism. 15 Certain important biomolecules might possibly be detected in real-time in which case real-time therapeutic interventions would be possible to regulate the underlying metabolic disturbances. Although we are still far from this ideal picture of a closed loop system, we did obtain valuable results during feasibility studies utilizing CRS.

Diabetes mellitus is a metabolic disease in which an absolute or relative shortage of insulin leads to an increased level of glucose irn the blood. which in the long run is responsible for the morbidity of the disease. Numerous patients need to monitor their blood glucose in order to self-administer the right amount of insulin. Nomally a monitoring device is used that requires a drop of blood, which cun be most inconvenient because of its invasive character. Thus, various research teams are in search of non-invasive means of determining the blood-glucose levels. Since the concentration of glucose in the aqueous humor is related to its concentration in blood, we investigated the possibility to use Raman spectroscopy for the non-contact monitoring of glucose in the eye. ${ }^{15} \mathrm{ln}$ witro experiments showed a linear relationship between the glucose concentrarion and the Raman intensity of the $\mathrm{CH}$-peak at $-2935 \mathrm{~cm}^{-1}$ in aqueous sugar solutions (Figure 6A). The proposed method seems sensitive enough since glucose concentrations below the physiological level of $\sim 50-100 \mathrm{mg} / \mathrm{dL}$ could be assessed. We are currenty investigating the feasibility of CRS for the non-contact sampling of gucose in the aqueous humor of anesthetized rabbits. However, the interpretation of the results are not straightorward since the changes in Ranan spectral features as observed in the in wito experiments are not specific for glucose alone when applied in wiwo. Other biomolecules possess chemical structures which are highly similar to glucose, such as lactate and urea. Additionally, other situations carn change the level of CH-bonds in the aqueous humor such as an increased level of proteins as a result of breaking of the blood-agueous barrier in intra-ocular inflammation. Thus, further investigations are necessary in order to determine specific changes in Raman spectral 


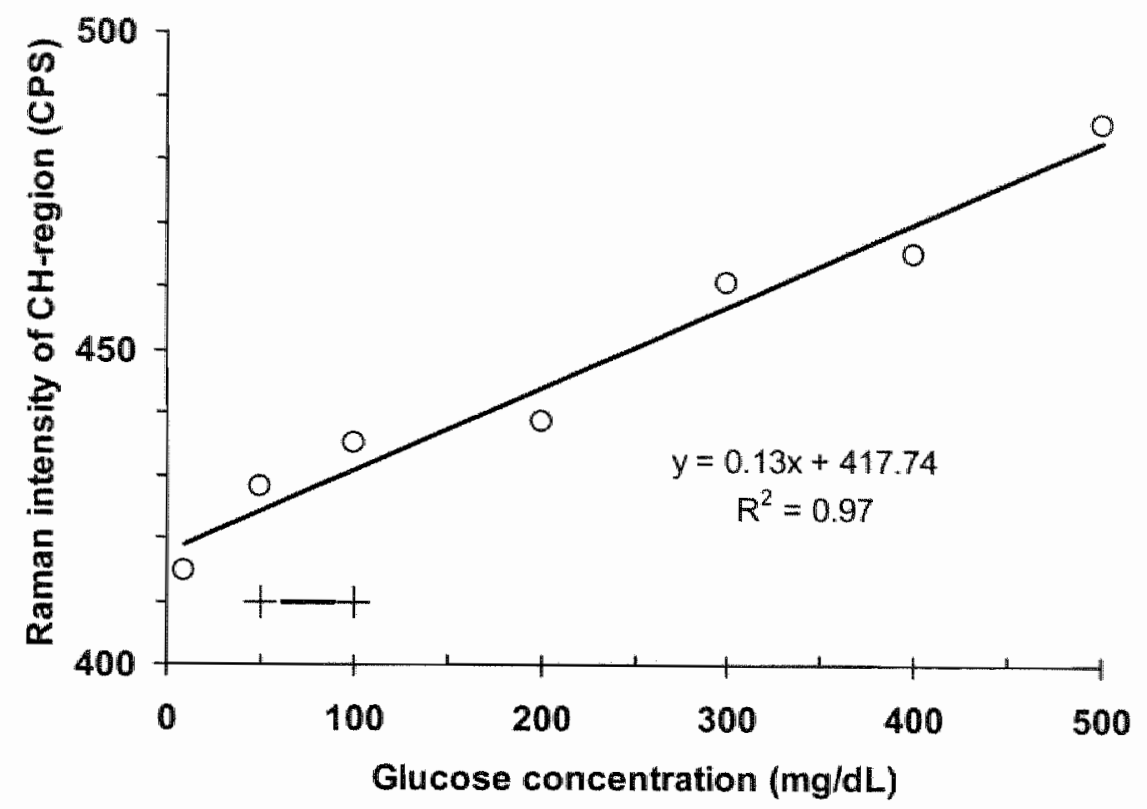

Figure 6A. Raman spectroscopic assessment of the glucose concentration in aqueous solucions (plinysiological value is $-50-100 \mathrm{mg} / \mathrm{dL}$ ).

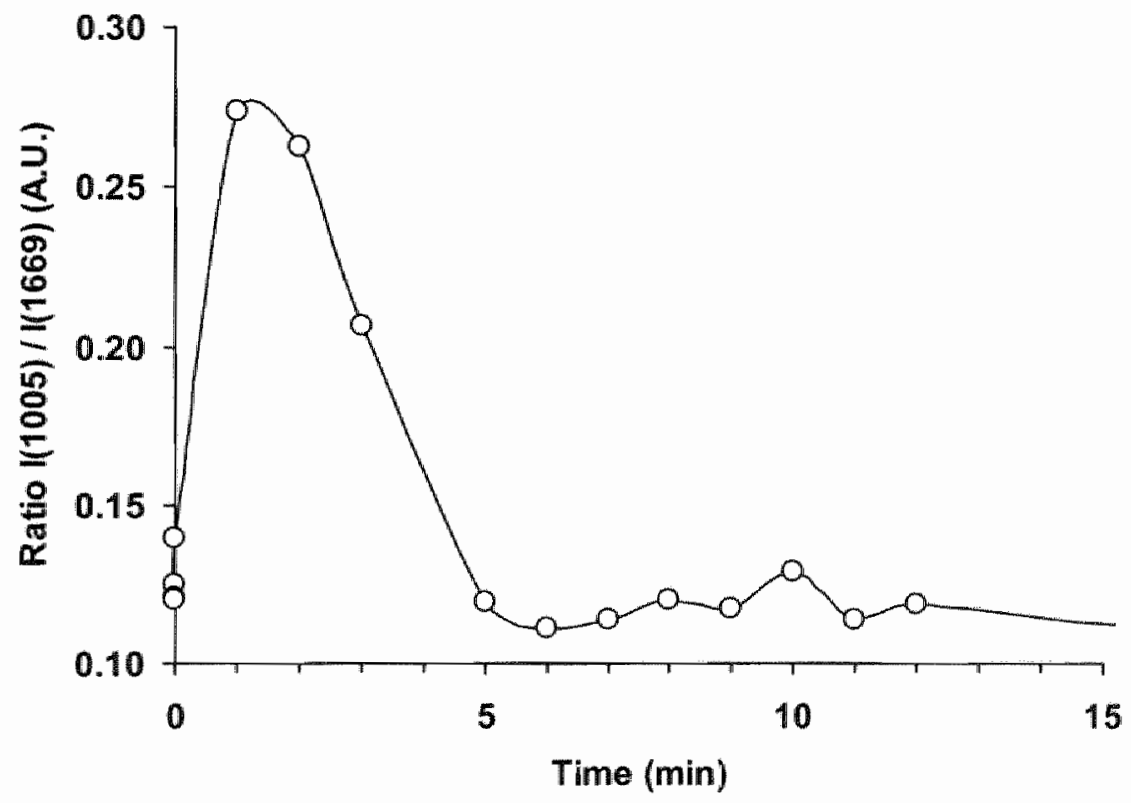

Figure 6B. Assessment of a phenylalanine Raman peak at $1005 \mathrm{~cm}^{-1}$ in the aqueous humor of the rabbit eye under in whe conditions as a function of time after an intravenous bolus injecthon of phenylalarine. 
features enabling the unambiguous assessment of the glucose concentration in the aqueous humor. One of the possible improvements could be the use of advanced spectral analysis algorithns, utilizing the partial least squares or principle components analysis routine which can be used to detect changes in a complete spectrum rather than one or two Raman spectral lines. ${ }^{i 6}$

Another biomolecule that might possibly be monitored is phenylalanine (PHE) which is elevated in untreated or insufficiently regulated phenylketonuría (PKU), an inborn error-of-metabolism. Newborns are screened for this underlying enzyme-deficiency through a bloodsample which is taken in the first few days after birth. In case PKU is diagnosed the patient has to remain on a phenylalanine-deficient diet for the rest of their lives. Much like glucosemonitoring, the level of PHE needs to be monitored on a regular basis in order to adjust the patients diet if necessary. Here RS could be of use, since it could perform these measurements in a non-contact fashion, and because phenylatanine has a very specific Raman signal at $\sim 1003 \mathrm{~cm}^{-1}$. Initial attenpts at detecting phenylalanine were performed in the aqueous humor of the eyes of an anesthetized rabbit. After an intravenous bolus-injection of phenylalanine (425 $\mathrm{mg}$ in $20 \mathrm{~mL}$ saline) Raman spectra in the lower wavenumber region (500-1800 $\mathrm{cm}^{-1}$ ) were obtained from the aqueous humor at regular time-intervals. The Raman intensity of the peak at $\sim 1003 \mathrm{~cm}^{-1}$ was determined and plotted as a function of time after injection. These results are shown in Figure 6B. As can be seen, the relative intensity of the phenyl-ring vibration increases rapidly due to the increase in phenylalanine in the aqueous humor, from the first minute after injection and returns to nomal within 5 minutes. This suggests that RS could indeed be used for monitoring changes in the concentration of phenylalanine and possibly other specific Raman active biomolecules.

Other potential applications of CRS in the aqueous humor entail pharmacokinetic studies and the detection of cells and proteins as a result of intra ocular inflammation, cumently being investigated in our laboratory.

\section{Non-tissue-specific applications}

Since Raman spectra are by definition temperature dependent, it is possible under certain circumstances to use RS for assessing the sample temperature. The most widely used method utilizes the relation between sample temperature and the Raman intensity ratio of the Stokes- vs. the anti-Stokes lines of the same Raman peak. ${ }^{7}$ In theory this method can be used for non-contact themometric assessments of samples irrespective of their nature over a wide range of temperatures. However, the extremely low Raman yield of the anti-Stokes lines in a Raman spectrum at physiological temperatures generally requires a prolonged exposure to laser light at high intensities, which is not desirable in 
tissues such as the eye because of the potential damaging effect of the visible light. Moreover the required light intensites might locally hoat whe sample interfering with the accuracy of the remperature measurenent. Another established method for assessing the temperature of a sample merely utilizes the Stokes-region of a Raman spectrum and entails the assessment of the temperam ture-dependent changes in the Raman spectral features of water. This method has been applied to non-invasively assess sub-surface ocean water temperatures and biological tissues. 18.19 The latter could be of significant interest in biology and medicine, since most living materials are embedded in water. Also in ophthalmology the application of RS for remote temperature measurements might be of clinical significance. Various therapeutic interventions in the cye, such as phaco-emulsification of the ocular lens, induced hyperthermin for increasing the therapeutic effec of ocular chemotherapy, and laser surgery of the comea, result in more or less pronounced temperature increases which ideally would need to be monitored because of the potential hazardous effect to the ocular tissues. Furthennore, with the use of a suibble remote themometric method it might be possible to quantify the temperature-reducing effect of ocular anti-inflammatory drugs and to validate temperature models of the eye. We used RS for non-contact temperature measurements of water at temperatures ranging from 13 to $48^{\circ} \mathrm{C}$ and of the aqueous humor of the rabbit eye under in wivo and in vitro conditions at temperatures ranging from 14 to $34^{\circ} \mathrm{C}$, applying the Raman integrated intensity ratio OH2/OH1 $=1(3430-3729) / 1(2878-3430)$ in the spectrum of water (Chapter 8 of this thesis). This OH2/OH1 ratio proved very suitable for non-contact themometric assessments in the aqueous humor, which is mostly comprised of water (Figure 7). However, this ratio was not directly applicable for themometric assessments in the cornea or the ocular lens because of the non-homogeneous distribution of water and proteins and consequenty the non-homogenous distribution of 'bound' and 'free" water in these tissues. Furthermore, the N-H vibrational modes of proteins at $-3300 \mathrm{~cm}^{-1}$ could have interfered thus resulting in an aberrant relationship between tisue cemperature and $\mathbb{R}$ aman intensity ratio. In conclusion we can remark, that tenperature information is included in both the Raman spectra of aqueous solutions as well as ocular tissues. The increasing concentrations of non-aqueous substances in rissues influences the linear relationship between the Raman intensiry ratio OH2/OH1 and tissue temperature. This has wo important implications: 1) when using RS for thermometric assessments care should be taken to extract the right information from the Raman spectra of tissues, and 2) the tissue temperature should remam. constant when perfoming comparison Raman spectroscopy in the same cisste, in order to avoid changes in Raman spectral features due to changing temperatures. The latter is of particular significance when probing tissues that exhibit temperature gradients, such as is obviously the case in the eye. 


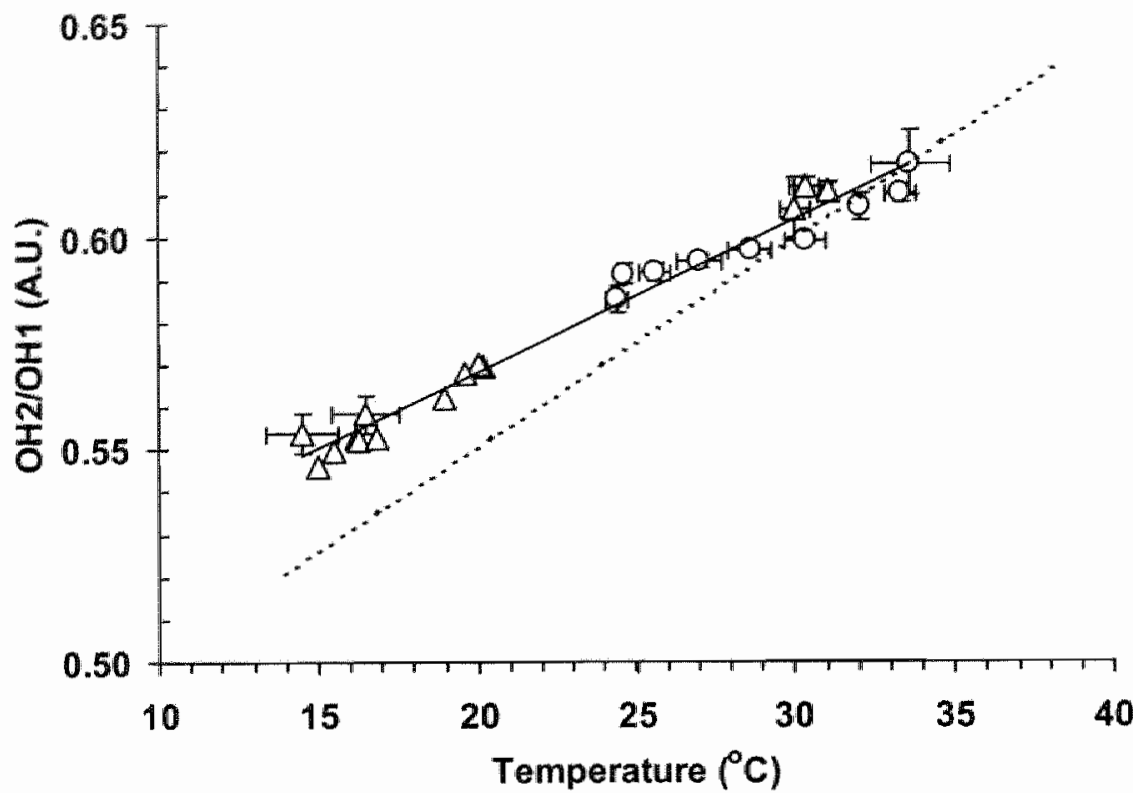

Figure 7. Relationship between Raman intensity ratio $\mathrm{OH2} / \mathrm{OH} 1(\mathrm{n}=162)$ and the water temperature of the nabbit aqueous humor in sith (solid line) and HPLC-grade water in a cuverte.

\section{Considerations for the use of CRS in the human situation}

Apart from the clinical relevancy of the proposed applications, future utilization of CRS for diagnostic purposes in ophthalmology is largely dependent on the design of anfe system. It should be obvious that when applying such a diagnostic system the benefts should significantly outweigh the risks of damage. injury or discomfort. The nain drawback of the currently used CRS system is the use of visible light sources which are potentially harmful to the retina of the eyc. In order to circumvent this problem we have various options:

1. use of wavelengths outside the visible range (ultraviolet, $180-400 \mathrm{~nm}$ or near infra-red, $700-1400 \mathrm{~mm})$,

2. increasing the detection efficiency enabling the use of low intensities of visible light, or

3. prevent the light from reaching the retina altogether.

Option 1) has the disadvantages of a possible increase in the occurrence of tissue-fluorescence and increased tissue absorption in the cornea in the case of 
using UV, while the use of NIR necessitates a significant increase in light exposure, since the Raman intensity is a function of the frequency of the scatcered light to the fourth power. Option 2) has some noom for inprovement but not to the extent of being able to decrease the light exposure by wo or three orders of magnitude, because the currenty used detection camera already has a high quantum efficiency of $80 \%$ at $700 \mathrm{~mm}$. Option 3) seems to be the safest and most feasible option for the near future. When the incident laser light is teshaped to obtain an annular shape and is focused on the comea the beam diverges behind the comea to become an ever increasing ring of light. With the righe size of annulus and a sufficienty small pupil size, all the incident light will be absorbed by the iris and not go past the pupil to hit the retina. However, movement of the subject might still pose the possibility for light of the annular beam to pass the pupil. Future application of the confocal Raman spectroscopy system in a safe fashion will prove whether this technique is suitable in the human situation.

\section{Conclusions}

This manuscript described the potential applications of confocal Raman spectroscopy in ophthamology. The advantageous characteristics of this biochemical assessment technique, such as non-contact probing yielding the possibility to assess living tissues, rapid detection, variable spatial resolution, scanning properties enabling the assessment of various ocular tissues (tearfilm, comea, aqueous, lens, vitreous, outside of the eye: pterygium), and the abilicy to assess water and physical properties such as temperature, make confocal Raman spectroscopy an attractive tool for biochemical investigations of the eye, whether under physiological or parhological situations. With adequate improvements in safety, the potential clinical uses could be explored in human subjects.

\section{References}

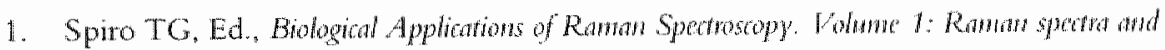
the Combonations of Biological Manomoleates. John Wiley \& Som, Chichester (1987).

2. Jongsma, F. H. M., Erckens, R. J., Wicksted, J. P., Baner, N. J. C., Hendrikse, F., Motamedi, M. and March, W. F. A confocall Raman system for scanning through ocular tissues: An in wiro study. Optical Enginecring 1997; 36(11): 3193-3199.

3. Baner NJC, Wicksted JP, Jongsma FHM, March WF, Hendrikse E, and Motamedi M. Noninwasive Assessment of the Hydration Gradient across the Cornon Using Confocal Raman Spectroscopy. Tuest Ophthatwol Vis Sici 1998; 39(4): $831-835$. 
4. Bauer NJC, Motamedi M, Whickred JP, et al Non-Invasive Assessment of Ocular Phamacokinetics using Confocal Raman Spectroscopy. I Oc Pham The 1999; $1.5(2): 123-134$.

5. Bater NJC, Hendrikse F, and March WF. In wivo Confocal Raman Spectroscopy of the Human Comea. Comea 1999, 18:483-488.

6. Erckens RI. Motanedi M, March WF, Wicksted JP. Raman spectroscopy for noninwasive characterization of ocular tissue: potential for detection of biological molecules. Joumal of Ranan Spectroscopy. 1997, 28:293-298.

7. Castoro JA, Bettelhem AA, Bettelhem FA. Water gradients across bovine comea. Intrist. Ophthithol. Vis. So 1988; 29:963-968.

8. Sugrue M.F. The Preclinical Phamacology of Dorzolamide Hydrochloride. a Topical Carbonic Anhydrase Inhibitor [review]. I. Ot. Phaw. Ther. 1996: $12(3): 363-376$

9. Huizinga A, Bot $A C C$, de Mul FFM, Vrensen CFJM, Greve J. Local wariation in absolute water content of human and rabbit eye measured by Raman microspectroscopy. Exp. Eye Res. 1989; 48:487-496.

10. Chan $T$, Payor $S$, Holden BA. Comeal thickness profles in rabbits using an ultrasonic pachonater. Inost. Ophinahol. Wis. So $1983,241408-1410$.

11. Dohery PJ, Wellish KL, and Maloney RK. Excimer Laser Ablation Rate and Corneal Hydration. Am J Ophudmol 1994; 118: 169-176.

12. Levin $S$, Carson $C A$, Gartet $S K$, and Taylor HR. Prewalence of central islands after excimer laser refactive surgery. J Catand Refar Surg 1995; 21: 21-26.

13. Seiler $T$, and McDonnell PJ Exciner Laser Photorefractive Keratectomy. Sunvey of Oph whatmol 1995; 40(2):89-118.

14. Siew DCW, Clover GM, Cooney RP, Wiggins PM. Micro-Raman spectroscopic study of organ cultured corneae. Jounal of Ranan Spectrosopy 1995; 26:3-8.

15. Wicksted JP, Erckens RJ. Motamedi M, and March WF. Raman Spectroscopy Studies of Metabolic Concentrations in Aqueous Solutions and Aqueous Humor Specimens. App Spatros 1995; 49(7): $987-993$.

16. Coetz MI, Core GL, Erckens R. March W, and Motamedi M. Application of a Multiwarate Technique to Raman Specta for Quantifation of Body Chenticals.

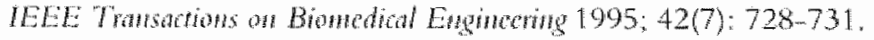

17. Malyj $M$ and Griftirhs J.E. Stokes/Anti-Stokes Raman Vibrational Temperatures: Reference Materials, Standard Lamps, and Spectrophotometric Calibrations. Appliced Speciroscopy $1983 ; 37(4): 315-333$.

18. Leonatd DA, Caputo B and Hoge FE. Remote sensing of subsurtace water remper ature by Raman scattering. Applied Optic 1979;18(11): 1732-1745.

19. Baranska $\mathrm{H}$ and Labudzinska. Applicd Spectrosopy 41: 1068 (1987). 
CHAPTER 5

Noncontact assessment of the hydration gradient across the cornea using confocal Raman spectroscopy

Noël JC Bauer, James P Wicksted, Franciscus HM Jongsma, Wayne F March, Fred Hendrikse, Massoud Motamedi

Invest. Ophthalmol. Vis. Sci. 1998; 39(4): $831-835$ 


\section{A BSTRACT}

Aim: The feasibility of Raman spectroscopy for the noncontact assessment of the axial comeal hydration is investigated.

Methads: A scanning confocal Raman spectroscopy system, with an axial resolution of $50 \mu \mathrm{m}$, was utilized to assess the water ( $\mathrm{OH}$-bond) to protein ( $\mathrm{CH}$-bond) ratio as measure for the concentration of water in collagen-based phantom media, and rabbit comeas.

Results: Over a wide range of corneal hydration $(H=0.0-8.3 \mathrm{mg}$ water/mg dry wt.) Raman spectra with high signal-to-noise ratios were abtained under both in vitro as well as in vivo conditions. The Raman intensity ratio $\mathrm{OH} / \mathrm{CH}$ showed strong correlation with the hydration of the phantom medium $\left(R^{2}>0.99\right)$ and rabbit comeas $\left(R^{2}>0.95\right)$. A high degree of reproducibility was seen in measurements performed at a specific depth within the cornea $(S D=1.2-2.7 \%)$. Quantitatively, the spatially resolved corneal water content as assessed with our method. showed an increasing gradient from the anterior to the posterior region, with a difference of $\sim 0.9 \mathrm{mg}$ water/mg dry wt. Significant qualitative differences in the axial hydration gradient were observed between the in vitro and in vivo situation, caused by the presence of an intact tearfilm in wivo. Characterization of the axiall comeal hydration using Raman spectroscopy provided a reliable estimation of total corneal hydration, as compared with conventional measurements using pachymetry and lyophilization.

Conclusion: The proposed noncontact confocal Raman spectroscopic technique has the potential to assess the axial corneal water gradient with a high degree of sensitivity and reproducibility. 


\section{Introduction}

Several techniques have been suggested in the past to investigate the comeal hydration and its non-uniform spatial distribution. These include refractive index measurements, ${ }^{1}$ optical sectioning, ${ }^{2}$ mechanical sectioning after in who freezing ${ }^{3}$, and differential scanning calorimetry. ${ }^{+}$A direct noncontact technique capable of quantifying the spatial distribution of water in the comea could potentially contribute to the diagnostics of the comea.

Raman spectroscopy (RS) is an optical technique that allows for the identification of molecular vibrations using monochromatic light from a laser. The technique has been utilized extensively to characterize the ocular lens and its transformation from normal to the cataractous state. ${ }^{5}$ More recently it thas been applied to determine the total water content in human organ cultured conneas. ${ }^{6}$ Furthermore, applications of RS for the noncontact quantitative assessment of biomolecules in aqueous humor specimens and aqueous solutions have been proposed. 7

The ratio of Raman intensities of the $\mathrm{OH}-$ bond $\left(-3100-3700 \mathrm{~cm}^{-1}\right)$ and the $\mathrm{CH}-$ bond $\left(-2850-3030 \mathrm{~cm}^{-1}\right)$, can be used to determine the absolute water content of tissue $e^{5-6}$. In the present study, we investigate the ability of this novel noncontact technique for the accurate assessment of the spatial distribution of water in phantom media with known properties and the rabbit connea, both under in vitro and in vito conditions.

\section{Materials \& Methods}

\section{Instrumentation}

Recently, we reported on the development of a scanning confocal Raman spectroscopy (SCRS) system with long-working distance for the noncontict biochenical characterization of ocular tissue. "The key components of the system are, 1) a single grating spectrometer (SPEX500M, Spex Industries, Edison, NJ), with CCD-camera for rapid signal detection, 2) an argon laser $(514.5 \mathrm{~mm})$, and 3) a long-working distance microscope objective lens $(25 \mathrm{x} / \mathrm{NA}=0.5, f=10 \mathrm{~mm}$, Jena, Karl Zeiss, Germany) that acts both as the focusing device for the incident light as well as the collecting lens for the Raman backscattered light. This lens permits noncontact probing of a considerable axial distance in the eye. An optical fiber coupled to the spectrometer collects the Raman backscattered light, and acts like a confocal pinhole. Changing the diameter of the fiber will change the probing volume, mainly by changing the integration depth $(\geq 20 \mu \mathrm{m})$. 
In order to assess the spatial distribution of water in the cornea, a high signal-to-noise ratio (SNR) and an integration depth significantly snaller than the concal thickness were required. Optmum probing parameters were found using a laser power of $25 \mathrm{~mW}$ and a 3 second integration time, in conjunction with an $11 \mu \mathrm{m}$ fiber, yielding an integration depth of $50 \mu \mathrm{m}$. Each spectrum reported here was the result of the average of three acquisitions.

\section{Hydration assessments in phantom media}

To demonstrate the ability of our method to quantify the hydration of a sample, commercially available collagen shields (BioCor II $24 \mathrm{HR}$, Bausch \& Lomb, Tampa, FL), clinically used to improve comeal wound healing, were used as a phanton medium. These shields are described by the manufacturer as clear, thin, pliable films fabricated from porcine collagen, with an average thickness of 0.013-0.071 mm. After rehydration in HPLC-grade water for 3 minutes, these shields have an average thickness of $\sim 0.200 \mathrm{~mm}$ and a hydration of $\sim 1.92 \pm 0.01 \mathrm{mg}$ water/mg dry wt. The Raman intensiry ratio $\mathrm{OH} / \mathrm{CH}$ of these shields was plotted against sample hydration ' $H$ ' (in mg water / mg dry wt), and their relationship investigated for linearity. Furthermore, to examnine the ability of RS to probe deep layers, Raman spectra were obtained at different probing depths $(100-700 \mu \mathrm{m})$ within a thick phantom medium $(1 \mathrm{~mm})$ made up of albumin ( $96 \%$ pure, Sigma, St. Louis, $\mathrm{MO}$ ) with a hydration of $\mathrm{H}=10$.

\section{In vitro and in vivo studies}

A total of 16 eyes of young NZW rabbits $(\sim 1.8 \mathrm{~kg})$ were enucleated immediately after euthanasia. The eyes were either stored in a moist chamber at $4^{\circ} \mathrm{C}$ $(n=4)$, used fresh $(n=7)$ or left exposed $(n=5)$ to the ambient enviromment $\left(23^{\circ} \mathrm{C}, 70 \%\right.$ humidity), yielding different degrees of corneal hydration. In 5 fresh eyes and 1 eye left to dehydrate in air, we used ultrasound pachymetry (Pach-Pen ${ }^{\text {tm }}$ XL, $20 \mathrm{MHz}$ transducer, Bio-Rad, Glendale, CA) as the standard to compare our methods with, and determined the central corneal thickness (CCT). Each CCT assessment was the average of 5 measurements. The hydration was calculated using CCT vs. hydration relationships as postulated by Hedbys and Mishima. ${ }^{2}$ In the other 10 eyes ( 2 fresh, 4 rehydrated, and 4 dehydrated) we used lyophilization in vata $\left(100 \mathrm{mTon},-60^{\circ} \mathrm{C}, 24 \mathrm{hr}\right.$.) as the standard. Before and after lyophilization, the comeas were probed with our technique and weighed on an analytical balance (0.1. nng readability), and comeal hydration was calculated as (wer wt. - dry wt.) / dry wt.

Under an approved animal prowocol that complied with the ARVO Resom lution on the Use of Animals in Research, the in win studies were performed on 
the 4 eyes of two fernale $\mathrm{NZW}$ rabbits $(3.6 \mathrm{~kg})$. The animals were restrained in holder, anesthetized using intramuscular ketamine bydrochloride $25 \mathrm{mg} / \mathrm{kg}$ ) and xylazine $(5 \mathrm{mg} / \mathrm{kg}$ ), while the involuntary eye novements were minimized by immobilizing the eye by a custom nade applanation device.

At the start of each scan, the laser beam was positioned in front of the central comea and was aligned such that the optical axis of the system and the comea matched. The entire comea was scanned by moving the microscope objective lens toward the eye with step-increments equal to that of the integration depth $(50 \mu \mathrm{m})$. Each scan was repeated three times to investigate reproducibility. Since each scan took 1-2 minutes to perform, changes im sample hydration nay occur leading to the observed differences among various scans. To establish the reproducibility of our measurements, each comea was probed repeatedly $(\mathrm{n}=10)$ at the same depth, in both the in sitro and in vivo situation. The standard deviation (SD) of the mean Raman intensity ratio $\mathrm{OH} / \mathrm{CH}$ for each single point assessment was utilized as a measure for the reproducibility.

\section{Spectral data analysis}

An algorithm was used (Matlab TM, Mathworks Inc) to correct for background noise observed in the Raman spectrit, using the spectral information in the high range $\left(3100-3700 \mathrm{~cm}^{-1}\right)$. Then the mean and standard deviation (SD) for the $\mathrm{OH}$ and $\mathrm{CH}$ peaks obtamed in the repeated measurements were calculated.

Complete scanning of the comea requires a series of measurements of Raman spectra. The CF-I-signal is mostly confuned to the conea and was used as a biological marker for the determination of the comeal boundaries. The actual distribution of the CH-signal as measured by our probe, which was noved from air (no $\mathrm{CH}$ ) through the comea and into the aqueous lnumor (no $\mathrm{CH}$ ), was curvefitted (cubic spline interpolation). The comeal boundaries were arbitrarily chosen as the probing depths corresponding to the $10^{\text {th }}$ and $90^{\text {th }}$ percentile of the area under the curve (AUC). These boundaries were also used to cvaluate the spatially resolved comeal hydration as well as total comal hydration.

Since rabbit cormeal thickness has been shown to be unifom, "and corncal hydration is a linear function of conneal thickness," we tested if it was feasible to determine total comeal hydration from the axial scans after assessment of the comeal boundaries. The Raman intensities of $\mathrm{OH}$ and $\mathrm{CH}$ were integrated berween these boundaries, and cotal comeal hydration as assessed with our method $\left(\mathrm{H}_{\mathbb{R}}\right)$ was then given by the ratio between these integrated internsicics; AUC $(\mathrm{OH} / \mathrm{AUC}(\mathrm{CH})$. The results were plotted vs total corneal hydration H as assessed both by lyophilization and ultrasound pachymetry, and analyzed for linearity in order to validate this method. 
The axial distribution of water within the comea, can be determined by plotting the Raman intensity ratio $\mathrm{OH} / \mathrm{CH}$ vs. the depth of probing. The spatially-resolved comeal hydration was evaluated qualitatively and quantitatively, under in witro and in vivo conditions, as well as during dehydration in air over time.

\section{Results}

No significant change in Raman intensity ratio $\mathrm{OH} / \mathrm{CH}$ ratio was observed at different depths $(100-700 \mu \mathrm{m})$ within an albumin sample with uniform water distribution $(\mathrm{OH} / \mathrm{CH}=5.25 \pm 0.03, \mathrm{n}=11)$. This implies that the Raman intensity ratio $\mathrm{OH} / \mathrm{CH}$ is independent of the probing depth, which justifies attributing differences in this ratio at different depths within an inhomogeneous medium like the comea to differences in hydration.

Figure 1 shows typical spectra of the normal rabbit cornea, and also illustrates the ability of our methods to assess the relative changes in $\mathrm{OH}$-intensity over a broad range of corneal hydration ( $\mathrm{H}=0-8.3 \mathrm{mg}$ water $/ \mathrm{mg}$ dry wt.) without significant loss of signal-to-noise ratio ( $\mathrm{SNR}=20-30$ ). It can also be seen that the Raman spectral response of a cornea in a freshly enucleated eye (graph B) exhibits the same characteristics as a normal cornea in the in wivo situa-

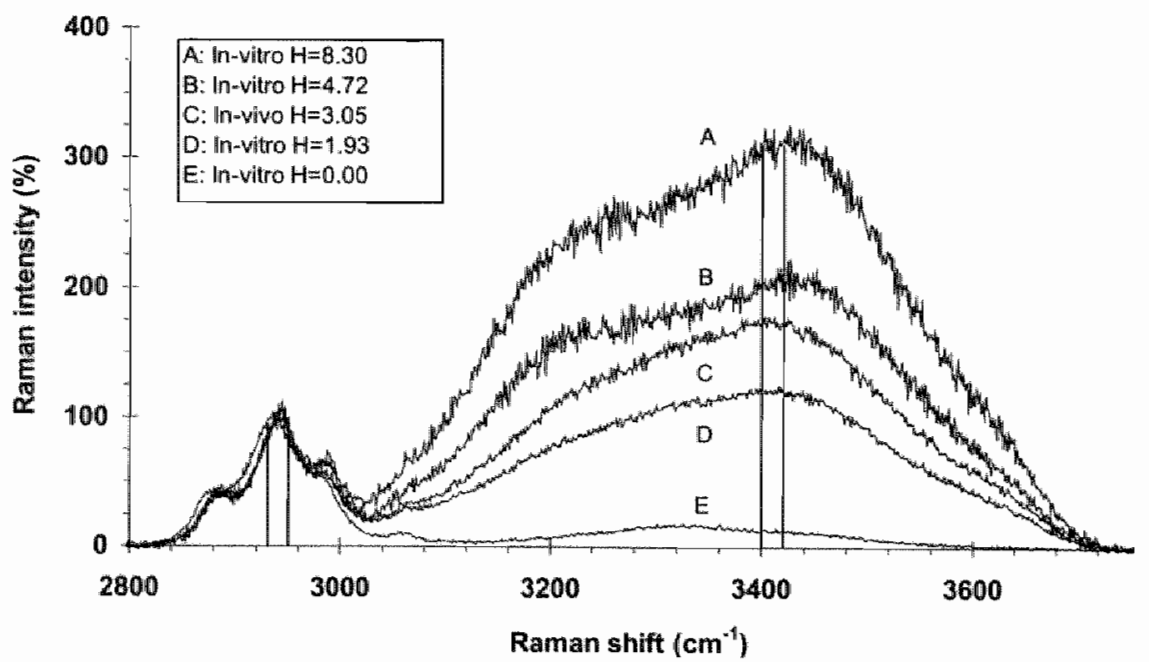

Figure 1. Lintwo and in witro assessment of Raman spectra from the anterior region of comeas at various degrees of hydration. The regions of the spectra that are used to obtan the absolnte $\mathrm{OH}$ - and $\mathrm{CH}$-sigmal intensity are outhed. 


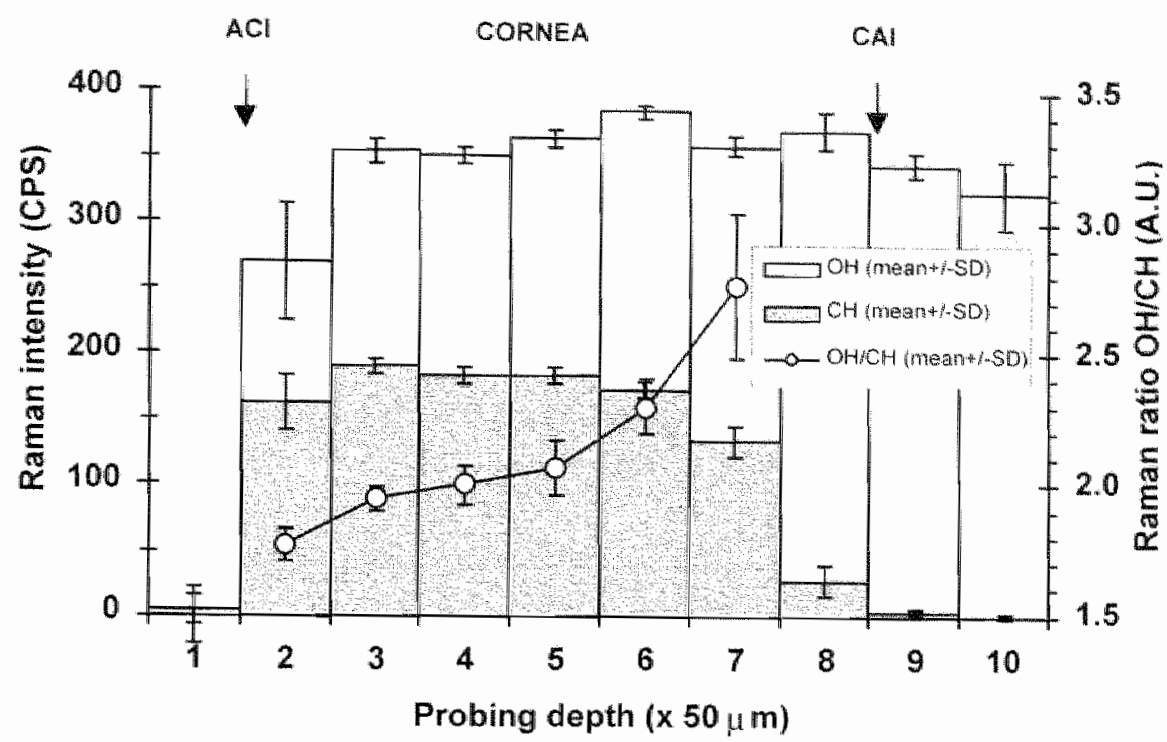

Figure 2. The axial distribution of the Raman intensities of $\mathrm{OH}$ and $\mathrm{CH}$ (bar grapha; lete ordinate and the Raman intensity atio $\mathrm{OH} / \mathrm{CH}$ (line graph; right ordinate) as function of the probing depth in a cornea of a freshly enucleated rabbit eye $(\mathrm{H}=3.80 \pm 0.20)$. The tear-film/comea interface (ACD) and the cornea/aqueous humor interface (CAD) can be identified by the changes in the extent of the CH-response (arrows).

tion (graph C). Since we observed a 40-50\% change in absolute $\mathbb{R}$ aman signal per $1.0 \mathrm{mg}$ water / $\mathrm{mg}$ dry wt. change in hydration, and because a change of $5 \%$ in the absolute signal is easily resolved at a SNR of 30 , we determined that the sensitivity of our methods both in vitro and in wo was $-0.1 \mathrm{nng} \mathrm{H} \mathrm{H}_{2} \mathrm{O} / \mathrm{mg}$ dry wt.

A strong correlation is found for the linear relationship $\mid a=b$ (mean $\pm S D$ ) $x$ $+\mathrm{c}(\mathrm{mean} \pm \mathrm{SD})]$ between corneal hydration as assessed with our method $\left(\mathrm{H}_{\mathbb{R}}\right)$ and the two conventional methods, i.e. Jyophilization $\left(\mathrm{H}_{\mathrm{L}}\right)$ and ultrasound pachymetry $\left(\mathrm{H}_{\mathrm{p}}\right)$. For the phantom medium simulating comeal structure (BioCor collagen shields) this relationship is described by: $\mathrm{H}_{\mathrm{R}}=0.45$ $( \pm 0.08) \mathrm{H}_{1}+0.23( \pm 0.01)$ where $\mathrm{R}^{2}=0.900(\mathrm{n}=17)$. For the rabbit comeas this relationship is given by either $H_{R}=0.49( \pm 0.03) H_{p}+0.47( \pm 0.44)$ where $\mathrm{R}^{2}=0.976(\mathrm{n}=14)$ or $\mathrm{H}_{\mathrm{R}}=0.46( \pm 0.04) \mathrm{H}_{\mathrm{L}}+0.14( \pm 0.01)$ where $\mathrm{R}^{2}=0.951$ $(n=24)$, depending on which conventional method was used. We calibrated the Raman intensity ratio $\mathrm{OH} / \mathrm{CH}$ using latter resu'ts. Thus we were able to quantify the axial distribution of corneal hydration. Furthermore, a correlation was observed for the relationship between the comeal thickness as assessed with our 


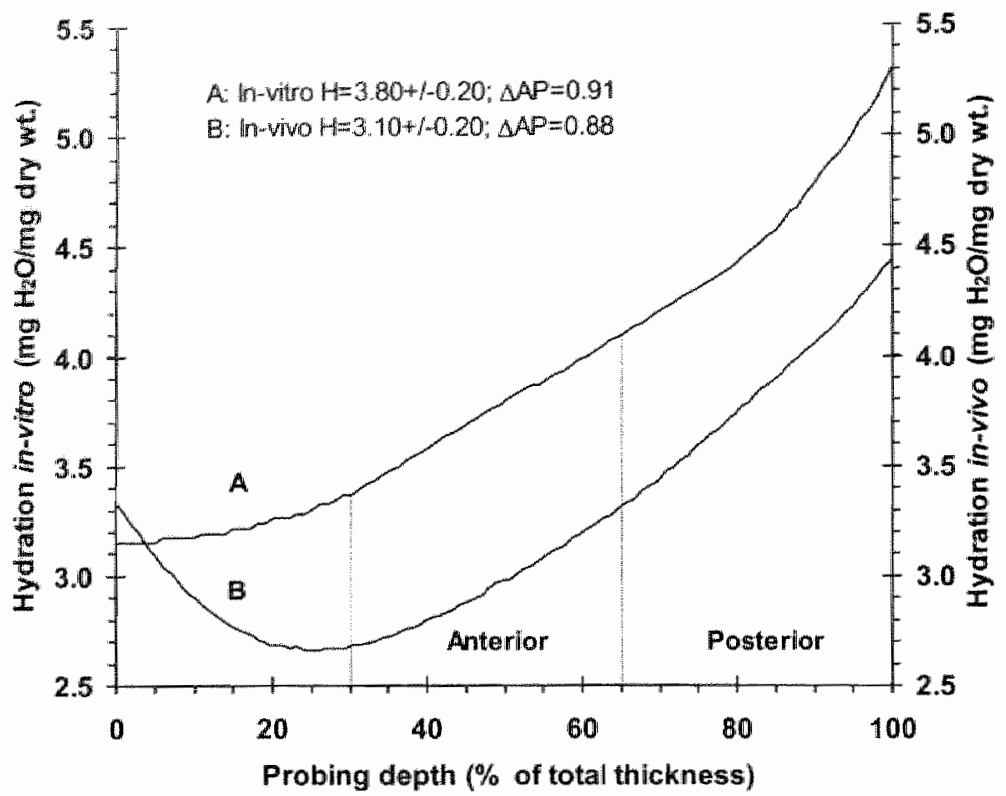

Figure 3. Comparison of in witro (graph A) and in wive (Graph B) axial distribution of rabbit comeal hydration as assessed with Raman spectroscopy ws. nomalized probing depth.

nethod $\left(C C T_{R}\right)$ and pachymetry $\left(C C T_{P}\right) ; C C T_{R}=0.81( \pm 0.02) C_{\mathbb{P}}$ where $\mathrm{R}^{2}=0.760(\mathrm{n}=14)$. The $\mathrm{SD}$ of 10 single point assesments of the Raman intensity ratio $\mathrm{OH} / \mathrm{CH}$ as a measure for the reproducibility was $1.2 \% \mathrm{in}$ vitro and $2.7 \%$ in vivo.

An wample of how intensities of Raman peaks can be used to assess the distribution of concal hydration is shown in Figure 2. Here the Raman intensities of OH and CH are ploted against probing depth for a fresh in vitro comea. The spatial distribution of the $\mathrm{OH} / \mathrm{CH}$ ratio illustrates the increase in hydration when probing from the anterior to the posterior region of the cornea. It can be seen that the assessment of the spectral response per probing depth is highly reproducibie, since the SD of the mear value for the Raman peaks ( $n=3$ ) for ach probing depth is rather small, even when probing deeper into the comea (steps 7 and 8). As demonstrated in this figure it is possible to outline the extent of the coma, by identifying the abrupt increase in both $\mathrm{CH}$-and $\mathrm{OH}$-signal at the anterior border (step 2) and the abrupt decrease of the CH-signal (step 8) at the posterior border.

Using our noncontact approach the axial distribution of water in the rabbit comea under in who and in whro conditions is exhibited in Figure 3. For the in 


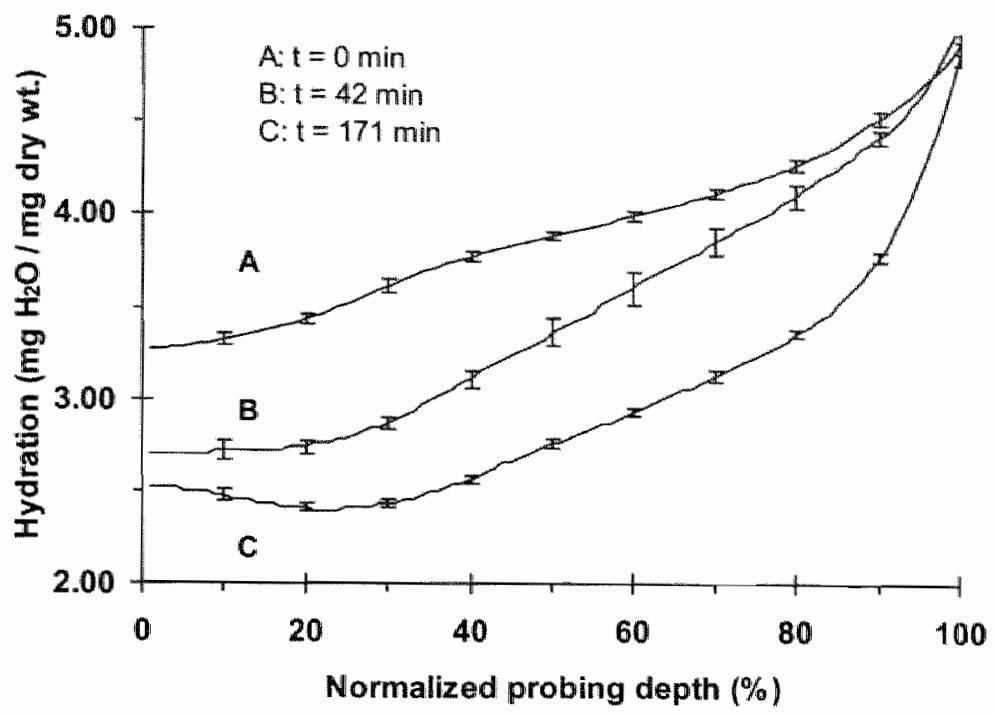

Figure 4A. Typical changes observed in the axial distribution of water in in intact rabbit cornea let exposed to the ambient environment $(23 \mathrm{C}, 70 \%$ rellative. humidity).

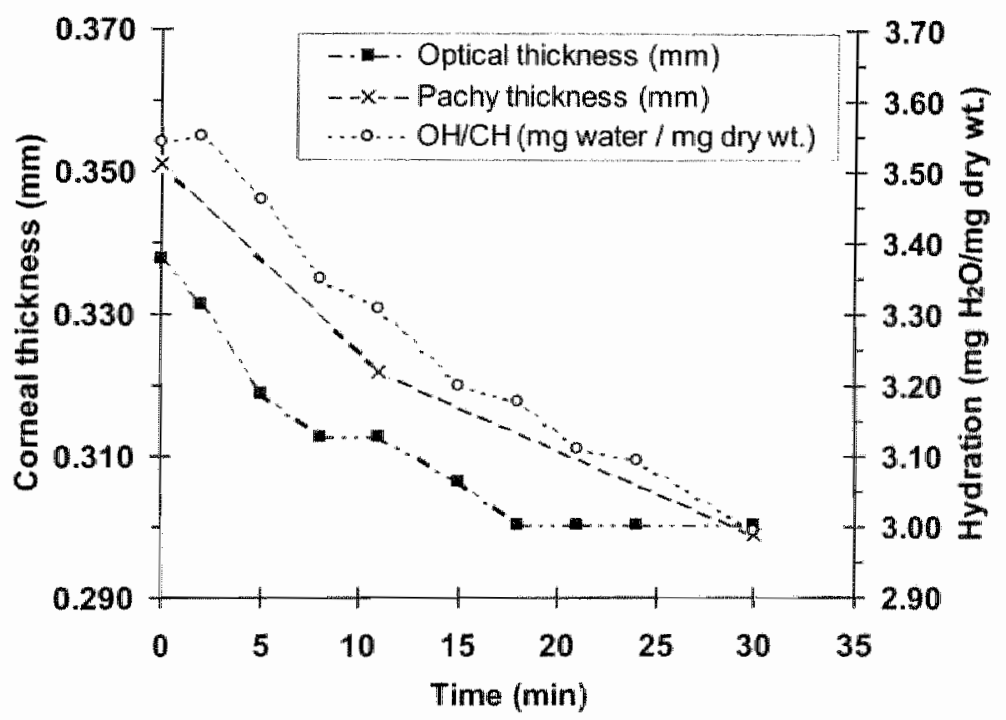

Figure 4B. Central aomeal thicknese (CCT) and the state of comeal hydration as measured by ulmasound pachymetry and by our optical method as function of delyydration time. 
wh measurements a "dip" in the anterior region of the comea was observed. Using a mechnical sectioning technique, Turss et al. found a difference of 0.81 in the hydration of the anterior region of the rabit comea as compared to the posterior region ${ }^{3}$ Our technique yielded values of 0.88 and 0.91 for $\mathrm{m}$ who and in witro comeas respectively ( $\mathrm{Fig}$. 3). Although these recults agree favorably with the literature, the vilues are obviously highly dependent on the stromal regions compared. Smaller regions at the periphery of both the anterior (A) and posterior (P) stroma for instance would yield a greater AP-difference in hydration in the conneas of Figure 3.

Figure $4 \mathrm{~A}$ shows the rypical changes that occur in the axial hydration gradient of the rabbit comea as function of time that the comea is exposed to the ambient environment. Significant changes in hydration appear in the anterior part of the stroma within the first 42 minutes, and throughout the posterior part of the cornea thereafer. The SD per probing volume at $t=0$ and $t=171$ are rather small, indicating that the changes in hydration during assessment of the axial scans are small. These results illustrate the feasibility of assessing the spatially resolved hydration of a comea over time, and thus the ability to identify the location within the comea responsible for a decrease in hydration. Fugure 4B shows the changes in CCT and $\mathrm{H}$ assessed by both pachymetry and our optical method as a function of tine in a rabit cornea exposed to air. It can be seen that all three parameters decrease over time in a similar mamer. Both total comeal hydration and CCT as assessed with our methods can again be shown to be linearly related to pachymetric measurements.

\section{Discussion}

In this investigation, we have shown the applicabulity of scanning confocal Raman spectroscopy to assess the axial hydration gradient of the comea both under in who as well as in mo conditions. The proposed optical sectioning technique offers some key advantages, including the ability to obtain direct informat tion about comeal hydration and its distribution, with a high axial resolution in a noncontact manner. The inherent specificity of Raman spectra, together with adequate sensitivity (SNR) over a wide range of corneal hydration ( $H=0.0$ to $\mathrm{H}=8.3$ ), may prowide a promising technique for qualitative and quantitative analysis of the axial distriburion of water in the conea.

The sensitivity of our approach was found to be $-0.1 \mathrm{mg} \mathrm{H} \mathrm{H}_{2} \mathrm{O} / \mathrm{mg} \mathrm{dry}$ wt. $(=-3 \%$ in a nomo-hydrated comea) (Fig. 1). Clinically, a comeal swelling of $5-10 \%$ subjectively increases the haze around lights noticeably, but only when comeal hydration increases by $100 \%$ to $\mathrm{H}=7$, will a dramatic decrease in visual acuity occur." Thus, the observed sensitivity of our methods is believed to be 
sufficient, not only to detect the cime- and spatially-resolved changes in hydration within a comea, but also to detect even the smallest clinically significant aberration in comeal hydration.

Total comeal hydration as assessed with both pachymetry and lyophilizarion showed a high correlation $\left(\mathrm{R}^{2}>0.95, \mathrm{p}<0.05\right)$ with the values for hydration as measured by the Raman technique, and both methods gave similar slopes for the regression curves, indicating consistency between the two conventional techniques used in this study.

The axial scan measurements demonstrated the spatial distribution of the Raman siguals for $\mathrm{OH}$ and $\mathrm{CH}$ as function of probing various layers of the comea (Fig. 2). In air Raman peaks corresponding to the $\mathrm{OH}$ and $\mathrm{CH}$ bonds are negligible and are contributed to noise. Since in a normal eye the aqueous humor is regarded as a homogenous medium manly consisting of water and a very low protein content, the Raman peaks corresponding to the $\mathrm{OH}$ and $\mathrm{CH}$ bonds when probing past the comea were expected to exhibit high and low amplitudes, respectively. Indeed, a high Raman peak corresponding to the $\mathrm{OH}$ bond and a Raman peak slightly higher than the noise level for the $\mathrm{CH}$ bond were observed in the aqueous humor. However, both the $\mathrm{OH}$ and $\mathrm{CH}$ Raman signals dropped gradually when probing deeper into the eye. This can be explained by changes in coupling efficiency of our optics and losses due to scattering. These changes also occurred in a homogeneous phanton sample made up of albumin $(\mathrm{H}=10)$ but did not change its Raman intensity ratio $\mathrm{OH} / \mathrm{CH}$. From $100-700 \mu m$ into the sample, the $\mathrm{OH} / \mathrm{CH}$ ratio was $5.25 \pm 0.03$, and no significant correlation was found between probing depth and $\mathrm{OH} / \mathrm{CH}$ ratio $\left\langle\mathbf{R}^{2}=0.05, \mathrm{p}<0.05, \mathrm{n}=11\right)$.

Qualitatively, the axial corneal hydration gradient can be assessed with our methods with a high degree of reproducibility. Although the actual hydration gradient has not been measured and compared by any other means, like mechanical sectioning, ${ }^{3}$ the trend and extent of the anterior-posterior corneal hydration gradient as found in the in trive conneas, was in close agrecment with our current knowledge regarding the non-isotropic properties of comeal hydration. ${ }^{3}$ A small difference in the hydration of the anterior part of the cornea is found between the in vito and the in vino comeas. The level of hydration control and the extent of the pre-corneal tear film are believed to be the cause of the observed 'dip' in hydration of the anterior part of the in two comea (Fig. 3B). The tear-filn/epithelium layer is more hydrated than the most anterior region of the stroma. It is likely that the depth resolution of $50 \mu$ m permitted identification of the tear-fim $(\sim 40 \mu \mathrm{m})$ plus epithelial layer $(-50 \mathrm{~mm})$. If desired, the axial resolution of our system can be further increased by utilizing a smaller integration depth (i.e. using a smaller fiber) and probing with smaller step-increments. 
Small changes can be observed in the axial hydration gradient within the same sample as a result of changing total comeal hydration (Fig. 4.A). This was shown in vilo, by following the axial hydration gradient across the same comea over time during dehydration in air. Furthermore, total corneal hydration and corneal thickness as measured by our optical method ws. ultrasound pachymetry in a dehydrating comea over time, showed congruent curves. This suggests that all three parameters can determine for total corneal hydration, with the sensitivity and spatial resolution of the proposed method as an advantage over the standard techniques.

Since the eye of a rabbit under anesthesia still experiences movement, the rabbit eyes were immobilized in this study, in order to demonstrate the feasibility of our techniques to assess the axial hydration gradient of the comea in the in wivo situation. The results of both the in vitro and immobilized in vivo corneas are highly comparable with regards to the reproducibility of both the single-point assessments as well as the assessments of comeal hydration as function of probing depth. However, future improvements have to be made by integrating an eye-tracking device into the current setup, in order to assess the hydration gradient of the cornea in who without any interventions.

A drawback which has to be overcome concerns the safety of this system, since it utilizes a potentially high dose of green light. We explicitly stress, that for future clinical application using scaming confocal Raman spectroscopy as a diagnostic tool, a system configuration will have to be chosen in such a fashion that both retinal and corneal laser safety thresholds are considered. Currently, the proposed method has the potential to be utilized as a highly specific and sensitive biochemical too! for the noncontact diagnostics of the spatially resolved hydration of the comea, in a variety of experimental settings. For example, the hydration of the anterior part of the cornea seems to play an important role in the successful ouccome of photorefractive keratectomy (PRK). During PRK, the hydration of the comea is altered by the application of a topical anesthetic, the epithelial debridement, and the laser treament itself. Knowledge of the hydration status of the comea prior and during PRK could possibly lead to a better understanding of the laser-tissue interaction.

In summary, the proposed biochemical optical sectioning technique using Raman spectroscopy has proven applicable in the in wivo animal setting, and could be of value in various experimental studies involving conea hydration. With adequate improvements in the system, a safe technique could be developed that would allow for the non-invasive diagnostics of human corneas in mino. 
Chapter 5 Comeal hydration in viwo

\section{Acknowledgments}

We thank Mr. Brent Bell and Mr. Marcel Goetz for their techmeal assistance, and Drs. Judy Brown and Miriam Brysk for their help with lyophilizing the corneas.

\section{References}

1. Maurice DM. The structure and transparency of the comea. J. Physiof. 1957; 136:263-286

2. Wilson G, O'Leary DJ, Vaughan W. Differential swelling in compartments of the conneal stroma. Imest. Ophthalmol. Vis. So. 1984; 25:1105-1108.

3. Turss R, Friend I, Reim M, Dohlman CH. Glucose concentration and hydration of the comeal stroma. Ophralmic Res. 1971; 2:253-260.

4. Castoro JA, Bettheim AA, Bettelhem FA. Water gradients across bovine comea. Inurest. Ophrhalmol. Vis. Sa. 1988; 29963-968.

5. Huizinga A, Bor ACC, de Mul FFM, Vrensen GFJM, Greve J Local variation in absolute water content of human and rabbit eye lenses measured by Raman microspectroscopy. Exp. Eyc Res. 1989; 48:487-496.

6. Siew DCW, Clover GM. Cooney RP, Wiggins PM. Micro-Raman specroscopic study of organ cultured comeac. Jonffal of Rawan Spectroscopy 1995; 26:3-8.

7. Erckens RJ, Motamedi M, March WF, Wicksted JP. Raman spectroscopy for noninvasive characterization of octlar tissue: potential for detection of biological molecules. Joun of Ramon Spectroscopy. 1997; 28:293-298.

8. Jongsma, F. H. M., Erckens, R. J., Wicksted, J. P., Bauer, N. J. C., Hendrikse, F., Motamedi, M and March, W. F. (1997). Confocal Raman system for noncontact scanning of ocular tissues: an in wifw study. Opfical Enginerimg 1997; $36(11)$ : 3193-3199.

9. Hedbys BO, Mishima S. The thickness-hydration rehtionship of the comea. Exp. Eyc Res. 1966; 5:221-228

10. Chan T, Payor S, Holden BA. Coneal thickness profles in rabbits using an ultasonic pachometer. Invest. Ophthant. Vis. So. 1983; 24:1408-1410.

11. Maurice DM. The Comea and selera. In: Davson H. ed. The Eve, $3^{1: 3}$ edicion . Orlando: Academic Press Inc. : 1984, Vol 16: 50 
CHAPTER 6

In vivo confocal Raman spectroscopy of the human cornea

Noël JC Bauer, Fred Hendrikse, Wayne F March

Comea 1999; $18: 483-488$ 


\section{A BSTRACT}

Am: To investigate the feasibility of a confocal Raman spectroscopic technique for the moncontact assessment of cormeal hydration in vivo in two legally blind subjects.

Methods: A laser beam (632.8 nm; $15 \mathrm{~mJ})$ was maintained on the cornea using a microscope objective lens (25x magnification, $\mathbb{N A}=0.5$, $f=10 \mathrm{~mm}$ ) both for focusing the incident light as well as collecting the Raman backscattered light, in a $180^{\circ}$ backscatter configuration. An optical fiber, acting as the confocal pinhole for elimination of light from out-of-focus places, was coupled to a spectrometer that dispersed the collected light onto a sensitive array-detector for rapid spectral data acquisition over a range from $2890-3590 \mathrm{~cm}^{-1}$. Raman spectra were recorded from the anterior $100-150 \mu \mathrm{m}$ of the cornea over a period of time before and after topical application of a mild dehydrating solution. The ratio between the amplitudes of the signals at $3400 \mathrm{~cm}^{-1}$ (OH-vibrational mode of water) and $2940 \mathrm{~cm}^{-1}(\mathrm{CH}$-vibrational mode of proteins) was used as a measure for corneal hydration.

Results: High signal-to-noise ratio (SNR 25) Raman spectra were obtained from the human corneas using $15 \mathrm{~mJ}$ of laser light energy. Qualitative changes in the hydration of the anterior most part of the corneas could be observed as a result of the dehydrating agent. Conclusion: With adequate improvements in system safety, confocal Raman spectroscopy could potentially be applied clinically as a noncontact tool for the assessment of corneal hydration in vivo. 


\section{Introduction}

Raman Spectroscopy (RS) is a powerful optical technique for the biochem-ical characterization of tissues and other biological media. "First introduced by Yu et al. in 1974, applications of RS in ophthalmology have mainly been limited to the elucidation of biochemical and conformational changes of the lems proteins. ${ }^{2}$ A small number of investigations have focused on Raman spectroscopic characterization of the comea,,$^{3-7}$ the aqueous humor, 8.9 the vitreous, ${ }^{11}$ and the retinal pigment. "Most of these studies were performed in vinn because the inherently weak Raman scattering usually demands the use of high level light energies and long exposure times, thus limiting safe and practical in wion applications of RS in the eye. ${ }^{12}$

We recently developed a high gain confocal Raman spectroscopy (CRS) system optimized for ophthalmic use in wino ${ }^{13}$ and shown its potential for the detection of biomolecules in ocular tissues," and for pharmacokinetic assessments of topical ocular drugs. ${ }^{14}$ Furthemore, we have shown that non-contact CRS can be applied in viwo for the rapid and sensitive assessment of the extent and distribution in hydration of the same comea over time. "This could potentially be of dinical relevance for the early diagnosis of disturbances in comeal deturgescence as a result of corneal dystrophies, ${ }^{15}$ the wearing of contact lenses, ${ }^{16}$ diabetes mellitus, ${ }^{17}$ topically applied ocular drugs, ${ }^{14,18}$ the laser-comea interaction during photorefractive surgery, ${ }^{19,20}$ and corneal procurement prior to transplantation. ${ }^{4}$

In this study we sought to determine the feasibility of CRS to obtain high-signal-to noise ratio Raman spectra of the human cornea in wivo at low level light energies and specifically directed our investigations to the Raman spectroscopic assessment of comeal hydration and changes herein as the result of topical application of a mild dehydrating agent.

\section{Methods \& Materials}

\section{Subjects}

Under an Institutional Review Board approved protocol two physically and mentally healthy subjects, A (65 yr.) and B $(69 \mathrm{yr}$ ), were enrolled from our ophthalmology outpatients clinic. The subjects were known to be legally blind in one eye due to dense nuclear cataract while having a vision in the contralateral eye $>1 / 60$ in order to see the fixation light. The subjects were not known for any comeal abnormalities or surgeries and did not wear contact lenses. Both subjects gave signed consent and were followed-up for four wecks 
while being encouraged to report any ocular abnomalities as a result of the procedure.

\section{Confocal Raman Spectroscopy (CRS)}

When monochromatic light interacts with matter almost all of it is scattered elastically, meaning without energy transfer between light and matter. The Raman phenomenon occurs when light is scattered inelastically due to the exchange of energy between photons and molecules, on the molecular vibrational level. The change in photon anergy (=frequency) is equal to the change in molecular vibrational energy, which is inherently specific for the molecular bond involved. Ranun spectroscopy spatially resolves the frequency changes of the scattered light, yielding a spectrum depicting the Raman intensity (= anount of photons) vs. the Raman shift (= photon frequency change; in $\mathrm{cm}^{-1}$ ) over a certain frequency range. Using this optical technique each Raman band in a spectum can be assigned to a known molecular vibrational mode, and spectral. analysis provides qualitative and quantitative information on molecular content and confomation." Raman spectroscopy has various advantageous properties, including the inherent specificity, the non-contact character, the ability to rapidly acquire information on the biochemical content and structure of whole biomolecules with a single spectrum, the applicability in gas, solid, or liquid samples, and the ability to assess aqueous solutions. Disadvantages usually include the need for high level light doses, since the Raman scatter yield is inherently low, while the potential occurrence of fuorescence could mask the useful Raman signal.

The development and perfomance of the high-gain confocal Raman spectroscopy (CRS) system has been described in detail elsewhere. ${ }^{13}$ We essentially used the same system for this study, with the exception of the laser light source and is displayed in schematic in Figure 1. In essence, the tight focus of a low power Helim-Ncon laser (NEC Co. Minato-Ku, Tokyo,Japan,632.8nm; 15 nW) was optically aligned with and maintamed at the anterior $100-150 \mu \mathrm{m}$ of the comea for a short period of time, using a long working distance microscope objective (HDMO) lens (magnification 25x, NAO.5, focal length = $10 \mathrm{~mm}$ ) both for focusing the incident light as well as collecting the Raman backscatcred light, in a 1 s.o backscatter configuration analog to an epi-illuminated microscope. An optical fiber, acting like a confocal pinthole for elimination of light from out-of-tocus places, was coupled to a spectrometer that dispersed the Raman shifted light onto a highly sensitve CCD-camena for rapid spectral acquisitions. A compurer digitally stored the data from the CCD and displayed the Raman specrum on a monitor. With the spectrometer centered at 3250 $\mathrm{cm}^{-1}$ a Raman spectum is obtained with a range of $2890-3580 \mathrm{~cm}^{-1}$. This 


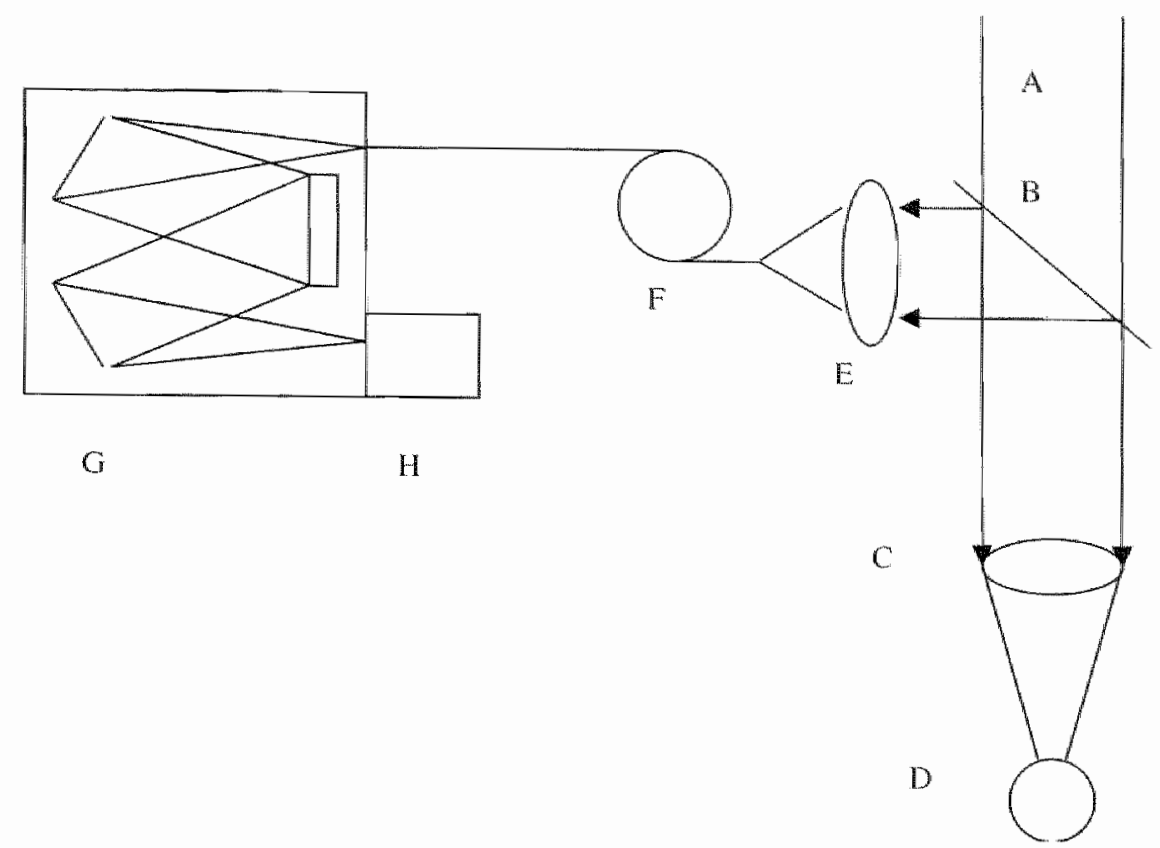

Figure 1. Schematic of the confocal Raman spectroscopy system. $A=$ collimated laser beam $(632.8 \mathrm{~nm} ; 15 \mathrm{~mW}) ; \mathrm{B}=$ beamsplitter; $\mathrm{C}=$ long working-distance microscope objective lens; $\mathrm{D}=$ sample $(\mathrm{i} . \mathrm{e}$. the eye) $\mathrm{E}=$ exit lens; $\mathrm{F}=$ optical fiber; $\mathrm{G}=$ spectroneter; $\mathrm{H}=$ CCD-camera.

entails our region of interest, since the Raman signals corresponding to the aliphatic $\left(-2940 \mathrm{~cm}^{-1}\right)$ and aromatic $\left(-3065 \mathrm{~cm}^{-1}\right) \mathrm{C}-\mathrm{H}$ vibrational modes of proteins and the $\mathrm{OH}$-vibrational modes $\left(-3240-3540 \mathrm{~cm}^{-1}\right)$ of water can be assessed simultaneously in a single spectrum. The Raman intensity ratio $\mathrm{OH} / \mathrm{CH}=\mathrm{I}(3400) / /(2940)$ is directly related to corneal hydration in $\mathrm{mg}$ $\mathrm{H}_{2} \mathrm{O} / \mathrm{mg}$ dry we ${ }^{4,6}$, and was used to assess changes in the relative water content of the anterior region of the comea as a result of the topical application of a dehydrating drug. All individual spectra were obtained using a laser power of 15 $\mathrm{mW}$ as measured in front of the LDMO lens at exposure times from 1 to 5 seconds per spectrum.

\section{In vivo assessment of human corneal hydration}

Five minutes before the procedure, the subjects received one drop of Alcaine (proparacaine hydrochloride $1 \%$, sterile ophthalmic solution. Alcon Inc., CA) in case of accidental touching of the cornea and a mioticum (Timpilo, 
ophthalmic solurion, Merck \& $\mathrm{Co}, \mathrm{CA})$ to limit the effects of fluorescence backscatter from the cataractous lens. The subjects were positioned in a modjfied adjustable headrest from a slitlamp and the head was restrained to reduce movement artifacts. Optical fixation was performed by instructing the patient to look towards a fixation light. After the focus of the attenuated laser beam was positioned at the surface of the comea, the attenuation filter was removed and probing started. The subjects were instructed to keep their eyes open during acquisition of the spectral data, but were allowed to blink in-between acquisitions. Three sets of Raman spectra of the anterior 100-150 $\mu \mathrm{m}$ of the comea were recorded at five minute intervals; six baseline spectra of the normal comea, and six spectra of the same corneal region after the first and a second topical application of a single drop of Muro 28 ( $\mathrm{NaCl} 5 \%$, Ophthalmic Solution, Bausch \&Lomb, Tampa, FL), clinically used to reduce coneal hydration prior to surgery. The six spectra in each set were obtained at exposure times of 1,2, and $5 \mathrm{~s} .(\mathrm{n}=2$ per exposure time).

\section{Data analysis}

All data were analyzed as previously described. ${ }^{6}$ In short, after background correction of each spectrum the amplitudes of the $\mathrm{OH}$ - and $\mathrm{CH}$-vibrational modes were assessed using the Raman bands at $\sim 3400 \mathrm{~cm}^{-1}(\mathrm{OH})$ and 2940 $\mathrm{cm}^{-1}(\mathrm{CH})$, respectively. As previously reported the Raman intensity ratio $\mathrm{OH} / \mathrm{CH}$ is linearly correlated with comeal hydration, as validated with either lyophilization or pachynetry in both rabbit as well as human comeas. 4.6 However, our previously assessed calibration data were not valid here because of significant differences in the optical setup and the spectral response, since in this study a Helium-Neon laser $(632.8 \mathrm{~nm}$ ) was used in stead of an Argon laser $(514.5 \mathrm{~mm})$. Furthermore, no calibration was performed in the present study since only the superficial part and not the total thickness of the connea was assessed with our optical method unlike when using pachymetry. However, relative changes in the Raman intensity ratio $\mathrm{OH} / \mathrm{CH}$ could be assessed as a measure for the change in comeal hydration of the superficial layer of the cornea, by comparing all spectra to the ones prior to application of Murol28. Statistical analysis was performed using the Student's t-test $(p<0.05)$ for comparison of the mean Raman intensity ratio $\mathrm{OH} / \mathrm{CH}$ before and atter application of the dehydrating agent. 


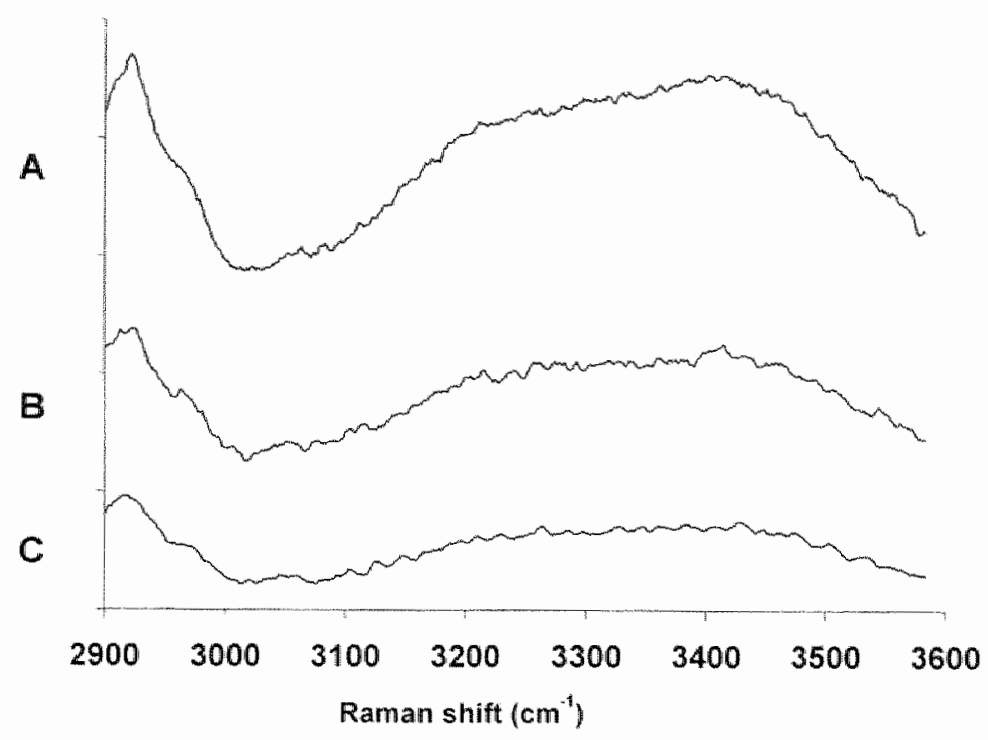

Figure 2. Representative Raman spectra (from $2900-3600 \mathrm{~cm}^{-1}$ ) of the hunan cornea in who, depicting the Raman modes of collagen (CH-vibrations at 2940 and $\left.3065 \mathrm{~cm}^{-1}\right)$ and water (OH-vibrations from $3100-3540 \mathrm{~cm}^{-1}$ ). Experimental conditions: CRS system utilizing a low power Helium-Neon laser $6632.8 \mathrm{~nm}$; $15 \mathrm{~mW}) . \mathrm{A}, \mathrm{B}$, and $\mathrm{C}$ are obtained with exposure times of 5,2 , and $1 \mathrm{~s}$, , and yield a signal-to-noise ratio of 60,35 , and 25 , respectively.

\section{Results}

The CRS technique yielded rapid acquisition of high signal-to-noise ratio (SNR) Raman spectra of the human cornea in who using low power laser irradation. Figure 2 depicts the typical Raman spectra of a normal human cornca in the higher Raman shift range from 2900-3600 $\mathrm{cm}^{-1}$. Even at exposure time of 1 s. the signal-to-noise ratio was sufficient ( 25$)$ to clearly distinguish the Raman modes for the $\mathrm{CH}$ - and $\mathrm{OH}$-vibrations. The spectral acquisitions were reasonably reproducible, with an average standard deviation (SD) for the Raman intensity ratio 1(3400)/I(2940) per set of six Raman spectra in both subjects of $8.8 \%( \pm 2.7)$. Potentially accountable for the extent of the SD were the eye movement artifacts, although the focus was maintained at approximately the same site within the comea, and the fact that the coneas slightly dehydrated over time as a result of maintaining the eycs open.

The application of Muro1 28 decreased the hydration of the anterior part of the cornea, as can be seen from Figure 3, depicting Raman spectra of subjects A 


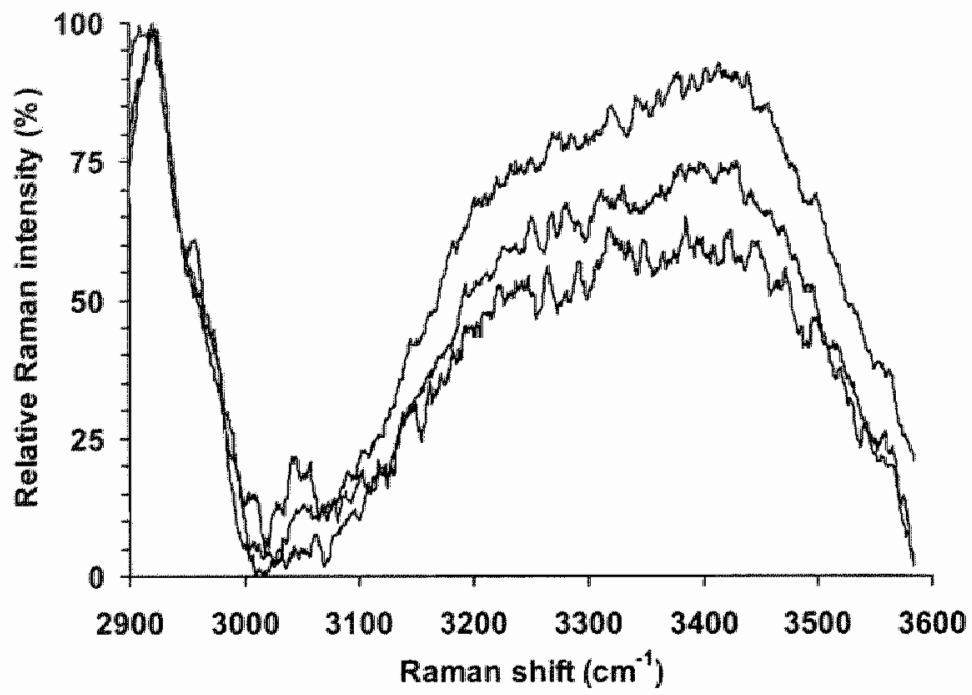

Figure 3. An wiw Raman spectra of the comea of subject A normalized to the anplitude of the CH-vibrations at $2940 \mathrm{~cm}^{-1}$ illustrating the decrease in Raman spectral amplitude of the OH-vibrations of water at $3400 \mathrm{~cm}^{-1}$ due to the dehydrating eftect on the comea of Muro 128 .

from the same comeal region before and 5 minutes after both the first and the second application of Muro 128, respectively. The largest decrease in the Raman intensity ratio $\mathrm{OH} / \mathrm{CH}$ in subject $\mathrm{A}$ was $\sim 35 \%$ from normal after the second topical application of Muro 128 (Figure 3). On average however, this decrease in comeal hydration was less pronounced. This is illustrated in Figure 4 depicting the mean ( \pm standard error) of the Raman intensity ratio $\mathrm{OH} / \mathrm{CH}$ for each set of 6 Raman spectral assessments in both subjects, normalized to the hydration before topical application of Muro128. The dehydrating effect of Murol28 was larger in subject $\mathrm{A}$ than in subject $\mathrm{B}$, with a maximum change of the Raman intensity ratio $\mathrm{OH} / \mathrm{CH}$ of $\sim 12 \%$ and $\sim 4 \%$, respectively. However, no significant changes in hydration were observed for subject $B$, while in subject A significant changes in comeal hydration were assessed only after the second application of Murol28. The fact that the subjects were allowed to blink in-between spectral assessments might have decreased the expected effect of the topical dehydrating agent. This too might be a reason for the observed difference between the two subjects, since subject A was more compliant to keeping the eyes open than subject $B$. 


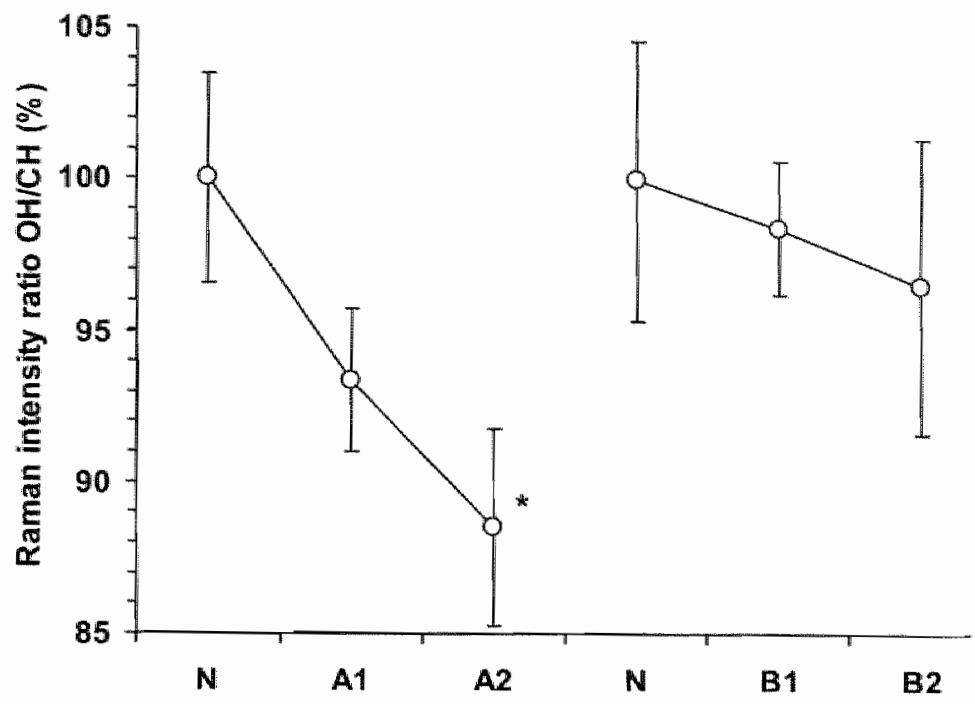

Figure 4. Relative changes in the Raman intensity tatio $\mathrm{OH} / \mathrm{CH}$ as a me: sure for the comeal hydration in the human connea in wino. $N=$ normal. A I, A2, $B 1$, and B2, are the first and the second application of Muro 28 in subject $A$ and $B$ respectively. *is statistically significant difference from $N(p<0.05)$.

The subjects did not experience any discomfort from the procedure, neither during the exposure to the laser light nor during the four weeks thereafter as assessed with a general ophthalmological examination. In addition, it seems reasonable to believe that the laser-cornea interaction had no effect on the integrity of the comea since no pain was perceived in the corneas with normal sensitivity after the anesthetic had lost its effect.

\section{Discussion}

These are the first successful in wipo Raman spectra obtained from the comeas of human subjects. Raman spectra in the region of 2900$)-36,00 \mathrm{~cm}^{-1}$ were recorded from the anterior $100-150 \mu \mathrm{m}$ of the conea by maintaining the focus of the laser-beam at the same distance from the cye through optical feedback. These spectra were reproducible and yielded the $\mathrm{CH}$-vibrational modes of proteins as well as the $\mathrm{OH}$-vibrational modes of water in a single acquisition using a minimum of $15 \mathrm{mf}$ of laser light. The Raman intensity ratio I(3400)/I(2940) was used for the qualitacive assessment of comeal hydration 


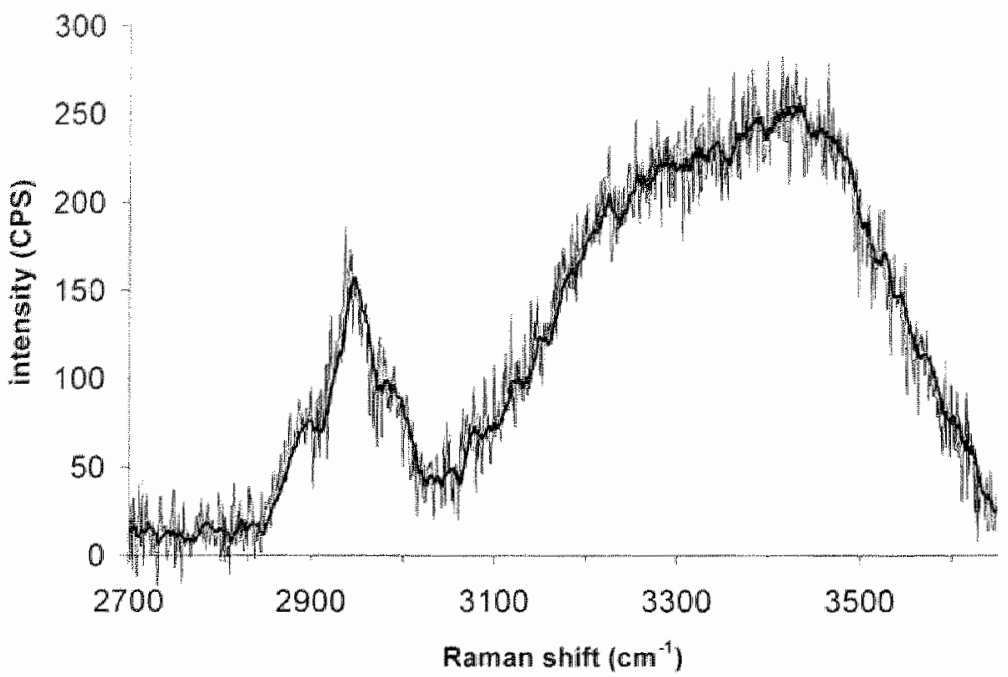

Figure 5. A low intensity (3 mJ) Raman spectrum of a humau comea in who in the high spectral Raman shift region (2700-3650 $\mathrm{cm}^{-1}$ ) using the Argon laser (514.5 nm; $0.6 \mathrm{~mW}: 5 \mathrm{~s}$ exposure tine). Calculated light exposure on the retina would be safe according to Ref. 21 . Signal-to-noise natio $\sim 25$.

from the anterior region of the cornea over a variable period of time before and after ropical application of a mild delhydrating drug.

The same optical setup was utilized as for our previous in wino animal study except for the use of a Helium-Neon ( $\mathrm{HeNe}$ ) in stead of an Argon (Ar) laser because of its relative safer wavelength. ${ }^{6}$ In the previous report we established the validity of the relationship between the Raman intensity ratio $\mathrm{OH} / \mathrm{CH}$ and comeal hydration, and performed calibration measurements using both ultratsound pachymetry and a lyophilization technique, thus showing rhe potential of confocal Raman spectroscopy for the non-contact assessment of the extent and distribution of comeal hydration in anesthetized rabbits. ${ }^{6}$ Although the relationship between Raman spectral features and comeal hydration is still valid at present using the HeNe-laser, no calibration (such as using pachymetry) could be performed since the hydration of only the superficial part of the cornea was assessed, because movement artifacts compronised spatially resolved measurements of the total thickness of the comea. The occurrence of movement artifacts could possibly be of more significance in seeing eyes because of the increased discomfort due to the intense light. Currently, we are exploring the possibility of incorporating an eye-tracking device into our setup, for eliminarion of movement artifacts during assessments in vive. Furthermore, a significant 
decrease in exposure time $(<50 \mathrm{~ms})$ would decrease the occurrence of movement artifacts.

The discrepancy between system sensitivity and retinal safety is the main drawback of the confocal Raman spectroscopy system for ophthalmic use still to overcome in order to enable the safe clinical application of this optical technique for the noncontact assessment of comeal hydration in vin. Ideally this system would yield real-time ( $<50 \mathrm{~ms} / \mathrm{spectrum})$ data acquisition at minimal light exposures. In the present study, $15 \mathrm{~mW}$ of HeNe-laser light was used and a 1 second exposure time in order to get high signal-to-noise ratio (SNR) spectra of the cornea. According to the ANSI standards for laser safety the ocular maximum permissible exposure (MPE) for a HeNe laser at $632.8 \mathrm{~mm} \mathrm{is} 1.8 \mathrm{t}^{3 / 4}$ $\mathrm{mJ} / \mathrm{cm}^{2}$, for exposure times $(\mathrm{t})$ between $18 \mu \mathrm{s}$ and $450 \mathrm{~s}_{2} 21$ This is equal to a maximum light exposure of $\sim 1-2 \mathrm{ng} / \mathrm{s} / \mathrm{cm}^{2}$ for exposures between 1 and $10 \mathrm{~s}$. Since the high numerical aperture LDMO yields a retinal irradiation area of -2.7 $\mathrm{cm}^{2}$ when focusing in the comea, as calculated using a ray-tracing program, a HeNe-laser irradiation of $15 \mathrm{~mW}$ for $1 \mathrm{~s}$. is $\sim 4 x$ the MPE. Thus, the projected light levels used were not safe for the retina, and legally blind patients had to be used (see also Chapter 1 of this Thesis).

Increasing the sensitivity of the proposed method will yield high SNR spectra at light exposures that are safe for the retina. This can be achieved for example by increasing the axial length of the probing volume from $120 \mu \mathrm{m}$ (as used here) to $500 \mu \mathrm{m}$ by utilizing a larger confocal pinhole, i.e. fiber diameter, resulting in a higher $\mathbb{R}$ aman yield but lower spatial resolution. Furthemore, higher NA objectives will also have a higher Raman yield but at the cost of a shorter working distance. Another method of increasing the system sensitivity is by using a shorter wavelength laser. The Raman intensity $(I)$ is in direct proportion to both the frequency of the incident light to the fourth power $\left.(I \sim)^{+}\right)$, yielding $2.5 \mathrm{x}$ higher signals using an Ar-laser at $514.5 \mathrm{~nm}$ as opposed to a HeNe-laser, as well as the sensitivity of the CCD connera, which is $>2 x$ higher in the same Raman frequency shift region using the Ar-laser as compared to the HeNe-laser. ${ }^{13}$ Since the MPE for the more intense Ar-laser $(514.5 \mathrm{~mm}$ ) is the same as for the HeNe-laser $(632.8 \mathrm{~nm})$ for exposures between $18 \mathrm{~s}$ and $10 \mathrm{~s}, 21$ and the Raman yield is $>5 \mathrm{x}$ higher with the Ar-laser, Raman spectra with similar signal-to-noise ratios can be obtaned requiring only $1 / 5^{\text {th }}(=3 \mathrm{ml})$ of the total light energy as opposed to using a HeNe-laser, and would be below the MPE for exposure times $>1 \mathrm{~s}$. This was tested in a human conca in witro with the optical setup as used in our previous report ${ }^{6}$ but using only (1.6 mW of Ar-Jaser light and a single $5 \mathrm{~s}$. exposure time, yiclding a SNR of -25 and a projected retinal exposure of $\sim 1 / 5 x$ the MPE (Figure 5). More promising however are techniques currently being devised in our lab that preclude light exposure to the retina altogether while focusing at the comea. In this manner, light levels that 
would potentially be hazardous to the retina but not the comea could be applied yelding high SNR spectr from small probing volumes at short acquisition times, allowing for rod time spatially resolved assessments of coneal hydration in as safe and noncontact manner.

The confocal Raman spectroscopic (CRS) technique as presented here has various advantageous propertics, as outlined in detail in one of our previous reports. ${ }^{13}$ The high gain of this optical system design is the result of the $180^{\circ}$ backscatter configuration utilizing a high numerical aperture objective lens, and a highly sensitive COD camera. The confocal arrangement prevents the detection of stray light and enables the probing of small optical volumes, yielding adequate spatial resolution in thicker tissues, such as the comea. The diametar of the optical fiber can be changed to alter the integration depth from $20-900 \mu \mathrm{m}$. The objective lens is part of a telecentric setup, and can therefore be moved along its optical axis without changing the location of its focal plane, while the long, working distance of $\sim 13 \mathrm{~mm}$ allows for noncontact probing of ocular cissues at depths ranging from the superficial tearfim to the anterior vitreous without moving the sample and without causing probing artifacts. ${ }^{6}$ Lastly, the CRS technique provides direct information on the biochemicall content of ocular tiswes, i.e. comeal hydration, unlike for example ultrasound pachymetry, which derives comeal hydration through comeall thickness measurements.

Thus, we believe that with adequate improvements in system safety, confocal Raman spectroscopy could potentially be applied as a noncontact tool for the assessment of comeal hydration in wipo with clinical relevance for the early diagnosis of the extent and localization of disturbances in comeal deturgescence.

\section{Acknowledgements}

This work was sponsored ilu part by a Research to Prevent Blindness Unrestricted Grant. We thank Dr. Massoud Motamedi in the Dept. of Biomedical Engineering of the University of Texas Medical Branch in Galveston and Dr. James P. Wicksted in the Dept. of Physics of the Oklahoma State University for their valuable contributions towards this project. We also thank Mr. Brent Bell lor his technical support.

\section{References}

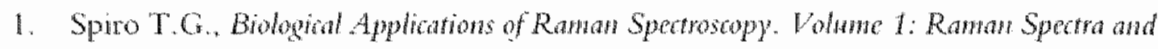
Conformation of Bologial Macronolecules. John Wiley \& Sons. New York, 1987. 
2. Yu N.-T and East E.J. Laser Raman Specroscopic Srudies of Ocular Lens and lts Isolated Protein Fractions.J Brol Chem, 1975: 250:2196-2202.

3. Mizuno A. Tsuji M. Fuji K. Kawauchi K., Ozaki Y. Near-infrared Founer thansfom Raman spectroscopic study of cornea and selera. Japan J Ophwahw, 1944; $38(1): 44-48$.

4. Siew DCW, Clover GM, Concy RP, and Wiggins PM. Micro-Raman Spectroscopic Study of Organ Cultured Comene. I Ramar Speros 1995; 26: 3-8.

5. Goheen SC. Lis $\mathrm{U}$, and Kattiman JW. Raman Spectroscopy of Intact Feline Comeal Collagen. Biodim Biophys Acta, 1978; $536(1): 197-204$.

6. Baner NJC, Wicksted JP. Jongsma FHM, March WF, Hendrikse F, and Motamedi M. Noninvasive Assessment of the Hydration Gadient Across the Comea Using Confocal Raman Spectroscopy. Intwest. Ophthalmol. Vis. Soi. 1998; $39(4): 831-835$.

7. Frushour B.C. and Koenig J.L. Raman Scattering of Collagen, Gelatin, and Elastin. Biopolymers $1975 ; 14: 379-391$.

8. Wicksted JP, Erckens RJ, Motamedi M, and March WF. Raman Spectroscopy Studies of Metabolic Concentrations in Aqueous Solutions and Aqueous Humor Specimens. Appl Spectros 1995; 49(7): $987-993$.

9. Erckens RJ, Motamedi M, Wicksted JP, and March WF. Raman Spectroscopy for Non-Invasive Characterization of Oculat Tissue: Potential for Detection of Biological Molecules. f. Ramon Spectros 1997; 28: 293-299.

10. Sebag \., Nie S., Reiser K., charles M.A., Yu N.T. Raman spectroscopy of human vitreous in proliferative diabetic retinopathy. Inwest Ophthalmol Vis So 1994; $35(7): 2976-80$.

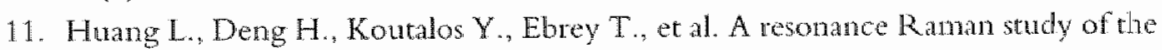
$C=C$ stretch modes in bovine and octopus visual pigments with isotopically labeled retinal chromophores. Phtorohon Photobiol 1997; 66(6):747-54.

12. Yu N.T., Kuck JFR, and Askren CC. Laser Raman Spectroscopy of the Lens in situ, measuted in an anestherized rabbit. Cur Eye Res 1981/82; 1(10): 615-618.

13. Jongsma F.H.M., Erckens R.J. Wicksted J.P., Buner N.J.C. at al. Confocal Raman Spectroscopy System For Noncontact Scaming Of Ocular Tissues: an th Vitm Study. Opt Eng 1997; 36(11): 3193-319\%.

14. Bauer NJC, Motamedi M, Wicksted JP, el at. Non-Invasive Assessment of Ocular Phamacokinetics using Confocal Raman Spectroscopy. J Or Pham Ther 1999; 15(2): $123-134$.

15. Mandell RB, Polsc KA, Brand RJ, Vastine D, Demartini D, Flon R. Corneal hydration control in Fuchs" dystrophy. Inver Ophthathol Vis So 1989; 30(5), 845 852.

16. Polse KA. Changes in conneal hydration after discontinuing contact lens wear. AmJ Opfon Arth Am Ac Opom 1972; 49(6): 511-516.

17. Herse PR. Comeal hydration control in nommal and alloxan-induced diaberic

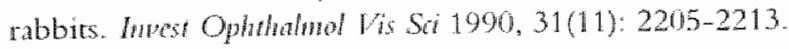


18. Herse $\mathbb{P}$ and Siu A. Shonterm Efects of proparacane on comeal thickness. Ana Ophthatmol 1992: 70(6): 740-744.

19. Dougherty $\mathrm{PJ}$. Wellish $\mathrm{KL}$, and Maloney R. Excimer laser ablation rate and comed hydration. An J Ophhalmol 1994; 118(2): 169-176.

20. Fields CR, Taylor SM, and Barker FM. Effect of conieal edema upon the smoothness of exciner laser ablation. Optom Vis Si 1994; 71(2): 109-114.

21. Anerican National Standards Institute. Safe Use of Lasers. In: ANSI Standard Z136.1, Laser Institute of America, Orlando, 1993; 28-41. 
CHAPTER 7

\section{Noncontact assessment of ocular pharmacokinetics using confocal Raman spectroscopy}

Noël JC Bauer, Massoud Motamedi, James P Wicksted,

Wayne F March, Carrol AB Webers, Fred Hendrikse

J Ocular Pharm. Ther. 1999; 15(2):123-134 


\section{A BSTRACT}

Aim: A laser scanning confocal Raman spectroscopy (CRS) system was applied for the noncontact quantification of the transpart of a drug through the rabbit comea in vivo.

Methods: Employing CRS, the changes in the amplitude of a drugspecific Raman signal were assessed over time in the tearfilm and corneal epithelium of the living rabbit eye $(n=6)$, after topical application of $25 \mu \mathrm{L}$ Trusopt $2 \%$ TM. This allowed for quantification of pharmacokinetic variables. The effect of the drug on comeal hydration was also monitored.

Results:" CRS demonstrated adequate sensitivity and reproducibility, for continuous real-time monitoring of the Trusopt concentration. Each concentration-time curve had a bi-phasic trend; the rapid initial phase ( $t<8 \mathrm{~min}$.) corresponds to the nonproductive losses of Trusopt from the tears $\left(k_{10}=0.24 \pm 0.04 \mathrm{~min}^{-1}\right)$, and the slower later phase $(t>20 \mathrm{~min}$.) is the result of transfer from the drug from the corneal epithelium to the stroma $\left(k_{23}=0.0047 \pm 0.0004 \mathrm{~min}^{-1}\right)$. Drug absorption into the corneal epithelium occurred at a rate of $k_{12}=0.034 \pm 0.006 \mathrm{~min}^{-1}$. Trusopt caused an acute dehydrating effect, with a maximum decrease in corneal hydration of $\sim 15 \%$, $\sim 60$ min. after drug application.

Conclusion: CRS has the specificity, sensitivity, reproducibility and spatial resolution for employment as a potentially valuable tool for the study of ocular pharmacokinetics. 


\section{Introduction}

Ocular pharmacokinetics studies the absorption, distribution and eliminattion of ophthalmic drugs as function of concentration and time. These studies are necessary in order to detennine the effectiveness of (potential) ocular drugs, and to optimize therapeutic dosing regimens. The assessment of pharmacokinetics of topical ocular drugs has been a challenging issue for researchers in this field.

Ocular tissues or fluids can not be harvested without seriously interfering with the anatomical integrity of the eye, limiting the applicability of invasive assessments in the human to sampling of aqueous humor durng intraocular surgery, in order to determine the concentration of a preoperatively instilled ocular drug. ${ }^{1,2}$ Consequently, we usually rely on animals, in particular the rabbit, as the subjects of choice in pharmacokinetic research. ${ }^{3}$ Because of the obvious differences in anatomy and physiology the application of phannacokinetic findings to the human might not always be possible. Furthermore, time-dependent drug concentration measurements by means of invasive assessment techniques require a large number of rabbits, since one rabbit is used for one time-point. Noncontinuous sampling will only provide statistically reliable data if sufficient animals per time-point are assessed, at sufficient, adequately spaced, time-points. It is not uncommon to use as many as 200 rabbits in a single pharmacokinetic comparison study of two ocular drugs. ${ }^{4}$

Noncontact pharmacokinetic assessment techniques, whilst they are safe to apply in the human eye, could potentially resolve these issues. Currently, however, no adequate noncontact technique is available for application in ocular pharmacokinetics. Although not specifically designed for pharmacokinetic measurements, non-invasive fluorometry of the anterior segment of the eye has various hallmark characteristics sought after in a suitable pharmacometric technique. ${ }^{5}$ It is a non-invasive, sensitive, and safe technique, which yields real-time and continuous quantitative information from all ocular media (tear-film, cornea, aqueous humor and the crystalline lens). This technique has been applied to complement pharmacological studies in the eyc, by providing information on tissue-specific physiological properties, i.e. cellular permeability, diffusion rates, and flow of tear-film and aqueous humor. ${ }^{5-?}$ Furthermore, fluorometry has the potential to assess the contribution of each tissue or cell-layer to ocular drug transport necessary for the validation of current ocular pharnacokinetic models. 3.4 .8 However, fluorometry is inherently nonspecific, and can be hampered by the presence of tissue auto-fluorescence. Therefore the development of a non-invasive technique that combines all afiorementioned properties could potentially provide for accurate determination of the pharmacokinetic behavior of ophthalmic drugs in the human eye. ${ }^{8}$ 
The objective of this study was to investigate the feasibility of applying a novel laser scanning confocal Raman spectroscopy (CRS) system for noncontact phamacokinetic assessments in the living rabbit eye. Raman spectroscopy is an optical technique that allows for biochemical assessments by identifying specific laser-light induced molecular vibrations. This technique has been urilized in the past to characterize the biochemical changes in the ocular lens during its transformation from normal to the cataractous state; see for example Ref. (9). More recently we applied the CRS technique to determine the temporal and spatial distribution of comeal hydration in an in vivo animal model. ${ }^{16}$ Furthermore, applications of CRS for the noncontact quantitative assesment of biomolecules in aqueous humor specimens and aqueous solutions have been proposed. 11

Unlike fluorometry, the inherent specificity of Raman spectroscopy (RS) has the potential to differentiate between the biochemical signature of ocular tissues and ocular drugs, and could therefore enable the monitoring of drug concentrations in ocular tissues. Furthermore, the confocal configuration of the proposed CRS system yields adequate spatial resolution in the tissue of interest, with a cross-sectioning capability of $20 \mu \mathrm{m}$ or more..$^{10,12}$ In addition, the CRS system, like fluorometry, has the potential to assess all ocular mediat in a noncontact manner, and provide quantitative information in a real-time and continuous fashion. 12

Thus, we utilized CRS to monitor the time-dependent concentration changes of a commonly used topical ocular drug within the anterior region of the comea (tear-film and corneal epithelium), in an in vivo animal model. The drug of choice was Trusopt $2 \%$ (dorzolamide $\mathrm{HCl} 2 \%$, ophthalmic solution, Merck Co., CA), because of its strong Raman signal, and because the pharmacokinetic behavior of this compound has not yet been elucidared completely. ${ }^{3}$ Furthermore, we applied CRS to assess the changes in corneal hydration following the application of this drug.

\section{Materials and methods}

\section{Instrumentation}

The characteristics and performance of our laser scamning confocal Raman spectroscopy (CRS) system for the noncontact biochemical characterization of ocular rissue has been described previously. ${ }^{12}$ In short, the key components of the system are a single grating spectrometer (SPEX500M, Spex Industries, Edison, NJ), with CCD-camera for real-time signal detection, an argon laser $(514.5 \mathrm{~nm})$, and a long-working distance microscope objective lens (magnifica- 
tion $25 x$, numeric aperture $=0.5$, focal length $=10 \mathrm{~mm}$, Jena, Karl Zeiss, Oberkochen, Gemany). The application of this lens not only yelded high light gathering power, but also noncontact probing of all ocular tissues of interest, by wintue of its long working distance of $\sim 13 \mathrm{~mm}$. This entrance lens was applied in a $180^{\circ}$ backscatter configuration (analog to an epi-illuminated microscope), and hence utilized for focusing as well as for collecting the Raman scattered light. An optical fiber at the exit site of this Raman spectroscopy system, for mansport of the Raman scattered light towards the spectrometer, was placed in confocal alignment with the entrance lens (LDMO). Thus, this fiber acs like a confocal pinhole, and it effectively eliminates light from out of-focus places, allowing for the assessment of thin layers. Changing the diameter of the fiber will change the probing volume, mainly by changing the integration depth ( $220 \mu m$ ). Apat from the hydration assessments, all spectra were obtained using a laser power of $50 \mathrm{~mW}$ and a 60 sexposure time, in conjunction with a $50 \mu \mathrm{m}$ fiber, yelding an integration depth of $120 \mu \mathrm{m}$, and each spectrum was acquired by focusing the long-working distance microscope objective lens (LDMO) in such a manner that only the precomeal tearfilm and the comeal epithelimm were included in the probing volume.

\section{In vitro and in vivo studies}

To demonstrate the ability of our method to quantify drug concentrations, a commercially avaiable topical ocular drug (Trusopt, dorzolamide $\mathrm{HCl} 2 \%$ ophthalmic solution, Merck, CA), clinically used to reduce aqueous humor formation by inhibition of the enzyme carbonic anlyydrase, was used. The drug was diluted with high-performance liquid chromatography-grade water to concentrations ranging from 0.01 to $2 \%$ (undiluted), and assessed with the CRS technique in nitr. The Raman intensity of a dorzolamide-specific pealk at 1420 $\mathrm{cm}^{-1}$ was plotted against sample dmg concentration (ou), and their relationship) investigated for linearity.

Under an approved animat prococol that compled with the ARVO Resom Iution on the Use of Animals in Research, the in wiro studies were performed on the eyes of in total 9 female NZW rabbits $(3.0-4.0 \mathrm{~kg}) ; 3$ rabbits were used for assessment of changes in drug concentration versus time at the anterior region of the comea $(n=6$ eyes); 6 rabbits $(n=9$ eyes) were used to assess the changes in comeal hydration as function of time after application of Trusopt. The animals were restrained in a holder, and anestherized using intramuscular ketamine hydrochloride $(25 \mathrm{mg} / \mathrm{kg}$ ) and $x y$ lazine $(5 \mathrm{mg} / \mathrm{kg})$.

Before drug application, five Raman spectra were obtained in the Raman shife range from $517-2018 \mathrm{~cm}^{-1}$, with the LDMO properly focused and optically aligned to the comea of the anesthetized rabbit (vide supra), in order to obtain 
baseline values for the Raman peak of interest at $1420 \mathrm{~cm}^{-1}$. At time $t=0,25 \mu \mathrm{L}$ of Trusopt $2 \%$ was applied in one eye, and the LDMO was immediately $<3$ sec.) and continuously manually $(<10 \mu \mathrm{m})$ adjusted to keep the focus in place. Raman spectra were obtained at regular intervals from $t=0$ to $t=120$ min.; yidding $\sim 20-25$ Raman spectra per eye during the course of the concentration assessments. An algorithm was used (Matlab, Mathworks, Natick, MA) to calculate from each single spectrum the amplitude of the drug-specific Raman peak of Trusopt at $\sim 1420 \mathrm{~cm}^{-1}$ (in count-per-second, CPS) using the spectral information in the low range $\left(517-201.8 \mathrm{~cm}^{-1}\right)$. These values were normalized to the background noise and plotted as a function of time.

Initially, the log-linear concentration versus time curve for each eye was analyzed qualitatively, in order to identify the different phases corresponding to the transfer of drugs from one compartment to the other (see Appendix). The data belonging to each phase was then used to calculate the time-dependent pharmacokinetic drug transfer rate constants (in $\mathrm{min}^{-1}$ ). Various other pharmacokinetic parameters could be derived using these constants. The details on the calculation of pharmacokinetic variables are described in the Appendix.

Comeal hydration was determined using a previously reported method, which entails a laser power of $25 \mathrm{~mW}$, a 3 s exposure time per spectrum, and an $11 \mu \mathrm{m}$ fiber ( $50 \mu \mathrm{m}$ integration depth). Spectra in the higher Raman shift range $\left(\sim 2700-3600 \mathrm{~cm}^{-1}\right.$ ) yield OH-vibrations (largely caused by the comeal water) and $\mathrm{CH}$-vibrations (mainly caused by structural proteins of collagen), and the Raman intensity ratio $\mathrm{OH} / \mathrm{CH}$ is directly proportional to the local degree of hydration ( $m$ g water / mg dry wt.). Assessment of comeal hydration was obtained by axially scanning the whole thickness of the cornea with $50 \mu \mathrm{m}$ steps. The integrated results of each axial scan are strongly correlated with total comeal hydration as assessed with lyophilization or pachymetry. ${ }^{10}$ Comeal hydration as function of time was assessed in five corneas of four rabbits after topical application of Trusopt $2 \%$, and in another four eyes of two rabbits without drug application, and compared in order to investigate the acure effects of Trusopt on comeal hydration.

\section{Results}

Figure 1 displays typical. Raman spectra in the lower $R$ aman shift region (truncated to $700-1800 \mathrm{~cm}^{-1}$ for clarity) of [A] the original $2 \%$ Trusopt, [B] the anterior region of a nomal $N Z W$ rabbit comea in piso before drug application, and a similar comeal region in wim at $[\mathrm{C}] \mathrm{t}=1$ and $[\mathrm{D}] \mathrm{t}=120 \mathrm{~min}$, respectively, following application of $25 \mu \mathrm{L}$ of Trusopt $2 \%$. The spectra of Trusopt $2 \%$, and of the living conea at $\mathrm{t}=1 \mathrm{~min}$. after drug application, display a strong Raman 


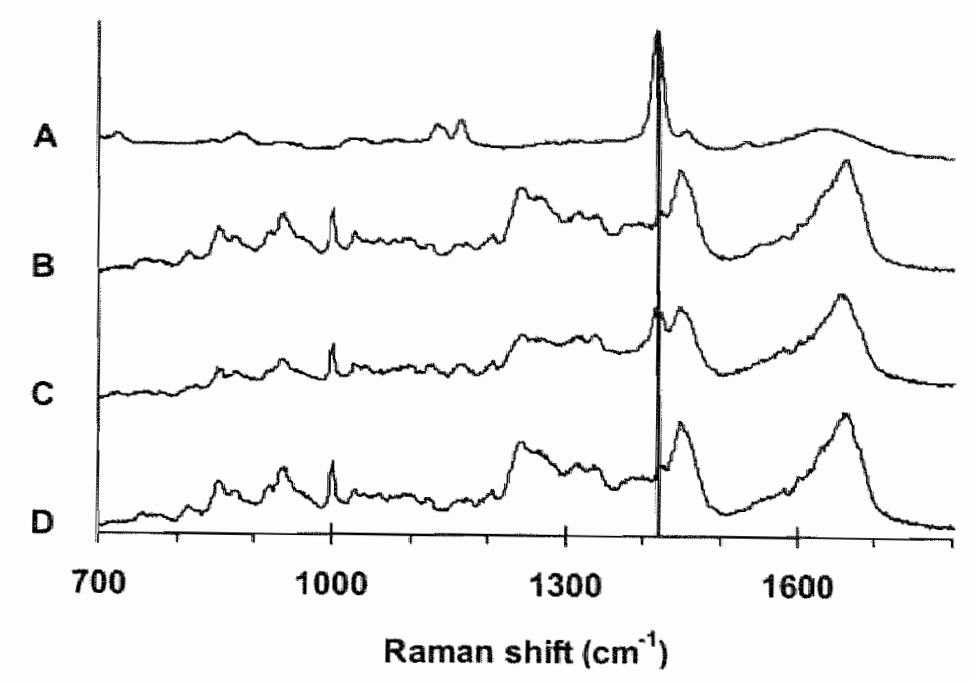

Figure 1. Typical Raman spectra of (A) the original Trusopt $2 \%$. (B) a normal $N Z W$ rabbit comea in witw, and the same comea at $1(\mathrm{C})$ and 120 (D) minutes following application of $25 \mu \mathrm{L}$ of Thusopt $2 \%$ to that eye. Vertical line identifes the Raman shift position $\left(1420 \mathrm{~cm}^{-1}\right)$ attributed to the spexific Raman vibration of dorzolamide.

signal at the same Raman shift position of approximately 1398 to $1440 \mathrm{~cm}^{-1}$ with a maximum at approximately $1420 \mathrm{~cm}^{-1}$ (ring stretch vibration of 2 -substituted thiopenes). In the normal cornea a weak signal can be observed at the Raman shift position of approximately $1445 \mathrm{~cm}^{-1}$. The strong Raman signal at $1420 \mathrm{~cm}^{-1}$ is caused by the double ring-structures of dorzolamide, and was monitored during the pharmacokinetic measurements. Furthermore, it can be seen in this figure, that the spectra of a normal cornea and the same cornea at $t=120 \mathrm{~min}$. after drug application display no significant differences, suggesting that there are no adverse effects of dorzolamide on protein structure and conformation in the corneal stroma.

Figure 2 depicts the intensity of the Raman peak at $1420 \mathrm{~cm}^{-1}$ as a function of the concentration of Trusopt in the range $0.01-2.00 \%$ as assessed in vitro. A strong linear relationship can be seen $\left(R^{2}=0.999, n=8\right)$, proving the validity of the proposed method to assess drug concentrations. The limit of detection with the described experimental conditions used in this study is a Trusopt concentration of approximately $0.02 \%(200 \mu \mathrm{g} / \mathrm{mL}=0.55 \mathrm{mM})$, but could be significantly lower at longer exposure times or higher dight-energy levels. In all cases this sensitivity proved sufficient for assessment of drug concentrations in wivs up to 2 hours after drug application. 


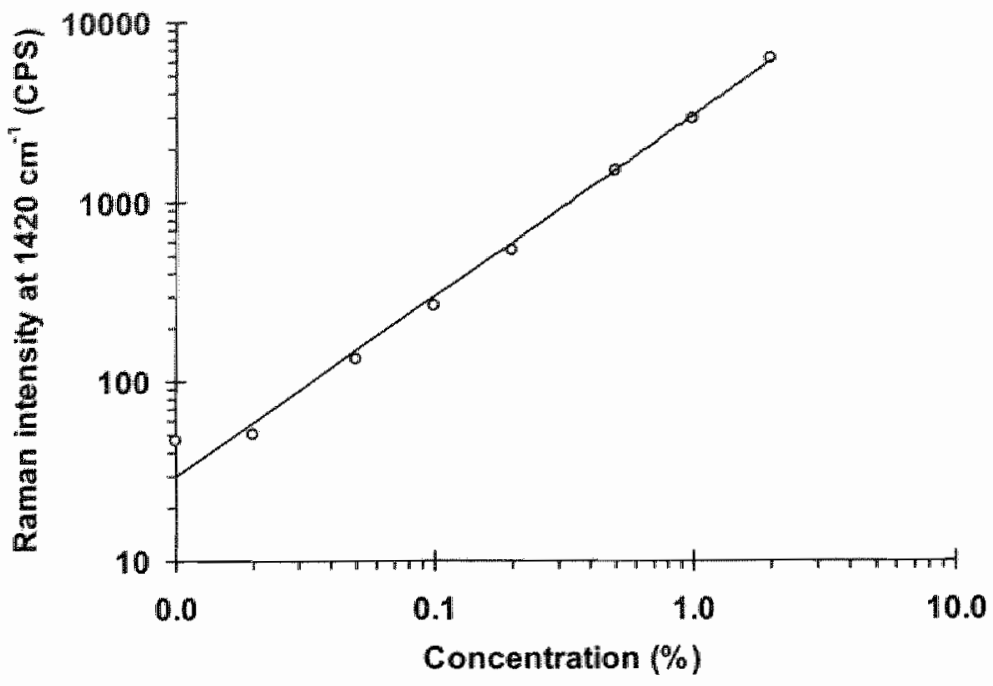

Figure 2. Relationship between Raman intensity $(D)$ and concentration $(O)$ of Trusopt in HPLC-gnade water from 0.01 to $2 \%(2 \%$ is the original solution $)$ In formula: $1=2960, \pm 70) C ; r=0.9997, p<0.05, n=8$.

Figure 3 shows a typical semi-logarithmic plot of the dorzolamide concentration versus time as assessed with the CRS technique after topical application of $25 \mu \mathrm{L}$ of Trusopt $2 \%$ in one eye. It can be seen that the drug concentration versus time follows a bi-phasic trend with a fast first apparent decay rate from $t=0$ to approximately 7 nimutes (A), and a slower second one from approximately 20 minutes onwards (B). These regions were used to calculate $k_{10}$ and $k_{23}$, respectively (see Appendix). Table I summarizes the phamacokinetic transfer ate constants as assessed using confocal Raman spectroscopy of all 6 eyes. The values for the transfer rate constants are (mean $\pm S D$ ): $k_{10}=0.24 \pm 0.04$, $k_{12}=0.034 \pm 0.006$, and $k_{23}=0.0047 \pm 0.0004 \mathrm{~min}^{-1}$. From these values it is possible to derive other phamacokinetic variables (Table 2). The standard deviations (SD) suggest that the proposed nethod is reproducible, given our small data set, with an average SD for a] calculated variables of $\sim 12 \%$ (tange $9-16 \%$ ).

Comed hydration in the "treated' rabbits $\left(\mathrm{H}_{\mathrm{T}}\right)$ decreased as a function of time after application of Trusopt $2 \%,\left(\mathrm{H}_{\mathbb{T}}=-0.0085 \mathrm{t}+3.81, \mathrm{r}=0.96, \mathrm{p}<0.05, \mathrm{n}=33\right)$ as can be seen from Figure 4. Significant changes in hydration were observed from 30 to 70 minutes. The maximum change in hydration occurred at $\sim 60$ mintes after drug deposition and was $\sim 0.55 \mathrm{mg}$ water / mg dry wt. (approximately $15 \%$ of $\left.\mathrm{H}_{1}\right)$. Comeal hydracion in the control rabbits $\left(\mathrm{H}_{\mathrm{O}}\right)$ did not change appreciably over time $\left(\mathrm{H}_{\mathrm{C}}=-0.0010 \mathrm{t}+3.96, \mathrm{r}=0.87, \mathrm{p}<0.05, \mathrm{n}=18\right)$. 


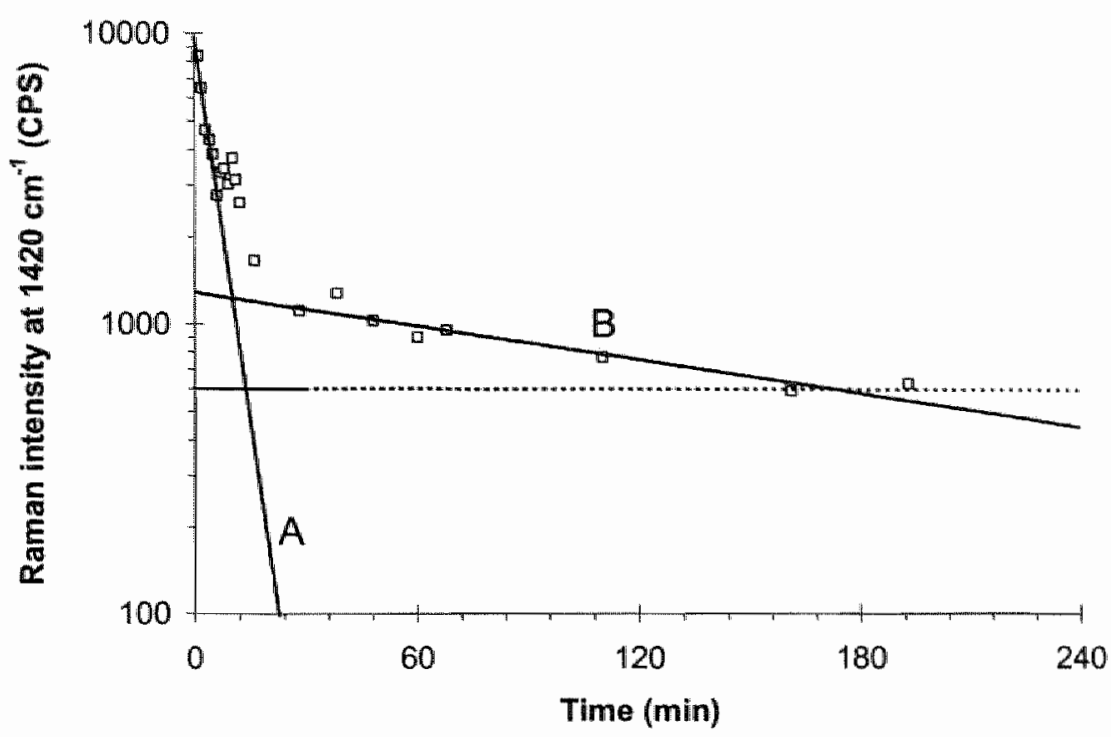

Figure 3. Typical results showing a log-linear graph depicting the amplitude of the Trusopt-specific Raman peak at $1420 \mathrm{~cm}^{-1}$ ws. time after application of $25 \mu \mathrm{L}$ of Trusopt $2 \%$ to the eye in the NZW rabbit in mo. (A) and (B) are the curve-fits yielding the pharmacokinetic variables $\mathrm{k}_{\| 0}$ and $\mathrm{k}_{2,}$, respectively. Broken horizontal line is the Raman intensicy before drug application, and the data is nomalized using this value.

Table 1. Pharmacokinetic transfer rate constants of Trusopt $2 \%$ as assessed using laser scanning confocal Raman spectroscopy in the living rabbit cornea $(n-6) .^{*}$

\begin{tabular}{|c|c|c|c|c|c|}
\hline Eye & $\begin{array}{l}k_{10} \\
\left(\min ^{-1}\right)\end{array}$ & $r$ & $\begin{array}{l}k_{23} \\
\left(m_{i n}^{-1}\right)\end{array}$ & $r$ & $\left(\mathrm{~min}^{+1}\right)$ \\
\hline 100 & 0.30 & 0.88 & 0.0050 & 0.63 & 0.041 \\
\hline 105 & 0.24 & 0.75 & 0.0047 & 0.31 & 0.033 \\
\hline 200 & 0.23 & 0.71 & $\mathbb{N A}$ & NA & NA \\
\hline 205 & NA & NA & 0.0052 & 0.79 & NA \\
\hline 300 & 0.24 & 0.98 & 0.0042 & 0.94 & 0.036 \\
\hline 305 & 0.20 & 0.98 & 0.0044 & 0.82 & 0.026 \\
\hline Meantso & $0.24 \pm 0.04$ & . & $0.0047 \pm 0.0004$ & - & $0.034 \pm 0.006$ \\
\hline
\end{tabular}

${ }^{*} r$ is correlation coefficient with p<0.05; NA is not awailatble; See Appendix for details. 
Toble 2. Derved phamacoknetic wariables of Trusopt 2 in the living rabbit conea (n-6) using the pharriacokinetic transtar patte constants of Table 1 .

\begin{tabular}{|c|c|c|c|c|}
\hline Fye & $\begin{array}{l}\text { trentears } \\
\text { (min) }\end{array}$ & $\begin{array}{l}\text { 4/2 mepith } \\
\text { (inin) }\end{array}$ & Tom & $\mathrm{K}_{\mathrm{mon}}\left(10^{-5} \mathrm{~cm} / \mathrm{min}\right)$ \\
\hline 100 & 20 & 139 & 14 & 250 \\
\hline 105 & 25 & 14 & 17 & 2.35 \\
\hline & 30 & 3 & - & 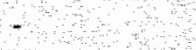 \\
\hline & - & 133 & 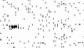 & 2,60 \\
\hline $\mathrm{n}$ & 25 & 165 & 17 & 2,10 \\
\hline & 3.1 & 158 & 20 & 220 \\
\hline $\operatorname{ean}+\mathrm{SD}$ & $2,6=0,4$ & 148413 & $17+2$ & $2,35 \pm 0.21$ \\
\hline
\end{tabular}

See Appendix for detanls on denvations and description of variabiles.

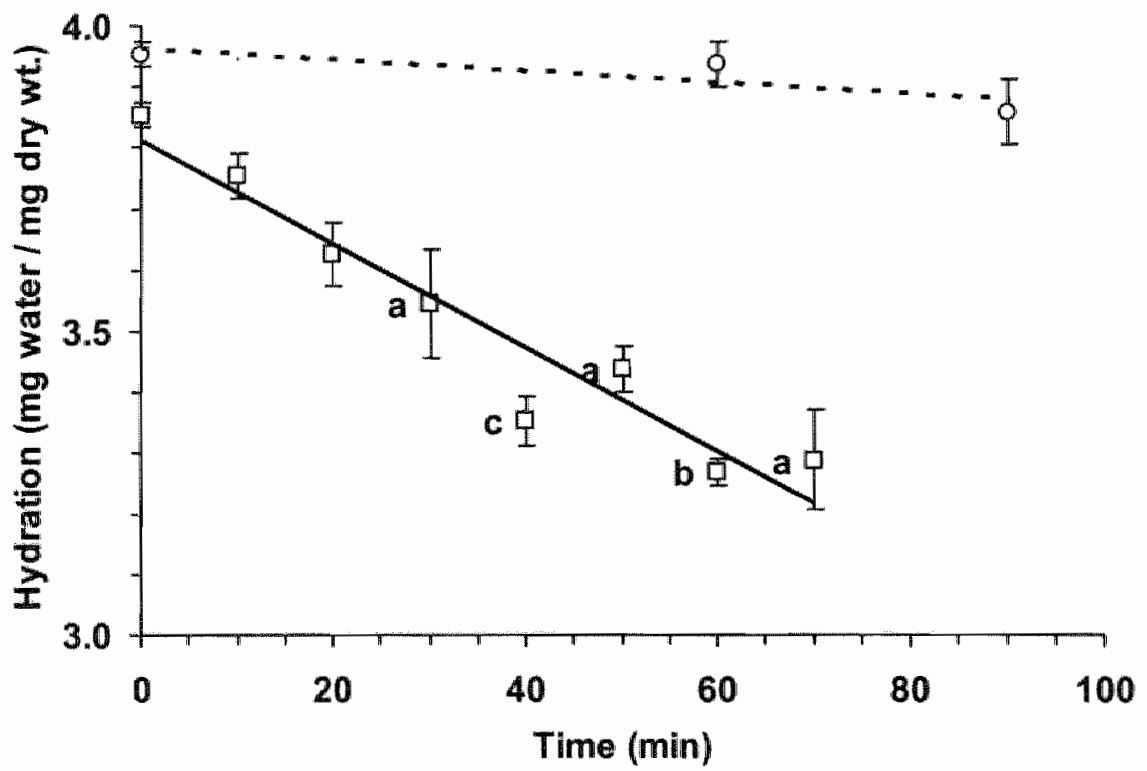

Figure 4. Comeal hydration in the rabbit under in wira conditions as function of time Solhd and dotted lines represent the "treated" and control rabbits, respectively. P-walues for the diffrence in mean hydration berween $t=0$ and $t>0$ min. as determined by the Student's t-test in the Trusopt-trated eyes are given by a $(p \leq 0.05), b(p \leq 0.005)$, and $c(p \leq 0.001)$ 


\section{Discussion}

In this manuscript we present the results on the application of laser scanning confocal Raman spectroscopy (CRS) for ocular phamacokinetic measurements. This optical technique is believed to have significant advantages over current assessment techniques. The non-contact character of CRS allows for in wivo applications and permits multiple assessments of the concentration of a drug in the same sample over time (up to 120 minutes after drug application). This reduces the amount of animals needed to obtain valuable pharmacokinctic information. More importantly, the confocal modality of the proposed Raman spectroscopic technique permits probing of specific tissue layers, allowing determination of drug concentration changes in the different layers of the anterior comea. A challenging approach to pharmacokinetic drug transport would be to temporally and spatially resolve the distribution of the drug in the cornea after drug deposition, to improve the predictive value of phamacokinetic models. The feasibility of such a method was shown in an earlier study with regards to comeal hydration. ${ }^{10}$ The higher requirements of this type of technique heralds a major increase in signal-to-noise ratio, since both the assessment volume as well as the exposure time need to be decreased significantly for reliable results. Future work by our group in this area is directed towards that goal.

The most significant advantage of CRS over fluorometry is its intherent specificity. This allows for precise analysis of molecular vibrations, and can be utilized to identify ocular drugs by their unique characteristics, thus being able to differentiate drugs from ocular tissues. CRS enables, for the first time, a direct monitoring of the pharmacokinetic drug transport within the eye. The specificity of CRS can also be put to use to study the effects of the drug on the tissue it is being applied to. In theory, tissue-protein changes will exhibit themselves in Raman spectroscopic changes in the lower (signature) region of the Ranan spectrum from $517-2018 \mathrm{~cm}^{-1}$. The present study did not find significant spectral changes in this signature region as a result of drug application, as shown by comparing the spectral response of a normal comea and the same cornea two hours after drug application. However, hydration changes due to application of Trusopt $2 \%$ were easily quantified, as presented in Figure 4. The dehydrating effect of Trusopt could be due to an increased level of evaporation on the surface of the cornea, maybe through an increased tear production due to the irritating effect of the drug.

The concentration changes of dorzolamide were measured at the anterior region of the rabbit cornea under in pive conditions. Qualitatively, the log-linear drug-concentration curves followed the bi-phasic trend commonly observed for other topical ocular drugs. ${ }^{14-16}$ The first apparent decay rate (from 0 to 7 minutes) is caused by non-productive losses of the drug from the tears, meaning 
the amount of drug that is not lost through transfer via the comea into the axucous, but by other means, like for example tear overtow, transport via the tear duct, or the scleral or conjunctival circulation. This non-productive loss, here defined as $\mathrm{k}_{10}$, detemines the length of presence of the drug in the precomeal tearfilm (nomally $<10$ minutes with ophthalmic solutions). This rate (nomally $0.05-0.30 \mathrm{~min}^{-1}$ ) is higher the more irritating the drug is to the eye, like Trusopt, which car cause stinging. Indeed, with $\mathrm{k}_{10}=0.24 \pm 0.05 \mathrm{~min}^{-1}$, our results indicate that the non-productive drug loss of Trusopt is at the higher end of the aforementioned range. Although the transport of dorzolamide to the site of-action seems to be mainly through the sclera, a small portion is taken up by the cornea to reach the aqueous humor. ${ }^{17}$ The drug transfer from the tears into the epithelium, is not directy visible in the concentration-time curves. This value was derived using $k_{10}$, and the drug-concentrations at $t=0$ for both the tears and the epithelium, according to function [2] of the Appendix, and yielded $0.034 \pm 0.06 \mathrm{~min}^{-1}$, indicating that dorzolamide is easily taken up by the corneal epithelium, with an absorption coeficient of $\sim 10.2 \cdot 10^{-3} \mathrm{~cm} / \mathrm{hr}$. The latter half of the sccond apparent decay rate is contributed to the transfer of drug out of the epithelium, defined as $k_{23}$, which was $0.0047 \pm 0.0004 \mathrm{~min}^{-1}$, yelding an epithelial permeability of $-1.4 \cdot 10^{-3} \mathrm{~cm} / \mathrm{hr}$. This is comparable to the epithelial permeabilities for dexamcthasone, pilocarpine, and timolol, ${ }^{14}$ but significantly better than previously reported values for transcomeal absorption of other topically active carbonic anhydrase inhibitors. ${ }^{18}$ Data taken from a previous study shows that the concentration change of Trusopt in the whole conea occurs at a rate of $\sim 0.005 \mathrm{~min}^{-1}$. ${ }^{13}$ This is comparable to the value found in our study for $\mathrm{k}_{23}$. Since transport of a drug through the whole comea is governed by the slowest transport rate, the transport of dorzolamide from the epithelium into the stroma can now be identifed as the limiting factor for drug transport of dorzolamide through the comea. This finding suggests that the posterior site of the comeal epithelinm is more obstructing to drug transport than the anterior site, and thus that dotzolamide is relativaly more lipophilic than hydrophilic, because $k_{12}>k_{23}$. This could be an explanation of the alternate route of transport of dorzolamide through the sclera. For transport via the cornea it can be stated that for Trusopt, as previously stated for pilocarpine, the comeal epithelium acts both as a barrier for transport as well as a depot for sustaned release of this compound into the stroma, with an epithelium half-life time of $\sim 148$ minutes. ${ }^{19}$

Although all three determined phamacokmetic transfer rate constants seem to be realistic for this type of topical ocular drug, no further comparison can be made with the litenature although the reproducibility of our measurements are high. Apart from the mentioned study by Sugrue, no ocular pharmacokinetic rate constants are published for Trusopt $2 \% 13$ 
Apart from direct drug monitoring in the eye another interesting application of RS would be to assess more directly the drug-tissue interactions, like binding of a carbo-anhydrase inhibitor to its receptor, which has been possible with resonance RS using an ultra-violet light source, by correlating spectral line shifting with drug-receptor complex formation. ${ }^{2 / 2}$ Furthermore, since netabolites and the original drug would display differences in Raman signature, these metabolites could be detected, and with it the identificition of metabolic activity in the tissue of interest. Over time and at various positions within the comea, the Raman shift position of dorzolamide did not change significantly, suggesting that either our technique is not sensitive enough for these kinds of assessments or that no drug-tissue interaction or metabolic activity is taking place. In the light of previous phamacological studies, we have to assume that the sensitivity of our technique is not adequate.

Since Raman scattering is inherently weak the sensitivity of the Raman scattering will be determined by the amount of light energy, the wavelength used (the shorter the wavelength the higher the Raman scattering), the sensitivity of the detector, and the Raman cross-section of the molecular vibrations to be studied (stronger bonds exhibit a higher Raman scattering). In this study, we compromised between sensitivity and safety and opted for an Argon laser at a relatively high power setting of $50 \mathrm{~mW}$ and long exposure times $(60 \mathrm{sec}$ ). Future clinical application using laser scanning confocal Raman spectroscopy as a diagnostic tool has to be preceded by significant improvements in the safety. With the introduction of more sensitive detectors preferably in the infra-red spectrum these apparent disadvantages will definitely decrease, as the exposure times can be decreased, and longer, less damaging wavelengths can be chosen, increasing the (clinicall) applicability and safety of CRS for possible use in the human situation. ${ }^{21}$ Furthemore, a more sensitive analysis technique could be used to extract more useful information from the individual Raman spectra. This could be performed using the so-called Partial Least Squares technique, currently being developed in our lab for purpose of pharmacokinetic measurements.

The fact that the drug in question should have a detectable Rannan signal poses another disadvantage. However, in the light of the potential use of this technique it would theoretically be possible to label drugg with a specinc Ramin active compound, or design drugs with an incorporared Raman active bond.22 Thus, the mentioned disadvantages are not absolute per se. We have shown in this study that the non-contact optical technique of CRS is a powerful biochemical analytical tool, which tas the potential to be applied for pharmacokinetic measurements.

In conclusion, we believe that this study has shown that the potential of a novel non-contact technique based on Raman spectroscopy could be utilized 
for the study of ocular phamacokinetics, allowing for continuous assessment of the concentration of a topical eye drug at different regions within the comea under in wiv conditions. CRS has inherent beneficial characteristics potentially applicable to study drug-tissue interactions, whether it be adverse effects on the tissue in question. metabolic processes, or monitoring direct drug-receptor binding.

\section{Acknowledgments}

This work was sponsored in part by a Research to Prevent Blindness unestricted grant, and a grant from the Department of Encrgy (DOE FG03m 95ER61971).

\section{References}

1. Uterman D., Matz, K., Meyer, K. Gentamicinspiegel in Kammerwasser des Menschen nach parenteralen, subkonjunktivaler und lokaler Applikation. Khn. Monatsbl. Augenhilk, 171:579, 1977.

2. Donnenfeld E.D., Perry, H.D., Snyder, R.W., Moadel, K., Elsky, M., Jones, H. Intracomeal, Aqcous Humor, and Vitreous Humor Penetration of Topical and Onal Otoxacin. Ardr. Ophhatmol, 115:173-176, 1997.

3. Untt A., Salminen, A. Anmal Pharmacokinetic Studies. In Ophthalmic Drug Delivery Systems, Mitra A.K. ed., Mareel Dekker, Inc, New York, 1993, p$121-136$.

4. Schoenwald R.D. Ocular drug delivery: Pharmacokinetic considerations. Clis. Phamtocokinef., 18(4):255-269, 1990 .

5. Brubaker R.F., Matuice, D.M. Mclaren, J.W. FLuorometry of the Anterior Segnent. In Noninvasive Diagnostic Techniques in Ophthalmology, Masters B.R. od. Springer-Verlag, New York, 1990, p. 248-280.

6. Egan C.A., Hodge, D.O., Mclaren, J.W., Boume, W.M. Effect of Donzolanide on Corneal Endothetial Function in Normal Human Eyes. Mnest. Ophrhalmol Kis. Sa, $39(1) 23-29,1998$.

7. Adler C.A., Matrice, D.M., Paterson, T.M. The effect of viscosity of the vehicle on the penatration of lluorescein into the human eye Exp. Eye. Res., 11:34, 1971.

8. Lee V.H.L., Robinson, J.R. Review; Topical Ocular Drug Delivery: Recent Developments and Future Challenges. J. Oc. Pham, 2(1):67-108, 1986.

10. Dai S., Qi, L., Bai, C., Ni, T, and Deng, X. Laser Raman spectroscopy study on experimental galactose-induced cataract. Yon Ko Hswch Pao [Eye Science], $11(3): 143-146,1995$. 
11. Bater N.J.C., Wicksted, J.P., Jongma, F.H.M., March, W.F., Hendrikse, F., and Motamedi, M. Non-Invasive Assessment of the Hydration Gradient Across the Comea using Confocal Raman Spectoscopy. Inwert. Ophrmalmol. Th. Sci. 39(4):831-835, 1998 .

12. Erckens R.J., Wicksted, J.P., March, W.F., and Motamedi, M. Raman Spectroscopy for Non-Invasive Characterzation of Ocular Tissue: Potential for Detection of Biological Molecules. J. Ram. Spertor., 28:293-299, 1997.

13. Jongsma F.H.M., Erckens, R.J., Wicksted, J.P., Bater, N.J C. Hendrikse, F., March, W.F., and Motamedi, M. Confocal Ramm Spectroscopy System for Non-Contact Scaming of Ocular Tissues: an in vitro scudy. Ophical Engincering; $36(11): 3193-3199,1997$.

14. Sugrue M.F. The Preclinical Plarmacology of Dorzolanide Hydroduloride, a Topical Carbonic Anhydrase Inhibitor [review]. J. Oc. Phamt. Ther, 12(3): 363$376,1996$.

15. Mishima S. Clinical Pharmacokinetics of the Eye: Proctor Lecture. Inwor. Ophlmalmol. Vis. Sa, 21:504-541, 1981.

16. Nagataki S., Mishima, S. Phamacokinatics of Instilled Drugs in the Human Eye. Int. Ophthalmol. Clinic, 20(3):33-49, 1980.

17. Schoenwald R.D. Ocular pharmacokinetics/Pharmacodynamics. In Ophthatmic Drug Delivery Systems, Mitra A.K. ed Marcel Dekker, Inc. New York, 1993, p. $83-110$.

18. Schoenwald R.D. "Deshpande, G.S., Rethwisch, D.G. Barfknecht, C.F. Penertation into the anterior chamber via the conjunctival/scleral pathway. J. Ocalar Phamacol, 13:41-59, 1997.

19. Sharir M., Pierce Jr., W.M., Chen, D., Zimmeman, T.J. Phammacokinetics, adic-base balance and intracular pressure effects of ethyloxaloylasolamide-A novel topically active carbonic anhydrase inhibitor. Exp. Exo Res, 58(1):107-116, 1994.

20. Sieg J.W., Robinson. J.R. Mechanistic studies on transcomeal permeation of pilocarpine. J. Pham Sa, 65:1816-1822, 1976

21. Kumar K., and Carey, P.R. The Resonance Raman Specta and Exciation Profiles of some 4-sulfanylazobenzenes. Can f. Chem, 55:1444-1453, 1977

22. Baraga J.J. Feld, M.S., Rava, R.P. Rapid Near-mnfared Ramm Spectroscopy of Human Tissue with a Spectrograph and CCD dacector. Appl Spratrosc., $46(2): 187-190,1992$.

23. Sijtsena N.M., Duindam J.J., Puppels, G.J., Otto, C., and Creve, J. Jnaging with Extrinsic Raman Labels. Appl. Spetrosic, 50(5):545-551, 1996.

24. Cavanagh H.D., Petroll. W.M., and Jester, J.V. Confocal Microscopy: Uses in Measurement of Cellular Structure and Function. In Progress in Retinal and Eye Reseandh, Elsevier Science Ltd., London, 1995, p. 527-565. 


\section{Appendix}

The diagram below shows the pharmacokinetic model that was used in the present studly:

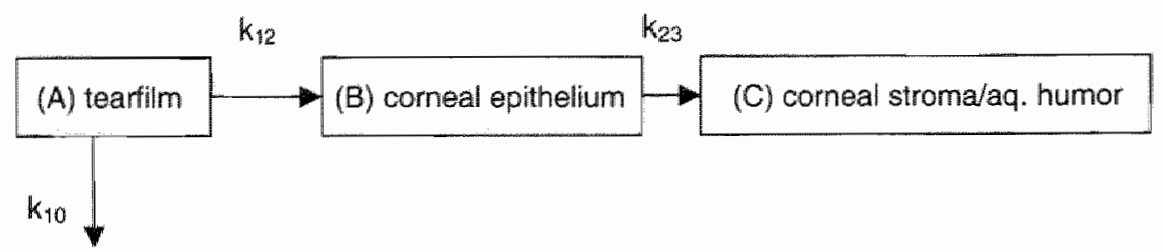

A confocal Raman spectroscopic technique was used to assess the changes in drug concentration in the pre-corncal tears and corneal epithelium of the rabbit comed in wisa. The site of focus (with an axial length of $110 \mu \mathrm{m}$ ) includes the tearfilm $(\sim 41-46 \mu \mathrm{m})^{23}$, and comeal epithelium $(\sim 40 \mu \mathrm{m})$, but not the comeal stroma/aqueous humor, and is constantly kept at the interface between the two layers. A three compartment model is adopted, to best describe the transfer of drug from the site of focus (see Scheme above). ${ }^{4,14,16}$ The first compartment is (A) the tearfilm, the second is (B) the corneal epithelium, and the third is the (C) comeal stroma/aqueous humor. Thus, the change in drug concentration as a function of time cau be described with three pharmacokinetic transfer rate constants, describing the non-productive losses from the tearfilm $\left(k_{10}\right)$, the transfer of drug from the tears into the epithelium $\left(k_{12}\right)$, and the transfer of drug from the epithelium into the pharmacokinetically equivalent compartment of the comeal stroma and aqueous humor $\left(\mathrm{k}_{23}\right)$. These compartments are equal because the thin lipophilic endothelium seems to play an insignificant role for the comeal permeability of hydrophilic ocular drugs. The early part $(<10 \mathrm{~min}$.) of the concentration-time curve only describes the non-productive losses of drug from the tears $k_{10}$, and not the transfer of drugs from tears into the epithelium $k_{12}$, since the later has no net effect on the Raman intensity of the drug-specific signal, because both layers are assessed simultaneously with our methods. Thus, $\mathrm{k}_{12}$ cannot be determined directly, but can be derived however (see below). 
Assuming first-order kinetics, $\mathrm{k}_{10}$ can be calculated by fitting a single exponential, according to [1] to this part of the concentration-time curve,

$$
\mathrm{C}(\mathrm{t})=\mathrm{C}(0) \mathrm{e}^{-k t} \text {, (in counts-per-second, CPS) }
$$

with $\mathrm{C}(0)$ being the tearfilm drug-concentration at $\mathrm{t}=0$, and $k$ being the numerical value for $\mathrm{k}_{10}$ (in $\mathrm{min}^{-1}$ ).

The constant $\mathrm{k}_{23}$ is calculated by fitting a single exponential according to [1] to the terminal $\log$-linear phase of the concentration-time curve; with $\mathrm{C}(0)$ being the extrapolated drug-concentration in the epithelium at $t=0$, and $k$ being the numerical value for $k_{23}$.

The transfer constant $\mathrm{k}_{12}$ can not be measured directly, as said before. However, both intercepts $\mathrm{C}(0)$ and $\mathrm{k}_{10}$ can be used to derive $\mathrm{k}_{12}$, since

$$
\mathrm{k}_{12}=\mathrm{k}_{10} \cdot\left[\mathrm{C}(0)_{\text {epi }} / \mathrm{C}(0)_{\text {tear }}\right],\left(\text { in } \min ^{-1}\right) \text {; Rer. (14) }
$$

Other pharmacokinetic variables which can be derived for the tissue of interest using $k_{10}, k_{12}$, and $k_{23}$ are (Ref. 14):

- the half-life times of the drug in each compartment,

$$
\mathrm{t}_{1 / 2}=\ln (2) / k,(\text { in } \mathrm{min})
$$

with $k$ being any of the three transfer rate constants.

- the time to peak in the comeal epithelium,

$$
\mathrm{TP}_{\mathrm{epi}}=\ln \left(\mathrm{k}_{10} / \mathrm{k}_{23}\right) /\left(\mathrm{k}_{16}-\mathrm{k}_{23}\right) \text {, (in min) }
$$

- the permeability of the epithelial barrier.

$$
K_{\text {epi }}=\left(k_{23} \cdot V / Q\right)=\left(k_{23} \cdot T\right),(\text { in } \mathrm{cm} / \mathrm{min})
$$

with $\mathrm{V}, \mathrm{Q}$, and $\mathrm{T}$ the volume, the surface area, and the average thickness $\left(=5 \cdot 10^{-3} \mathrm{~cm}\right)$ of the epithelial layer, respectively,

- and, the fraction absorbed into the comea,

$$
F=\left(1-\left[k_{10} /\left(k_{10}+k_{23}\right) \mid\right) \cdot 100 \%=\left|k_{23} /\left(k_{23}+k_{10}\right)\right| \cdot 100 \% \text { (in \% } \% \text {. }|6|\right.
$$


CHAPTER 8

Remote temperature measurements in the eye using confocal Raman spectroscopy

Noël JC Bauer, Wayne F March, Fred Hendrikse, Massoud Motamedi 


\section{A B STRACT}

Aim: The application of a suitable technique for remote temperature measurements in biological tissues could be of significance in monitoring its physiological state. For example, temperature measurements in the eye could yield the monitoring of various causes of ocular hyperthermia (inflammation, or induced by laser or ultrasound). We sought to determine the feasibility of Raman spectroscopy (RS) for remote temperature measurements within the aqueous humor of the rabbit eye in vivo.

Methods: Using a Confocal Raman Spectroscopy (CR5) system (250 mJ argon light at $51.4 .5 \mathrm{~nm}$ ) high signal-to-noise ratio Raman spectra from $2580-3800 \mathrm{~cm}^{-1}$ were recorded in HPLC-grade water (13-48 ${ }^{\circ} \mathrm{C}$; calibrated thermocouple) and the aqueous humor of the rabbit eye under in wivo and ex vivo conditions (14-34 ${ }^{\circ} \mathrm{C}$; calibrated intra-ocular thermocouple).

Results: The ratio between the integrated Raman intensities of two temperature dependent $\mathrm{OH}$-vibrational regions $(\mathrm{OH} 2 / \mathrm{OH} 1)$ in the spectra of water showed high linearity with the prevailing temperature ( $T$ $\left.{ }^{\circ} \mathrm{C}\right)$, both in pure water $\left(0.0049( \pm 1.2 \%) T+0.4522( \pm 0.5 \%), \mathbb{R}^{2}=0.99\right.$. $\mathrm{n}=50, \mathrm{p}<0.05)$ as well as in the rabbit aqueous humor $(0.0036( \pm 2.8 \%)$ $\left.T+0.4966( \pm 0.6 \%), R^{2}=0.98, n=162, p<0.05\right)$ with a high degree of reproducibility and sensitivity $\left(\sim 0.2 \sim 0.7^{\circ} \mathrm{C}\right)$.

Conclusion: Raman spectroscopy can be used for sensitive temperature assessments in the aqueous humor of the rabbit eye under in vivo conditions. 


\section{Introduction}

Raman spectroscopy (RS) is a powerful optical technique for the biochemical characterization of biological media. ' Furthermore RS can also be applied for temperature assessments, since $\mathbb{R}$ aman scattering is per definition a temperature dependent process. A well established method for thermometry using $\mathbb{R} S$ entails the assessment of the Stokes/anti-Stokes Raman intensity ratio. ${ }^{2}$ Because the anti-Stokes lines are usually extrenely weak at physiological temperatures the applicability of this method in living biological tissues is limited. Another previously reported method consists of assessing the temperature-dependent changes in the shape of the Raman spectrum of water, ${ }^{3,4}$ and has been applied for the remote temperature assessments of sub-surface ocean-waters ${ }^{5}$ and biological tissues. ${ }^{6}$ The latter could have significant applications in biology and medicine, since most biological tissues are embedded in water.

The focus of our research is mainly aimed at the application of RS in ocular tissues. Thus, we have investigated the feasibility of RS for temperature measurements in the eye. This is of clinical significance because it could possibly yield the evaluation of the temperature reducing effect of ophthalmic anti-inflammatory drugs,, 7.8 and the monitoring of therapeutic interventions involving potentially hazardous increases in intra-ocular temperature. The latter could be an issue during phaco-emulsification of the ocular lens, "laser photo-refractive surgery of the cornea, ${ }^{10}$ or localized heating of the eye during chemotherapy of intra-ocular tumors. ${ }^{11}$ In addition, currently used steady-state temperature or heat-transfer models of the eye could be validated through the accurate determination of local variations in temperature within the eye. 1,12 However, no suitable technique is available for these kinds of assessments. Invasive methods such as using thermocouples are generally too intrusive for application in the eye and are unpractical for spatially resolved tenperature measurcments. The non-invasive detection of infra-red radiation from the cye does usually not permit direct intra-ocular temperature assessments, because of the strong water absorption of this kind of radiation. This technique has been used in the past though to measure comeal temperature as a predictor for the pharndcological potential of ocular anti-inflammatory drugs.

We previously reported on a non-contact confocal Raman spectroscopy (CRS) system specifically designed for the rapid and sensitive characterization of biochemical properties of ocular tissues in wivo. ${ }^{13}$ Apart from the application of CRS for pharmacokinetic measurements in the eye, ${ }^{14}$ we assessed the spatial and temporal distribution of comeal hydration in anesthetized rabbits. ${ }^{15}$ Furthermore, we successfully recorded the first in vivo Raman spectra of human comeas and were able to detect changes in corneal hydration due to the application of a topical dehydrating agent. ${ }^{16}$ 
The non-contact character of the CRS technique and the ability to assess small volumes of material could also yield the possibility to apply this technique for remote temperature measurements within the eye. Thus, with this project we sought to determine the feasibility of CRS for temperature measurements in aqueous solutions and the aqueous humor of the rabbit eye under in tivo circumstances.

\section{Materials and Methods}

We used a non-contact confocal Raman spectroscopy (CRS) system, of which a detailed description and the overall performance have been described elsewhere $^{13}$, for Raman spectroscopic assessments of aqueous solutions and aqueous humor of tabbit eyes under in vivo and in vitro circumstances at various temperatures. For calibration purposes HPLC-grade water was heated to $\sim 50^{\circ} \mathrm{C}$, transferred to a quartz cuverte and left to cool to $\sim 30^{\circ} \mathrm{C}$ while monitoring the temperature with a calibrated themocouple as the standard. Raman spectra in the Raman shift range from 2580 to $3780 \mathrm{~cm}^{-1}$ were recorded at regular intervals using $25 \mathrm{~mW}$ of Argon-laser light and exposure times of $10 \mathrm{~s}$.

In addition we tested if the Raman spectral features of water would change due to the applied laser energy. Consequently, Raman spectra were recorded in HPLC-grade water at a constant temperature of $\sim 23^{\circ} \mathrm{C}$ at irradiation powers ranging from 5 to $150 \mathrm{~mW}$ and exposure times ranging from 1 to $120 \mathrm{~s}$.

Under an Institutional Review Board approved animal protocol that complied with the ARVO Resolution on the Use of Animals in Research, the animal studies were performed on 16 eyes of in total $9 \mathrm{NZW}$ rabbits $(-3.5 \mathrm{~kg})$. Prior to Raman spectroscopic assessments the rabbits were anesthetized with Ketamine and Xylazine and were restrained in a holder to reduce movement artifacts. For reference temperature measurements we used either a rectal thermoprobe alone $(n=13$ eyes), or in conjunction with a needle-themocouple $(\mathrm{n}=3$ eyes) which was positioned in the aqueous humor of the eye. In order to obtain a wide range of intra-ocullar temperatures, the aqueous humor of the rabbit cyes were probed in wivo at different core-temperatures with or without applying additional whole body heating with a heating pad $\left(-40-41^{\circ} \mathrm{C}\right)$, after euthanasia with the eye cooling down in-situ, and during warming up of a cold-stored $\left(15^{\circ} \mathrm{C}\right.$; $1 \mathrm{hr}$.) enucleated eye in vitro. All experiments were performed at room temperatures of $\sim 20^{\circ} \mathrm{C}$.

Initially, the Raman spectra of HPLC-grade water were analyzed qualitarively, in order to find temperature dependent Raman spectral features. Consequently, the most valid, sensitive, and reproducible Raman spectral feature was 
utilized to predict the temperature in aqueous solutions and the aqueous humor of the rabbit eyes.

\section{Results}

Figure 1A shows typical Raman spectra in the range from 2580 to 3780 $\mathrm{cm}^{-1}$ of HPLC-grade water at various temperatures. It can be seen that the Raman spectral features of water change as a function of temperature, since the regions from $\sim 3000-3400$ and $-3500-3650 \mathrm{~cm}^{-1}$ show marked differences in intensity and shape with changing temperature. However, these changes are rather subtle and can be visualized more clealy when plotting the change in Raman intensity per degree change in temperature ( $\Delta \mathrm{N} / \Delta \mathrm{T})$ as a function of the Raman shift, as depicted in Figure $1 \mathrm{~B}$. With increasing temperature, the region labeled $\mathrm{OH} 1\left(2878-3430 \mathrm{~cm}^{-1}\right)$ decreases in intensity while the region $\mathrm{OH}_{2}$ $\left(3430-3729 \mathrm{~cm}^{-1}\right)$ increases in intensity. These changes are in the order of $0.5 \%$ of the maximum photon counts at $\sim 3190$ and $3550 \mathrm{~cm}^{-1}$ per ${ }^{\circ} \mathrm{C}$ change in temperature. The occurrence of an isoskedastic point at $\sim 3430 \mathrm{~cm}^{-1}$ comesponds well with the literature. ${ }^{17}$ Both data taken from the HPLC-water in vim and the rabbit aqueous humor in wro yield comparable results, as can be seen from the dashed and sollid curves in Figure 1B, respectively, suggesting a consistency under both circumstances in the relationship between the changes in the Raman spectral features of water and the tempetature.

In order to find the most suitable Raman spectroscopic predictor (RP) for the temperature in an aqueous sample, eight $R$ aman spectroscopic features were tested for their reproducibility, sensitivity, and validity, by evaluating the relationship $R P=A\left( \pm S E_{A}\right) T+B\left( \pm S E_{B}\right)$, where $A$ and $B$ were respectively the slope and the intercept of the curve-fit between water temperature (T in " $C$ ) and the Raman spectroscopic predictor. The standard errors $S E$ and $S E_{13}$ were used as a measure for the reproducibility, while the correlation coefficient $R^{2}$ could $b$. used as aneasure for the accuracy. The results are described in Tablo 1. As can be seen, the best predictor for water temperature using Raman spectal information was the integrated Raman intensity ratio $1 R(3430-3729) / \mathrm{IR}(2878-3430)$ with the lowest $S E_{A}$ and $S E_{B}$, and the highest $R^{2}$. The relationship beweon this predictor $(\mathrm{OH} 2 / \mathrm{OH} 1$ ) and the water cemperature of $\mathrm{HPLC}$-gade water (T) from $30-46^{\circ} \mathrm{C}$ is depicted in Figure 2. In formula: $0 \mathrm{H}_{2} / \mathrm{OH}=0.0049$ $( \pm 1.2 \%) \mathrm{T}+0.4522\left( \pm 0.5 \%, \mathrm{R}^{2}=0.99, \mathrm{n}=50, \mathrm{p}<0.05\right.$. This particular ratio was used for the for the remainder of the experiments.

The influence of the laser beam on the Raman spectral features of water revealed no appreciable change in the integrated Raman intensity ratio $\mathrm{OH} 2 / \mathrm{OH} 1$ due to the applied laser power or exposure time. Analyzing similar 


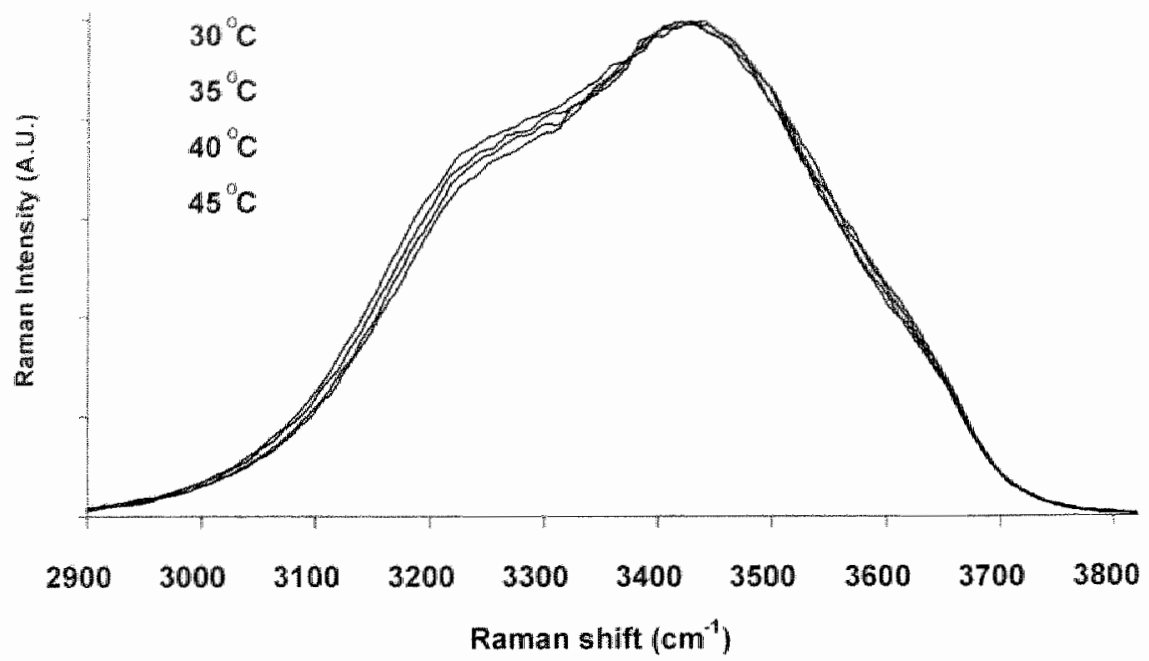

Figure 1A. Raman spectra of HPLC-grade water in quartz cuvette at difterent temperatures (calibrated themocouple)

138

है

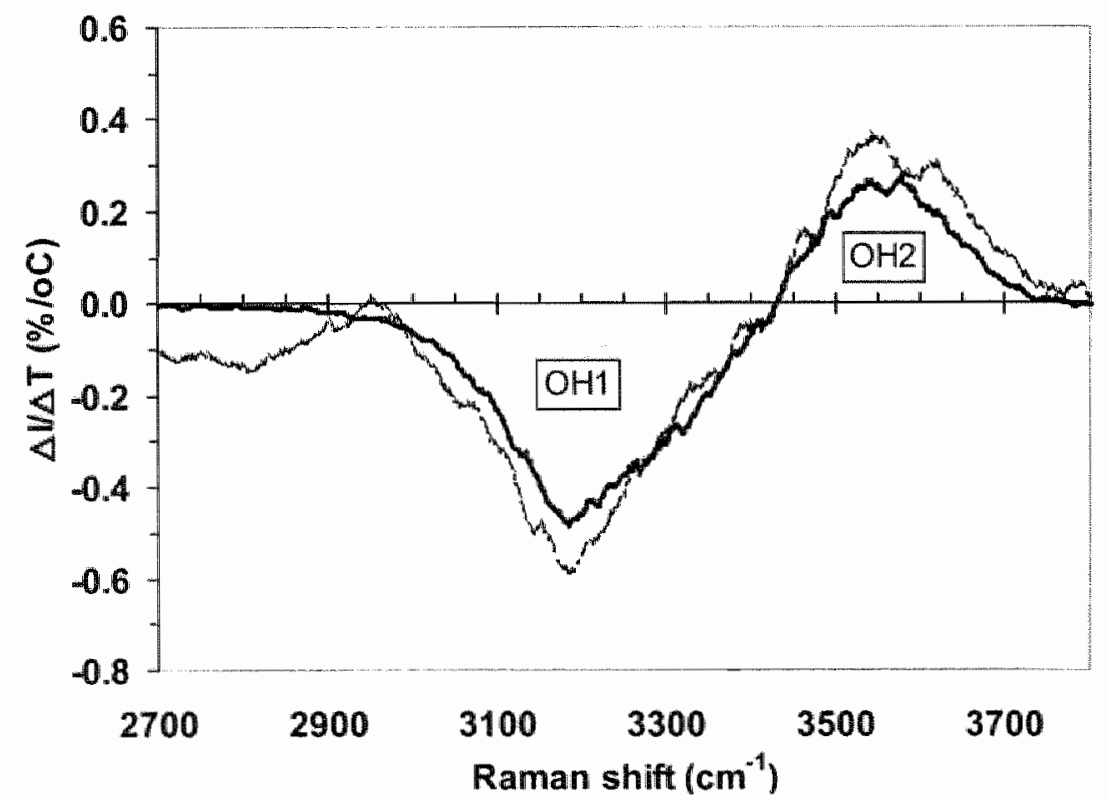

Figure $1 B$. Ratio of the change in Ranan intensity (AI) in the spectrum of water vs, the change in temperature $(\Delta T)$ as a function of Raman shift position within $H P L C$-grade water (bold line) and the rabbit aqueous humor (dashed line). 
Table 1. Raman spectroscopic predictors of water temperature. $R P=A\left( \pm S E_{j}\right) T+B\left( \pm S E_{i}\right)$; with $\mathrm{T}$ - waten temperature $(O C)$

\begin{tabular}{|c|c|c|c|c|c|}
\hline $\begin{array}{l}\text { Raman spectroscopic } \\
\text { predictor }(\mathrm{RP})^{*}\end{array}$ & A & $\mathrm{SE}_{\mathrm{a}}(\%)$ & $B$ & $\mathrm{SE}_{6}(\%)$ & $R^{2}$ \\
\hline $1(3184)$ & 0.47 & $0.01(25)$ & 74 & $0.45(0.6)$ & 0.9720 \\
\hline$I(3558)$ & 0.25 & $0.01(50)$ & 47 & $0.48(1.0)$ & 0.3916 \\
\hline$I(3558) / 1(3184)$ & 0.014 & $0.0003(1.9)$ & 0.53 & $0.01(19)$ & $0,98 x$ \\
\hline $\operatorname{IR}(2878-3430)$ & -96 & $3.0(3,1)$ & 25170 & $118(0.5)$ & 0.9551 \\
\hline $\operatorname{IR}(3430-3729)$ & 43 & $1.7(3.9)$ & 12075 & $65(0.5)$ & 0.9311 \\
\hline $\begin{array}{l}\operatorname{IR}(3430-3729) / \\
\operatorname{IR}(2878-3430)\end{array}$ & 0.0049 & $6 \mathrm{E}-5(1.2)$ & 0.4522 & $0.0023(0.5)$ & 0.9928 \\
\hline $1(3558)-1(3184)$ & 0.72 & $0.014(1.9)$ & 25 & $0.5(21)$ & 0.9825 \\
\hline $\begin{array}{l}\operatorname{IR}(3430-3729) \\
\operatorname{IR}(2878-3430)\end{array}$ & 140 & $21(1.5)$ & 13100 & $84(0.6)$ & 0.9887 \\
\hline
\end{tabular}

" $\mathrm{I}=$ Raman peak intensity; $\mathrm{IR}=$ integrated Ramam intensity.

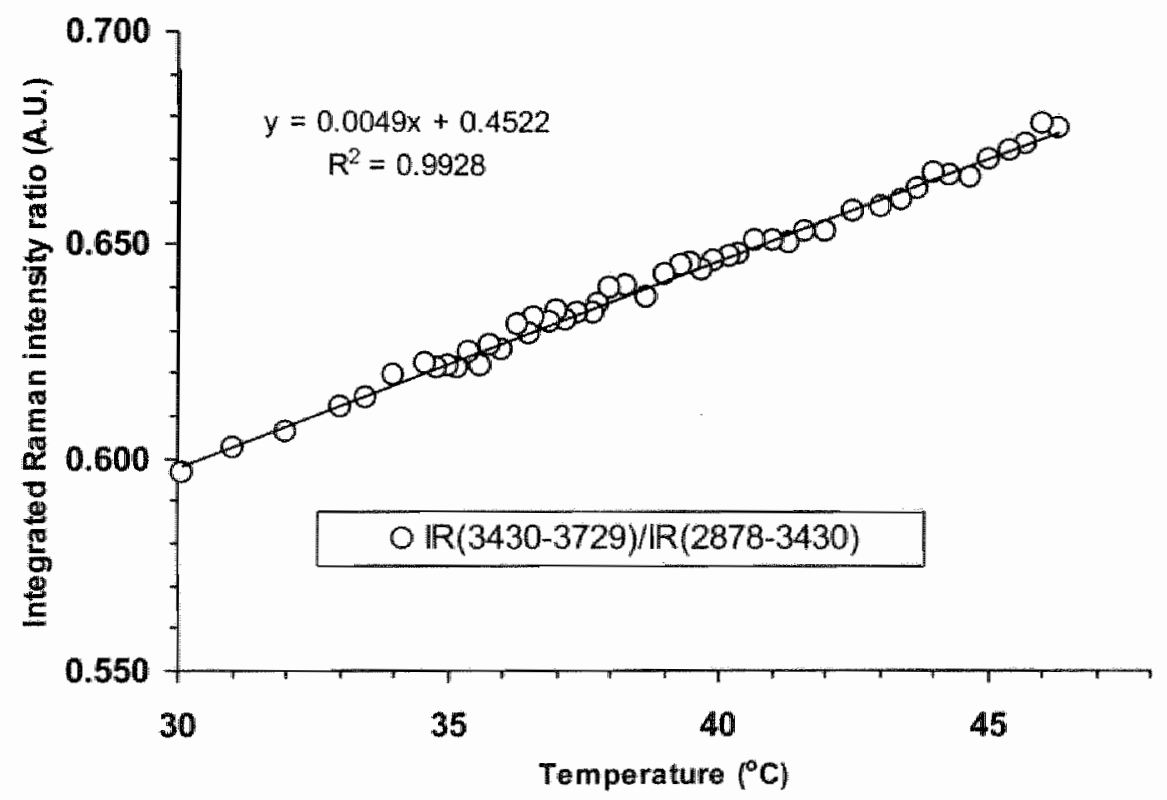

Figure 2. Integrated Raman intersity ratio of OH-peak regions $2878-3430$ and $3430-3729$ $\mathrm{cm}^{-1}$ as a function of water temperature. 


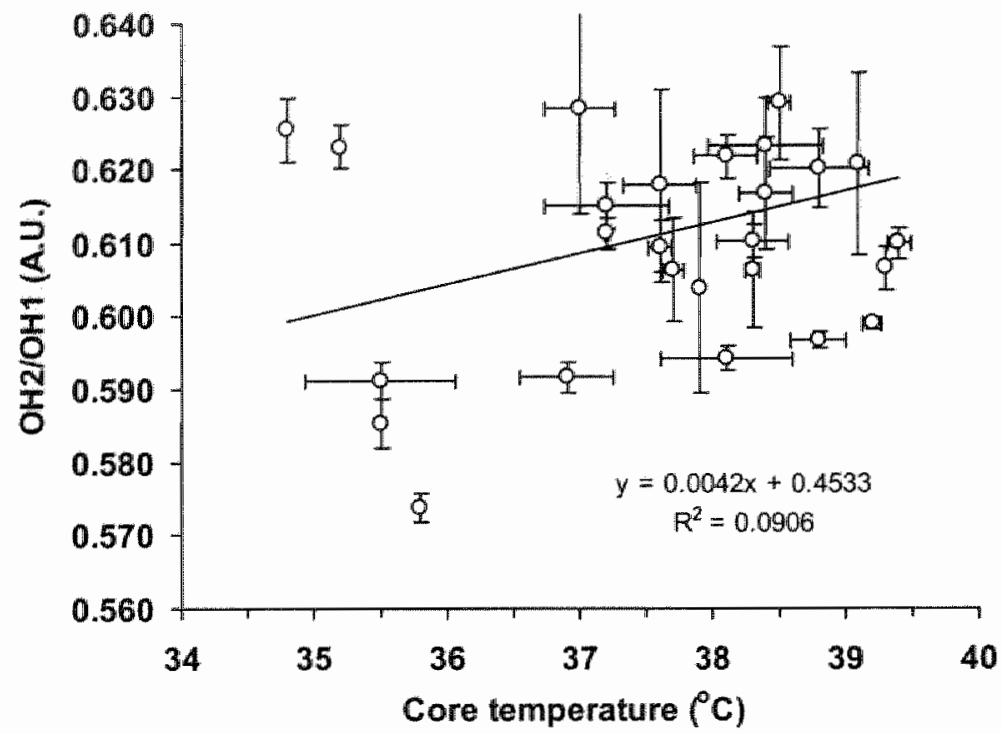

Figure 3. Relationship berween Raman intensity ratio $\mathrm{OH} 2 / \mathrm{OH} 1$ in the aqueous humor ( $\mathrm{n}=358$ assessments) and the core temperature of the rabbit $(n=16 \mathrm{eycs})$.

signal-to-noise ratio spectra of HPLC-grade water at $\sim 23^{\circ} \mathrm{C}$ showed a ratio $\mathrm{OH} 2 / \mathrm{OH} 1$ of $0.5670 \pm 0.0016$, corresponding to a calculated cemperature of $23.4 \pm 0.1 \% \mathrm{C}$ and a standard error of $\sim 0.3 \%$

In Figure 3 the results are shown on the assessment of the integrated Raman intensity ratio $\mathrm{OH} 2 / \mathrm{OH}$ in the aqueous humor of all eyes as a function of the rabbit core temperature. It can be seen that the retation core temperature vs. ratio $\mathrm{OH} 2 / \mathrm{OH}$ in the aqueous humor resembles the values found in the in witro water experiments with $\mathrm{OH} 2 / \mathrm{OH} 1=0.0042 \mathrm{~T}+0.4533 \approx 0.0049 \mathrm{~T}+0.4522$, although the correlation is rather weak $\left(\mathbb{R}^{2}=0.09\right)$.

The results on the non-contact Ramm spectroscopic assessment of the agueous humon temperature (range $14034^{\circ} \mathrm{C}$ ) using the intra-ocular thermocouple as a standard aro shown in Figure 4 . A strong linear relationship was found betwen the neasured aqueous humor temperature and the Raman intersity ratio $\mathrm{OH} 2 / \mathrm{OH} 1$, with $\mathrm{OH} 2 / \mathrm{OH} 1=0.0036( \pm 0.0001) \mathrm{T}+0.4966$ $( \pm 0.0030)\left(R^{2}=0.9763, n=162\right)$. The slope of this relationship differed slightly from the results obtaned from the in pirro water experiments. However, the in wipo assessments agreed well with the HPLC-grade experiment (dashed line in Figure 4). In anesthetized rabbits at a steady-state core temperature of $38.9 \pm 0.70 \mathrm{C}$, the measured aqueous humor temperature was $33.5 \pm 0.2^{\circ} \mathrm{C}$. 


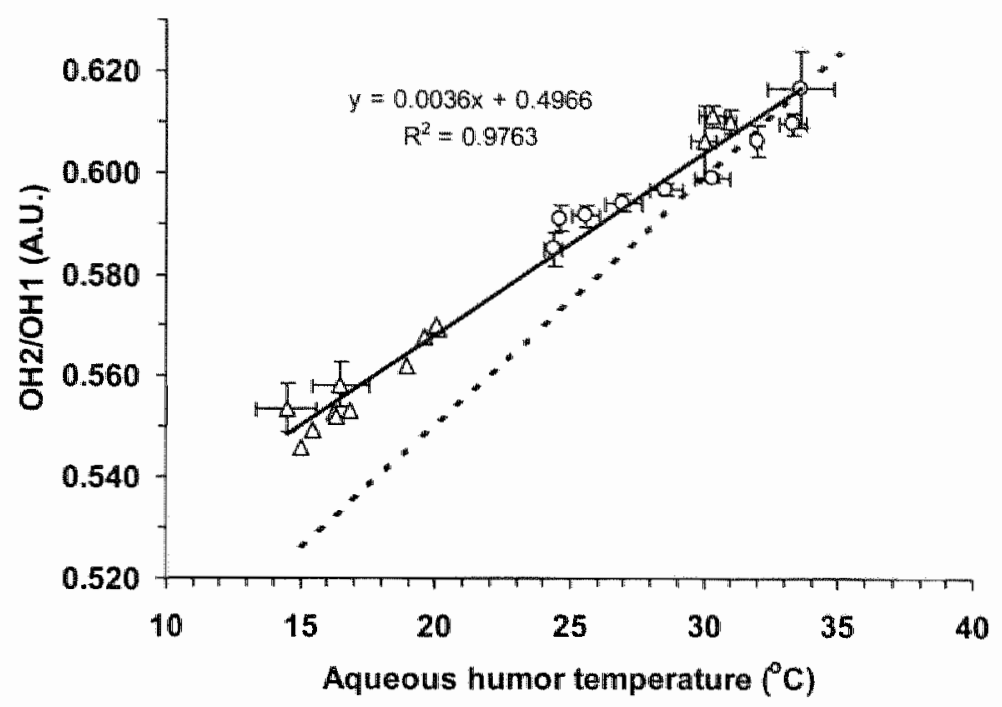

Figure 4. Relationship between the Raman intensity ratio $\mathrm{OH} / \mathrm{OH}$ $(n=162)$ and the aqueous humor tenperature of rabbit eye A (squares: in whro

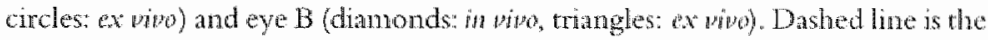
similar relationship in HPLC-grade water in nitro (see Fig. 2).

Non-contact Raman spectroscopic assessment of the aqueous humor revealed an integrated Raman intensity ratio $\mathrm{OH} 2 / \mathrm{OH} 1$ of $0.613 \pm 0.005$ ( $\mathrm{n}=65$ assessments), corresponding to a calculated temperature of $32.8 \pm 0.3^{\circ} \mathrm{C}$ (using the HPLC-grade water data for calibration). No statistical significant difference between the measured and the calculated intraocular temperature could be assessed. In comparison, in anesthetized rabbits without the intracoular thermoprobe at a steady-state core-temperature of $37.9 \pm 0.6{ }^{\circ} \mathrm{C}$, an integrated Raman intensity matio OH2/OH1 of $0.617 \pm 0.009$ was found $(n=199$ assessments), corresponding to a calculated temperature of $33.6 \pm 0.13$ utilizing the HPLC-grade water finds for calibration.

\section{Discussion}

We have used confocal Raman spectroscopy (CRS) to determine the temperature-dependent changes in the Raman spectra of aqueous solutions and the aqueous humor of the rabbit eye at various temperatures in order to test the feasibility of CRS to assess the intra-ocular temperature. 
A highly linear relationship was found between the Raman intensity ratio $\mathrm{OH} 2 / \mathrm{OH} 1$ and the temperature of the aqueous humor of rabbit eyes over a temperature tange of 14 to $34^{\circ} \mathrm{C}$ with a high degree of reproducibility as neasured by the standard error of the slope of this relationship of $\sim 1.2 \%$. The sensitivity of the proposed thermometric application of CRS is solely a characteristic of the signal-to-noise ratio of the recorded spectra and is determined by the incident light energy used and the shot noise of the CCD camera. The aforementioned standard error corresponds to a standard deviation of $\sim 8 \%$. Thus, a difference in integrated Raman intensity ratio of $\sim 16 \%$ corresponding to a temperature difference of $\sim 0.2^{\circ} \mathrm{C}$ is easily resolved at the experimental conditions used in this study. In the in wivo studies a sensitivity of $\sim 0.7^{\circ} \mathrm{C}$ was calculated. It seems that our method is more sensitive than previously reported

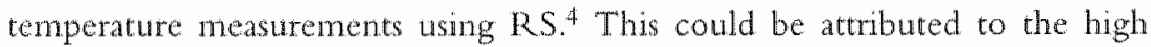
signal-to-noise ratio Raman spectra which we can obtain with our confocal system, but more importantly the fact that the whole Raman spectral characteristics of water can be recorded in one spectrum.

A slight difference in the Raman intensity ratio $\mathrm{OH} 2 / \mathrm{OH} 1$ ws. temperature relationship was observed between the animal and the HPLC-grade water experiments, although both relationships were highly linear. Since the in wivo animal results agreed favorably with the HPLC-grade water experiments, additional variables in the in pitro situation besides the temperature could have influenced the changes in the shape of the Raman spectrum of water. The occurrence of the applied euthanasia agent in the aqueous humor and the fact that the blood-aqueous barrier breaks down after euthanasia of the rabbits with a consequent leakage of proteins into the aqueous humor, could possibly have resulted in the occurrence of interfering fluorescence or otherwise altered the background properties of the spectra, possibly explaining the difference in slope of the $\mathrm{OH} 2 / \mathrm{OH} 1$ ratio vs. temperature relationship between the in witro and in viso results. However, we did show that the proposed method was easily applicable in the in vivo situation, and only utilized ocular tissues in vifro to obtain a wide range of intra-ocular temperatures in cases where whole body heating in wino did not suffice. Thus we found that the intra-ocular aqueous humor temperature of anesthetized rabbits at steady-state core temperatures within the normal physiological range and a room-temperature of $20^{\circ} \mathrm{C}$ is $-33.5^{\circ} \mathrm{C}$ as assessed using non-contact confocal Raman spectroscopy.

In conclusion, the Raman spectrum of water is subject to changes as a result of changing temperatures. This implicates that care should be taken when comparing Raman spectra of biological tissues containing water, i.e. that either the temperature is kept constant or the Raman spectra are corrected for the temperature dependent changes. More importantly, since most biological tissues consist at least in part of water, confocal Raman spectroscopy might possibly be 
used to non-invasively assess the temperature of these tissues. This pilot study showed that confocal Raman spectroscopy can be applied for remote temperature measurements within the aqueous humor of the rabbit eye under in sivo circumstances with a high degree of sensitivity, specificity, and reproducibility.

\section{References}

1. Carey PR. Biochemical Applications of Raman and Resonance Ranan spectroscopies. In Horecker B, Kaplan NO, Marmur J, and Scheraga HA. Eds.,

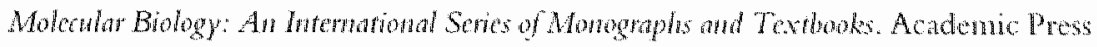
Inc., New York (1982).

2. Malyj M and Griffiths J.E. Stokes/Anti-Stokes Rman Vibrational Temperatures: Reference Materials, Standard Lamps, and Spectrophotometric Calibrations. Applicd Spectroscopy 37(4): 315-333 (1983).

3. Walrafen GE. J. Chem. Phys. 47: 114 (1967).

4. Veluning $R$ and Schweiger G. Optical Detemination of the Temperature of Transparent Microparticles. Applied Spectrosopyy 46(1): 25-27 (1992).

5. Leonard DA, Caputo B and Hoge FE. Remote sensing of subsurface water tenperature by Raman scattering. Applicd Optics 18(11): 1732-1745 (1979).

6. Baranska H and Labudzinska. Applicd Spectroscopy 41: 1068 (1987).

7. Fujishima H, Toda I, Yagi Y, and Tsubota K. Quantitative evaluation of postsurgical inflammation by infrared radiation thermometer and laser flare-cell meter. J Cataract Refract Surg 20: 451-454 (1994).

8. Tanaka M, Hasegawa T, Matsushita M, Miichi $H$, and Hayashi S. Quantitative Evaluation of Ocular Anti-Inflammatory Drugs Based on Measurements of Corneal Temperature in Rabbits: Dexamethason and Glycyrthizin. Ophthalmic Ressima 19: $213-220$ (1987).

9. Berger JW. Talamo JH, LaMarche KJ et al. Temperature measurenents during phacoemulsification and erbium:YAG laser phacoablation in model systenss. J Contrater Refruct Surg 22: 372-378 (1996).

10. Betney S, Morgan PB, Doyle SJ, and Efron N. Comeal Temperature Changes During Photorefractive Keratectomy. Connca 16(2): 158-161 (1997).

11. Lagendijk JJW. A mathematical model to calculare temperature distributions in human and rabbit eyes durng hyperthermic treatment. Prys. Med. Biol. 27(11): $1301-1311$ (1982).

12. Scott JA. A finite dement model of heat transport in the human eye. Mhys. Med. Biol. 33(2): 227-241 (1988).

13. Jongsma F.H.M., Erckens R.J., Wicksted J.P., Bater N.J.C., et al, Confocal Raman Spectroscopy System For Noncontact Scaming Of Ocular Tissues - an In Vitw Study. Optical Enginecring 36(11):3193-3199 (1997). 
14. Batur WJC, Motamedi M, Wicksted JP, March WE, Webers CAB, and Hendrikse F. Non-Invaswe Assessment of Ocular Phamacokinetics using Confocal Raman Spectoscopy. J Otular Pharm Ther 15(2): 123-134 (1999).

15. Bauer NJC, Wicksed JP, Jongsma FHM, March WF, Hendrikse F, and Motamedi M. Noninvasive Assessment of the Hydration Gradient Across the Comea Using Confocal Raman Spectroscopy. Inuest. Ophthalmol. Vus. Sa. 39(4):831-835 (1998).

16. Bauer NJC, Hendrikse F, and March WF. in vivo Confocal Raman Spectroscopy of the Human Comea. Comten 18: 483-488 (1999).

17. Walrafen GE, Hokmabadi MS and Wang WH. J Chem Phys 85: 6964 (1986).

18. Huringa A, Bot CC, de MulFFm, Vrensen GFJM, and Greve J. Local Variation in Absolute Water Content of Human and Rabbit Eye Lenses Measured by Raman Microspectroscopy. Exp Eye Res 48: 487-496 (1989).

19. Aliota F, Fontana MP. Maisano $\mathrm{G}$, Migliardo $\mathrm{P}$, and Wanderlingh F. Coexistence of structures in electrolytic solutions investigated by Raman scattering. Oprica Acta 27(7): $931-938$ (1980). 


\section{Summary and Conclusions}

Raman spectroscopy (RS) is a powerfull optical technique for biochenical assessments, based on the phenomenon that a fraction of the incident monochromatic light is scattered with a different frequency due to the interaction of light with matter, on the molecular vibrational level. A Raman spectrum depicts these frequency changes in the form of discrete and specific Raman lines. Each of these lines can be assigned to specific molecular bonds, and Raman spectroscopic analysis yields biochemical characterization of the sample in question, from simple molecules such as water to complex proteins, or tissues. Although RS has been applied in the past in various fields of biology and medicine, in vivo application of this technique in the field of ophthahnology has been limited. The aim of this thesis was to investigate the potential applications of RS for non-contact biochemical assessments of (intra)ocular tissues and thids of the intact eye under in vito circumstances, utilizing a novel confocal Raman spectroscopy system.

Chapter 1 hypothesizes that the successful in pino application of Raman spectroscopy in ophthalmology is of clinical significance since numerous ocular as well as systemic diseases and disorders express themselves through changes in the biochemical properties of ocular tissues and fluids, which could potentially be diagnosed and/or monitored applying the proposed technique. Against this background a general introduction into the theoretical, practical and optical aspects, including safety, of the application of Raman spectroscopy in ophthalmology is given, and the aim of this thesis is presented (see above).

Chapter 2 gives an in-depth description of the principles and practice of applied Raman spectroscopy in biology and medicine in gencral, and ophthalmology in specific. Furthermore, the characteristics of a suitable Raman spectroscopy system as a diagnostic tool for biochemical assessments in the eye under in vipo circunstances are outlined.

Chapter 3 presents the description and performance of the confocal Raman spectroscopy system which was applied in the studies contained in this thesis. The light source of this optical system is provided by an Argon laser or a Helium-Neon laser. A beam-expander yields a collimated beam of light with a diancter matching the back aperture of the focusing optics, which is a high numerical aperture (NA $=0.5)$ long working distance $(13 \mathrm{~mm})$ microscope objective lens (LDMO). This LDMO is used both for focusing the incident light onto the sample as well as collecting the backscattered light. A holographic type beam-splitter deflects only the Raman backscattered light towards a camera lens. which focuses the Raman light onto a fiber-optic. This fiber acts as the pinhole 
in this contocal alignment (sce Chapter 1, Figure 1), and transports the Raman light into spectrometer. where it is dispersed and consequently detected by a highly sensitue back-thinned CCD-detector, which digitizes this signal so that it can be stored in a computer and displayed on a screen. The key pertormance characteristics of this system are (1) its free working distance of $13 \mathrm{~mm}$, allowing non-contact assessment of the tear-fim, the comea, the aqueous humor the lens, and the vitreous humor; (2) its confocal alignment, yiclding optical sectioning capabilities of "optical" tissue slices as thin as $20 \mu \mathrm{m}$, while minimizing Whe detection of light from out-of-focus places in the same tissue or nearby other vissues, effectively increasing the sigual-to-noise ratio; (3) its sensitivity, through the highly efficient use of the LDMO, as well as the application of a sensitive CCD -detector; and (4) its adequate temporal resolution for rapid spectral acquisitions. Additionally, through telecentric alignment of the focusing optics the LDMO can be moved along its optical axis without changing its back focal distance, allowing dynamic probing of static objects. Applying this optical system. discrete and specific Raman spectra were obtaned from the comea, the aqueous humor and the lens, typically utilizing $25 \mathrm{~mW}$ of laser light at oxpostre times as short as $1 \mathrm{sec}$.

It is concluded that this confocal Raman spectroscopy system might offer a novel optical sectioning technique for rapid non-contact biochemical characterization of various (intra) ocular tissues.

Chapter 4 describes the general working area in ophthalmology for which the confocal Raman spectroscopy system is thought to be most suitable. Funthermore, this chapter provides an insight into our ongoing efforts of establishing potential applications of confocal Raman spectroscopy in ophthalmology. Apart from the projects described in more detail elsewhere in this thesis, some pilot studies are mentioned such as the detection of biomolecules in the aqueous humor (i.e. glucose and phenylanine), the assessment of biochemical changes in procured comeal buttons, and the biochemical characterization of a more or less common fibrovascular proliferative allment, i. a aterygum.

Chapter 5 presents the results on the application of confocal Raman spectroscopy for the assessment of the hydration gradient across the cornea in who. The confocal properties of the proposed technique yielded the optical sectioning capability by which biochemical assessments could be performed of tisste slices significanty smaller than the full thickness of the comea. Utilizing at specific Raman intensity ratio between two Raman spectral lines, the hydration was assessed of phantom media and rabbit comeas in win, with a high degree of sensitivity and reproducibility. The water content of rabbit comeas showed a significant increase from anterior to posterior, in line with our current understanding regarding the non-homogeneous distribution of coneal hydration. Furthermore, the characterization of the axial comeal hydration provided a reh- 
able estimation of total comeal hydration as compared with conventional measurements using pachymetry and lyophilization. We concluded that the proposed confocal Raman spectroscopy technique has the potential to assess the extent and distribution of the comeal water content in-mo with a high degree of sensitivity and reproducibility.

Chapter 6 describes the first ever application of this type of Raman spectroscopy in human subjects. The aim was to investigate the feasibility of confocal Raman spectroscopy for the assessment of comeal hydration in two legally blind subjects. Raman spectra from the anterior 100-150 $\mathrm{mm}$ of the comea were recorded over a period of time before and after topical application of a mild dehydrating drug. The results showed that high signal-to-noise ratio spectra were obtained using as little as $15 \mathrm{~mJ}$ of laser light energy. Furthermore, changes in conneal hydration as a result of the dehydrating agent could be observed. We concluded that with adequate improvements in the safety the proposed technique could potentially be applied clinically as a rool for the non-contact assessment of comeal hydration in the human situation.

In Chapter 7 the aim was to apply confocal Raman spectroscopy for the quantification of the transport of a topically applied ocular drug through the rabbit conea under in wiwo circumstances. The amplitude of a drug-specific Raman signal was assessed in the tearfilin and the corneal epithelium as a function of time after instillation of a single drop of dorzolamide $2 \%$ to the eyes of 6 anesthetized rabbits. A three-compartment pharnacokinetic model was used to describe the drug transport from the tearfilm (compartment 1) via the corneal epithelial layer (comparment 2) into the corneal stroma (compartment 3). Pharmacokinetic transfer rate constants ( $k$ ) for the drug transport from one compartment to the other could be calculated by fitting the pharmacokinetic equations belonging to the three-compartment model of drug-transport to the data obtained from the Raman spectroscopic assessments. The drugconcentration versus time curve in each eye had a bi-phasic trend, with a rapid initial decrease in drug-concentration corresponding to the hon-productive losses from the tears $\left(\mathrm{k}_{10}=0.24 \pm 0.04 \mathrm{~min}^{-1}\right)$, and a significantly slower later phase as a result of the transfer of drug from the conneal epithelaum to the corneal stroma $\left(k_{23}=0.0047 \pm 0.0004 \mathrm{~min}^{-1}\right)$. The rate of drug uptake from the tears into the corneal epithelium could allso be established $\left(\mathrm{k}_{12}=0,034 \pm 0.006\right.$ $\left.m^{-1}\right)$. The standard deviations of these phamacokinetic variables suggested good reproducibility. Furthemore, Raman spectroscopy is inherently specific, a strong advantage over currently used fluorometric assessments of ocular pharmacokinetics. In combination with the non-contact probing, the adequate sensitivity and spatial resolution, we concluded that confocal Raman spectroscopy has the potential to be employed as a valuable tool for the study of ocular phamacokinetics in a non-contact manner. 
In Chapter 8 we sought to determine the feasibility of confocal Raman spectroscopy for remote temperature measurements within the aqueous humor of the rabbit cye under in vivo circumstances. We used the temperature-dependent changes in the Raman spectral features of water. As it turned out the amplitude of one OH-wibrational mode decreased while another $\mathrm{OH}$-vibrational mode of water increased with an increase in temperature. The ratio between the Raman intensity of these two $\mathrm{OH}$-vibrational modes showed a strong linear correlation with the prevailing temperature as measured with a Golden Standard (needle thermocouple), both in HPLC-grade water $\left(R^{2}=0.99\right)$ as well as in the rabbit aqueous humor $\left(R^{2}=0.98\right)$ with a high degree of reproducibility and a sensitivity of $-0.5^{\circ} \mathrm{C}$. We concluded that, since the Raman spectral features of water and probably also other biochemicals are dependent on the prevailing temperature, care should be taken to keep the temperature constant during comparative Raman spectroscopic studies. Furthermore, it was proven that confocal Raman spectroscopy can be utilized. for sensitive temperature measurements in the aqueous humor of the rabbit eye under in wivo conditions and in a non-contact manner.

In summary, this thesis describes the potential applications of confocal Raman spectroscopy for the biochemical characterization of various ocular tissues and fluids in vivo. At present this technique is perfected and optimized and can be successfully applied for in two aninal research. Whether this novel optical technique will find its way into the clinical practice of ophthalmology depends on various factors. First and foremost is the safety issue as explained in Chapter 1. In general, the use of longer wavelengths is advocated in order to prevent fluorescence which can obscure the Raman signal. However, the confocal technique which we have applied has proven to be adequate in this perspective when using the $514.5 \mathrm{~nm}$ argon laser. The ANSI report on the Safe Use of Lasers does not show any wavelength dependency in ocular hazard in the 400-700 $\mathrm{mm}$ range. Since the Raman intensity is in direct proportion to the frequency of the incident light to the fourth power, the Raman yield is $-2.5 \mathrm{x}$ higher when using the argon laser at $514.5 \mathrm{~mm}$ as opposed to the helium-neon lisser at $632.8 \mathrm{~mm}$. Moreover, the sensitivity of the CCD-camera is $2 \mathrm{x}$ higher in the same Raman frequency shift region by using the argon laser as compared with the helium-neon laser. Thus, the Raman yield is $\sim 5 \mathrm{x}$ higher when using the argon laser then when using the helium-neon laser. In the future, the use of even shorter wavelength could be considered. A reliable source in this respect would be the helium-cadmium laser $(425 \mathrm{~nm})$, yielding $2 \mathrm{x}$ higher Raman signals as opposed to the argon laser. True non-invasive application of Raman spectroscopy in the eye using a laser is only possible when the light load is either significantly reduced to below $1 \mathrm{~mW} / \mathrm{cm}^{2}$ or light exposure to the retina is prevented altogether. This last option has our utmost attention, since this will 
permit utilizing higher laser light energies safely, yielding high signal-to-noise ratio spectra without chemical or thermal damage to the ocular tissues. Secondly, it needs to be established whether the proposed method is adequately practical in use in a clinical setting. Until now, spectral analysis is performed manually which is extremely time-consuming. First, each spectrum has to be pre-processed by determining the valuable signals from the background noise (shot-noise of the CCD camera, auto-fluorescence). Secondly, multiple Raman peaks in each single spectrum have to be assigned to a specific molecular bond. Only then, qualitative and (under certain circumstances) quantitative data analysis is possible. Computerized spectral analysis could certainly increase the practical application of Raman spectroscopy but whether this is possible still needs to be established. Thirdly, at this point the operation of the experimental setup demands much time in the form of aligning, calibration, and stabilization, which certainly leaves room for improvement in the future. Lastly, the added value of this optical technique has to be established with regards to the currently used non-invasive diagnostic tools in ophthalmology. Since the confocal Raman spectroscopy system described in this thesis in fact combines the advantages of confocal microscopy with a powerful chenical analytical technicue in a highly efficient manner, it was possible to investigate ocular tissues and fluids in a totally new manner. Instant information on the biochemical composition of transparent ocular tissues and fluids can now be obtained rapidly in a non-contact manner from almost any depth within the eye under in wivo conditions. Furtherw more, the proposed optical technique is adequatelly flexibility to allow for either time-dependent or spatially-resolved biochemical assessments, or a combination of both, in practically every ocular tissue or fluid.

Future efforts should be directed towards optimization of the proposed technique with regards to safety, practicality and operational procedures, to enable the application of Raman spectroscopy in the human cye in wivo. Only when safety is guaranteed we can open the way for investigating the rue clinical potential of confocal Raman spectroscopy in ophthalmology. 


\section{Samenvatting en Conclusies}

Raman spectroscopie (RS) is een krachtige optische techniek voor biochemische bepalingen, gebaseerd op het fenomeen dat een fractie van het opvallend licht wordt verstrooid met een andere frequentie, als gevolg van een interactie van het licht met de materie op moleculair nivo. Een Raman spectrum toont deze frequentie veranderingen in de vorm van discrete en specifieke Raman lijnen. Elke lijn kan toegewezen worden aan een specifieke moleculaire verbinding, warna met behulp van Raman spectroscopische analyse stoffen bioche misch gekarakteriseerd kunnen worden, uiteenlopend van simpele moleculen zoals water tot complexe eiwitten en weefsels. Ondanks dat RS in het verleden werd toegepast in verschillende biologische en medische disciplines, zijn er weinig in vimo toepassingen beschreven van deze techniek in de oogheelkunde. Het doel van dit proefschrift was dan ook om de mogelijke toepassingen van RS te onderzoeken voor contactloze biochemische bepalingen van (intra) oculaire weefsels en vloeistoffen van het intacte oog onder in wivo omstandigheden, gebruikmakend van een nieuw confocaal Raman spectroscopie systeem.

In Hoofdstuk 1 wordt de hypothese geponeerd dat de succesvolle in win toepassing van Raman spectroscopie in de oogheelkunde van klinisch significant belang is, omdat talrijke oogheelkundige alsook systemische afwijkingen tot uiting komen in veranderingen van de biochemische eigenschappen van oculate weefsels en vloeistoffen, welke eventueel gediagnostiseerd dan wel vervolgd zouden kunnen worden met behulp van deze techniek. Tegen deze achtergrond wordt een algemene inleiding in de theoretische, praktische en optische aspecten (inclusief de veiligheid) van de toepassing van Raman spectroscopie in de oogheelkunde gegeven, en het doel van het proefschrift wordt gepresenteerd (zie boven).

Hoofdstuk 2 geeft cen uitgebreide beschrijving van de principes van toegepaste Raman spectroscopie in de biologie en geneeskunde in het algemeen en oogheelkunde in het bijzonder. Verder worden de eisen voor een bruikbaar Raman spectroscopisch systeem gedefinicerd, om deze techniek als diagnostisch hulpmiddel te kumnen gebruiken voor biochemische bepalingen in het oog onder in mino onstandigheden.

Hoofdstuk 3 beschrijft de mogelijkheden van het confocale Raman spectroscopie systeen welke gebruikt werd in de studies die in dit proefschrift beschreven zijn. De lichtbron van dit optische systeen is een Argon laser dan wel een Helium-Neon laser. De smalle laserbundel wordt verbreedt tor een evenwijdige bundel net een diameter die overeenkomt met de achterste apertur van her focusserende microscoop-objectief (LDMO), welke een hoge 
numerieke apertuur heeft $(\mathrm{NA}=0.5)$ en een lange nije-werk afstand $(13 \mathrm{~mm})$. Deze LDMO wordt zowel gebruikt om het laserlicht op het object te focusseren alsook on het teruggekatatste licht weer op te vangen. Een holografische deelspiegel zorgt ervoor dat alleen het Raman licht wordt geleid naar een camera-lens, wellke op zijn beurt het Raman licht weer op een fiber foctsseert. Deze fiber dient als het confocale 'pinhole' (zie Hoofdstuk 1. Figurr 1), en transporteert het licht verder naar een spectrometer, waar het licht afhankelijk van de kleur wordt afgebogen en vervolgens gedetecteerd door een zeer gevoelige CCD-camera. Deze digitaliseert het signal zodat het op een computer opgeslagen en op een beeldscherm afgebeeld kan worden. De sterke punten van dit systeem zijn (1) de vrije-werk afstand van $13 \mathrm{~mm}$, wadadoor op een contactoze wijze de traanfilm, het hoomvlies, het kamenwater, de lens en ther glasachtig lichaam gekarakteriseerd kunnen worden; (2) de confocale opstelling van de optische onderdelen, welke het mogelijk makt optische coupes te maken van minstens $20 \mu \mathrm{m}$ dikte, terwijl de detectie van strooilicht van het weefsel of omliggende weefels wordt geminmaliseerd, en zodoende de signat-ruisverhouding vergroot; (3) de hoge gevoeligheid, door efficiënt gebruik te maken van het microscoop objectief alsook de toepassing van een hoogwardige CCD-detector; en (4) de adequate resolutie in tijd, voor snelie spectrale data acquisitie. Tevens makt de telecentrische vitlijning het mogelijk de LDMO te transleren over de optische as van het systeem zonder verandering in de achterste brandpuntsafstand, zodat het mogelijk is statische objecten dynamisch te meten. Met de toepassing van dit optische systeem werden discrete en specifieke Raman spectra verkregen van het hoomvlies, het kamerwater, en de intraoculaire lens, gebruik makend van $25 \mathrm{~mW}$ laserlicht en een $1 \mathrm{~s}$. exposicie-tijd. Er wordt geconcludeerd dat dit confocale Raman spectroscopie systeem een nieuwe technick is die door middel van optische coupes, op een snelle manier (intra)oculaire weefsels en vloeistoffen biochemisch kan karakteriseren.

Hoofdstuk 4 beschrijft het algemene werkterrein in de oogheellundige discipline warvoor confocale Raman spectroscopie met name geschikt wordt geacht. Tevens geeft dit manuscript enig inzicht in de voortgande queeste nar de mogelijke toepassingen van confocale Raman spectroscopie in do oogheelkunde. Naast de projecten die in meer detail terugkomen als aparte hoofstukken in dit proefschrift, worden enkele pilot-studies genoend zoals het detecteren van biomoleculen in het kamerwater (bijv. glucose en fenylalanine). het bepalen wan biochemische veranderingen in donorcorneas, en de biochemische analyse van cen min of meer vak voorkomende fibrovasculaire andoening van het oog, het pterygium.

Hoofdstuk 5 presenteert de resultaten van de toepassing van confocale Raman spectroscopie voor de bepaling van de water gradiënt in de connea in wwo. De confocaliteit leende zich bij uitstek voor het maken van optische weefsel coupes welke significant dunner waren dan de gehele dikte van het hoornvilies. Gebruik makend van een bepaalde Raman intensiteitsratio tussen 
twee Raman spectrale lijnen kon de watergraad van aen test medium en het hoonvlies van het konijn, in wive en met een hoge mate aan gevoeligheid en reproduceerbarheid bepaald worden. Het watergehalte van her konjne-hoornvies wordt hoger naamate men meer van anterieur naar posterieur gaat, wat in overeenstemming is met onze huidige opvating omtrent de niet-homogene verdeling van de comea hydratie. Tevens kon met behulp van de bepaling wan de axiale watergraad een juiste schatting gemaakt worden van de totale comea hydratie, als we dat vergeleken met conventionele methoden zoals pachymetric en vriesdrogen. Wij concludeerden dat het voorgestelde confocale Raman spectroscopie systeem in potentie de hoogte en de verdeling van de comea hydratie kan bepalen onder in wo omstandigheden, met een hoge mate aan sensitiviteit en reproduceerbarheid.

Hoofdstuk 6 beschrijf de allereerste keer dat deze vom van $R$ aman spectroscopie is toegepast op proefpersonen. Het doel van de studie was te onderzocken of het mogelijk was met confocale Raman spectroscopie de cornea hydratie te bepalen in twee zogenaande legally blind" personen. Er werden Raman spectra genomen van het anterieure $100-150 \mu \mathrm{m}$ deel van de comea over een bepalde rijd voor an na topicale toediening van een milde dehydrerende oogdruppel. De resultaten lieten zien dat Raman specra vervaardigd konden worden met een hoge signaal-ruis verhouding gebruik makend van slechts $15 \mathrm{~m}$ ] laser licht. Tevens konden veranderingen in de comea hydratie worden aangetoond als gevolg van toediening van de dehydrerende oogdruppel. Wij concludeerden hieruit dar met adequate verbeteringen in de veiligheid de voorgestelde techniek mogelijk gebruikt kan worden in een klinische setting on contactloos de conea hydratie te bepalen in de humane situatie.

Het doel van het onderzoek beschreven in Hoofdstuk 7 was de toepassing van confocale Raman spectroscopie voor de kwantificatie van het transport van een topical toegediende oogdruppel in de konijne-comea onder in wro onstandigheden. De amplitude van een farmacon-specifick Raman signaal werd bepald in de trantilm en het comea-epitheal als functie van de tijd na het indruppelen wan een enkele druppel dorzolamide $2 \%$ in de ogen van 6 konjinen onder algehele anesthesie. Een drie-compartmenten model werd gebruikt om thet transport van het farmacon te beschrijven vanuit de tranfilm (compartiment 1) via het comea epithed (compartiment 2) nat het comeale stroma (compartnnent 3). Farmacokinetische snelheids-constanten ( $k$ ) woor het transport van het ene compartment nar het andere konden worden berekend door met farmacokinetische formules, behorend bij het drie-compartimenten model, het famacon transport te modelleren aan de hand van de data wan de Raman spectroscopische bepalingen. De concentratie vs. tijd curven van ieder oog hadden elk een bi-fastsch verloop, mer een snelle exrste daling wan de farmacon-concentratie als gevolg van niet-productieve verliezen uit de tranfilm $\left(k_{10}=0.24 \pm 0.04 \mathrm{~min}^{-1}\right)$, en cen significant langzamere fase als gevolg van het famacon-transport vanuit het cornea-epitheel nar het comea-stroma 
$\left(k_{23}=0.0047 \pm 0.0004 \mathrm{~min}^{-1}\right)$. Tevens kon de opname van farmacon vanuit de tranen naar het comea-epitheel bepaald worden $\left(\mathrm{k}_{12}=0.034 \pm 0.006 \mathrm{~min}^{-1}\right)$. De standaard deviaties van deze farmacokinerische variabelen suggereren een goede reproduceerbaarheid. Tevens is Raman spectroscopie inherent specifiek, wat een groot voordeel is over de thans gebruikte fluorometrische bepalingen van de oculaire farmacokinetiek. Samen met het contactloos bepalen, de adequate gevoeligheid en de spatiele resolutie, leidde dit tot onze conclusie dat confocale Raman spectroscopie mogelijk gebruikt zou kunnen worden als een waardevolle contactloze techniek voor oculair farmacokinetische bepalingen.

In Hoofdstuk 8 trachtten we te bepalen of het mogelijk was om mer behulp van confocale Raman spectroscopie contactoos de temperatuur te bepalen in het kamerwater van het konijnc-oog onder in viro onstandigheden. We gebruikten daarbij de temperatuur-athankelijke veranderingen in het Raman spectrum van water. Het bleek dat de amplitude van een van de $\mathrm{OH}$-signalen verkleinde terwijl de amplitude van een ander $\mathrm{OH}$-signaal juist vergrootte. De ratio tussen de Raman intensiteiten van deze twee $\mathrm{OH}$-signalen vertoonde een sterke lineaire correlatie met de temperatuur zoals gemeten met de Gouden Standaard (naald thermo-koppel), zowel in HPLC-zuiver water $\left(R^{2}=0.99\right)$ alsook in het kamerwater van de konijne-ogen $\left(R^{2}=0.98\right)$ met cen hoge mate aan reproduceerbaarheid en een sensitiviteit van $\sim 0.5^{\circ} \mathrm{C}$. Wij concludeerden, gezien de temperatuur-afhankelijkheid van de Raman signalen van water en waarschijnlijk ook van andere biomoleculen, dat er tijdens vergelijkende Raman spectroscopische studies op gelet moet worden dat de temperatuur constant gehouden wordt. Tevens werd geconcludeerd dat confocale Raman spectroscopie toegepast kan worden voor sensitieve en contactloze temperatuur bepalingen in het kamerwater van konijne-ogen onder in wive omstandigheden.

Samenvattend beschrijft dit proefschrift de potentiële toepassingen van confocale Raman spectroscopie voor biochemische bepalingen van verschillende oculare weefsels en vloeistoffen. Op dit moment is deze technek geoptimaliseerd voor en kan succesvol toegepast worden in in wo proefdier studies. Het hangt van verschillende factoren af of deze nieuwe optische techiek zijn weg zal vinden in de klinische praktijk van de oogheelkunde. Allereerst en meest belangrijke factor is de veiligheid, zoals reeds beschreven in Hoofdstuk 1. In het algemeen wordt het gebruik van langere golflengten aambevolen om zo de detectie van fluorescentie, welke het Raman signaal kan maskeren, te verminderen. Desalniettemin hebben we kumen aantonen dat confocale Raman spectroscopie in dit opzicht adequat kan worden toegepast gebruik makend van de $514.5 \mathrm{~mm}$ argon laser. Het ANSI rapport aangaande de 'Safe Use of Lasers' toont geen verband tussen oogheelkundig gevaar en de golflengte van zichtbaar licht tussen de 400 en $700 \mathrm{~nm}$. Omdat de Raman intensiteit direct afhangt van de frequentie van het gebruikte laser licht tot de vierde macht, zall bijvoorbeeld deze intensiteit 2.5 maal hoger uitvallen bij gebruik van een argon laser $(514.5 \mathrm{~nm})$ vergeleken met een helium-neon laser $(632.8 \mathrm{~nm})$ met 
cenzelfde vermogen. Tevens is de gevoligheid van de CCD-camera 2 mat hoger in de zelfde Raman 'shif' regio als de argon laser gebruikt wordt in plaats van de helium-neon laser. In de toekomst zou zelfs het gebruik van nog kortere golflengten overwogen kunnen worden. In dit perspectief zou de helium-cadmium laser ( $425 \mathrm{~nm}$ ) een betrouwbare lichbron kunnen zijn, welke een 2 mal hoget Ramam signal zou geven dan de argon laser. Echte niet-invasieve tocpassing van confocale Raman spectroscopie is slechts mogelijk als de retinale blootstelling an laserlicht significant gereduceerd wordt tot minder dan $1 \mathrm{~mW} / \mathrm{cm}^{2}$ of wanneer blootstelling van de retina an het directe laserlicht geheel wordt vermeden. Deze latste optic heef onze volledige aandacht, omdat dit ons in staat zou stellen on op een veilige manier hogere licht energieen te gebruiken, welke spectra met een hoge signaal-ruis verhouding. zouden opleveren zonder themale of chemische schade aan de oculaire weefsels. Ten weede moet vastgesteld worden of de voorgestelde techniek praktisch genoeg is voor gebuik in de kinische setring. Nu wordt de spectraal analyse nog grotendeels manueal uitgevoerd wat extreem tijdrovend is. Ten eerste moet elk spectum voorbewerk worden teneinde de waardevolle signalen van de achtergrond signalen ("shot-noise" van de CCD-camera, auto-fluorescentie) te scheiden. Dan moeten de afzonderljike Raman pieken in elk spectrum toegewezen worden an specifieke moleculaire verbindingen. Pas dan is kwalitatieve en (onder bepalde onstandigheden) kwantitatieve data analyse mogelijk. Compurer-ondersteunde data analyse zou hier zeker uitkomst kunnen bieden, maar of dit mogelijk is moet nog onderzocht worden. Ten derde vergen de operationele handelingen van de experimentele opstelling, zoals het uitlinen, de kalibratie en de stabilisatie, nog veel tijd, wat zeker nog ruimte tot verbetering overlat. Tenslotte zal de toegevoegde warde wan deze optische techniek afgewogen moeten worden tegen de reeds in gebruik zijnde conventionele niet-invasieve achnicken in de oogheelkunde. Omdat het hier beschreven contocale Raman spectroscopic systeem de voordelen bundelt van confocale microscopie met een krachtige biochemisch analytische techniek in een hoogst efficiënte manier, was het mogelijk oculaine weefsels op een geheel nieuwe manier te onderzoeken. Directe infomatic betreffende de biochemische compositie van ansparante oculare weetsels en vlocistoffen kan nu verkregen worden op een contactloze manier op bijna elke diepte in he oog onder in tmo omstandigheden. Tevens is de vorgestelde techniek uitemate flexibel zodat zowel tijd-aflankelike alsook plats-athankelijke biochemische bepalngen gedaan kunnen worden, of een combinatic van beiden, in bijna elke oculair weefel of vloeistof.

In de toekomst zal de voorgestelde techniek geoptimaliseerd moeten worden met het oog op de veiligheid, het practisch nut, en de operationele procedures, zodat de toepassing van $\mathbb{R}$ aman spectroscopie in het humane oog onder in wing omstandigheden mogelijk gemake kan worden. Pas als de veiligheid is gegarandeerd zullen we de weg kunnen openen om het werkelijke klinische potentieel van confocale Raman spectroscopic in de oogheelkunde te kumen onderzocken. 


\section{Dankwoord}

Bij dezen wil ik iedereen die een vooraanstaande rol heeft gespeeld bij het totstandkomen van dit proefschrift bedanken. Bedenkend wie ik vooral niet moet vergeten, kijk ik terug naar hoe het allemaal ook alweer begonnen en gelopen is. Daar ik aan het eind van mijn co-schappen mijn zinnen had gezet on later als oogarts door het leven te gaan, wilde ik als voorbereiding daarop een keuze-wetenschapsstage oogheelkunde gaan doen. Dus belde ik eind 1994 met de afdeling oogheelkunde van het AZM in Mastricht. In een vloeiende veel-regelige volzin legde ik de stage-begeleidster mw. drs. M.R. Beintema mijn bedoelingen uit. Margot, ik kan me nog levendig herinneren hoe jij zei: "Zo, da"s pas met de deur in huis vallen". Jij was erg enthousiast en zorgde ervoor dat ik meteen aan de slag kon met een interessant project in het lab van Frans Jongsma, waarvoor dank. Samen met dr Paul Derhaag werd een begin gemaakt an een onderzoek waarn ik veel van mijn beta-kwaliteiten kwijt kon. De stage werd afgesloten met de scriptie "Computer-aided analysis of video images on morphometrical changes of the microcirculation of the bulbar conjunctiva in type I diabetics". Al met al zouden deze onderzoeks-perikelen de aanzet zijn tot iets groters. Het bleek namelijk dat er een promotieonderzoeks-plaats in Texas beschikbaar zou komen, en of ik daar eens over zou willen nadenken. Met een mogelijke promotie en een opleidingsplaats ooghee-kunde in Maastricht in het vooruitzicht was de keuze niet zo moeilijk.

Mijn promotor en heden tevens mijn opleider prof. dr F. Hendrikse gunde mij het vertrouwen om dit promotie-onderzoek tot een goed einde te brengen. Professor Hendrikse, de gesprekken die wij in de loop van de afgelopen jaren aangaande het verloop en de uiteindelijke afronding van dit promoticonderzoek hebben gehad, waren telkens weer een stimulans voor mij om de gestelde doelen in de afgesproken tijd te halen. I $k$ wil u bedanken voor de mogelijkheden welke deze promorie mij geboden heef, op research en ander gebied, voor de aanmoedigende en stimulerende begeleiding rijdens de afrondingsfase, en voor het kritisch beoordelen van de manuscripten in dit proefschrift.

Een volgend persoon die een zo grote rol heeft gespeeld bij het totstandkomen van dit proefschrift, is (nu ondertussen zelf gepromoveerd) dr F.H.M. Jongsma. Frans, ik heb jouw hulp voor, tijdens en ma mijn onderzoeksjaren in Galveston zeer gewardeerd. Ontelbare uren zijn we bezig geweest het confocale Raman spectroscopie systeem te verbeteren, ideeen uit te werken, experimenten te verrichten, manuscripten voor te bereiden etc. Jou schijnbaar oneindige hoeveelheid kennis van zaken in de optica en jouw evenzecr onver- 
moebare enthoustame en mzet zijn van onschatbare warde geweest in dezen. Niet in de laatste plaats ben jij ten slotte 'uivinder' van dit apparaat. De ujd welke we samen aan dit project hebben gewerkt zijn voor mij onvergetelijk geweest. Tevens heb jij als geen ander mijn proefschrift cot in de puntjes gelezen en bekritiseerd. Frans, ik hoop dat we nog lang zullen kunnen samenwerken, wel of niet aall een Raman spectroscopie project.

Dts R.J. Erckens, mijn voorganger in Galveston, wil ik hier natururlik ook niet onvermeld laten. Roel, jij maakte me wegwijs in het hele Ramangebeuren, en leerde me de fijne kneepjes van het ingewikkelde apparat, om het te laten doen wat ik wilde. Terens vomden jouw inspanningen de grondslag van dit onderzoek. Ik bedank je voor de talrijke uren welke we nog samen hebben kunmen werken, en de tijd erma.

The research presented in this thesis was performed at the Biomedical Laser and Spectroscopy Program of the Department of Ophthalmology at the Universiry of Texas Medical Branch, Galveston, Texas, under guidance of Professor and Chairman Dr W.F. March and Dr M. Motamedi, to whom I both. foel greatly indebted.

Dr March, as my promotor I would like to thank you for giving me the opportunity to work with you and your colleagues. Your never ending anmount of enthusiasm in ophthamic scientific research in general and the Raman-project in specific were contagious, to say the least. You always had and kept faith in the project, and always came up with new ideas and visions. Through you l personally met some of the most interesting people in the field of Ophthalmology of which Dr Theo Seiler, Dr Nussenblatt, and Dr John Marshal, have stayed fresh in my memory. You always proudly showed your guests the lab, giving me the opportunity to explain what we were doing, but which also meant a nice break from the daily routine. I would also like to thank some of your staff by name, who have made small or large contributions toward this thesis: Dr Judith Brown and Dr Stefan Trocme (comeal viability study and human donor comens), Richard (photography), Rosemary Moore (pathology), Dr Chartise Gundersson (phamacology work), and Dr Erik van Kuijk (pterygitum study).

Massond, as director of the Bionedical Laser and Spectroscopy Program and a wery diverse vesearcher, and now as my co-promotor, you taught me the fine art of writing scientific publications, for which I am grateful. After long hours of working on a paper, writing and re-writing it, thinking this latest version would certainly be okay, it finally came to your attention. Most of the times still more nodifications were made, and the whole process was repeated. You always claimed that you never had a paper rejected, just because by the time you submitted it, it was just perfect for that particular journal. And indeed. Most of the times your predictions were correct, and the papers got accepted the 
first time. I would also like to thank you for the possibilities you gave me in enlarging my knowledge in optics and lasers in your lab, where so much interesting research was and is still going on.

I ann greatly indebted to DrJ.P. Wicksted. Jim, your inmense knowledge in optics, lasers, and (Raman)spectroscopy were an invaluable asset to this project. I thank you for all the effort and time you invested in this project. We had the most interesting discussions about our work, and through you I learned a lot concerning the principles, physics and practice of Ranan spectroscopy. It was a pleasure to work with you during your stays in Galveston over the summer. Elaine and I will also never forget the great time we had at your home in Stillwater.

Brent Bell, I thank you for your technical assistance and the blood, sweat and tears you spilled to get that dam machine going when it was broken. Marcel Goetz I thank for teaching me the ins and outs of the Matlab-program, which helped me a great deal in creating my own custom-made spectral analysis programs. Marcel, unfortunately the time we spent together on the project was short but nonetheless intense. I hope you have found you niche in San Francisco.

Mijn co-promoter dr ir G.J. Puppels dank ik voor her kritisch doorlezen van mijn proefschrift. Gerwin-Jan, bedankt voor de inspanningen welke je je hebt getroost om een antal hoofdstukken in mijn proefschrift duidelijker, correcter en leesbaarder te maken.

De leden van de beoordelingscommissie prof. dr H.A.J. Struijker-Boudier, prof. $d r$ W. Th. Hermens, prof, $d r$ A. Persoons, prof. dr F. Spaans, en $d r$ ir D. Sterenborg dank ik voor het beoordelen van dit proefschrift.

Een woord van dank is tevens op zijn plaats voor mijn huidige collega's van de afdeling oogheelkunde van het AZM Mastricht, waaronder de stafartsen, polimedewerkers, en niet in de laatste plaats mijn collegae arts-assistenten, voor hun steun en hulp tijdens de afrondingsfase van mijn pronotio.

Tevens dank ik de fima Alcon, voor de financiele ondersteuning bij de publicatie van dit proefschrift.

And last but by no means least, I thank my lovely wife Elaine. Dearest Elaine, you have always said that behind every successful man there is an even more successful wife. Well, I guess I have to agree with you, since without your support, patience, and encouragement especially in this year past, I would have never made it. You succeded in pulling me through, and I love you for helping me through thick and thin. We did it! 


\section{Curriculum Vitae}

Noel Jozef Catharinus Bauer werd geboren te Heerlen op 11 November 1968. In 1987 werd met goed gevolg het eindexamen Gymnasium $\beta$ behald aan het Bisschoppelijk College Schöndeln te Roermond. Vanaf 1987 studeerde hij geneeskunde aan de Rijksuniwersiteir Limburg te Maastricht, welke in 1995 werd voltooid met het behalen van het basisartsexamen. Aansluitend werd het onderzoek in het kader van deze dissertatie verricht aan de University of Texas Medical Branch at Galveston, Texas, van 1995 tot 1998, onder begeleiding van Prof. dr Wayne F. March, dr Massoud Motamedi en prof. dr Fred Hendrikse. Sedert augustus 1998 is de auteur werkzaam als arts-assistent in opleiding tot oogarts bij de afdeling oogheelkunde van het Academisch Ziekenhuis Maastricht (opleider prof. dr F. Hendrikse).

Hij is getrouwd met Elaine Wilson en heeft een zoon, Brandon. 


\section{Publications}

NJC Bauer, WF March, JP Wicksted, F. Hendrikse, FHM Jongsma, M. Motamedi. "Ir viwo confocal Raman spectroscopy of the human eye." ARVO Abstract Invest. Ophthalmol. Wis. Sa. 1996; 37(3): S753.

RJ Erckens, NJC Bauer, WF March, FHM Jongsma, F. Hendrikse, M. Motamedi. "Non-invasive in vivo assessment of comeal dehydration in the rabbit using confocal Raman spectroscopy." ARVO Abstract Invest. Ophthathol. Vis. Sci. 1996; 37(3): $\$ 360$.

NJC Bater, WF March, F. Hendrikse. "Confocale Raman spectroscopie van de humane comea." Nederlands Oogheelkundig Gezelschap, Breda, 1996.

RJ Erckens, FHM Jongsma, NJC Bauer, JP Wicksted, M. Motamedi, F. Hendrikse, WF March. "Het detecteren van intraoculaire siliconen olie net Raman spectroscopie in een in wivo model." Nederlands Oogheelkundig Gezelschap, Breda, 1.996.

NJC Baner, MJ Goetz, FHM Jongsma, WF March, M. Motamedi. "In yimo confocal Raman spectroscopy of ocular tisste". $14^{\text {th }}$ Annual Meeting on Biomedical Engineering (1996). University of Houston, Texas, USA.

FHM Jongsma, RJ Erckens, JP Wicksted, NJC Bauer, F Hendrikse, WF March, M Motamedi. "Confocal Raman spectroscopy system for non-contact scanning of ocular tissues; an in vitro study". Optical Engineering 1997; 36(11): 3193-3199.

NJC Bauer, SJ Koons. JP Wicksted, FHM Jongsma, F. Hendrikse, M. Motamedi, WF March. "Non-invasive assessment of the axial hydration gradient after comeal abrasion of the rabbit eye". ARVO Alswrat Imest. Ophthatmol. Vis. Sa. 1997; 38(4): 5535 .

NJC Bauer, S.J. Koons, JP Wicksted, FHM Jongsma, M. Motancdi, WF March, F. Hendrikse. "Kwantitatieve bepaling van de hydratic van het anterieure stroma in in vire konijne comeas na de-epithelialisatic". Nederlands Oogheelkundig Gezclschap, Groningen, 1997.

NJC Bauer, JP Wicksted, FHM Jongsma, WF March, F. Hendrikse, M Motamedi. "Non-invasive assessment of the hydration gradient across the comea using scanning confocal Raman spectroscopy". Hwest. Ophthalmol. Wis. Sci. $1998 ; 39(4): 831-835$. 
NJC Bauer, M. Motamedi, JP Wicksted, WF March, F. Hendrikse. "Confocale Raman Spectroscopie voor Farmacokinetische Bepalingen in het Oog". Nederlands Ooghe elkundig Gezelschap, Maastricht, 1998.

NJC Bauer, M. Motamedi, JP Wicksted, F. Hendrikse, WF. March. "Non-invasive ocular pharmacokinetics via Raman spectroscopy". ARVO Abstract. Inwest. Ophthatwol. Vis. Sci. 1998; 39(5):

NJC Bauer, M. Motamedi, JP Wicksted, F. Hendrikse, WF. March. "Confocal Raman Spectroscopy For the Non-Invasive Assessment of Ocular Pharmacokinetics". 16 $6^{\text {th }}$ Amual Meeting on Biomedical Engineering (1998). University of Houston, Texas, USA.

NJC Batuer, M Motamedi, JP Wicksted, WF March, CAB Webers, F Hendrikse. "Non-Invasive Assessment of Ocular Pharmacokinetics using Confocal Raman Spectroscopy".J Ocular Pharm. Ther. 1999; 15(2): 123-134.

NJC Bauer, F. Hendrikse, WF. March. "In vivo Confocal Raman Spectroscopy of the Human Comea". Comen 1999; 18:483-488.

JP Wicksted, NJC Bauer, RJ Erckens, FHM Jongsma, EE Smit-Kepel, M Motamedi, Wayne F March. "Noninvasive Assessment of Ocular Tissue using Confocal Raman Spectroscopy". The International Society for Optical Engineering. Bionnedical Applications of Raman Spetroscopy. SPIE Jamuary 1999; wol. 3608: pp. $111-122$.

NJC Bauer. Potential Applications of Confocal Raman Spectroscopy in Ophthalmology. Thesis. University of Maastricht, The Netherlands, Decenber 1999. 